\title{
Devonian fish remains from the Dulcie Sandstone and Cravens Peak Beds, Georgina Basin, central Australia
}

\author{
G. C. Young' and D. Goujet ${ }^{2}$ \\ ${ }^{1}$ The Australian National University, Canberra ACT 0200, Australia \\ ${ }^{2}$ Laboratoire de Paléontologie, Muséum national d'Histoire naturelle, 8, rue Buffon, Paris, France
}

\begin{abstract}
Fossil fish remains belonging to the Wuttagoonaspis assemblage are described from the Devonian rocks of the Georgina Basin, central Australia. The study is based on some 450 samples from 30 localities in the lower Dulcie Sandstone of the Dulcie Syncline (Northern Territory), and Cravens Peak Beds of the Toko Syncline (western Queensland). First recorded from the Darling Basin of western New South Wales, the diverse Wuttagoonaspis assemblage was probably the first vertebrate fauna to become established in rivers and lakes of the Australian continent. It occurs over an area of about one million $\mathrm{km}^{2}$, but up to now only one species has been described from the type area. The Georgina Basin assemblage is highly endemic, with some 20 genera representing about 13 taxa of family or higher rank. It includes three of the four major groups of jawed vertebrates (placoderms, acanthodians, osteichthyans), and at least two agnathan groups: pituriaspids (previously described), and thelodontids (unstudied). Amongst placoderms, the order Arthrodira is represented by at least six families, one of which is new (family Bulbocanthidae). Seven new arthrodire species are assigned to the following new genera: Lurapullaspis, Toombalepis, Tnoralaspis, Ethabukaspis, Tokolepis, Cravenaspis, and Mithakaspis. A new species, Wuttagoonaspis milligani sp. nov., is erected within the genus Wuttagoonaspis Ritchie, 1973 (endemic family Wuttagoonaspidae), the only named taxon from the Darling Basin assemblage. Huginaspis australis sp. nov. is assigned to the genus Huginaspis Heintz, 1929 (family Phlyctaeniidae), previously known from the EarlyMiddle Devonian of Spitsbergen. Tnoralaspis petercooki gen. et sp. nov. has its type locality at Gosses Bluff in the Amadeus Basin (Pertnjara Group). The new actinolepidoid family Bulbocanthidae (Lurapullaspis johannseni gen. et sp. nov.) is also known from the Early Devonian of western USA, Spitsbergen, and Severnaya Zemlya. Toombalepis tuberculata gen. et sp. nov. is placed in the actinolepidoid family Antarctaspidae, also known from the Devonian of Antarctica (Antarctaspis White, 1968) and South China (Yujiangolepis Wang et al., 1998). Cravenaspis trematosus gen. et sp. nov. is provisionally placed in the phlyctaenioid family Arctaspididae, also known from Spitsbergen. Mithakaspis lyentye gen. et sp. nov. is referred to the cosmopolitan family Groenlandaspidae, together with another new genus (unnamed), and two indeterminate species cf. Groenlandaspis Heintz, 1932. The placoderm order Petalichthyida is represented by an indeterminate genus and species, and the class Acanthodii by indeterminate fin spines. Osteichthyan remains apparently include three orders of sarcopterygians (?rhizodontids, ?porolepiforms, onychodontids), but the material is insufficient to erect new taxa.

Many of the studied localities have yielded remains of large fishes up to one metre long, indicating deposition in substantial water bodies, although previous interpretations have suggested aeolian deposition for part of the sandstone succession. The distribution of taxa and/or morphotypes across the studied localities is analysed. Differences in diversity seem to be related to sample size, and remains referred to Wuttagoonaspis $\mathrm{sp}$. from most localities indicate a broad correlation between the lower Dulcie Sandstone and the Cravens Peak Beds. Faunal affinities with fossil assemblages in the Northern Hemisphere suggest that the Wuttagoonaspis fauna from the Cravens Peak Beds and lower Dulcie Sandstone is probably no older than Pragian, and no younger than early Eifelian. The different species of Wuttagoonaspis, and predominance of high-spined groenlandaspids in the new fauna, suggests a slight difference in age to the Wuttagoonaspis assemblage from the Darling Basin.
\end{abstract}




\section{INTRODUCTION}

Fossil fish remains from the Devonian rocks of the Georgina Basin of central Australia (Figure 1) were discovered during initial geological mapping by the Commonwealth Bureau of Mineral Resources (BMR) in 1958. Hills (1959) identified the placoderm genera Bothriolepis and Phyllolepis, and concluded a Late Devonian age for the Dulcie Sandstone in the southeastern part of the Dulcie Syncline. A second fish assemblage was discovered in the northwestern end of the syncline in 1961, and was also sent to Professor E.S. Hills (University of Melbourne) for study. His opinion, that this could be an older assemblage, was recorded by GilbertTomlinson (1968) in her review of fossil fish discoveries in central Australia, but the material was returned to BMR without finalising the study.

The second region to yield a few fossil fish remains in the early 1960's was the Toko/Toomba Range area in the eastern part of the Georgina Basin, following surveys by various petroleum exploration companies (see below), but again no published descriptions eventuated. Descriptions of thelodont scales from this area, and a summary of localities, were provided by Turner et al. (1981).

The present study is based on collections made by G.C. Young during two field trips to the Georgina Basin in 1974 and 1977. The presence at several localities of the endemic genus Wuttagoonaspis Ritchie (1973) was established during the field survey. This is the only described taxon from a very large collection of fish material from the Mulga Downs Group in western NSW (Darling Basin) made by $\operatorname{Dr}$ A. Ritchie (Australian Museum, Sydney). Part of the Georgina Basin material was prepared at BMR, cast in rubber latex and photographed, but it was evident that the Darling Basin collection included better preserved and more complete material. Consequently, except for some younger assemblages (described by Young 1988a), and groups not identified in Ritchie's material, including antiarchs (Young 1984), sharks (Turner and Young 1987), and agnathans (Young 1991a), this research was not proceeded with. Ritchie (1975) noted the presence of groenlandaspid arthrodires in the Georgina Basin, which were comparable to undescribed forms from western NSW, but no further publication has been forthcoming on the extensive Mulga Downs Group fish collections.

The Wuttagoonaspis fauna has been identified in the Amadeus Basin of the Northern Territory (Young 1985, 1988a), and may also occur in the subsurface in the Officer Basin of South Australia (Long et al. 1988). Equivalent strata extend into the subsurface in the Canning Basin of Western Australia (Johnstone et al. 1968), where associated turiniid thelodont scales were reported by Gross (1971). This diverse fauna is thus recorded over an enormous area of about one million $\mathrm{km}^{2}$ of central
Australia. Although vertebrate remains of Ordovician age are known from central Australia (e.g. Young 1997), these occurred in shallow marine deposits, and show affinities with South American Ordovician vertebrates. The Wuttagoonaspis assemblage occurs in fluviatile sediments deposited during the Devonian-Carboniferous uplift that terminated marine deposition across the centre of the Australian continent. Thus it can be considered as the first vertebrate fauna to occupy aquatic habitats on the newly established terrestrial environment across a vast expanse of the Australian craton.

Fish remains of the Wuttagoonaspis assemblage were first reported from the Mulga Downs Group by Mulholland (1940), and then erroneously assigned a Late Devonian age (Rade 1964; Fletcher 1964), yet up to now only one species has been described. The relatively thin surface exposures of Devonian sandstones in the Amadeus, Georgina and Darling Basins are represented by much thicker sequences in the subsurface of central Queensland (e.g. Adavale Basin) and western N.S.W. (e.g. Bancannia Trough). There is a commercial gas field producing from Devonian sandstones in the Adavale Basin, and the Devonian subsurface sequence in the Darling Basin (up to $8 \mathrm{~km}$ thick) has been a focus for hydrocarbon exploration (e.g. Bembrick 1997; Boreham et al. 1997; Alder et al. 1998). Bembrick's (1997: 7) review of the Devonian stratigraphy of the Darling Basin, advocated worm burrow horizons ('Skolithos') as the most reliable means of correlation, concluding that there were 'no published data to support ... ages assigned to ... fish remains', and that 'a definitive age from the western New South Wales fish fauna cannot yet be achieved'. However a number of publications have dealt with setting up a basic vertebrate biostratigraphy for the Devonian of East Gondwana (e.g. Young 1988b; 1993; 1995, 1996; Young and Turner 2000). The lack of a detailed systematic treatment of the Wuttagoonaspis assemblage, known over much of the central part of continental Australia, remained a major gap in knowledge.

With a view to addressing this problem, a reexamination of the prepared Georgina Basin material was undertaken during a 3-month (MarchJune 1999) Visiting Professorship (GCY) at the Muséum national d'Histoire naturelle in Paris, where a preliminary comparative study established the presence of closely related taxa in Early Devonian fish assemblages from Severnaya Zemlya, Spitsbergen, and western USA. This demonstrated that some components of the placoderm fauna were widely distributed, and therefore likely to give better data for age control. The entire collection of some 450 samples housed at the Australian Geological Survey Organisation (AGSO), Canberra (formerly Bureau of Mineral Resources), was 


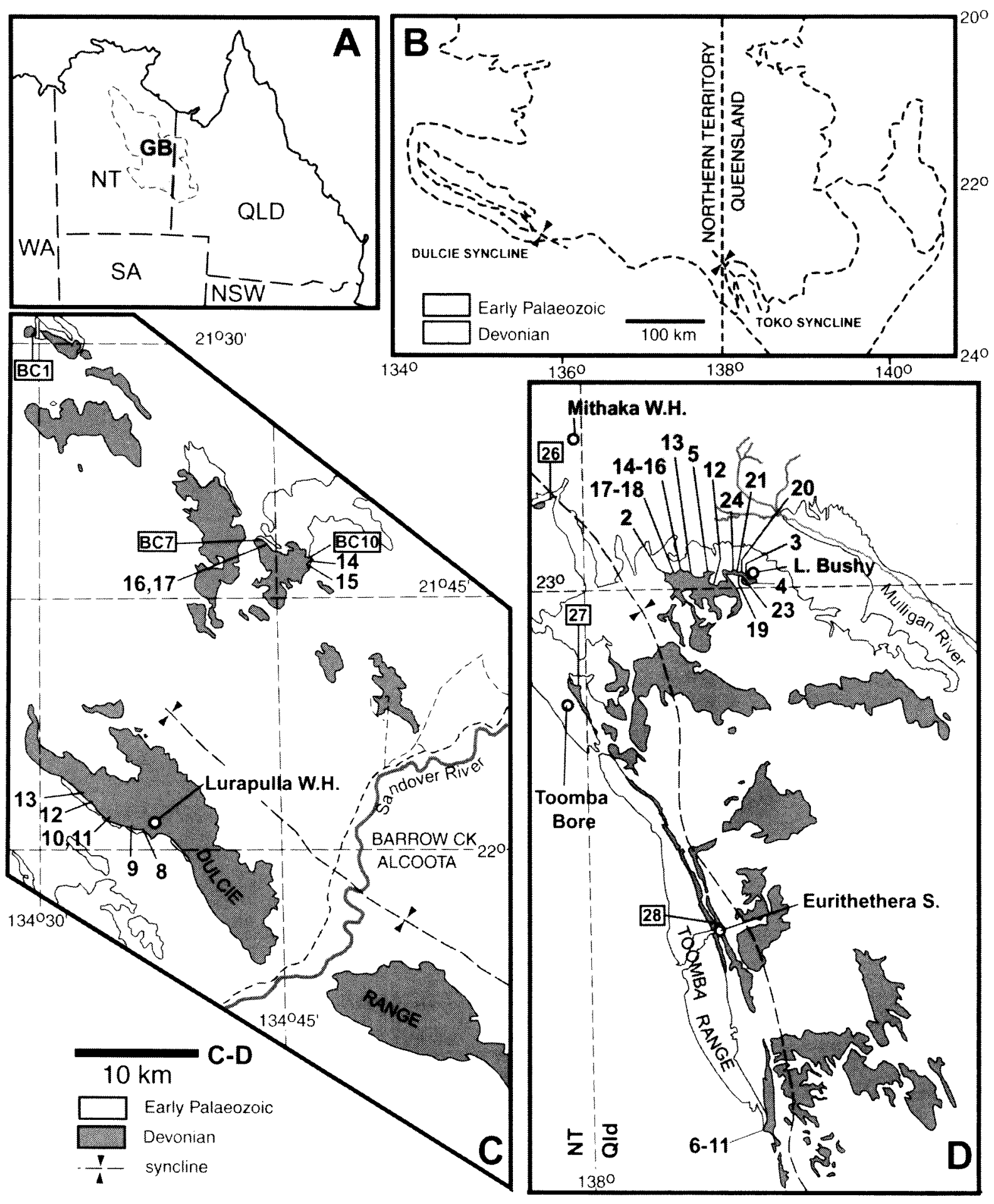

Figure 1 Locality map for the material described in this work. A, general location of the Georgina Basin (GB) in northern Australia. B, southern part of the Georgina Basin, showing the two main outcrops of Devonian rocks, in the Dulcie Syncline (NT) and Toko Syncline (Qld). C, northwestern part of the Dulcie Syncline, with general outcrop from the Barrow Creek and Alcoota 1:250 000 map sheets (first edition; see Haines et al. 1991 for more detail), showing fossil fish localities (8-17 collected in 1974; earlier localities BC1, 7, 10 in boxes). D, southern part of the Toko Syncline, with general outcrop from the Hay River-Mt Whelan Special 1:250 000 map sheet (Shergold 1985), showing fossil fish localities 2-24 collected in 1977 (earlier localities 26-28 of Gilbert-Tomlinson 1968 in boxes). 
examined during January-February 2001, to check studied latex casts against rock specimens.

After its description by Ritchie (1973), the relationships of the endemic placoderm genus Wuttagoonaspis were controversial (e.g. Miles and Young 1977; Young 1980; Goujet 1984a,b; Long 1984). Ritchie likened its skull roof to that of petalichthyid placoderms, although a relationship to the Phyllolepida now seems more likely (see below). Description of related taxa presented below provides new data for analysing this problem. The age of the Wuttagoonaspis fauna was assessed by Ritchie (1973) as probably 'Emsian-Eifelian', but there are difficulties with this younger age (Young 1995, 1996). The documentation of placoderm plates in the Darling Basin at a range of stratigraphic levels (e.g. in the underlying Winduck Group; Glen 1987), some associated with brachiopods (Sherwin 1987) which may be Lochkovian rather than Pragian in age (Sherwin 1994-96), suggests the possibility that Wuttagoonaspis is a longer-ranging taxon, occurring in assemblages of different ages. The present project involved an initial systematic study to establish a faunal list of represented taxa, so that their presence/absence at the various localities could be determined, on the working assumption that each locality could potentially be of different age. Many remains are fragmentary, requiring informal systematic treatment, but we consider this account to provide a workable systematic framework for more detailed study of the Wuttagoonaspis fauna in the Darling Basin. This is the lower part of a succession of fossil fish horizons ranging at least from the Early (Pragian) to the Late Devonian (Famennian) (e.g.Young and Turner 2000, figure 3). This time interval spans some 50 million years, so the fish assemblages have the potential to provide significant biostratigraphic age control of subsurface nonmarine Devonian sequences, in support of hydrocarbon exploration in onshore Palaeozoic sedimentary basins of the Australian craton.

The faunal list in Table 1 is equivalent to about 19 genera, representing about 13 taxa of family or higher rank. This gives a minimal indication of diversity of the Wuttagoonaspis assemblage, which apparently inhabited rivers and lakes across a vast area of the Australian continent during the EarlyMiddle Devonian. It can be compared with the modern freshwater fish fauna of Australia (302 species in 59 families; Allen et al. 2002). Allen (1989, table 1) listed 183 genera in 35 families, of which eight families have some endemic diversity (two or more endemic genera). There is at least a tenfold difference in generic diversity compared to the Wuttagoonaspis assemblage documented here, but Smith et al. (1988) noted that modern flood plain habitats in North America have 5-10 times as many species as documented for Cainozoic deposits. This

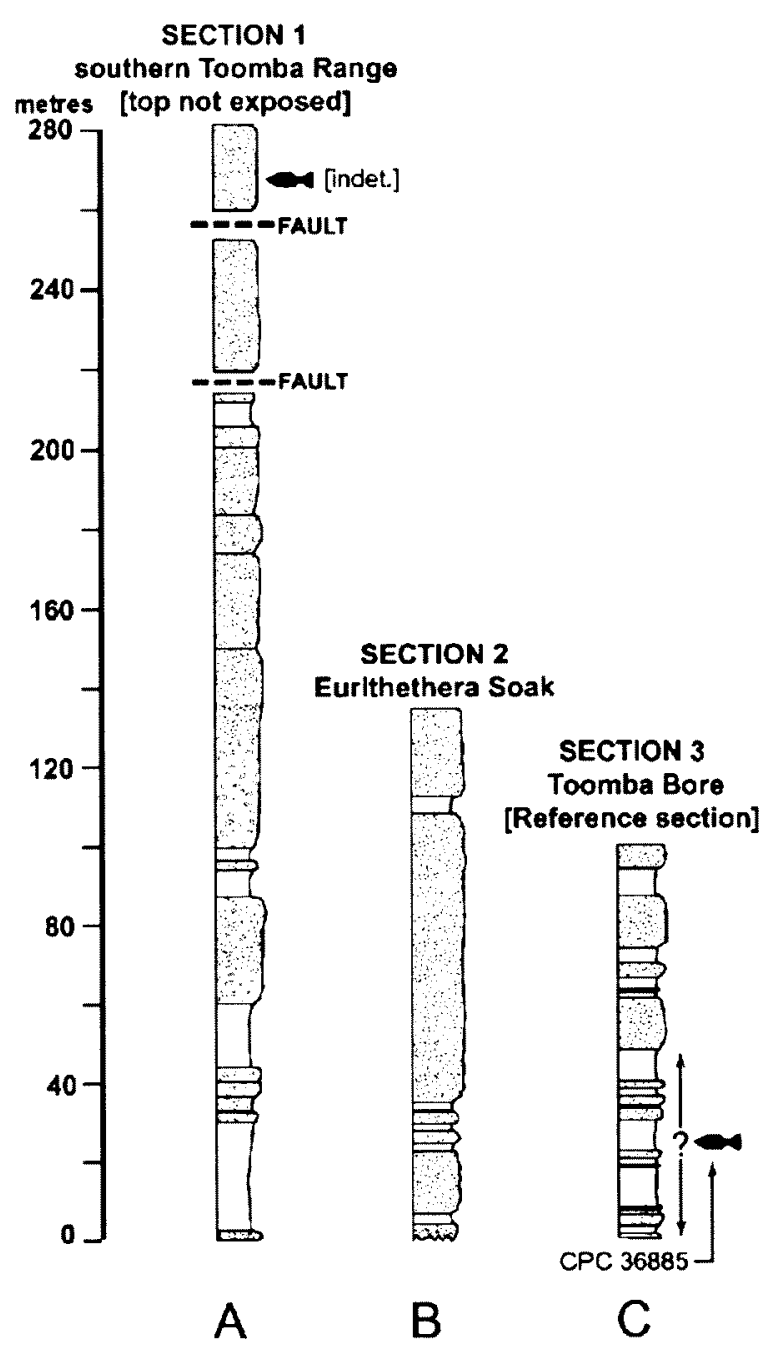

Figure 2 Three measured sections through the Cravens Peak Beds presented by Draper (1976: fig. 4), including the detail omitted in the simplified sections of Turner et al. (1981: fig. 3). A, southern Toomba Range, about $100 \mathrm{~m}$ south of localities 6-11 in Figure 1D; B, Eurithethera Soak, locality [28] of Figure 1D; C, Reference section (Smith 1972) as modified by Draper (1976), about $100 \mathrm{~m}$ east of Toomba Bore (near locality [27], Figure 1D).

indicates that ecological and fluvial processes destroy many fish bones, particularly of small species which comprise most of the diversity in the modern fauna. No doubt additional taxa will be discovered in the Wuttagoonaspis assemblage, but given these figures, the faunal list of Table 1 is considered a reasonable initial sample of the larger or more robust components of the assemblage, which would have a sufficient likelihood of being preserved to be expected from new localities.

\section{LOCALITIES}

\section{Early collections}

Gilbert-Tomlinson (1968: 200-203) summarised six original fish localities from the Georgina Basin, 
three from 'near the northwestern end of the Dulcie Syncline and in the lowermost 15 feet of section' on the Barrow Creek 1:250 000 map (BC1, 7, 10), and three localities in the Toko-Toomba Range area (Cravens Peak Beds). The latter were included ... with some reservation' because they were not in situ, lacked comparable fossils in adjacent outcrops, and were considered to have been probably transported by Aboriginal inhabitants. The Dulcie Syncline localities were shown on the Barrow Creek 1:250 000 geological sheet of Smith and Milligan (1964). Details of individual localities are as follows: BC1 ('50 miles north-west of Ammaroo homestead'). This is evidently a good fossil locality (F21989-995, 21997-22006 in the AGSO collection), but has not been re-collected since its discovery by E.N. Milligan in 1961. It is a remote site near the north-western extremity of Dulcie Sandstone outcrop (Figure 1C). Several placoderm taxa including Wuttagoonaspis have been identified in the fauna, and specimens from the original collection are illustrated in Figure 3B, C.

BC7 ('30 miles west-north-west of Ammaroo homestead'). Also collected by E.N. Milligan in 1961, this locality is on the northern limb of the Dulcie Syncline on the Lurapulla 1100000 sheet, and close to localities GY 74/16-17 (Figure 1C), with presumably the same stratigraphic occurrence (see below). Again, several placoderm taxa including Wuttagoonaspis have been identified from this locality; one of the specimens originally collected here is illustrated in Figure 3A.

BC10 ('28 miles west-north-west of Ammaroo homestead'). This locality, also discovered by E.N. Milligan in 1961, is about $5 \mathrm{~km}$ southeast of BC7, and adjacent to localities GY 74/14-15 on the Lurapulla 1:100000 sheet (Figure 1C). No specimens from BC10 were listed in the AGSO F-collection.

Locality 26 (Gilbert-Tomlinson 1968, figs. 1,5). A fossiliferous block collected at the base of a sandstone outcrop about $4.3 \mathrm{~km}$ south of Mithaka Waterhole was examined for Alliance Petroleum by H.O. Fletcher, Australian Museum, and considered identical to fossil fish remains from the Mulga Downs Group of western NSW (Wilson 1963). Associated Aboriginal artifacts suggested to Wilson that the fossil sample had been transported to the site. Draper (1976) considered the sandstone at the locality to be of post-Devonian age, but the sample most likely came from one of the small outcrops of Cravens Peak Beds in the vicinity (26, Figure 1D). Ritchie (1973: 71) identified a large submarginal plate of Wuttagoonaspis in this sample (AMF 50843). The locality is about $12 \mathrm{~km}$ NW of fossil localities in the Cravens Peak Beds collected in 1977 (see below). Locality 27 (Gilbert-Tomlinson 1968, figs. 1,5). A piece of sandstone 'preserving an impression of arthrodiran armour' was collected in 1964 by C.J. Mulders (Shell Petroleum) from the lower part of an outcrop of Cravens Peak Beds in the Toomba Range, about $1.2 \mathrm{~km} \mathrm{NE}$ of Toomba Bore, and some $15 \mathrm{~km} \mathrm{SW}$ of the main 1977 collecting area (see below). This specimen (CPC 36968) is illustrated in Figure 3D.

Locality 28 (Gilbert-Tomlinson 1968, figs. 1,5). Two samples collected in 1964 by geologists of French Petroleum (Cooper 1964) from a sandstone outcrop about $20 \mathrm{~km}$ ESE of Toomba Bore at Eurithethera Soak contained impressions of a lycopod plant, and fish remains identified by Gilbert-Tomlinson (1968: 203) as 'fragmentary arthrodiran plates, Phyllolepis, ... an unidentified genus with pustulose ornament; a possible dipnoan fragment'. The 'Phyllolepis' can now be positively identified as Wuttagoonaspis (see below), and with a cast of the plant specimen is illustrated in Figure 3; the whereabouts of the original samples is unknown. Gilbert-Tomlinson (1968: 203) noted the opinion that the fossils may have been transported to an Aboriginal corroboree ground. However outcrop of Cravens Peak Beds within $100 \mathrm{~m}$ of the site was established in subsequent mapping (Draper 1976).

\section{4 collection}

Fish localities in the upper part of the Dulcie Sandstone (GY1-7, Young 1988a: fig. 4) contain an Upper Devonian assemblage, as described by Young $(1985,1988 a)$. Ten other localities in the lower part of the Dulcie Sandstone (Figure 1C) are summarised below.

GY74/8-13. These collecting sites are along the southern flank of the Dulcie Range on the southeastern edge of the Barrow Creek 1:250 000 sheet (southern limb of Dulcie Syncline). According to Haines et al. (1991: 32) they come from the basal $10 \mathrm{~m}$ of the Dulcie Sandstone, although poor outcrop, and presence of fish impressions in scree, means that the actual interval of occurrence cannot be precisely established. The second edition of the Barrow Creek 1:250 000 geological map (Haines et al. 1991) also shows a faulted contact with the underlying Tomahawk beds (Cambro-Ordovician), adding uncertainty to stratigraphic level at these localities (but a normal contact is shown on the adjacent Huckitta map sheet; see Freeman 1986). The most easterly occurrence (locality 8 , Figure 1C) is recorded in field notes as being immediately above the contact with the underlying Tomahawk beds. The most northwesterly occurrence (GY74/ 13) is recorded from several hundred metres above a prominent trilobite layer within the Tomahawk beds. Fish remains are mainly indeterminate fragments with tuberculate ornament, except at 74/ 11, which produced some 50 samples assigned below to seven taxa.

GY74/14-15. These localities are along the northern limb of the Dulcie Syncline, in low outcrops of Dulcie Sandstone about $35 \mathrm{~km}$ across the sand 

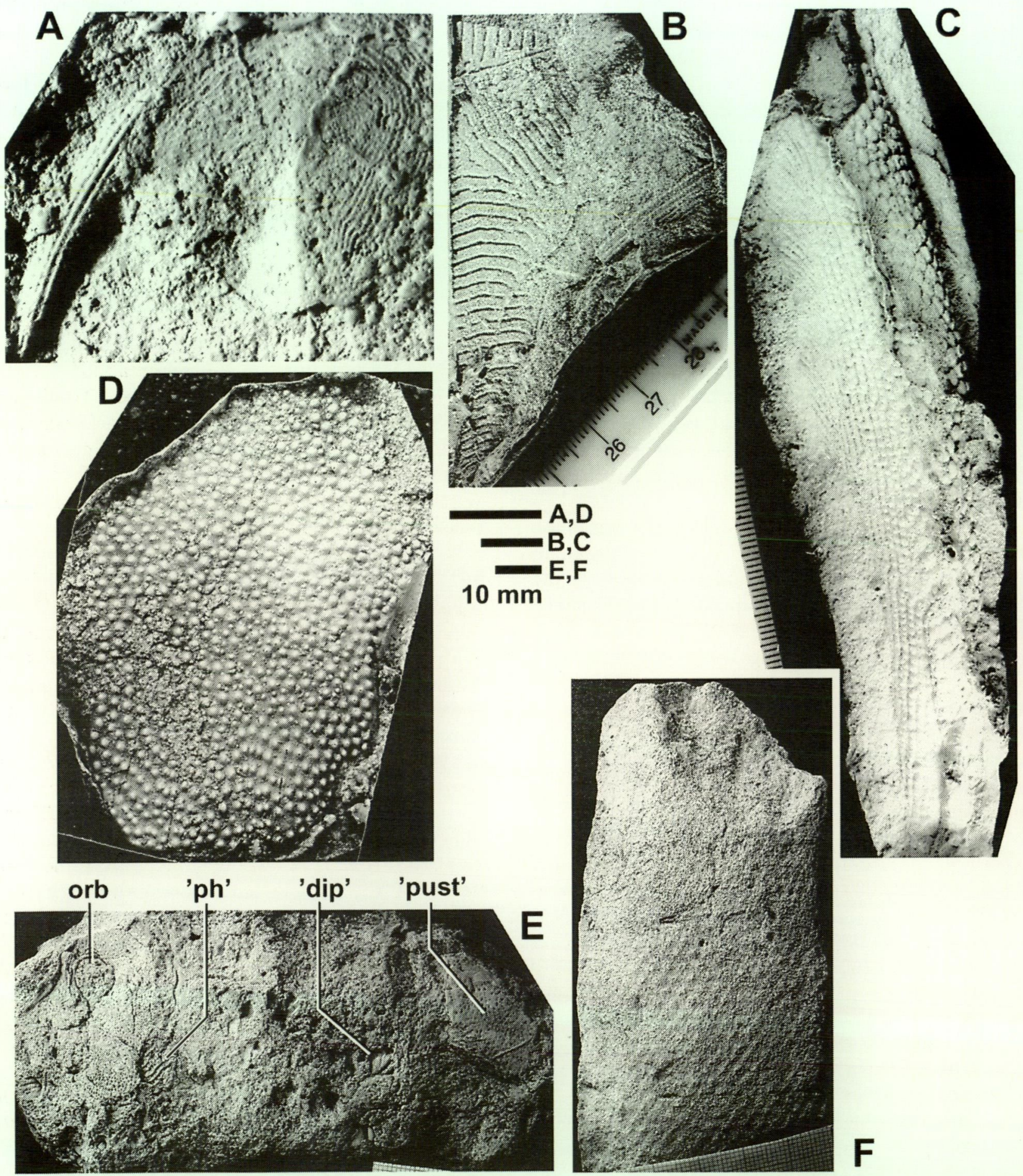

$\mathbf{F}$

Figure 3 Specimens collected in 1960's from the Wuttagoonaspis fauna in the Georgina Basin. A, Wuttagoonaspis sp. (CPC 36859), right AVL and SP plate (incomplete; cf. Figure 35B), from locality BC7, Dulcie Range (glass plate negative prepared for E.S. Hills); B, ?Lurapullaspis gen. nov., presumed part of skull roof (CPC 36914) from locality BC1, Dulcie Range; C, Wuttagoonaspis sp., SP plate (CPC 36864) from locality BC1, Dulcie Range; D, groenlandaspid gen. nov., probable AVL plate (CPC 36968), from locality 27 (Li57), Toomba Range; E, sample from Euthithethera Soak near Toomba Bore (CPC 37046) showing associated impressions, presumably those identified by Gilbert-Tomlinson (1968: 203) as 'Phyllolepis' (labelled 'ph'), a possible dipnoan ('dip'), and a 'genus with pustulose ornament' ('pust'); F, lycopod plant impression, also from Euthithethera Soak (CPC 37047). A-D are latex rubber casts, and E-F plaster copies, all whitened with ammonium chloride. 
dunes to the NE of the previous sites, and close to locality $\mathrm{BC} 10$ on the first edition of the Barrow Creek 1:250 000 sheet (Smith and Milligan 1964). As noted above, the early collections were reported to come from the lower $5 \mathrm{~m}$ of the Dulcie Sandstone. However at $74 / 14$, which may contain up to five taxa, a section measured with a tape in the direction of dip $\left(6^{\circ}\right)$, had the fish horizon near the top of a low scarp $60 \mathrm{~m}$ stratigraphically above the lowest sandstone bed exposed in the scree below. Both localities yielded remains with ridged ornament belonging to wuttagoonaspids or bulbocanthids.

GY74/16-17. These localities are about $5 \mathrm{~km} \mathrm{NW}$ of the previous localities, and very close to locality BC7 of Smith and Milligan (1964). A measured section at the camp site through about $16 \mathrm{~m}$ of sandstone (corrected for measured $6^{\circ} \mathrm{dip}$ ) showed fish fragments in the lowest exposed beds, and scattered through the lower half of the section. They were observed in discontinous mudflake layers at the base of cross-bedded cosets, with occasional larger plate impressions in the upper parts of underlying massive sandstones (again associated with large weathered mudclasts). The upper $8 \mathrm{~m}$ of section included some massive sandstone beds with Skolithos burrows about $1 \mathrm{~cm}$ in diameter and 3-4 $\mathrm{cm}$ apart. Fish fragments were observed in the lowest exposed beds of this section, but the base was covered by sand. They could represent a similar level ( $60 \mathrm{~m}$ above base) to the horizons at GY74/14-15, rather than within the lowest $5 \mathrm{~m}$ as first recorded. Six taxa are identified below from $74 / 17$.

\section{7 collection}

Some of the 18 localities in the Cravens Peak Beds collected in 1977 have been discussed and illustrated in Turner et al. (1981: fig. 2), Young (1984: fig. 1), Turner and Young (1987: fig. 1), and Young (1991a: fig. 1). A few fish samples were collected by J.J. Draper in 1975. The exposure of Cravens Peak Beds is largely restricted to the Mount Whelan and Glenormiston 1:250 000 sheets, with minor outcrop extending NW across the Queensland-Northern Territory border onto the Tobermory sheet. Stratigraphy of the Cravens Peak Beds was discussed by Draper (1976), who presented details of three measured sections, which showed an increase in thickness from south to north in the Toomba Range (see Turner et al. 1981, figs. 2,3). The original sections are reproduced in Figure 2 . The whole Cravens Peak Beds outcrop is included in the Hay River -Mount Whelan special geological map (Shergold 1985), and is delimited to the west by the major Toomba fault zone. Localities in the main collecting area, on the southwestern corner of the Glenormiston 1:250 000 sheet, can be conveniently considered in two groups (Figure 1D).
GY77/2, 5, 12-18. These localities lie along the northern margin of a large outcrop of Cravens Peak Beds which forms a low dissected mesa about 14 $\mathrm{km}$ SE of Mithaka Waterhole (Figure 1D), with low dips of less than $20^{\circ}$. No section was measured, but all localities are estimated to lie within the lower 50 $m$ of the formation. The entire outcrop is surrounded by Quaternary sand cover, so basal contact with underlying strata is nowhere exposed. The shot point localities which yielded the original thelodont scales from central Australia (Jones, in Reynolds and Pritchard 1964) were obtained in this vicinity (localities A-E, Turner et al. 1981: fig. 2). The nearest measured section, $100 \mathrm{~m}$ east of Toomba Bore (Draper 1976) is about $115 \mathrm{~m}$ thick, with one specimen of Wuttagoonaspis sp. (CPC 36885 ) collected from sandstone ferruginised in the base of the formation (Turner et al. 1981: fig. 3, section 3 ). Locality $77 / 5$ produced fish remains from the upper beds of a small outcrop. Locality $77 / 12$ lies a short distance to the southeast, and possibly a little higher in the sequence. Locality $77 /$ 13 represents isolated specimens between $77 / 5$ and $77 / 14$. Locality $77 / 14$ produced material from both sides of a small gully, and locality $77 / 15$ produced three large specimens from slightly farther west, in a bed near the top of the outcrop, presumably the same horizon as $77 / 14$. Localities $77 / 16$ and $77 / 17$ represent a western continuation of presumably the same horizon towards locality $77 / 2$, discovered by J.J. Draper (as field locality 077/29), which yielded a small collection containing five taxa. $77 / 17$ (named 'Manisky point' after field assistant Graham Manisky) produced several skulls (including Wuttagoonaspis) from a ferruginous sandstone outcrop projecting out from the main mesa, with other material including a Wuttagoonaspis internal skull impression from a friable lower horizon at the outcrop edge (five taxa in total). $77 / 15$ yielded a few large blocks containing large wuttagoonaspid, groenlandaspid and rhipidistian remains.

GY77/3, 4, 19-24. These localities (Figure 1D) lie around a second mesa about $2 \mathrm{~km}$ to the east of the previous outcrop, which surrounds on its western and southern sides a large claypan containing shallow water during the 1977 field season with the field name 'Lake Bushy' (after field assistant Ian 'Bushy' Steptoe). Locality 77/3, first located by J.J. Draper (as field locality $077 / 31$ ) produced a diverse fauna from two horizons. A section measured in this vicinity commenced in a gully containing small shelly fragments, presumed to be weathered outcrop of the basal calcareous unit identified in shot-hole samples mentioned above. Across a grasscovered flat is the first Cravens Peak outcrop, which yielded fish near the top of a low scarp estimated to be within $15 \mathrm{~m}$ of the lowest exposed bed. More fish remains (e.g. CPC 36961) came from near the top of a second low scarp set back by a recessive unit at its 
base, and forming a narrow bench. Unfortunately, details of this measured section could not be located in Georgina Basin field records held at the AGSO (December, 2001).

Locality $77 / 4$, about $1 \mathrm{~km}$ to the south, yielded fish remains from a similar coarse sandstone lithology on both sides of a gully. Localities 77/1924 represent similar horizons about $600 \mathrm{~m}$ northwest of $77 / 3$, in dissected gullies around the margin of the mesa. $77 / 19$ is one of the most productive localities, with abundant large Wuttagoonaspis, and the holotype of Pituriaspis doylei Young, 1991a (material labelled 77/22 was collected in a second visit to this locality). $77 / 20$ yielded material in scree downslope from the same fossiliferous horizon at $77 / 19$, a mudclast layer at the base of the uppermost sandstone unit forming the top of the scarp. $77 / 21$ is a slightly different lithology from slightly lower in the sequence, but still close to the top of the scarp. $77 / 23$ is up the gully and across to the other side from $77 / 19$, and yielded fossiliferous blocks in scree at the top of the outcrop, presumed to represent the same horizon. $77 / 24$ produced a single fossiliferous block from just below the top of the scarp.

\section{Other localities}

In addition to the specimens collected by J.J. Draper in 1975, some fossil fish localities were noted by N.T. Survey geologists C. Horsfall (H89, 90, near BC1) and N. Donellan (H948), on the northern limb of the Dulcie Syncline on the Huckitta 1:250 000 sheet southeast of the Bundey River (east of the area covered in Figure 1C). Farther to the southeast, J.H. Shergold (pers. comm.) recorded a fish plate low in the Dulcie Sandstone in the Point Spring-Picton Spring area. None of these specimens has been examined, and all other fish remains from this southeastern end of the Dulcie Syncline come from near the top of the sequence (Young 1988a). The Dulcie Sandstone extends onto the southwestern corner of the Elkedra 1:250 000 sheet, and Stidolph et al. (1988: 23) reported fossil fish fragments in a thin bed about 2 $m$ above the basal contact, near the top of a low cliff about $2.3 \mathrm{~km}$ southeast of Bluebush Bore'.

\section{PRESERVATION AND DEPOSITIONAL ENVIRONMENT}

The Dulcie Sandstone, first named by Tindale (1931), was described by Smith (1972: 38-39) as a 'freshwater Devonian sequence ... of cross-bedded quartz sandstone, with some beds of silty sandstone, calcareous sandstone, and pebble conglomerate'. Freeman (1986) noted prominent cross-bedding in a medium to thick-bedded quartz arenite with minor pebble layers, and Stidolph et al. (1988) suggested that much of the sandstone was of aeolian origin because of high angle cross-bedding, homogeneous grainsize, and other features. Haines et al. (1991) suggested a lacustrine environment for the lower part, and aeolian origin for the upper part of the Dulcie Sandstone, but fish remains, indicating fluvial conditions, occur at various levels throughout the sequence. Turner et al. (1981: 54) suggested a braided stream origin for the Cravens Peak Beds, and noted the occurrence of fish remains of considerable size, suggesting permanent bodies of fresh water. This was based on the size of large Wuttagoonaspis specimens (skulls over $200 \mathrm{~mm}$ long, with trunk armours approaching $300 \mathrm{~mm}$ across the spinal plates), indicating fish up to 1 metre long. Remains of such large Wuttagoonaspis have been found in both the Dulcie Sandstone (e.g. locality BC1) and Cravens Peak Beds (e.g. localities 77/15, $17,19)$. Rarer elements like the rhipidistian fishes also attained a large size (with teeth $40 \mathrm{~mm}$ long), so we can conclude that these sediments were in large part deposited in substantial water bodies. Draper (1976) described the lithology and sedimentary structures of the Cravens Peak Beds to comprise fining upward conglomerate-sandstone cycles, with cross-stratification and lensing of beds, minor shale interbeds, small-scale asymmetrical ripple marks, and scour and fill structures. In addition, simple vertical and subvertical burrows were said to be common in some beds in his measured Section 1 (southern Toomba Range; see Figure 2A). Within his Section 2, near Eurithethera Soak (Figure 2B), 'simple vertical burrows $(50 \mathrm{~cm}$ length, 1-2 cm diameter)' were said to be common in one bed (horizon unspecified). Possibly these burrowed horizons represent the trace fossil Skolithos, which if confirmed would represent evidence of a marine influence (this trace fossil is generally considered to indicate shallow marine conditions; e.g. Seilacher 1967, 1978; Frey 1978, Bjerstedt 1987).

The rare fossil fish remains discovered in initial surveys suggested that the remains may have been transported into the area (see above), but expert collecting (1974-77) yielded a large collection of over 500 samples from some 41 localities. The main geological reasons why often abundant localities could have been easily overlooked concern outcrop pattern, low dip of the strata, and the friable nature of the sandstone. A fourth (biological) reason is the morphology of the bony plates making up the external skeleton of placoderm (armoured) fishes, the most common component at all localities. Placoderm bones have a smooth inner surface, which is always concave, but with an ornament of strong tubercles or ridges on the convex external surface. It is the latter that leaves highly characteristic and noticeable impressions. However disarticulated bones have almost always come to rest with the concave side downwards (the stable position in water currents), 
so the characteristic ornament impressions are preserved on the under side of bedding surfaces, and may not been seen in outcrop, particularly when relief and dips are low. Most of the early finds were in tumbled and overturned blocks, normally close to small escarpments, or on the more steeply dipping limbs of folds. The sandstone is very friable, so fish plate impressions soon weather away when exposed upwards on tumbled blocks. This is in sharp contrast to the strong silicification of lithologically identical rocks with the same fish fauna in the Darling Basin of western NSW, where fossils appear to be much more abundant. This marked difference in silicification is presumably attributable to a major difference (e.g. inundation by Cretaceous seas; different Tertiary weathering regimes) in the postDevonian history of the two regions. Because of the rapid weathering of the Devonian sandstones in the Georgina Basin, it is unlikely that similar surface remains of fossil fish will ever be found again in the quantity obtained in the initial surveys of 1974 and 1977.

\section{STRATIGRAPHIC OCCURRENCE}

The distribution of taxa and/or morphotypes across the 26 localities collected in 1974 and 1977 is summarised in Table 1 . Given the nature of the outcrop, and the absence of a succession of fossil fish assemblages in stratigraphic section, there can be no guarantee of correlation of fossil localities. On the other hand, differences in diversity (Table 1) seem to be related to sample size. In total, some 450 samples were examined for this study, from about 30 localities. The most diverse of the adequately collected localities $(74 / 11,77 / 19$, with 11 and 13 taxa identified) are also the most abundant, with about 50 and 108 collected samples respectively. Localities 74/14-16 have 5-6 identified taxa from 15-25 samples, and 74/17 (about 40 samples) has yielded seven taxa, as have $77 / 3$ and $77 / 17(43,17$ samples respectively). In contrast, the least diverse localities $(74 / 8-10,12,13 ; 77 / 5,13-16,18,21,23$, 24) are also the smallest (1-7 collected samples). Amongst these are the only localities at which ridged ornament fragments belonging to either Wuttagoonaspis sp. or Lurapullaspis gen. nov. have not been identified.

\section{AGE OF THE FAUNA}

These data indicate that diversity at different localities is directly correlated with sample size. It is more likely therefore that missing taxa can be attributed to small samples at specific localities, rather than indicating real faunal differences which might constitute evidence of difference in age. It is assumed therefore that all the sampled localities are broadly similar in age, but it is noted that the distinctive median dorsal spines of Lurapullaspis gen. nov. (see Figure 10) have not yet been found in the Cravens Peak Beds. In addition, the strongly ridged morphotype amongst the various median dorsal plates assigned below to Mithakaspis gen. nov., is also only documented from the Dulcie Sandstone. Therefore there may be some finer scale age differences between the lower Dulcie Sandstone and Cravens Peak Beds fish assemblages, which cannot be properly assessed in this first systematic study, based largely on incomplete specimens.

Considering broader correlations outside the Georgina Basin, earlier evidence for a younger (?Middle Devonian) age compared to the Wuttagoonaspis fauna in its type area (Mulga Downs Group of the Darling Basin, western NSW), is now uncertain (Young and Turner 2000). This evidence derived from a suite of described taxa (Young 1984, 1991a; Turner and Young 1987) not known from the type area, including the shark Mcmurdodus, shared with the Antarctic Aztec fauna of probable Givetian age (Young 1982), and pterichthyodid antiarch remains, shared with the Hatchery Creek fauna of probable Eifelian age (Young and Gorter 1981). However, of previously described taxa, only the pituriaspid agnathans (Young 1991a) occur in association with the faunas described in this work. The other taxa are only recorded from the associated limestones (localities 6-11, Figure 1D), not dealt with here, for which stratigraphic position has been questioned (Young 1995: 20). Young and Turner (2000: fig. 4, column E) showed two possible positions for the microvertebrate assemblage MV6 in the limestone horizon, either below or above the sandstones of the Cravens Peak Beds. The latter assumes a faulted contact between the two lithologies, and at least two faults were identified in the original measured section (Draper 1976), although they were omitted from the simplified stratigraphic sections published by Turner et al. (1981: fig. 3). Details of the original measured sections are reproduced in Figure 2. Doubtful fish remains recorded from Section 1 (sample GEO 055/ 3 ), above the upper fault and some $260 \mathrm{~m}$ above the base (Figure $2 \mathrm{~A}$ ), are indeterminate impressions showing possible faint ornament. A specimen collected from scree at the base of Section 3 belongs to Wuttagoonaspis (see below). Thelodont scales (unstudied) have been identified in one sample of the lower Dulcie Sandstone from locality 74/14 (see Figure $23 \mathrm{C}$ ), which is consistent with a stratigraphic position between microvertebrate assemblages MV3 and MV6 (Young and Turner, 2000: fig. 4, column E), both of which contain turiniid thelodonts. Acanthodian remains from the limestone locality support a stratigraphic position above the sandstones of the Cravens Peak Beds (Burrow and Young, in prep.).

The new descriptions presented below confirm 
Table 1 Summary of distribution, across the 26 localities collected in 1974 and 1977, of the taxa described in this work, and the two agnathans described by Young (1991). $0=$ absent; $1=$ present; ? = doubtful occurrence; $T=$ type locality; underline = noted in specimen lists, but not studied.

1974

11111111

89012334567

Pituriaspis Young, 1991

Neeyambaspis Young, 1991

Wuttagoonaspis

Lurapullaspis

Toombalepis

Tnoralaspis

Ethabukaspis

Huginaspis

Tokolepis

Cravenaspis

groenlandaspid gen. nov.

cf. Groenlandaspis sp.indet. 1

cf. Groenlandaspis sp.indet. 2

Mithakaspis [tubercles]

Mithakaspis [reduced]

Mithakaspis [ridged]

phlyctaenioid indet. 1

phlyctaenioid indet. 2

phlyctaenioid indet. 3

?petalichthyid gen. nov.

Acanthodii indet.

Rhizodontida indet.

porolepiform indet.

Onychodontida indet.
0000000000

000000000000

$00001001 ? 10$

$0000 ? 0001 ? 1 \mathrm{~T}$

00010000000

0000000000000

0000000000000

$0000 \mathrm{~T} 0010000$

$0000 ? 00000000$

0000 T 0001000

0000001010100

0000000010000

0000000000000

0001000000001

$\begin{array}{lllllllllll}0 & 0 & 0 & 1 & 0 & 0 & 0 & 0 & 1 & 1\end{array}$

000010000001

$? ? 000000001001$

$\begin{array}{lllllllllll}0 & 0 & 0 & 1 & 0 & 0 & 0 & 0 & 1 & 0\end{array}$

00000100100

00000000000 ?

00001001100

$00000000000 ? 1$

$\begin{array}{lllllllllll}0 & 0 & 1 & 0 & 0 & 0 & 0 & 1 & 0 & 0\end{array}$

$0000 ? 00000000$
1977

111111112222

2345234567890134

$0 ? 000100010 \mathrm{~T} 0000$

$000000000000000 \mathrm{~T} 00000$

$11111011 ? 1 ? \mathrm{~T} 1100$

01100000000000001000

$000000000 \mathrm{~T} ? 1 ? 000$

0000000000000100000

0 ? T 0000000000 ? 00000

100000000000010000

$0 \mathrm{~T} 00000000000000000$

00000000000001000 ?

0001001001011010

000000000010000 ?

001000001000111000

$000001000000000 \mathrm{~T} 000$

011100000000000000000

0000000000000000

000000000000000000000

00000000000000000000

1000000010110000

$? 0000000000000100000$

0000010000010000001

$0000000001010 ? ? 00$ ? 0

0010000000010100000

$1 ? 00000000000000$ that younger bothriolepid-phyllolepid placoderm assemblages are not known from the Cravens Peak Beds (contra Gilbert-Tomlinson 1968, and Draper 1976), even though these occur in the upper part of the Dulcie Sandstone (about 490 and $600 \mathrm{~m}$ above base in the SE Dulcie Range; Young 1988a). A significant new result is that the Wuttagoonaspis described below from the Cravens Peak Beds is a different species to that described by Ritchie (1973) from the Mulga Downs Group. In addition, the high-spired groenlandaspid median dorsal (MD) plates (described below as Mithakaspis gen. nov.) are different to those recorded by Ritchie (1975) from the Darling Basin. This indicates that Wuttagoonaspis spp. and groenlandaspids are longer ranging taxa, and that the Georgina Basin localities may have a different age, possibly younger than the Wuttagoonaspis assemblage in the Mulga Downs Group, although the evidence is equivocal. Comparisons can be made here with the Beartooth Butte Formation in Wyoming, USA, where two previously correlated fish assemblages from localities $200 \mathrm{~km}$ apart, with several genera but only one species in common (Elliott and Johnson 1997: fig. 2), are now separated by up to four conodont zones spanning the early Pragian to mid-Emsian
(Blieck and Cloutier 2000: fig. 8). For groenlandaspids, it is clear that the simple scheme put forward by Ritchie (1975), of high-spired forms (e.g. Tiaraspis) in the Early Devonian, and an intermediate stage (from the assumed Middle Devonian of the Darling Basin) that gave rise to low crested Groenlandaspis spp. in the Late Devonian, is no longer tenable. Very high MD plates were recently recorded from the Late Devonian (Long et al. 1997a; Daeschler et al. in press), whilst the identification below of skull remains closely similar to the genus Groenlandaspis, otherwise only known from the Late Devonian, are two indications that the Georgina Basin assemblages could be somewhat younger than those so far documented from the Mulga Downs Group.

The age of the Wuttagoonaspis assemblage in its type area of the Darling Basin was most recently discussed by Young and Turner (2000). This fauna is recorded from the vicinity of the type locality (Wuttagoona Station, about $60 \mathrm{~km}$ NW of Cobar), to the south some $150 \mathrm{~km}$ (Glen et al. 1987; Young, unpublished), and to the west some $360 \mathrm{~km}$, in the Barrier Ranges north of Broken Hill (Coco Range Formation; Neef et al. 1995). Precise correlation of these widespread localities is uncertain. Unlike the 
Georgina Basin occurrences, the Wuttagoonaspis assemblage in the Mulga Downs Group is well placed in a stratigraphic sequence, with datable horizons above and below. The Mulga Downs Group is paraconformable, with local unconformity, on the underlying marine Winduck Group (Glen et al. 1992; Sherwin 1995), which also contains fish remains associated with marine invertebrates. The Gundaroo Sandstone within the Winduck Group supposedly also contains Wuttagoonaspis sp. (Sherwin 1987: 257) Sherwin (1995) assigned a general Lochkovian age to the marine faunas of the Winduck Group. Young and Turner (2000: fig. 3, column D) provisionally placed the Wuttagoonaspis fauna as largely contemporaneous with the Emsian Taemas-Buchan fish fauna, but it now seems likely that in the Darling Basin it extends down at least into the Pragian.

Some new evidence on the age of the Wuttagoonaspis fauna can be adduced from those new taxa described below which have close relatives in northern hemisphere faunas. The new actinolepid arthrodire Lurapullaspis johannseni gen. et sp. nov. described below is placed in the family Bulbocanthidae, for which the type is Bulbocanthus rugosus Bryant, 1932, from the Beartooth Butte Formation in Wyoming, USA. Two main vertebrate localities are documented for the Beartooth Butte Formation: Beartooth Butte, and Cottonwood Canyon (Elliott and Ilyes 1996). Although at least five genera are common to both localities, except for the lungfish Uranolophus wyomingensis, they are represented by different species, and spore data indicate that the Beartooth Butte locality is mid-late Emsian, and the Cottonwood Canyon locality is late Lochkovian-early Pragian (Elliott and Johnson 1997: 183). B. rugosus is only known from the younger locality. Related undescribed forms are known from strata of similar age in Spitsbergen, and from the upper Spokoinaya Formation in Severnaya Zemlya (E. Mark-Kurik, pers. comm.), which is apparently a little older, of Pragian age (Mark-Kurik 1998). Also described below is a new species of the genus Huginaspis from Spitsbergen, a taxon recorded from the Grey Hoek Formation and the 'Violet beds' of Huginaspisskardet, both assigned a probable Eifelian age by Denison (1978:58). The vertebrate biostratigraphy of the Lower Devonian (Red Bay Group and Wood Bay Formation) of Spitsbergen was discussed by Blieck et al. (1987). The Grey Hoek Formation probably spans the Emsian-Eifelian boundary (Blieck and Cloutier 2000: fig. 10), so an Emsian age for closely related species is not unlikely. Finally, another new actinolepid arthrodire, Toombalepis tuberculata gen. et sp. nov. is probably closely related to the Chinese form Yujiangolepis liujingensis described by Wang et al. (1998) from the base of the Nagaoling Formation at Liujing, Guangxi Province, which they align with the sulcatus conodont zone (early Pragian). Zhu (2000) places
Yujiangolepis in his macrovertebrate assemblage III (Sanchaspis-Asiaspis assemblage), assigned a Pragian age (Zhu et al. 2000: fig. 2). It is of possible relevance that the galeaspid Asiaspis from this assemblage has a broadly triangular head shield shape, as in the presumed agnathan Neeyambaspis from the Cravens Peak Beds (Young 1991a: 77 ).

In summary, the general evidence of age currently available indicates that the Wuttagoonaspis fauna from the Cravens Peak Beds and lower Dulcie Sandstone is probably no older than Pragian, and no younger than early Eifelian. Whether it is younger or older than the Wuttagoonaspis fauna from the Darling Basin must await detailed analysis of the faunal associations from the many known fish localities in stratigraphic succession in the Mulga Downs Group and underlying strata, in which sorne or all of the new taxa described below can be expected to occur.

\section{MATERIAL AND METHODS}

All surface material is preserved as clean impressions, and only those extracted from within sandstone blocks retained remnants of original bone as a white infilling. This was removed mechanically, sometimes softened with weak acid. The friable sandstone was impregnated with 'bedacryl' solution before casting with latex rubber. These were coated with ammonium chloride sublimate, and then photographed and/or drawn with a camera lucida. Most of the material is housed in the Commonwealth Palaeontological Collection at the Australian Geological Survey, Canberra (prefix CPC). Other material is held in the Geology Department, Australian Nationional University (prefix ANU V). Material mentioned from other institutions is indicated by prefix as follows: Australian Museum, Sydney (AMF), Muséum national d'Histoire naturelle, Paris (MNHN), Natural History Museum, London (BMP).

\section{Abbreviations}

Standard abbreviations for placoderm bones are used in the text, and with other abbreviations used in the figures are listed below:

a, angle; aa, anterior angle of trunk armour; ADL, anterior dorsolateral plate; $\mathbf{A L}$, anterior lateral plate; AMV, anterior median ventral plate; art, possible articular surface on quadratojugal bone; att.pq, attachment area for palatoquadrate; att.qu, attachment area for quadrate; $\mathbf{A V}$, anterior ventral plate; $\mathrm{C}$, central plate; $\mathrm{cd}$, glenoid condyle of dermal neck joint; cfAL, area overlapping AL plate; csc, central sensory canal; cr.pnu, paranuchal crista defining endocranial edge beneath PNu plate; den, posterior denticle on dorsal crest of MD plate; d.end, external opening or internal tube for endolymphatic duct; dlr, dorsolateral ridge; fo.pi, pineal fossa; 
f.pect, embayment or fenestra for pectoral fin; gr, groove; gr.AL, groove receiving overlap of AL plate; gr.Clm, groove receiving edge of cleithrum; gr.p, posterior groove on SP plate; gr.sca, groove for anterior semicircular canal; gr.scp, groove for posterior semicircular canal; IL, interolateral plate; la.th, lateral thickening; leg, leading edge groove of SP plate; 1.isp, infraspinal lamina of AVL plate; llc, main lateral line sensory canal; $\mathbf{M}$, marginal plate; MD, median dorsal plate; mdcr, median dorsal crest on MD plate; m.dep, median depression; $\mathbf{M x}$, maxilla; Nu, nuchal plate; $\mathbf{n}$, notch; $\mathbf{n}$. C, notch for central plate; nn, nasal notch; nPDL, notch for dorsal margin of PDL plate; n.Pi, notch for Pi plate; n.PrO, notch for PrO plate; n.ptnu, postnuchal notch of trunk armour; n.PtO, notch for PtO plate; oa, overlap area; oaAL, area overlapped by $\mathrm{AL}$ plate; oaAVL, area overlapped by AVL plate; oaC, area overlapped by $C$ plate; oaClm, overlap area for cleithrum; oaGu, overlap area for gular bone; oalL, area overlapped by IL plate; oaMD, area overlapped by MD plate; oaPDL, area overlapped by PDL plate; oaPL, area overlapped by PL plate; oaPMV, area overlapped by PMV plate; oaPVL, area overlapped by PVL plate; obr, oblique ridge of trunk armour; orb, orbit; $\mathrm{PaO}$, paraorbital plate; pap, para-articular process; pbl, postbranchial lamina; PDL, posterior dorsolateral plate; $\mathbf{P i}$, pineal plate; pi, pineal opening; pl.Pop, preopercular pitline; pl.Sq, squamosal pitline; $\mathbf{P M}$, postmarginal plate; pmc, postmarginal sensory groove; PMV, posterior median ventral plate; PN, postnasal plate; PNu, paranuchal plate; Po, postorbital bone (osteichthyans); Pop, preopercular; ppl, posterior pitline; pr, process; prd, dorsal process; PtO, postorbital plate (placoderms); ppr, posterior median ventral process on $M D$ plate; $\mathbf{Q j}$, quadratojugal; $\mathbf{R}$, rostral plate; $\mathbf{r 1 , 2}$, ornamental ridges on SP plate; $r c$, rostral sensory canal; r.comm, rostral commissure; ri, ridge; r.llc, ridge beneath lateral line canal; r.pq, ridge supporting palatoquadrate; s.av, anterior ventral sulcus on IL plate; SO, suborbital plate; soc, supraorbital sensory canal; sorc, supraoral sensory canal; Sq1,2, squamosal bones 1 and 2; sov, supraorbital vault; SP, spinal plate; s.scap, ridge marking edge of scapulocoracoid attachment; Ssq, subsquamosal; th, thickening; thel, thelodont scales; th.pi, thickening around pineal fossa; thPNu, paranuchal thickening; tub, tubercles; vlr, ventrolateral ridge; vpl, ventral pitline of trunk armour.

\section{SYSTEMATIC PALAEONTOLOGY}

\section{Class Placodermi M'Coy, 1848}

Order Arthrodira Woodward, 1891

Suborder Actinolepidoidei Miles, 1973

\section{Remarks}

The actinolepidoid arthrodires are a poorly defined group, diagnosed mainly on primitive characters (e.g. Denison 1984; Johnson et al. 2000). The five features of the trunk armour originally used to define the suborder (Miles 1973: 115) are shown to be primitive by the very similar trunk armour (except for the neck joint) in Eurycaraspis Liu, 1991. Denison's (1978: 46) diagnosis included skull characters, but the validity of this is uncertain if Wuttagoonaspis is included. Denison recognised only a single family Actinolepidae, with the same diagnosis as the suborder, and separated Wuttagoonaspis into a new suborder 'Wuttagoonaspina', but there is little merit in this, and the consensus tree of Goujet \& Young (1995: fig. 2) showed the relationships of Aethaspis, other 'actinolepids', Wuttagoonaspis, and phyllolepids, to be essentially unresolved. Johnson et al. (2000) followed Denison in recognising only one family (Actinolepidae), for which they specified six synapomorphies in a phylogenetic analysis (Johnson et al. 2000: fig. 8). However this analysis used petalichthyids as an outgroup, and failed to consider Eurycaraspis or Wuttagoonaspis, which share five of these six characters, invalidating the result. Here, we provisionally assign our described taxa to three families within the suborder, one of which is new. Denison (1978) included 'Dermal bones ... tuberculated' as a character of the suborder, but this applies only to some of the included families (Actinolepidae, Antarctaspidae).

\section{Family Wuttagoonaspidae Ritchie, 1973}

\section{Remarks}

Ritchie (1973: 68) assessed Wuttagoonaspis, the genotype and only member of this family, as 'a specialised euarthrodire showing clear evidence of derivation from the actinolepine arctolepids', which 'may provide a link between the arctolepids and the petalichthyids'. He concluded that Wuttagoonaspis was 'not very closely related' to Phyllolepis, even though noting an 'undeniable - if superficial - resemblance in the ornament of the two forms'. He also noted that both taxa 'share the distinctive feature of a large pentagonal centronuchal carrying four converging pairs of sensory canal grooves'. These include the supraorbital sensory canals, which often pass back to the ossification centres of paired $C$ plates in various brachythoracid arthrodires, but generally not in either actinolepids or phlyctaeniids (exceptions, discussed below, include Groenlandaspis and some of the variations in sensory groove pattern observed in Arctolepis).

This pattern of converging sensory grooves is also seen in other groups, and its scattered distribution 
suggests that it could be a primitive placoderm feature. Goujet (1984a: 250) considered presence of anterior ventral plates in the trunk armour to show that Wuttagoonaspis was a sister group to actinolepids, but subsequently this bone has been found in other groups (e.g. petalichthyids; Liu 1991), indicating that it is a plesiomorphy. Recent cladistic analysis of the Placodermi resolves phyllolepids and wuttagoonaspids as sister groups in three of six most parsimonious solutions (Goujet and Young 1995: fig. 1), supporting some earlier views (e.g. Miles 1971: 161, 181, 197; Long 1984: fig. 27; Liu 1991: fig. 20). Amongst actinolepids an elongate $\mathrm{Nu}$ reaching the $\mathrm{Pi}$ plate is also seen in Aethaspis and Baringaspis, but in neither do the sensory canals converge onto the Nu. As noted by Denison (1978), Wuttagoonaspis and the phyllolepids also lack $C$ plates. Given the wide distribution of these elements in the skull of most placoderm groups, their absence can be interpreted as a loss, and therefore potentially another shared derived character of these two genera.
Genus Wuttagoonaspis Ritchie, 1973

Wuttagoonaspis milligani sp. nov. Figures 3A,C, 4-9, 35B

fragmentary plates of ... Phyllolepis: Johnstone et al. 1968: 611

fragmentary plates of ... Phyllolepis: GilbertTomlinson 1968: 195

Wuttagoonaspis sp. in the northern Dulcie Range: Ritchie 1975: 572

Wuttagoonaspis: Turner et al. 1981: 52, 53

Wuttagoonaspis sp.: Young 1984: 65

Wuttagoonaspis: Shergold 1985: 21

Wuttagoonaspis sp.: Young 1986: figure 14A

Wuttagoonaspis: Young 1988a: 374

Wuttagoonaspis: Long et al. 1988: 74

Wuttagoonaspis: Young 1991a: 67

Wuttagoonaspis species: Stidolph et al. 1988: 23

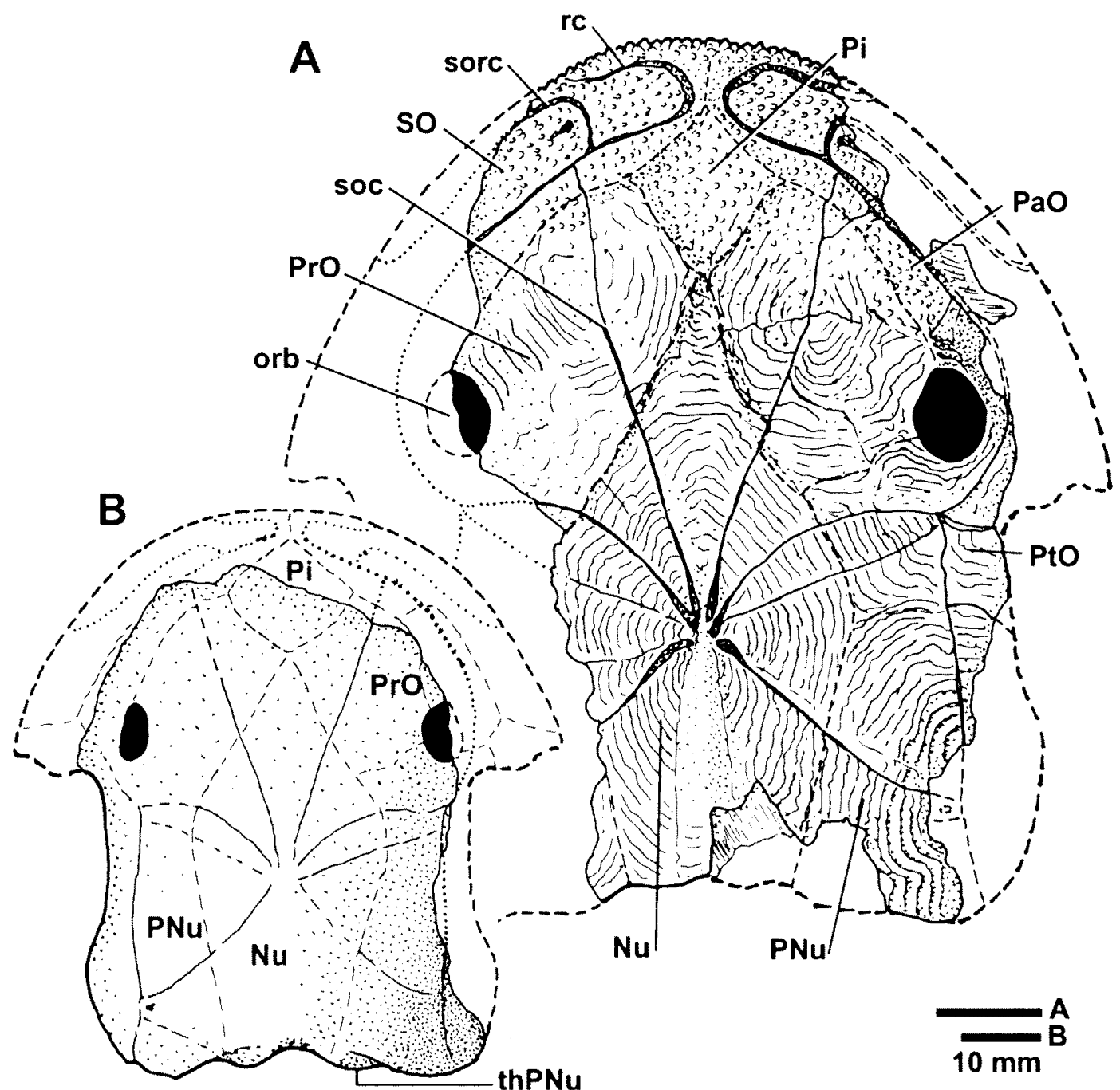

Figure 4 Wuttagoonaspis milligani sp. nov., skull restorations. A, ANU V2970; B, CPC 36872. Shape of anterolateral skull margins based on ANU V2971 and CPC 36878 (cf. Figs 5B, E). 
Wuttagoonaspis: Haines et al. 1991: 32

Wuttagoonaspis spp.: Young et al. 1993: 247

Wuttagoonaspis ... in the Georgina Basin: Young 1995: 20

Wuttagoonaspis ... in the Georgina: Young 1996: 103

Wuttagoonaspis sp.: Young and Turner 2000: 461

\section{Material}

AMF 50843; ANU V2970-73; CPC 25343, 36859 $913,37046$.

\section{Localities and Horizon}

$\mathrm{BC} 1,7 ; 74 / 11,14,16$ (northwestern Dulcie Syncline, in the Dulcie Sandstone); GEO 035/007; $77 / 2-5,12,14,15,17,19$ (Cravens Peak Beds). For localities see Figure 1. A locality summary for each taxon is given in Table 1, and locality details for each specimen are listed in the Appendix.

\section{Diagnosis}

A Wuttagoonaspis with a skull roof attaining a length of at least $210 \mathrm{~mm}$, in which the suborbital plates meet in the midline in front of the pineal, the rostral sensory grooves are closely spaced, and the nuchal plate extends forward in front of the orbits, separating the preorbital plates with a point contact with the pineal plate. The posterior skull roof margin has a midline angle of about $105^{\circ}$, and lateral thickenings flanking a midline embayment. The orbits are anteriorly placed, at about one third of midline length from the anterior margin, the skull is as broad or slightly broader than long, and the AL plate is higher than long.

\section{Etymology}

After noted coal exploration geologist E.N. (Ted) Milligan (1932-1999), who first collected this material from the Dulcie Sandstone.

\section{Remarks}

There is a large quantity of undescribed material of the type species $W$. fletcheri, but this new species is erected on the basis of comparisons with illustrated material of Ritchie (1973), and various casts of Australian Museum specimens (e.g. AMF 54141, 54670,61282 plaster copy). These suggest the differences in skull roof pattern given above, but they need to be substantiated with more complete material, and a detailed analysis of variation within the type species. The dermal ornament is similar in both species.

\section{Description}

\section{Skull roof}

The skull material of this form includes many incomplete portions of the dermal roof from both large and small individuals. It was already noted by Ritchie (1973) that some examples from the Georgina Basin exceed the size range of the type species, in which skull roof lengths up to $180 \mathrm{~mm}$ were recorded. The largest well-preserved example in this material (holotype: ANU V2971) has a midline skull roof length of $210 \mathrm{~mm}$. Other wellpreserved larger specimens (incomplete) include CPC 36874 and 36882, with ANU V2970 and CPC 36872 being well-preserved smaller examples. The following description is based mainly on comparisons of these specimens with casts of the type species W. fletcheri (AMF 61282 from Mount Jack; AMF 54141, 54670) held in the Geology Department, ANU.

ANU V2970 (Figure 5A), is an incomplete skull roof (39 mm between orbits, $75 \mathrm{~mm}$ midline length) with ornament that compares well with AMF 54141 and 61282 , both of which are smaller specimens. Bone sutures are indistinct, but can be discerned from ornament pattern, and a slight thickening at the surface along the margins of the main head plates ( $\mathrm{Pi}, \mathrm{Nu}, \mathrm{PrO}, \mathrm{PtO}$ plates), which is clearly visible in low angle lighting (also seen in $W$. fletcheri; Ritchie 1973: pl. 5, fig. 1). This shows that the $\mathrm{Nu}$ plate extended forward between the $\mathrm{PrO}$ plates, to meet the $\mathrm{Pi}$ in a point contact (Figure $4 \mathrm{~A}$ ). In illustrated material of $W$. fletcheri the PrO plates have a midline contact in front of a shorter $\mathrm{Nu}$, which reaches only a short distance in front of the level of the orbits. The anterior suture of the PrO in ANU V2970 is traceable from the lateral corner of the $\mathrm{Pi}$ to an angle in the supraorbital sensory canal (soc, Figure 4A). The paired anterior sensory canal loops (rc, sorc) are characteristic of Wuttagoonaspis, but with the rostral canals (rc, Figure 4A) very close to the midline (separated by $2 \mathrm{~mm}$ ). By contrast, in a slightly smaller skull roof of $W$. fletcheri (AMF 61282; interorbital width $36 \mathrm{~mm}$ ) which shows this anterior margin, the rostral canals are $10 \mathrm{~mm}$ apart, and they are widely spaced on other illustrated examples of Ritchie (1973). As in the type species this part of the skull extending back onto the $\mathrm{Pi}$ is covered with tubercles, the ridged ornament developing on the PrO plates and those further back. There is no sign of a suture in front of the $\mathrm{Pi}$, but it is assumed to be in the midline, based on other specimens (see below). Four sensory grooves/ pitlines of each side converge on the Nu ossification centre, as restored by Ritchie (1973: fig. 5A) for the type species, but again they meet closer to the midline than in that restoration. A paired posterior lineation separating a smooth zone is seen on examples of $W$. fletcheri (AMF 61282) to delineate a raised central part of the $\mathrm{Nu}$ with ridged ornament, so the absence of ornament here is probably due to postmortem abrasion. At the ossification centre the grooves are expanded, but this could also be partly a postmortem effect. Unfortunately the locality 

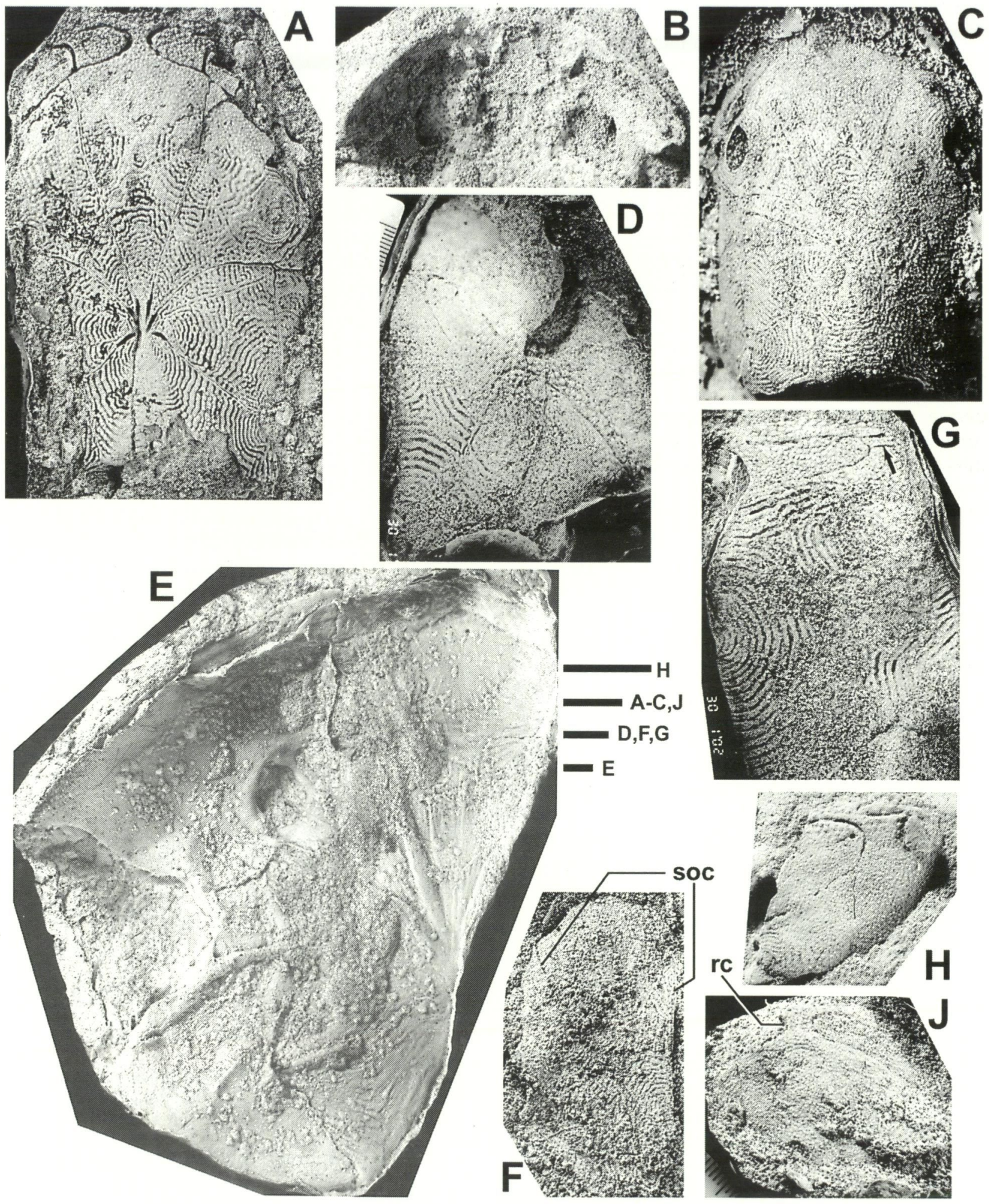

Figure 5 Wuttagoonaspis milligani sp. nov., skull material. A, ANU V2970, dorsal view; B, CPC 36878, internal view; C, CPC 36872, dorsal view; D-E, ANU V2971 (holotype), external view of right anterolateral skull margin (D), and preserved internal skull roof surface (E); F, CPC 36871 (left anterolateral skull portion); G, CPC 36881 (left anterolateral skull portion); H, CPC 36867, and J, CPC 36869, anterior skull fragments. All specimens are latex rubber casts whitened with ammonium chloride; scale bars $=10 \mathrm{~mm}$.

number was lost from this specimen, but it probably came from locality 3 . The under surface of the block shows two poor skulls in visceral view that are too incomplete for study (?Wuttagoonaspis, and a probable phlyctaeniid). The counterpart of this surface could not be located in the AGSO collection (February, 2001).

In CPC 36872 (Figure 5C) the sensory grooves and 
the ornament are apparently weathered and less distinct. This smaller skull (31 $\mathrm{mm}$ between orbits; midline length about $65 \mathrm{~mm}$ ), includes most of both orbits, but lacks anterior and anterolateral skull margins (Figure 4B). The Nu extends well in front of the orbits, but the contact with the $\mathrm{Pi}$ is not clearly preserved. The concentric ornament of the $\mathrm{PrO}$ plates is consistent with the suture pattern shown in Figure 4B. The well-preserved posterior margin of this specimen is apparently uncrushed, and lower and broader than in AMF 54141, (median angle of $105^{\circ}$, compared to $90^{\circ}$ in that specimen). This could be another specific difference. The $\mathrm{Nu}$ has a midline embayment, and laterally the posterior margin is embayed across the $\mathrm{Nu} / \mathrm{PNu}$ suture, where it has a bevelled edge, with a bulbous dermal thickening beneath the $\mathrm{Nu}$ in posterior view projecting out from the skull margin. Lateral to this the skull margin has a narrow edge, where the $\mathrm{PNu}$ slid over the flange of the ADL, as previously illustrated by Ritchie (1973: fig. 2a), and likened to that of actinolepids. However this 'paranuchal thickening' (thPNu, Figure 4B) may be an important difference. The same structure is seen on much bigger skulls (e.g. CPC 36874), and there is a corresponding morphology on the trunk armour (see below).

CPC 36878 (Figure 5B) shows the anterior border of a skull in visceral view, including both orbits. Interorbital width is about $28 \mathrm{~mm}$. This specimen was used to restore the anterior margin in a skull restoration (Figure $4 \mathrm{~B}$ ) based on the slightly larger CPC 36872 (31 mm between orbits).

ANU V2971 (Figure 5E), the largest well preserved skull (210 $\mathrm{mm}$ long), selected as the holotype, comprises most of the right half, preserved in visceral view. Sections of the external surface behind and in front of the right orbit are preserved in pieces of the counterpart, but do not include the midline. The visceral surface in Wuttagoonaspis fletcheri has previously been illustrated for only one specimen (Ritchie 1973: pl. 5, fig. 4; also Long 1995a: 114). This new example of the visceral surface displays several interesting features. There is a clear midline suture at the anterior margin (Figures 5E, 6A), in contrast to the transverse external suture between the $\mathrm{R}$ and $\mathrm{Pi}$ shown by Ritchie (1973: fig. 5A). This is consistent with the narrow space between rostral sensory grooves in ANU V2970 (Figure 5A). The internal sutures of the Pi are clear, and there is a small pit to the left of the midline, possibly the inner side of the pineal foramen. The radiating striations of the $\mathrm{Nu}$ extend anteriorly close to the $\mathrm{Pi}$, but actual contact cannot be demonstrated (the relevant areas on the counterpart are missing). Ritchie (1973) stated that in $W$. fletcheri the skull roof was wider than long in juveniles, but the reverse in adults. In this specimen of $W$. milligani sp. nov., the midline at the level of the orbits is accurately located by the radiating striations between the ridges beneath the supraorbital sensory canals (soc; part of the left canal is just preserved). This gives a restored width of some $220 \mathrm{~mm}(2 \times 110)$. The orbits are anteriorly placed (one third of total length from the anterior margin) as in the juvenile restoration of Ritchie (1973: fig. 2f), larger individuals of the type species having the orbits farther back ( $45 \%$ of total length from anterior margin). Other noteworthy features are the ridges beneath the sensory grooves (pmc, soc, Figure 6A), and the strong ridge on the lateral orbital margin, presumably marking the limit of the palatoquadrate (r.pq) as in other placoderms. In contrast to the previously illustrated example (Ritchie 1973: pl. 5, fig. 4), no strong ridge is evident beneath the central sensory groove. The posterior groove in the new specimen is clearly seen to be the dermal tube for the endolymphatic duct, a defining character for arthrodires first proposed by Goujet (1984b). It arises beneath the paranuchal crista (cr.pnu), which would have enclosed the lateral edge of the endocranium, and terminates at the suture with the Nu plate, with an open end where the tube would have entered the endocranium (d.end, Figure 6A). This is equivalent to its position in arthrodires, where the dermal section terminates at the $\mathrm{C} / \mathrm{PNu} / \mathrm{Nu}$ suture triple junction (e.g. Lehmanosteus; Goujet 1984a: fig. 111).

Sections of sutures for the $\mathrm{PNu}, \mathrm{Nu}, \mathrm{M}$ and $\mathrm{PtO}$ plates can be discerned, but other areas of the visceral surface are poorly preserved. A slightly displaced apparent suture on the anterolateral skull border in front of the orbit was not included in Ritchie's (1973: fig. 5A) reconstruction, but can be interpreted as the lateral margin of a PN element. Ritchie named a much larger $P N$ including the entire anterolateral border as the PN, but this interpretation was rejected by Young (1980) because that element must have covered the upper jaw (palatoquadrate), and therefore must be the SO plate. An extra 'paraorbital' (Pa) plate was identified by Young (1980: fig. 23D) between the SO and the PrO of Wuttagoonaspis, but there is evidence in some skulls (e.g. AMF 61282 from Mt Jack) that this comprised anterior and posterior elements, the former possibly being the homologue of the PN of other placoderms.

Information on the external surface (Figure 5D) is provided by three adjoining impressions of the counterpart which are on separate blocks (samples numbered 19u.1-3). The posterior midline and left posterolateral margin are possibly represented on another piece (sample 19t.2; not a precise fit due to missing fragments). Much of the ornament has been lost, and observed features on two pieces of the counterpart are shown in Figure 6B, one including the orbit, with a section of the lateral line groove, the adjoining anterior piece including the rostral 


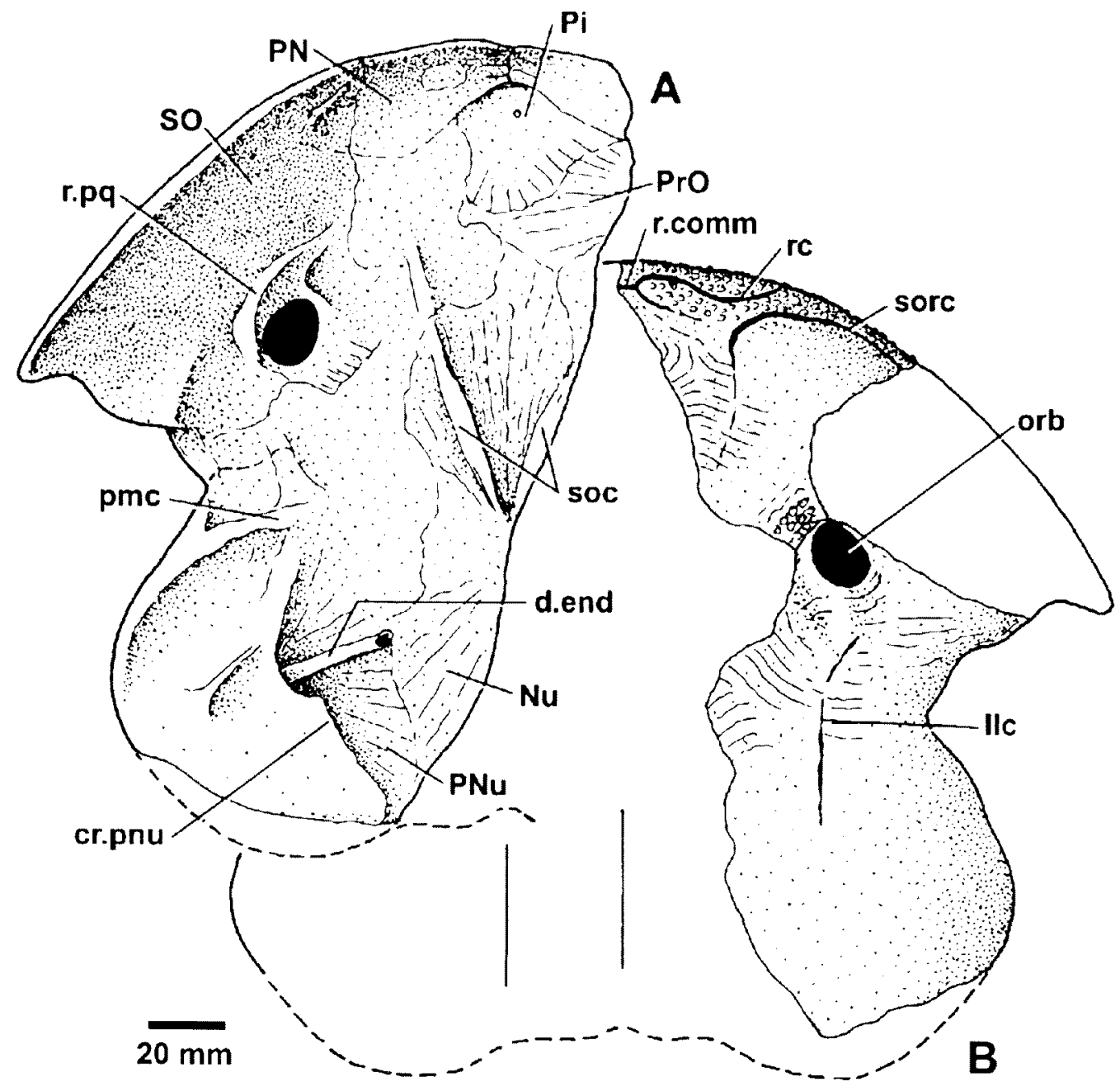

Figure 6 Wuttagoonaspis milligani sp. nov., part restoration of the skull in the holotype, ANU V2971. A, preserved part of right side of skull roof, ventral view; B, preserved parts of skull roof external surface.

margin, with the rostral and suborbital sensory canals (Figure 5D).

CPC 36874 is the posterior portion of the skull of a similar-sized large animal $(100 \mathrm{~mm}$ from the midline to the lateral corner of the PNu) including the posterior part of the nuchal and most of the right PNu. In the absence of the anterior part of the skull it looks like Actinolepis. The vaulted form of the skull is well shown at the posterior margin. An associated large AVL and SP plate described below (on a separate block, but only four samples were collected from this locality) is assumed to come from the same individual. The posterior median embayment in the $\mathrm{Nu}$ is flanked by rounded processes, just as in the specimen figured by Ritchie (1973: pl.5, fig. 1). The ornament is typical of that described for the genus, with a strong concentric ridged pattern, the ridges often showing coalesced tubercles. The sensory grooves are narrow and only partly visible. The junction of the posterior pitline and the lateral line canal on the PNu is clear, but the endolymphatic opening cannot be seen.

The abundant material from locality $77 / 19$ occurs as a jumble of plates within large broken sandstone blocks, representing a range of sizes. CPC 36879 is a small skull roof in part and counterpart $35 \mathrm{~mm}$ wide near the posterior margin. The anterior margin in front of the orbits is missing. This is one of the smallest Wuttagoonaspis from this abundant locality, and shows that the population contributing to this assemblage included a large range of sizes. CPC 36877 is another incomplete skull of similar size showing the middle part of the posterior margin, with smooth lateral thickenings flanking a median embayment, as in the much bigger CPC 36874 described above. CPC 36883 is another small skull preserved in visceral view (estimated midline length $35 \mathrm{~mm}$ ). It shows a broad posterior half as illustrated by Ritchie (1973: fig. 2F), but again with a more embayed posterior margin. CPC 36880 is a portion of the left side of a skull roof $130 \mathrm{~mm}$ long from the posterior border to the anterolateral margin. The ornament shows the position of the suture between the $\mathrm{Nu}$ and the left $\mathrm{PNu}$, and a distinct lateral notch in the posterior margin of the $\mathrm{Nu}$. The midline is not quite preserved, and the 

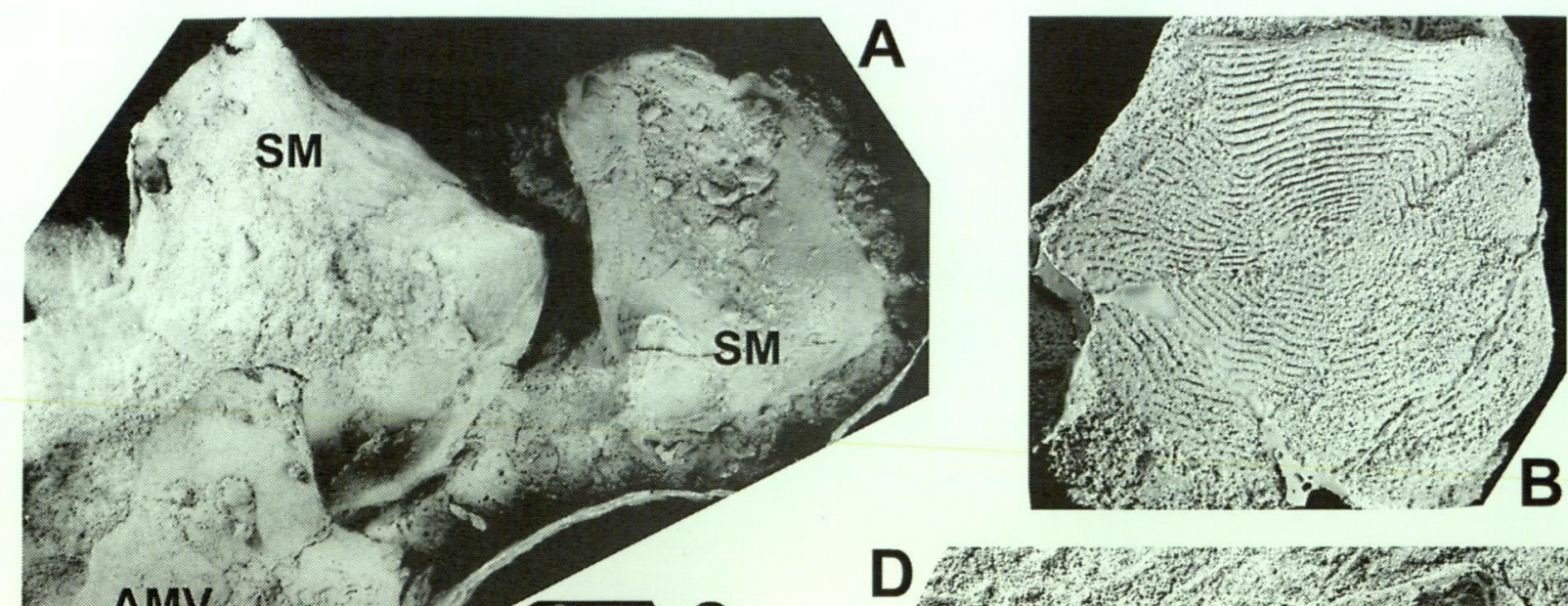

AMV
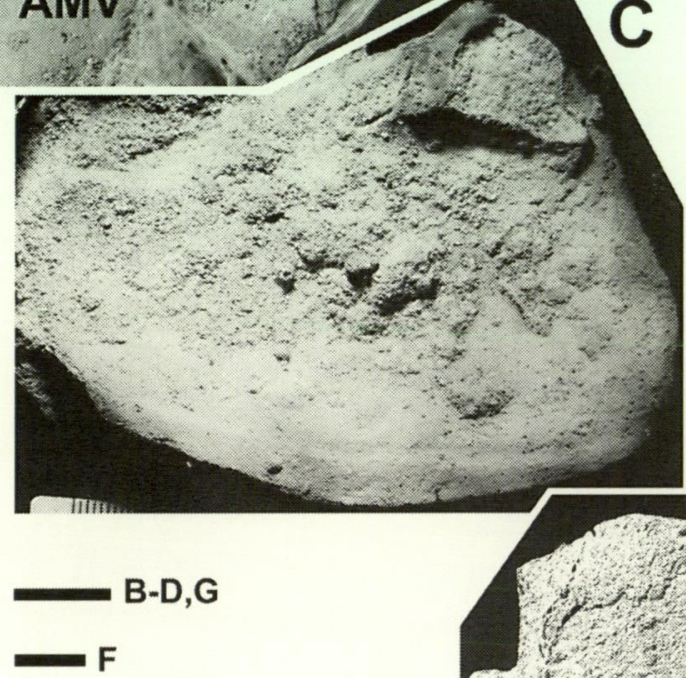

$-\mathrm{A}, \mathrm{E}$
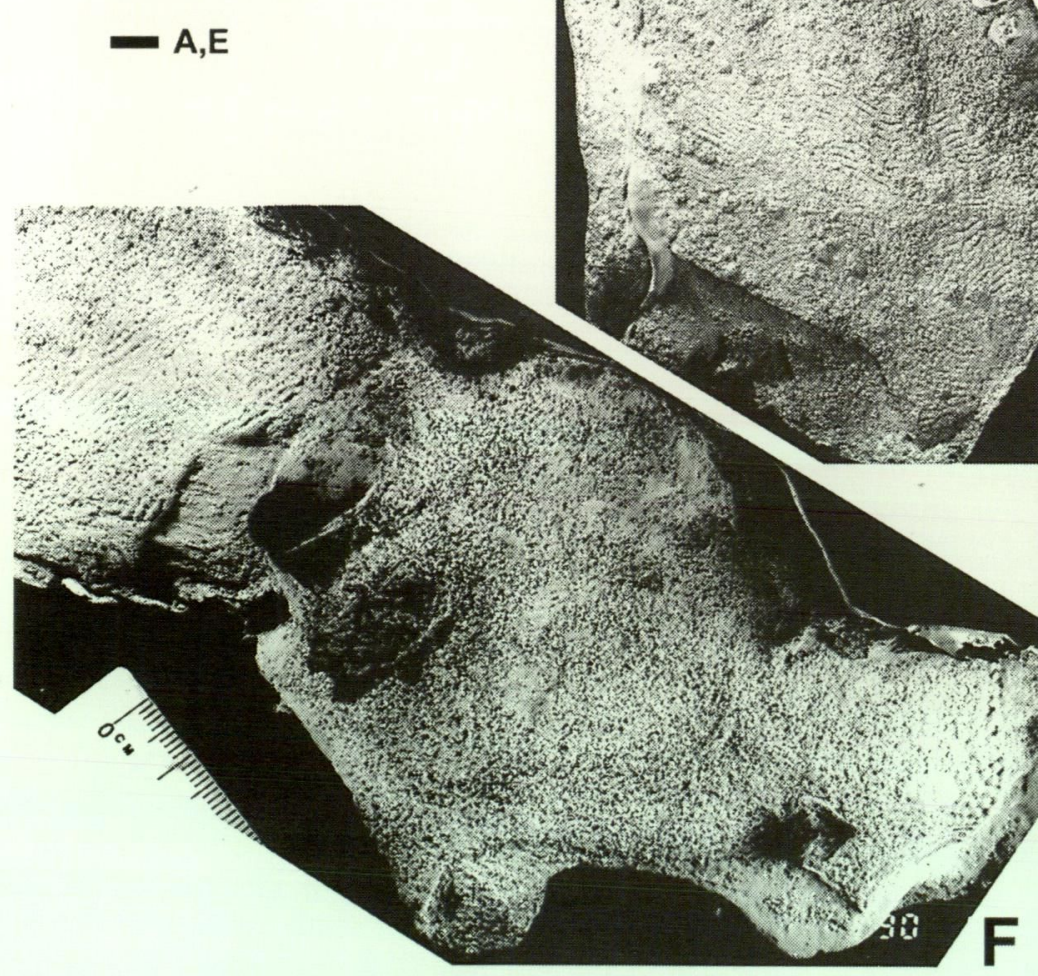

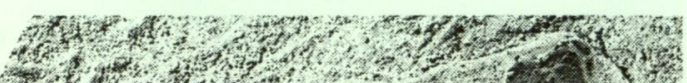

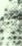

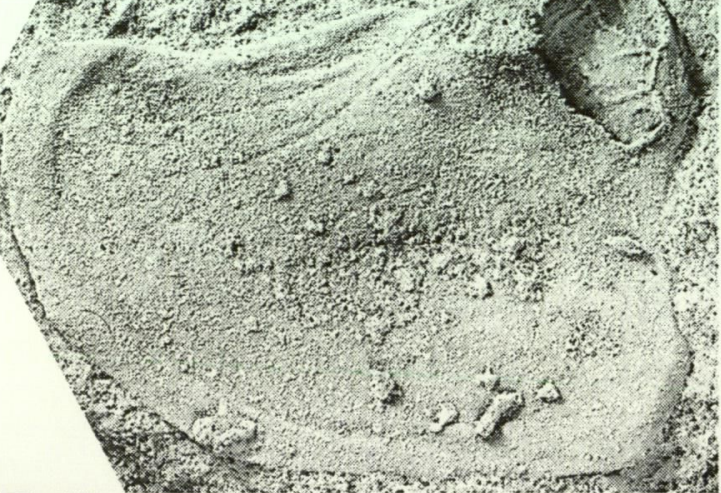

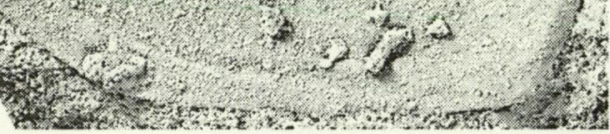

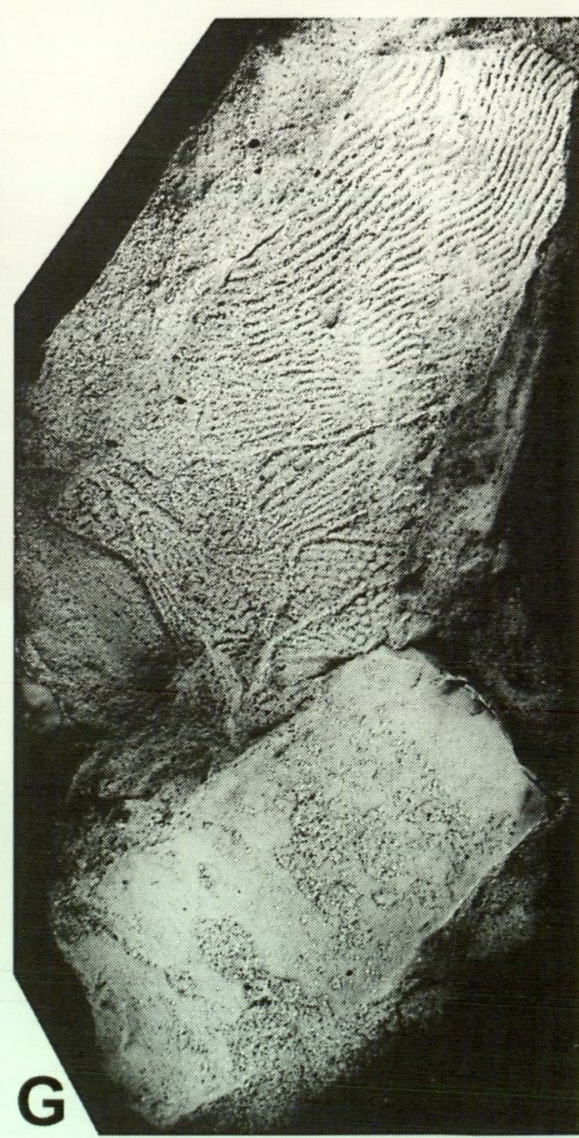

Figure 7 Wuttagoonaspis milligani sp. nov., cheek and trunk armour remains. A, incomplete AMV (CPC 36911) and SM plates (CPC 36894), internal view; B, right SM, external view (CPC 36886); C, left SM, internal view (ANU V2972); D, left SM, internal view (CPC 25343); E, left ADL and PDL, external view (CPC 36908); F, left ADL and PDL, external view (CPC 36910); G, left side of MD, with attached ADL and PDL, external view (ANU V2973). All specimens are latex rubber casts whitened with ammonium chloride; scale bars $=10 \mathrm{~mm}$ 
ornament indicates a median convexity, unlike the previous specimen. In specimens from Mt Jack illustrated by Ritchie (1973: pl. 5, fig. 1) the ornament pattern suggests a posterior median process on the Nu at earlier stages of growth.

CPC 36882 is the anterior part of a large skull roof, $85 \mathrm{~mm}$ between the orbits, which lacks ornament except for tubercles around the anterior skull margin and near the orbits, although this is possibly a postmortem effect. Neither sutures nor sensory grooves can be discerned, but its broad rostral margin shows a central thickened tuberculate median section, which compares closely with a much smaller skull from Mt Jack (AMF 61282), where this part forms the $R$ plate as in Ritchie's (1973) skull reconstruction. Adjacent to this skull is an incomplete right SM plate. CPC 36881 (Figure 5G) is portion of a large skull roof with a straight apparently natural margin some 200 mm long, which must be a break along the left supraorbital canal. A notch near the anterior end is where the skull has broken around the left sensory loop. The 'rostral canal' of Ritchie (1973) is clearly visible, with two short transverse grooves directed towards the midline (arrow, Figure 5G).

Fragments with ridged ornament of Wuttagoonaspis type are seen at most localities, but the following examples of skull roof portions can be definitely assigned to the genus. CPC 36868 is a small right $\mathrm{PrO}$ (32 $\mathrm{mm}$ long) showing the posterior angle and orbital notch as in Ritchie's reconstruction (1973: fig. 5A), but with an incomplete mesial margin. The ornament (poorly preserved) is apparently much less ridged than in the type material. An adjacent $\mathrm{PrO}$ in internal view is probably from the opposite side. CPC 36871 (Figure $5 \mathrm{~F}$ ) is a larger example (length $56 \mathrm{~mm}$ ) with part of the right PrO attached to the left, and broken off along the right supraorbital canal (soc, Figure 5F). The anterior segment of the $\mathrm{Nu}$ between the supraorbital canals is attached, as is the left $\mathrm{PtO}$ and the Pi plate. The latter shows an anterior corner on the counterpart, rather than the short margin with the rostral of Ritchie's reconstruction (1973: fig. $5 \mathrm{~A}$ ), but otherwise the pattern of ridged ornament, sutures and sensory grooves compare well with $W$. fletcheri. CPC 36875 (Figure 37B) shows the left anterolateral portion of a skull roof with coarse tubercles in front of the orbit and around the skull margin, as in the type species (Ritchie 1973: pl. 5, fig. 3). CPC 36876 is a poorly preserved internal impression of a skull showing the supraorbital vault, with the counterpart preserving some of the skull margin. CPC 36884 is a small incomplete skull showing the left side with articular processes for the SM plate. The specimen (CPC 37046) from Euthithethera Soak identified by Gilbert-Tomlinson (1968: 203) as 'Phyllolepis', is a small impression of ridged ornament besides a larger skull portion showing its inner surface, with the characteristic enclosed orbit of Wuttagoonaspis (orb, Figure 3E).

Some other specimens broken along the supraorbital sensory canal as in CPC 36871, 881 include CPC 36873 , a large skull roof $(125 \mathrm{~mm}$ midline length) preserving the left $\mathrm{PrO}$ and left part of the $\mathrm{R}$ and $\mathrm{Nu}$, and CPC 36868, a smaller right skull roof portion with tuberculate ornament. CPC 36869 (Figure 5J) shows the R, Pi and part of the right SO with sensory loop, the left sensory loop preserved as a broken margin ( $\mathrm{rc}$, Figure 5J), which again indicates a narrow interspace $(4 \mathrm{~mm})$ as in other specimens (e.g. Figure 5A). CPC 36867 is a smaller example, similarly preserved, except that the right sensory loop forms the broken margin. CPC 36870 is a poorly preserved anterior skull portion including the left orbit, preserved in part and counterpart with an associated SM. On the same block is a skull roof of Tokolepis gen. nov. (see below). The same locality $(77 / 3)$ has produced large SP plates (CPC 36904) comparable in size to the large AVL and SP from locality $77 / 4$ (Figure 4A).

There remains some uncertainty about the midline suture and sensory canal configuration on the rostral margin of the skull roof in this new material. The median suture is clear at the rostral margin on the inner surface in CPC V2971 (Figure $5 \mathrm{E}$ ). Externally a transverse groove extends to the midline from the loop of the rostral canal (Figure $6 \mathrm{~B}$ ), in the position of the Pi-R suture in W. fletcheri, but it has the appearance of a sensory groove rather than a suture. CPC 36881, which preserves the rostral canal loop of the left side (Figure 5G), shows two similar transverse grooves, so at least one of these would appear to be a rostral commissure of the sensory canal system (r.comm). In both specimens the preserved edge lies close to, or on, the midline. If there is also a transverse suture in this position, it would seem that the $\mathrm{R}$ plate was very small, and completely excluded from the internal surface by the median suture of the PN plates as described above.

\section{Cheek}

The SM was previously illustrated from the Mulga Downs Group by Ritchie (1973: fig. 4; pl. 4, fig. 1B). The internal surface of a left plate from locality $77 / 19$ in the Cravens P'eak Beds (CPC 25343), illustrated by Young (1986: fig. 14A), shows the attachment surface for the opercular cartilage (Figure 7D). With the various large incomplete skulls just described from this locality are many disarticulated SM plates, ranging in size from 75$100 \mathrm{~mm}$ long, and 55-75 mm deep. Association of these elements suggests some current sorting. A large SM (AMF 50843; $83 \times 50 \mathrm{~mm}$ ) was recorded by Ritchie (1973: 71) from locality 26 of GilbertTomlinson (1968), and an incomplete SM (CPC 
36885) was identified from locality GEO 035/007 collected in 1975 by J.J. Draper.

The external surface of the SM is well shown by several examples. CPC 25343 was smooth, but this could be due to postmortem abrasion, or may be a preservation or weathering phenomenon in the friable sandstone lithology at this locality, since there are several examples with excellent ornament preservation on parts of an otherwise smooth external surface impression. CPC 36888 is a large plate (65 mm deep, $90 \mathrm{~mm}$ estimated length). The ridges of the concentric ornament are broader anteriorly, and narrow inside the posterodorsal margin. Along the anteroventral margin the ridges break up into aligned coarse tubercles. The central part of the external surface is poorly preserved, but is well displayed in another large incomplete specimen (CPC 36890 , length $95 \mathrm{~mm}$ ), which shows the radiating ridges running posteriorly from the ossification centre, which is centrally placed, but a little closer to the front of the bone. The same ornament pattern is seen in the SM previously figured by Ritchie (1973: pl. 4, fig. 1b), and posteriorly radiating ornament is well displayed on one of the two smaller SM plates in this material (CPC 36886, Figure 7B). In proportion this bone is higher (approx. $50 \mathrm{~mm}$ ) and shorter (about $55 \mathrm{~mm}$ ) than another example (CPC 36892) of similar length (about $55 \mathrm{~mm}$ ), but which is only $39 \mathrm{~mm}$ high near the anterior margin. CPC 36886 also differs in having a distinct raised zone of coarse tubercles near the anteroventral margin, which would be an extension of the tuberculate zone forming the anterolateral borders of the skull roof and extending along the pectoral spine (e.g. Ritchie 1973: pl. 4, fig. $4 ;$ pl. 6, figs 5-6).

The inner surface of the $\mathrm{SM}$ is gently concave (Figure 7C, D). The dorsal margin is similarly developed in most specimens, with a small angle behind the opercular cartilage attachment forming the anterior end of a shallow embayment. CPC 36894-895 (Figure 7A) are left and right plates exposed in visceral view and very similarly developed, but from two different sized individuals. The embayed part has a thick bevelled edge, to abutt against the 'articular process' identified by Ritchie (1973, figs 4, 5A, pl. 4, fig. 1a) on the lateral margin of the skull (his PM plate). The posterodorsal corner is thickened and slightly inflected, and presumably articulated against and/ or just beneath the posterolateral corner of the skull. A shallow groove and occasional striations pass anterodorsally to the notch at the posterior border of the opercular cartilage, and may be homologous to the 'spiracular groove' in other placoderms. CPC 36898 , preserved in part and counterpart, has a slight posterodorsal notch, which may be enlarged in some specimens.

The rounded posteroventral margin of the SM would have formed the opercular opening. It is is sharp-edged, with a distinct groove inside the margin (Figure 7D), also seen in CPC 36890, and other specimens. Medium to large examples with the anteroventral part preserved show a short thickened anteroventral margin (CPC 36888, 893) but this is less clear in the only smaller specimen (CPC 36892), where it is more rounded. The short anteroventral margin presumably abutted against the corresponding part of the PSO plate, which in the holotype of $W$. fletcheri has a narrow overlapped margin (Ritchie 1973: pl. 4, fig. 1a). CPC 36892 shows a shallow notch in the middle of the anterior margin, also evident on several other specimens. Above and below the notch the margin is thick and bevelled, but at the notch it is thin.

Many examples show the opercular cartilage, but the best preserved is the left SM previously figured. The broken region of perichondral bone has a triangular shape, and shows traces of a vascular network on the inner surface of the dermal bone. The posterodorsal corner shows remnants of a muscle insertion area, exactly as in acid-prepared examples of the acanthothoracid Romundina (e.g. MNHN specimen DB4). This close similarity suggests that we are dealing with a primitive placoderm character shared between two otherwise disparate groups. The opercular cartilage in CPC 36887 is apparently almost complete, with a prominent anteroventral ridge forming a ventral support for the cartilage (whether this is dermal or perichondral cannot be determined in these negatively prepared specimens). The space between the dermal 'articular processes' of Ritchie (1973), where the SM articulated via the opercular cartilage with the endocranium, is clearly shown in his skull reconstruction (Ritchie 1973: fig. 4).

\section{Trunk armour}

Apart from the internal surface of an AVL with SP attached (Ritchie 1973: pl. 6, fig. 6), the ventral plates of the armour have not previously been illustrated for Wuttagoonaspis. Several examples showing attached AVL, SP and IL plates are described here, the best detail exhibited on large specimens (Figure $8 \mathrm{D}, \mathrm{E}$ ).

CPC 36905 (Figure 8E) is the internal impression of a right AVL with IL and portion of the SP plate from a large individual (AVL about $90 \mathrm{~mm}$ across, but the mesial margin is poorly preserved). Preserved length from the postbranchial lamina of the IL to the posterior edge of the AVL is about 105 $\mathrm{mm}$. The three component bones are slightly displaced with respect to each other, but their morphological relations are clear. In anterior view the IL shows typical strong ridged ornament of the postbranchial lamina, but is smooth laterally (IL, Figure 9B). It is about $92 \mathrm{~mm}$ long with a notched mesial margin, and a low dorsal process (pr.d) 


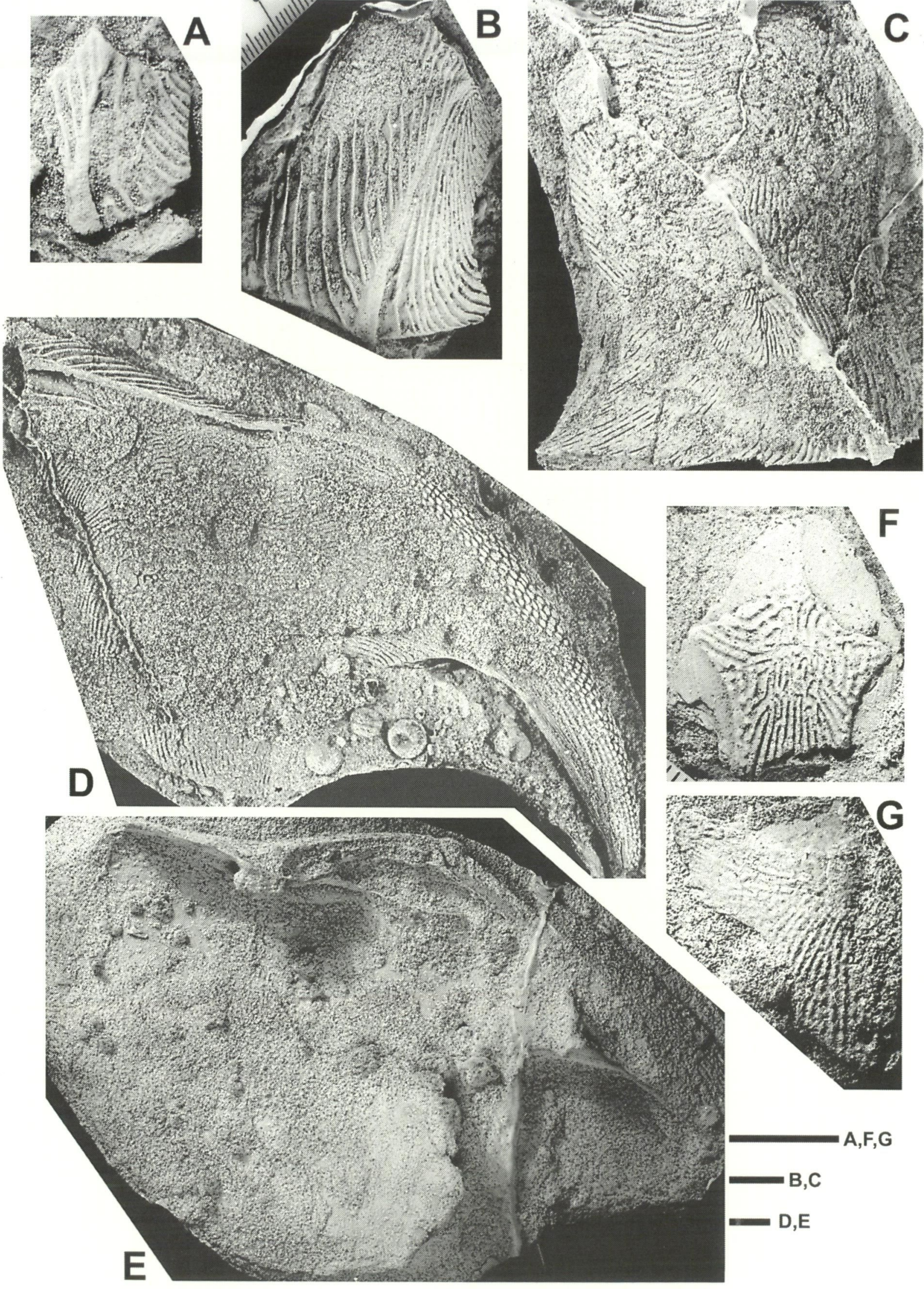

Figure 8 Wuttagoonaspis milligani sp. nov., lateral and ventral plates from the trunk armour. A, incomplete AL plate, external view (CPC 36861); B, incomplete AL plate, external view (CPC 36907); C, right AL plate, external view (CPC 36903); D, left AVL, AV, IL and SP plates in ventral view (CPC 36874); E, right AVL, IL and SP plate (incomplete), internal view (CPC 36905); F, incomplete AMV plate, external view (CPC 36912); G, incomplete right PVL plate, external view (CPC 36906). All specimens are latex rubber casts whitened with ammonium chloride; scale bars $=10 \mathrm{~mm}$. 


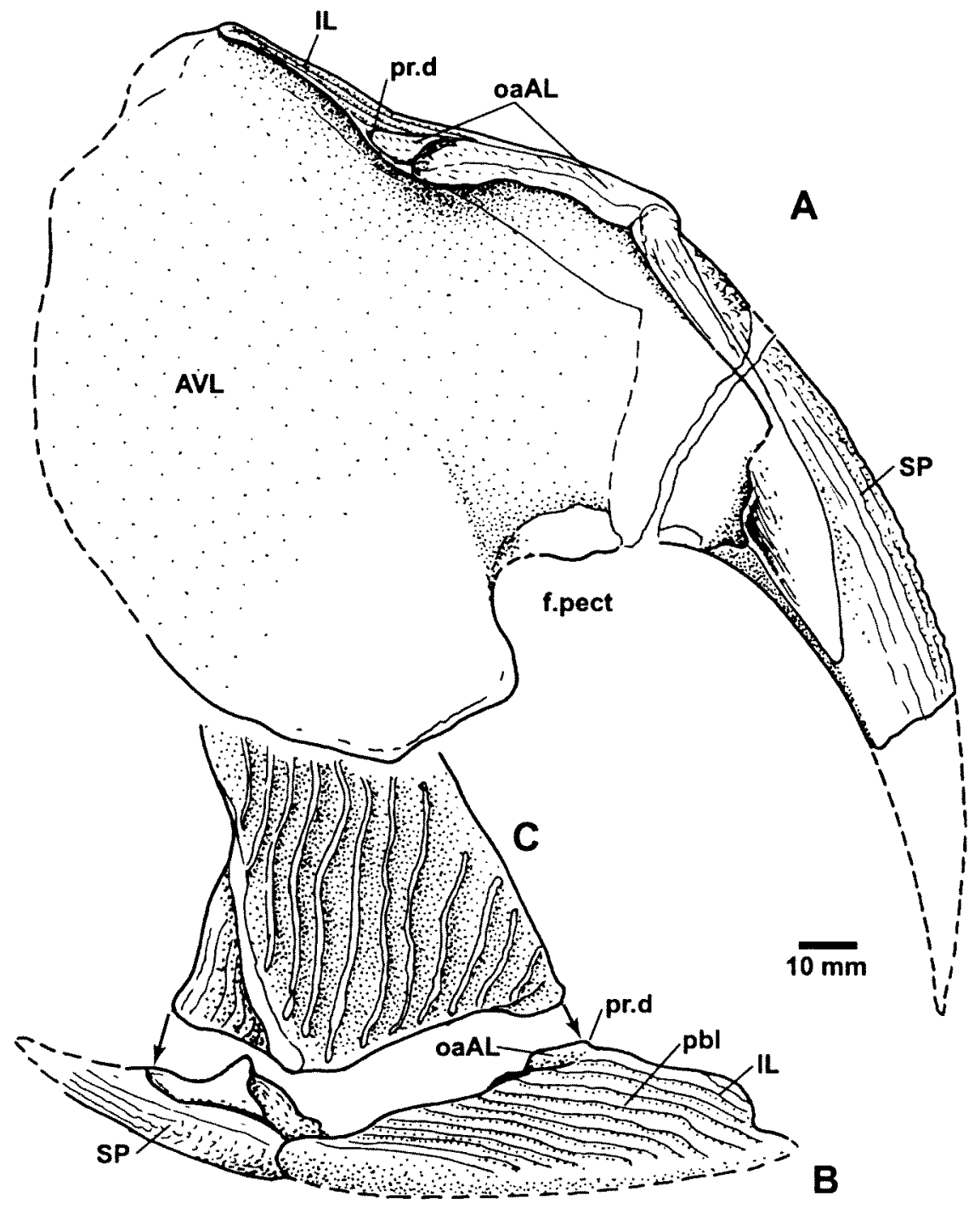

Figure 9 Wuttagoonaspis milligani sp. nov. Right AVL, IL and incomplete SP plate (CPC 36905) in dorsal (A), and anterior (B) views, slightly restored. C, anterior view of ventral part of right AL plate (after CPC 36903, 907), showing how it fits on the IL and SP plates (arrows).

marking the mesial extent of contact with the $\mathrm{AL}$ plate. Compared to some other taxa (e.g. Eurycaraspis; Liu 1991: fig. 11), where this process has a lateral position, in W. milligani it lies in the mesial half of the IL, indicating more marked mesial inflection of the postbranchial lamina of the AL than in most other forms. The overlap for the AL (oaAL) is mainly visible in dorsal view (Figure 9A), where it forms a thickened butt joint extending to the lateral edge of the bone, which is the anterolateral angle of the trunk armour. The SP also has a distinct overlap area for the $\mathrm{AL}$, which projects upwards as a strong flange lateral to the pectoral fenestra fitting inside the $\mathrm{AL}$, with a smooth vertical posterior face, in this large specimen some $20 \mathrm{~mm}$ high. The partly preserved pectoral fenestra on the AVL is flared upwards (f.pect).

A large right AL (CPC 36903), which comes from a slightly smaller individual (Figure $8 \mathrm{C}$ ), is close enough in size to the previous specimen to demonstrate the connection to the IL and SP plates. The ventral margin of the AL (Figure $9 \mathrm{C}$ ) is subdivided by a distinct corner into a longer SP attachment (62 $\mathrm{mm}$ long), and shorter IL contact $( \pm 30 \mathrm{~mm})$, the latter with a small overlap area for the triangular area. The corresponding lengths of CPC 36905 are 50 (IL) and 75 (SP), so perhaps the IL grew allometrically.

CPC 36874 (Figure 8D) shows another large left AVL, AV, IL and SP preserved in association, this time as an external impression. The SP plate (completely preserved in the impression) is $120 \mathrm{~mm}$ long. Estimated width between the tips of the SP plates is about $275 \mathrm{~mm}$, and between the anterolateral corners of the ventral wall of the trunk armour about $200 \mathrm{~mm}$. This size compares well with the large skull from this locality described above, which is therefore assumed to come from 
the same individual. CPC 36864 (Figure 3C) is an even longer SP plate (preserved L $130 \mathrm{~mm}$, incomplete), which in curvature, ornament and overall shape is closely comparable to CPC 36874 .

CPC 36859 (Figure $3 \mathrm{~A}$ ) is a much smaller poorly preserved right AVL and SP in ventral view. It is compared with a ?petalichthyid example of similar size in Figure 35B. Both specimens show concentric ridged ornament, but they differ markedly in shape, CPC 36859 being generally similar to the corresponding elements of Kujdanowiaspis illustrated by Denison (1958: fig. $112 \mathrm{H}$ ), as originally stated for Wuttagoonaspis by Ritchie (1973). The AV plate is indicated by a slight notch on the mesial margin. The SP of CPC 36859 is ornamented with horizontally elongate tubercles along the leading edge, separated by a groove from three more closely spaced tuberculate ridges on the preserved ventral surface (probably $4-5$ originally). Ritchie (1973: 63) described the SP of Wuttagoonaspis as 'gently curved ... with about half of its length projecting free', as in this specimen. The anterior margin is not clear, but is restored after the AVL, IL and SP previously illustrated (Ritchie 1973: pl. 6, fig. 6). CPC 36909 is a similar but larger AVL and SP from the left side. CPC 36859 is apparently more elongate than that previously illustrated, but is also much smaller (AVL length along ventrolateral ridge about $35 \mathrm{~mm}$ ). In the much larger examples described above these plates are much shorter and broader (Figure 8D, E), indicating allometry in growth of the armour.

Other plates from the ventral trunk armour include CPC 36906 (Figure 8G), an incomplete small right PVL showing the overlap for the AVL, and CPC 36912 (Figure 8F), an incomplete anterior part of the AMV, resembling that figured by Ritchie (1973: fig. 2c) in the slight asymmetry for the anterior overlap areas, and position of the ossification centre. However the ornament projection between overlap areas is more pronounced in Ritchie's specimen. This difference is also evident in another larger example (CPC 36911), a large cruciform bone $90 \mathrm{~mm}$ long and an estimated $80 \mathrm{~mm}$ wide, preserved mainly as an internal impression (AMV, Figure 7A).

The lateral wall of the trunk armour is represented by a range of specimens from various localities. CPC 36899-900 are small incomplete AL plates with ridged ornament, provisionally referred to this taxon. CPC 36902 shows the posterior margin of a left AL, similarly developed but somewhat larger than the almost complete CPC 36903 (Figure 8C). CPC 36901 shows widely spaced ridges running down to the ventral border of the postbranchial lamina, broken from a left $\mathrm{AL}$ about twice the size of CPC 36903. CPC 36907 (Figure 8B) is a better preserved similar fragment, with striking angled ribbing of the postbranchial lamina, terminating at a broad smooth ridge running up from the ventral corner, lateral to which are more closely spaced vertical ridges of the lateral lamina. CPC 36861 from $\mathrm{BC} 1$ is another similarly preserved fragment (Figure 8A), but only one third the size (17 $\mathrm{mm}$ long). In the only AL previously figured (Ritchie 1973: pl. 4, fig. 5), the ridge separating the postbranchial lamina from the lateral lamina is tuberculate rather than smooth, so this may be a specific difference.

CPC 36913 is an incomplete left AL with a ventral margin of the lateral lamina some $63 \mathrm{~mm}$ long, and total height at least $90 \mathrm{~mm}$. As far as preserved it is similar in size and ornament to CPC 36903. The ornament on both specimens curves ventrally from the ossification centre, to meet the ventral border at a high angle, as in all the examples illustrated by Ritchie (1973: fig. 2d-e; pl. 4, figs. 2, 5; pl. 6, fig. 8). This is in contrast to another incomplete $\mathrm{AL}$ with ridged ornament (Figure 10F), which has horizontal alignment subparallel to the ventral margin of the bone, and is assigned below to Lurapullaspis gen. nov.

The most complete example of the AL plate of $W$. milligani (CPC 36903; Figure $8 \mathrm{C}$ ) is considerably higher than long (L/H 58/83 mm), which contrasts with the previously illustrated $\mathrm{AL}$ of $W$. fletcheri (with similar length and height). This may be another specific difference, although the new examples are much larger.

ANU V2973 (Figure 7G) shows a broken slice with ridged ornament across portion of a left ADL, PDL and MD, but sutures cannot be discerned. CPC 36910 (Figure 7F) is a large left ADL and PDL in association, the two trunk plates together indicating a lateral wall of the armour some $100 \mathrm{~mm}$ long. The ADL has an articular flange with a distinct mesial angle, as described below for Lurapullaspis gen. nov., and also figured by Ritchie (1973: pl. 6, fig. 7). The ventral border of the ADL has a deep notch as in Ritchie (1973: pl. 4, fig. 6). The PDL shows a distinct narrow posterior overlap area for the PL plate, not evident in the previously illustrated example (Ritchie 1973, figure 2B). An adjacent plate (first interpreted as an associated MD) shows an overlap and faint sensory groove identifying it as another left ADL (Figure 7F, top left), preserved en echelon as in the SM plates described above, and thus more evidence for current sorting at this locality. CPC 36908 is a similar sized left ADL and attached PDL (incomplete). As in the previous specimen the ADL has a convex preserved dorsal margin (Figure 7E), with no sign of the overlap area for the MD seen in the example illustrated by Ritchie (1973: fig. 2a). Possibly a broken portion of the MD was attached to these ADLs. No separate MD with concentric ridged ornament, such as illustrated for W. fletcheri by Ritchie (1973: pl. 6, fig. $1)$, has been identified in this material. 
Family Bulbocanthidae nov.

\section{Diagnosis}

Actinolepid arthrodires in which the median dorsal plate carries an elongate, longitudinally ridged, dorsal spine, with large denticles on its posterior margin.

\section{Remarks}

This family is named from the genus Bulbocanthus Bryant, erected by Bryant (1932: 253) for small spines from the Early Devonian of Beartooth Butte in Wyoming, which he defined as follows:

'Spines small, with bulbous inserted portion. Exserted portion thin, sinuous in lateral view and tapering. Sides ornamented with numerous carinae. Posterior edge set with denticles directed upwards.'

Bryant provisionally referred the genus to the 'Elasmobranchii', but was uncertain of its affinities, and also suggested that it may later prove to belong to some member of the Heterostraci' (Bryant 1932: 254). The genus was included by Zangerl (1981: 105) under the heading 'Ichthydorulites (presumably belonging to elasmobranchs)', and described as "very flat spines with denticles along both edges, vaguely similar to Listracanthus denticles, but with a bulbous base'. However no illustrated specimen shows two denticulated edges, although this was implied in Bryant's original description. Capetta et al. (1994: 593) cited Bulbocanthus rugosus Bryant 1932 as the 'oldest elasmobranch (?) spine' known from the fossil record.

The only species, $B$. rugosus Bryant, was described as follows (Bryant 1932: 253): 'Spine with a flattened bulb-like root. Exserted portion flattened, thin, slightly sinuous, long and tapering. Sides ornamented with meandering, crenulated ridges. Posterior margin with a series of flattened denticles directed somewhat upwards.' He also noted an internal cavity extending nearly to the apex of the spine.

The type specimen ( $37 \mathrm{~mm}$ long, maximum width of 'exserted portion' $4 \mathrm{~mm}$ ), was illustrated by Bryant (1932: pl. 6, fig. 2), and another complete and several broken spines were said to occur on the same slab. An additional specimen was illustrated by Bryant (1934: pl. 18, fig. 4). Further material of this form now indicates that it was based on complete trunk armours of a small arthrodire (representing the 'bulbous inserted portion'), which carried a very elongate median dorsal spine. On the very similar morphology we suggest that Bulbocanthus is closely related to the new genus described below. Related forms occur in the Early Devonian of Spitsbergen and Severnaya Zemlya (Goujet, Mark-Kurik, unpubl.).
Lurapullaspis gen. nov.

Lurapullaspis johannseni sp. nov. Figures 3B, 10-13, 15F

an actinolepid: Haines et al. 1991: 32

actinolepid nov.: Young et al. 1993: 247

\section{Material}

CPC 36914-930.

\section{Localities and Horizon}

$\mathrm{BC} 1 ; 74 / 11,14,16,17$ (northwestern part of the Dulcie Syncline, in the Dulcie Sandstone); 77/3, 20 (Cravens Peak Beds). For localities see Figure 1. A locality summary for each taxon is given in Table 1 , and locality details for each specimen are listed in the Appendix.

\section{Diagnosis}

A bulbocanthid actinolepidoid with ridged ornament, attaining a trunk armour length of at least $30 \mathrm{~mm}$, with a median dorsal spine almost three times the length of the trunk armour. Dorsal spine with large, widely spaced posterior denticles, sometimes alternating with smaller denticles, and a distinctive chevron pattern on its anterior border. MD/PDL suture steeply inclined, and short common suture between PDL and AL plates. Lateral line sensory groove inflected dorsally at the PDL ossification centre. Ridged ornament concentric on the MD, steeply inclined on the PDL, aligned subparallel to the ventral margin on the ventral quadrant of the $A \mathrm{~L}$, and radiating on the SM.

\section{Etymology}

After aspis (Gk), a shield, and Lurapulla Waterhole, on the Lurapulla 1:100 000 map (SE corner of the Barrow Creek 1:250 000 sheet), in the vicinity of the type locality. The specific name is after Lindsay Johannsen, owner of Baikal Station, SE of the Dulcie Range (Huckitta 1:250 000 sheet).

\section{Remarks}

Ritchie (1973, p. 62) in his description of Wuttagoonaspis fletcheri made reference to 'other median dorsals ... with a Wuttagoonaspis-like ornament, but with a high, sharply pointed dorsal spine'. This is probably a reference to a form with close affinity to that described below. However, we note that at least some of these high-spined examples from the Mulga Downs Group differ from this new taxon in having dorsal spines ornamented with transverse rather than longitudinal ridges (e.g. ANU V620; plaster copy of AMF specimen). Because both taxa have ridged ornament, and are poorly known, there is some uncertainty about referring isolated bones to this new taxon 


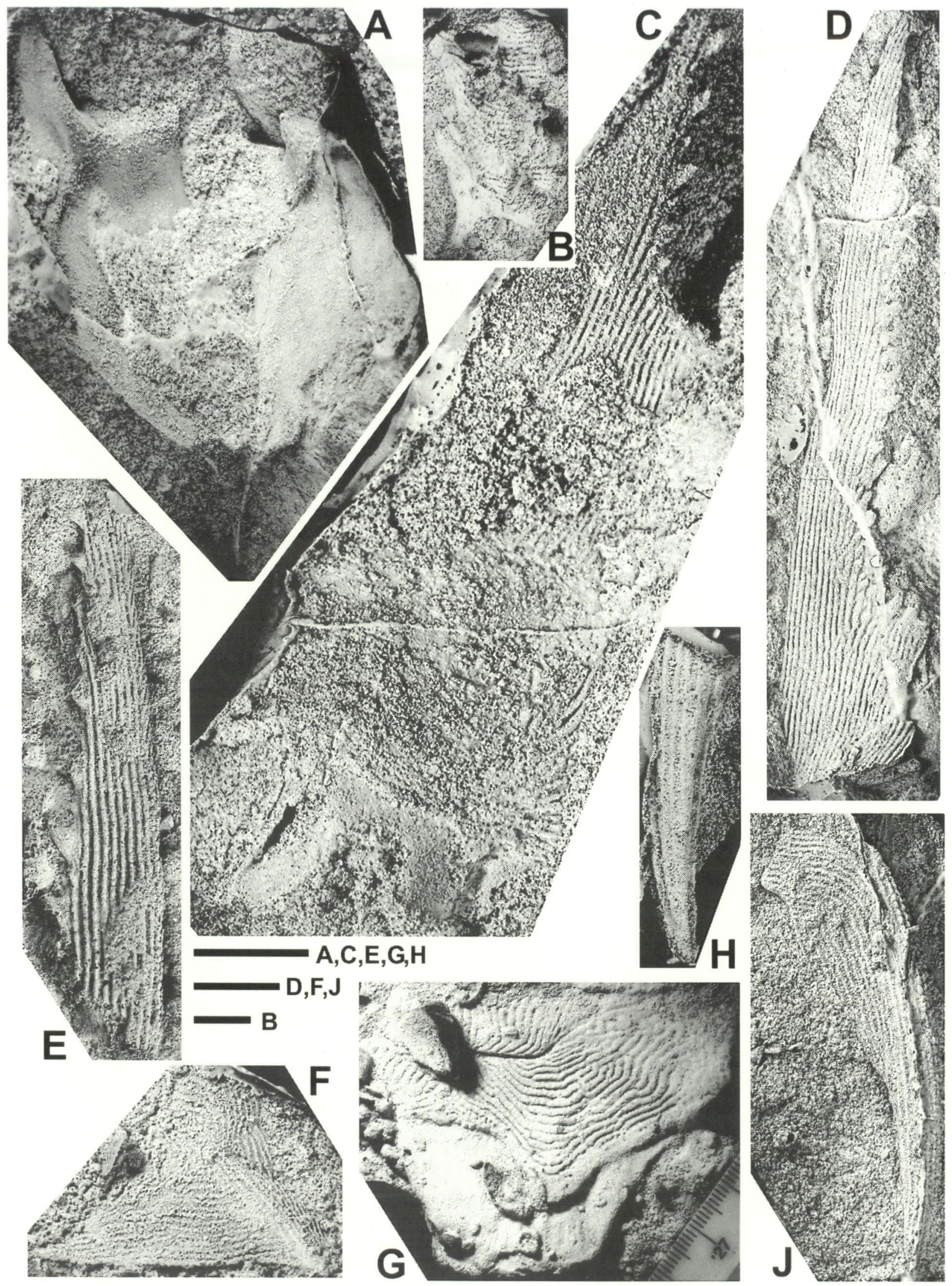

Figure 10 Lurapullaspis johannseni gen. et sp. nov. A,C, holotype trunk armour (CPC 36921) in ventral view (A), and left lateral view (C) showing incomplete dorsal spine; B, left ADL plate, CPC 36925; D, detached median dorsal spine, left lateral view (CPC 36920); E, incomplete median dorsal spine, right lateral view (CPC 36916); F, right AL plate, CPC 36925; G, left PDL plate, CPC 36923; H, incomplete SP plate, provisionally assigned to the taxon (CPC 36928); J, left AVL and SP plate provisionally assigned to the taxon (CPC 36917). All specimens are latex rubber casts whitened with ammonium chloride; scale bars $=10 \mathrm{~mm}$. 
(provisional until more complete material is described). The ornament in some specimens included below differs from that of typical Wuttagoonaspis in having broader flat ridges delineated by narrow grooves. As noted below this ornament type is also documented from the Mulga Downs Group of western NSW (Ritchie 1973), and at present it is not clear whether ornament might be distinctive at generic or specific level. The new taxon differs from Bulbocanthus in its much larger size, and the proportionately smaller dorsal spine, which has larger more widely spaced posterior denticles. The longitudinal ridges on the spine may be less continuous in Bulbocanthus. Lurapullaspis gen. nov. differs also in the ridged ornament of the trunk armour bones, a feature by which it can be distinguished from undescribed presumed bulbocanthids from Spitsbergen and Severnaya Zemlya, which apart from the dorsal spine, have tubercular ornament.

\section{Description}

This small collection comes from six localities. Some material is only provisionally included, and it is not clear whether ornament permits incomplete remains of the new taxon to be distinguished from

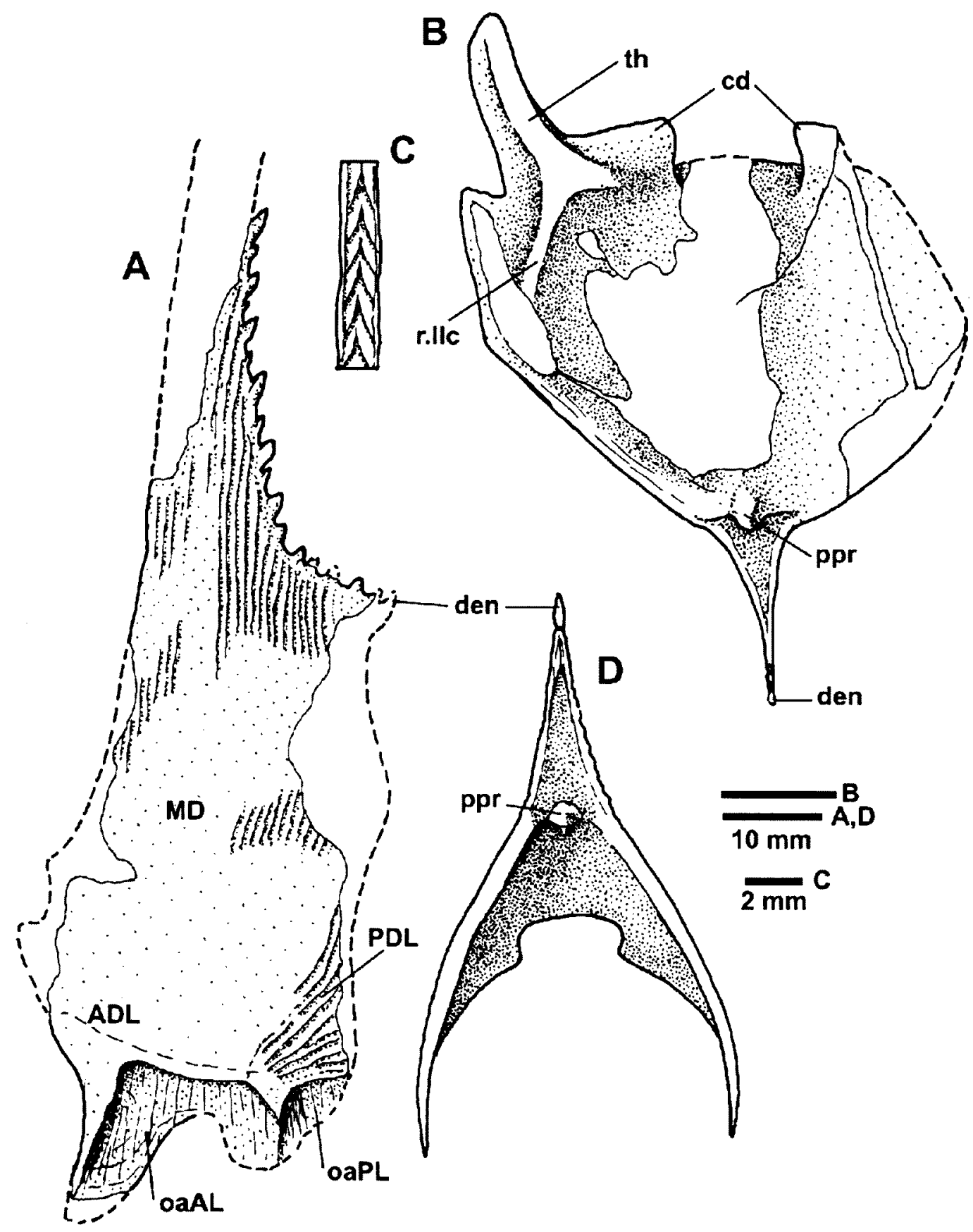

Figure 11 Lurapullaspis johannseni gen. et sp. nov. A, B, D, holotype trunk armour (CPC 36921) partly restored in left lateral $(A)$, ventral $(B)$ and posterior (D) views; $C$, detail of ornament on anterior edge of median dorsal spine, CPC 36918. 
Wuttagoonaspis, nor whether these are the only forms in the assemblage with ridged ornament (see Remarks above). CPC 36921 (Figure 10A, C), selected as the holotype, is an incomplete trunk armour preserved as external and internal impressions, which includes MD, ADL and PDL plates. The MD carries a distinctive steeply inclined and laterally compressed dorsal spine, with longitudinal ridged ornament, and a posterior row of postero-dorsally directed denticles, in which large and small alternate. The spine is only partly preserved in the holotype (Figure 11A), and this is the only specimen to clearly indicate the orientation of the spine in relation to the trunk armour. The original length of the spine is indicated by a second example of a spine (CPC 36920) which is $87 \mathrm{~mm}$ long, and has broken off the MD plate (Figure 10D). This apparently came from an individual about the same size as the holotype, because at the level of the posterior crest both specimens have some 22 ridges across one side.

The external impression of the holotype shows the left side of the armour, with MD, ADL and PDL plates (Figure 11A). The base of the spine is broadened antero-posteriorly as a low posterior crest, which also carries dorsally pointed large denticles. The ventral part shows overlap areas (oaAL, oaPL) on the ADL and PDL plates, but their common suture is indistinct. The overlap areas are clearly separated by a ventral projection of the ornamented surface, with a small notch in front

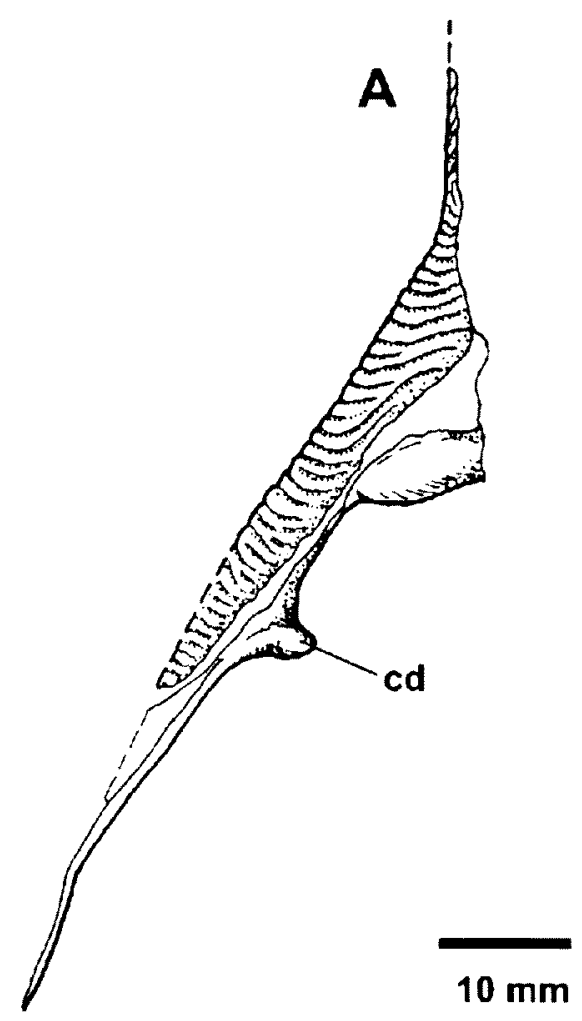

marking the position of the ADL/PDL suture. The ornament on the ADL is not preserved, and the posterior margin of the armour is incomplete, with radiating ridged ornament from the anteroventral part of the PDL plate (PDL, Figure 11A). The short margin of the PDL in contact with the AL plate is different from the PDL illustrated by Ritchie (1973) for Wuttagoonaspis fletcheri, but he noted (p. 63) that this was peculiar to material from the type locality (Wuttagoona station), the PDL's from other sites resembling Bryantolepis, which has a shorter PDL/ AL contact (Denison 1958: fig. 109H). Possibly distinctive of the PDL of Lurapullaspis is the near vertical orientation of the ridges in the posterodorsal part of the plate, although they are also steeply inclined in Wuttagoonaspis. The PDL was evidently short, because the complete inner surface of the right side on the counterpart measures only $25 \mathrm{~mm}$ in length from the notch to the posterior border.

The counterpart (Figure 10A) shows the inner surface of the armour, with a thickening down the anterior margin of the ADL (th, Figure 11B), as described in other forms (e.g. Denison 1958), and a posterior ridge underlying the lateral line canal on the external surface (r.ll). The inner surface of the $\mathrm{MD}$ is largely non-preserved. The distinct notch at the front is formed by the articular processes of the ADL's of each side, which are only $10 \mathrm{~mm}$ apart. In posterior view (Figure 11C) the high and narrow configuration of the armour is evident. A small

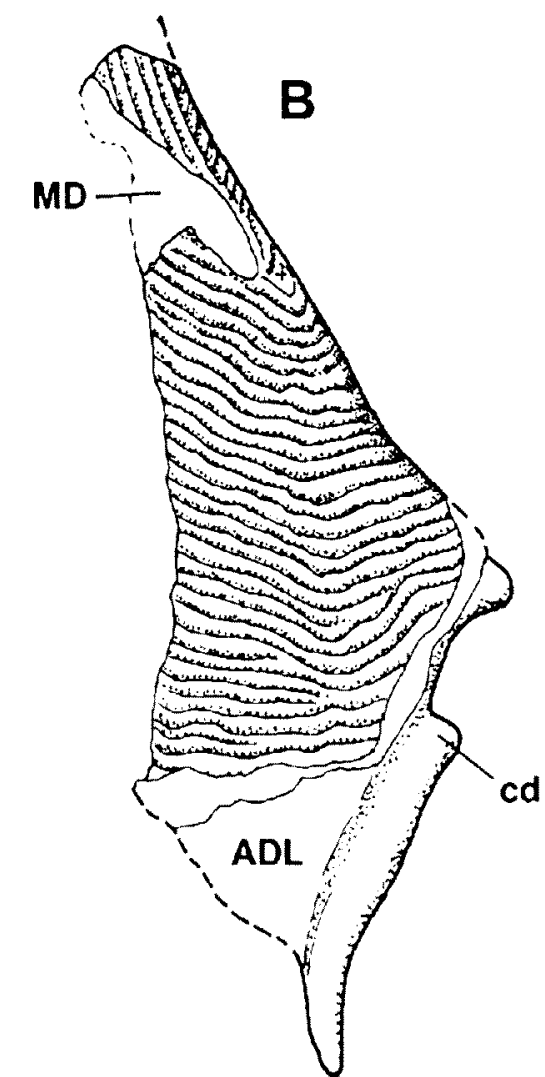

Figure 12 Lurapullaspis johannseni gen. et sp. nov. Incomplete trunk armour (CPC 36927) in anterior (A), and right lateral (B) views. 
posterior process (ppr) is developed inside the apex of the two laminae of the MD. A similar process is seen in CPC 36918, which preserves the inside of the MD and a short basal section of the spine with strong longitudinal ridged ornament. This process may be compared to the median septum behind the transverse thickening in Actinolepis (Mark-Kurik 1973: pl. 11, fig. 6). However, there is no transverse thickening in Lurapullaspis. Above the process in the holotype is a high triangular area that possibly abutted against a posterior median dorsal element, or an enlarged scale. The apex of this triangular area is $16 \mathrm{~mm}$ above the posterior process, with the upper $5 \mathrm{~mm}$ angled outwards as a narrow posterior edge. At this point, the laminae of both sides come together to form the first large posterodorsally directed denticle on the crest behind the median dorsal spine (den). This permits the restoration of the posterior margin in Figure 11A.

Some less complete specimens show the spine still attached to the MD plate. CPC 36919 is a MD about $55 \mathrm{~mm}$ long, with the dorsal spine broken off near the base. The ossification centre is a rounded swelling some $20 \mathrm{~mm}$ from the anterior margin. The ornamented ridges are transversely oriented at this margin, but become tightly concentric anteriorly around the ossification centre, and posteriorly extend longitudinally along the dorsal spine. The same feature is seen in CPC 36927 (Figure 12, 15F), which also includes the right ADL showing the neckjoint articulation. This specimen is clearly different from the illustrated ADL of Wuttagoonaspis, which has a typical sliding joint of actinolepid type, but this is variable as noted above. In CPC 36927 the dorsomesial edge of the articular flange is thickened and truncated to form a type of incipient condyle ( $\mathrm{cd}$, Figure 12A). This may be the more developed type of neck-joint noted by Gardiner (1984: 393; specimen BMNH P56000) to occur in the Wuttagoonaspis assemblage in 'a closely related species from Mount Grenfell, NSW'. However similar articulations are seen in Actinolepis from Spitsbergen (MNHN specimen SVD 213), so this may not be as significant as Gardiner believed. In most actinolepids the articular flange appears flat in external view, but in internal view the flange is thickened, giving the impression of a 'condyle', so incomplete preservation from different perspectives can be unreliable. Associated with CPC 36927 is an incomplete ventral portion of the trunk armour with SP plate, which has stronger ridging than in Wuttagoonaspis, possibly a distinguishing character. CPC 36928 (Figure 10H) is a similar ridged SP plate, provisionally included here. CPC 36922 from the type locality is provisionally identified as a broken fragment of a much larger MD, with a broad base of the dorsal spine indicating a plate considerably larger than preserved length $(78 \mathrm{~mm})$.

A detailed description of the ornament of the elongate dorsal spine is likely to be of value, because its laterally compressed shape and great length mean it could often be found broken off as an isolated spine. Although this is a small sample, the ornament is apparently highly distinctive, and would permit even small fragments of spines to be identified if the ornament was preserved. The spines are flattened in cross-section, with a denticulate posterior margin. The lateral faces are ornamented with about 22 closely spaced smooth longitudinal ridges at the base of a spine about 80 $\mathrm{mm}$ long, reducing to $1-2$ ridges at the tip of the spine. These ridges (Figures $10 \mathrm{C}-\mathrm{E}$ ) are clearly more continuous than in Bulbocanthus rugosus (e.g. Bryant 1934: pl. 18, fig. 4). The anterior border of the spine carries a distinctive chevron pattern in the two specimens where this region is unworn and well preserved (Figs. 11C, 12B). The large, upwardly directed denticles along the posterior margin of the spine are best seen in CPC 36916, 920 and 921. Only the lower few denticles are preserved in CPC 36919, but this specimen indicates that the posterior crest and spine carried only a single posterior row. The denticles are laterally flattened and slightly curved, and normally are widely spaced, often with an intervening smaller denticle (Figure 10C, 11A).

CPC 36930 (Figure 13A) is another example showing the external surface of articulated ADL, PDL and MD plates in left lateral view, but the dorsal spine and crest are not preserved. The ornament is well preserved as broad flat ridges separated by narrow grooves, which generally have crenulated margins caused by the rounded fused tubercles forming the ridges. Similar ornament is seen on a specimen assigned to Wuttagoonaspis from Mt Jack Station in the Darling Basin (Ritchie 1973: pl. 6, fig. 7), which is similarly preserved with the dorsolateral plates in articulation with the MD. In CPC 36930 bone sutures are well displayed, and the PDL shows a clear overlap area for the AL plate (oaAL). Noteworthy is the steeply inclined MD/ PDL suture. The posterior margin of the PDL is incomplete, so it is unknown how far this plate extended dorsally towards the crest behind the dorsal spine. The ADL carries a pitline as a groove running half the length of the plate beneath the main lateral line groove (llc), which is inflected dorsally at the PDL ossification centre, whereas in Wuttagoonaspis illustrated by Ritchie (1973: fig. 2b) it runs straight back across the plate to its posterior margin. CPC 36923 (Figure 10G) from the type locality is a much larger left PDL provisionally included here, with a similarly developed sensory groove. Its anterior preserved part may include portion of the ADL. This PDL also shows a distinct posterior overlap area for the $\mathrm{PL}$, and the anterior overlap for the AL is more extensive. This is one of several features by which this specimen differs from 

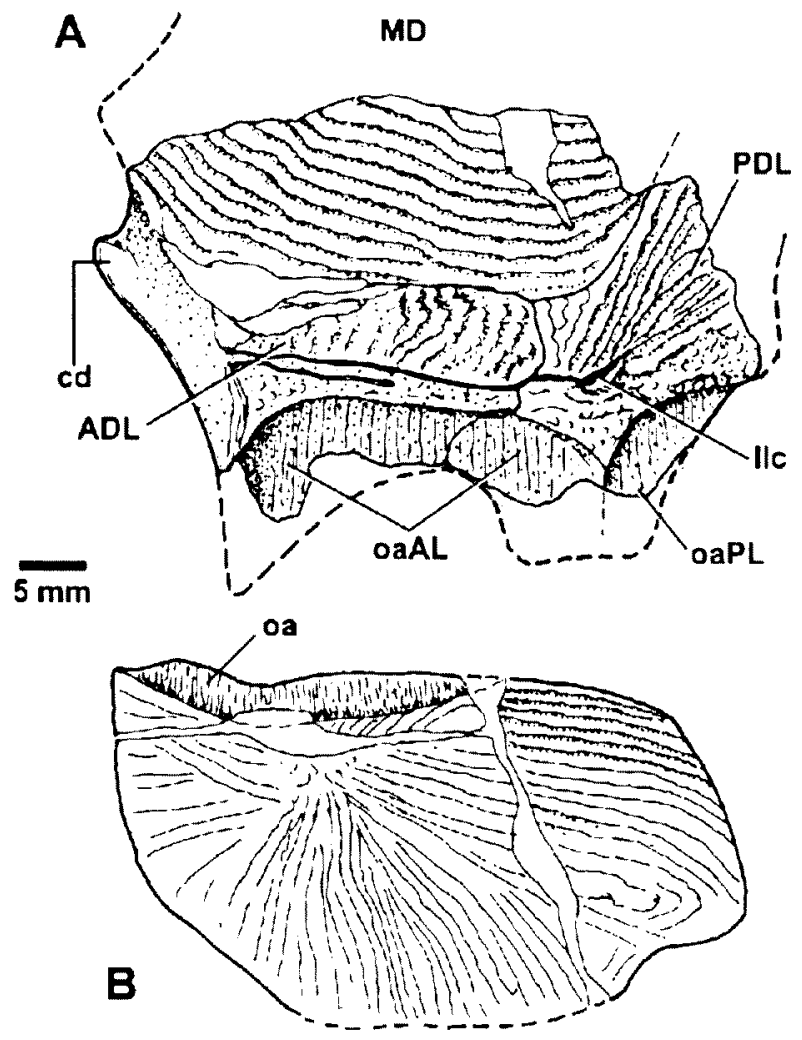

Figure 13 Lurapullaspis johannseni gen. et sp. nov. A, incomplete trunk armour (CPC 36930) in left lateral view; $B$, presumed left SM plate (CPC 36929 ) in lateral view.

the various PDL's illustrated by Denison (1958: fig. 109), including that of Bryantolepis, said by Ritchie (1973: 63) to closely resemble that of Wuttagoonaspis in its general shape (although its ornament is completely different).

Other isolated bones are provisionally assigned to this genus and species, mainly because they have similar ridged ornament, but differ in shape or other characters from the corresponding elements in Wuttagoonaspis. This assumes that this is the only other taxon in the fauna with this type of ornament. CPC 36914 (Figure 3B) is a large fragment $(78 \times 20$ $\mathrm{mm}$ ) with an ornament of broad flat ridges $2-3 \mathrm{~mm}$ across separated by narrow grooves. Converging ornament suggests a bone suture, and a sensory groove crosses the fragment at one end. It may be part of a skull, but even the largest available skulls of Wuttagoonaspis (e.g. CPC 369881) have ornament with wider grooves, so this example is provisionally referred to Lurapullaspis. CPC 36915 is a small fragment with similar ornament from locality 74 / 11, which may also belong to this taxon. CPC 36929 (Figure 13B) is the impression a left SM plate, which had similar ridged ornament, but a much more elongate shape (53 $\mathrm{mm}$ long by $\sim 30$ deep), compared to the corresponding bone in Wuttagoonaspis. There is a clear anterodorsal overlap area occupying about three quarters of the dorsal margin. The plate is gently arched anteroposteriorly and transversely, and is most tumid at the ossification centre, which is about a third the length from the front and just beneath the overlap area. There is also a shallow posteroventral notch. The ornament radiates in all directions, in contrast to Wuttagoonaspis where it is concentric except for the posterior margin. Again these differences suggest that it can be provisionally assigned to this taxon.

CPC 36925 (Figure 10B,F) is an incomplete right $\mathrm{AL}$, lying beside another impression of a left ADL, presumably from the same individual, with an articular condyle identical to CPC 36927 described above. It has ridged ornament, with a ventral margin to the lateral lamina some $37 \mathrm{~mm}$ long. It differs from the specimens assigned above to Wuttagoonaspis, and all those illustrated by Ritchie (1973: fig. 2d-e; pl. 4, figs 2, 5; pl. 6, fig. 8), in the orientation of the ornament ridges on the ventral quadrant (Figure 10F), which are entirely horizontal, and aligned subparallel to the ventral margin. In contrast, the Wuttagoonaspis AL's have ornament ridges that curve ventrally from the ossification centre, to meet the ventral border at a high angle. CPC 36926 is an incomplete larger example that is similar as far as preserved.

CPC 36917 (Figure 10J) is a SP with an associated lamina apparently with natural margins, which is quite different in shape to the SP of Wuttagoonaspis. The ridged ornament indicates that, if complete, this specimen could also be shown to belong to Lurapullaspis.

\section{Family Antarctaspidae White, 1968}

\section{Remarks}

The poorly known genus Antarctaspis from the Antarctic Aztec Siltstone described by White (1968) resembles the taxon described below in having a long $\mathrm{Nu}$ which separates the $\mathrm{C}$ plates, and makes anterior contact with a median bone (rostral and/or pineal), and paired $\mathrm{PrO}$ and $\mathrm{PtO}$ plates. In addition, the central and supraorbital sensory canals converge to the centrally placed $\mathrm{Nu}$ ossification centre, as in the new taxon described below (Figure $14 \mathrm{~B})$. The suture pattern is unclear in the holotype as illustrated by White (1968: pl. 2), and a cast of the counterpart (Figure 16B) shows the dense tubercular ornament, which obscures bone sutures. White (1968) inferred bone sutures from the radiating structure of the bone observed in the holotype, including paired $C$ plates separated by an elongate Nu. Denison (1978) interpreted Antarctaspis to have a very long $\mathrm{PNu}$, and no $\mathrm{C}$ plates, on which basis he placed the family in a new suborder Antarctaspina within the order Phyllolepida, and Long (1984: fig. 27) followed that 
interpretation. However, it now seems clear that there were two bones flanking the $\mathrm{Nu}$ (the normal arrangement), and White's (1968) original identification of $\mathrm{C}$ plates corresponds closely to their position in the new material described below. They may not have extended as far posteriorly as he inferred, and were evidently proportionately larger in the Antarctic form. The suggested relationship to Phyllolepida is no longer supported by shared derived characters (see above; Goujet and Young 1995). We recognise two other genera belonging in this family: Yujiangolepis Wang, Pan and Wang, 1998, and Toombalepis gen. nov.

Yujiangolepis was placed in the Phlyctaeniidae by Wang et al. (1998). However the central position of the PNu ossification centre on the holotype of the type species, which includes the branching point for the posterior pitline (Figure 16C), indicates that this form is an actinolepidoid. Wang et al. (1998: 67) listed the following diagnostic characters of the genus: hexagonal headshield with developed posterolateral corners; posterior margin straight with slight central concavity; $\mathrm{R}$ plate fused to $\mathrm{PN}$; Pi plate extending back between PrO's; large orbital notch; long supraorbital and central sensory lines; long and narrow $\mathrm{Nu}$ plate. Of these only the last two characters are distinctive.

In $Y$. liujingensis the supraorbital and central sensory canal grooves converge posteriorly to the midline. This area in the holotype shows fine concentric ornament just in front of the broken margin (Wang et al. 1998: pl. 1, fig. 1), indicating a median ossification centre, rather than the junction between three bones (two C's and the Nu) shown in their restoration (Wang et al. 1998: fig. 2). This ossification centre could only be for an elongate $\mathrm{Nu}$, and the alignment of tubercles along the posterior margin of the $\mathrm{Nu}$ in the holotype also shows that the ossification centre was anteriorly placed, rather than at the posterior margin as occurs in all phlyctaeniids (Denison 1978: fig. 31). A reinterpretation of the skull of $Y$. liujingensis is given in Figure 16C.

The inflections of the supraorbital sensory canals at the level of the pineal foramen, with a lateral flexure to the front, is seen in another Chinese arthrodire, Jiuchengia described by Wang and Wang (1983), but this is clearly a brachythoracid, with C plates in median contact behind the RP bone.

As noted above, Antarctaspis has a similar long $\mathrm{Nu}$ on which the central and supraorbital sensory canals canals converge, and the ornament comprises coarse tubercles (see White 1968, Young 1991b: fig. 15.10). There is also evidence of a posterior pitline in this specimen (ppl, Figure 16B). As interpreted by White (1968) the $C$ are proportionately larger, and the suture pattern for the anterior contact with a median RP, PrO and PtO plates, are a little different. It is of interest that this is the second direct comparison which can be made between the Cravens Peak Beds and the Aztec fish fauna of Antarctica, the chondrichthyan Mcmurdodus also occuring in both faunas, and nowhere else (Turner and Young 1987).

Toombalepis gen. nov.

Toombalepis tuberculata sp. nov. Figures 14, 15A-E, 16A, 17

diverse arthrodires: Young 1991a: 67 (pars)

?homostiid nov.: Young et al. 1993: 247

Material

CPC 36931-939.

\section{Localities and Horizon}

74/11 (southern limb of the Dulcie Syncline, in the Dulcie Sandstone); 77/17-20 (Cravens Peak Beds). For localities see Figure 1. A locality summary for each taxon is given in Table 1, and locality details for each specimen are listed in the Appendix.

\section{Diagnosis}

A large antarctaspid actinolepidoid with a flat skull roof to $190 \mathrm{~mm}$ in length. $\mathrm{Pi}$ and $\mathrm{PrO}$ plates notching the anterior margin of the $\mathrm{Nu}$ plate with slight overlap. Orbital notch shallow. External depressions on PrO plates posteromesially directed. Nu plate with bulbous ventral thickening in front of ossification centre. Ornament of discrete tubercles, showing some concentric alignment in smaller individuals.

\section{Etymology}

After the Toomba Range, western Queensland, and lepis (Greek), scale. The specific name refers to the tuberculate ornament.

\section{Remarks}

The Chinese species Yujiangolepis liujingensis, is based on a skull about $50 \mathrm{~mm}$ long (Wang et al. 1998. pl.1, fig. 1), but the Australian material ranges upward in size to the equivalent of skulls at least $190 \mathrm{~mm}$ long. The Australian taxon differs in having apparently a more narrow skull, with less pronounced orbital notches. There were posteromesially directed depressions on the $\mathrm{PrO}$ plates, rather than lateral depressions as in $Y$. liujingensis. The ornament of Yujiangolepis shows stronger concentric alignment, although ornament is somewhat variable in our material, so it may not be a reliable character. The skull material shows that our new species attained a large size, and provisionally included here for the purpose of description are various isolated trunk armour plates 


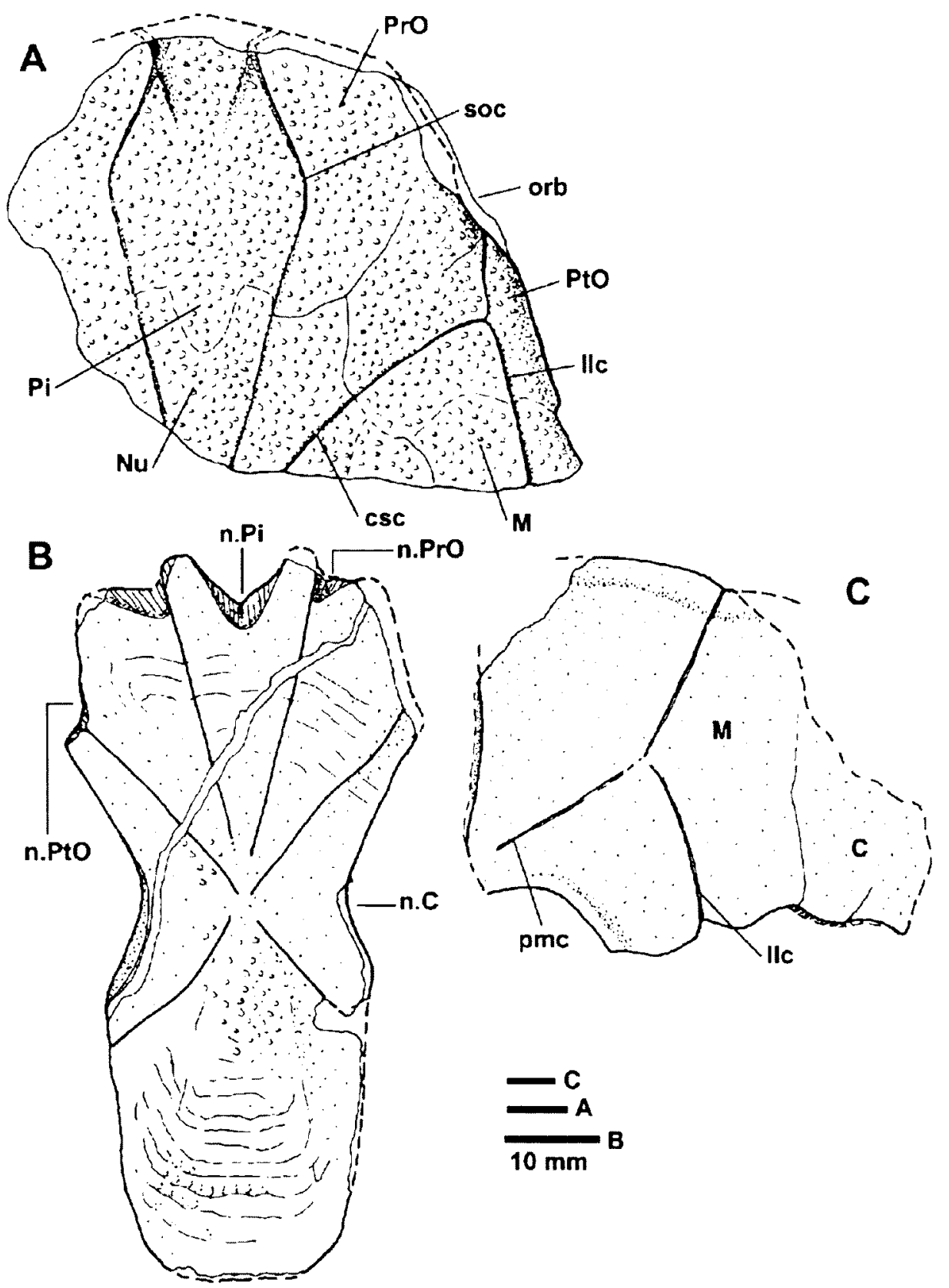

Figure 14 Toombalepis tuberculata gen. et sp. nov. A, incomplete skull (CPC 36932; holotype); B, isolated Nu plate (CPC 36938); C, left M and C plate from skull roof (CPC 36939).

from large arthrodires, which have a similar ornament of coarse tubercles. Other material indicates that another actinolepid in the fauna was also ornamented with coarse tubercles, but that form had a highly vaulted trunk armour (see below), which is unlikely to have combined with the rather broad flat skull roof indicated for Toombalepis tuberculata gen. et sp. nov.

\section{Description}

The primary material for erecting this species is a small collection of isolated skull bones or portions from the skull roof (Figure 14). These permit a composite skull reconstruction which compares well with similar undescribed remains from the Mulga Downs Group in the Darling Basin (Australian Museum collection). Two incomplete portions from the skull indicate the large size attained by this species (Figure 15A,B). The key to interpreting the skull is provided by CPC 36938 , an isolated $\mathrm{Nu}$ plate with clear notches across the anterior and down the lateral margins for the adjacent skull bones (Figure 14B). This came from a smaller individual than the other specimens $(75 \mathrm{~mm}$ long; maximum breadth at least $35 \mathrm{~mm}$ ). It has three pairs of sensory grooves converging on the centrally 

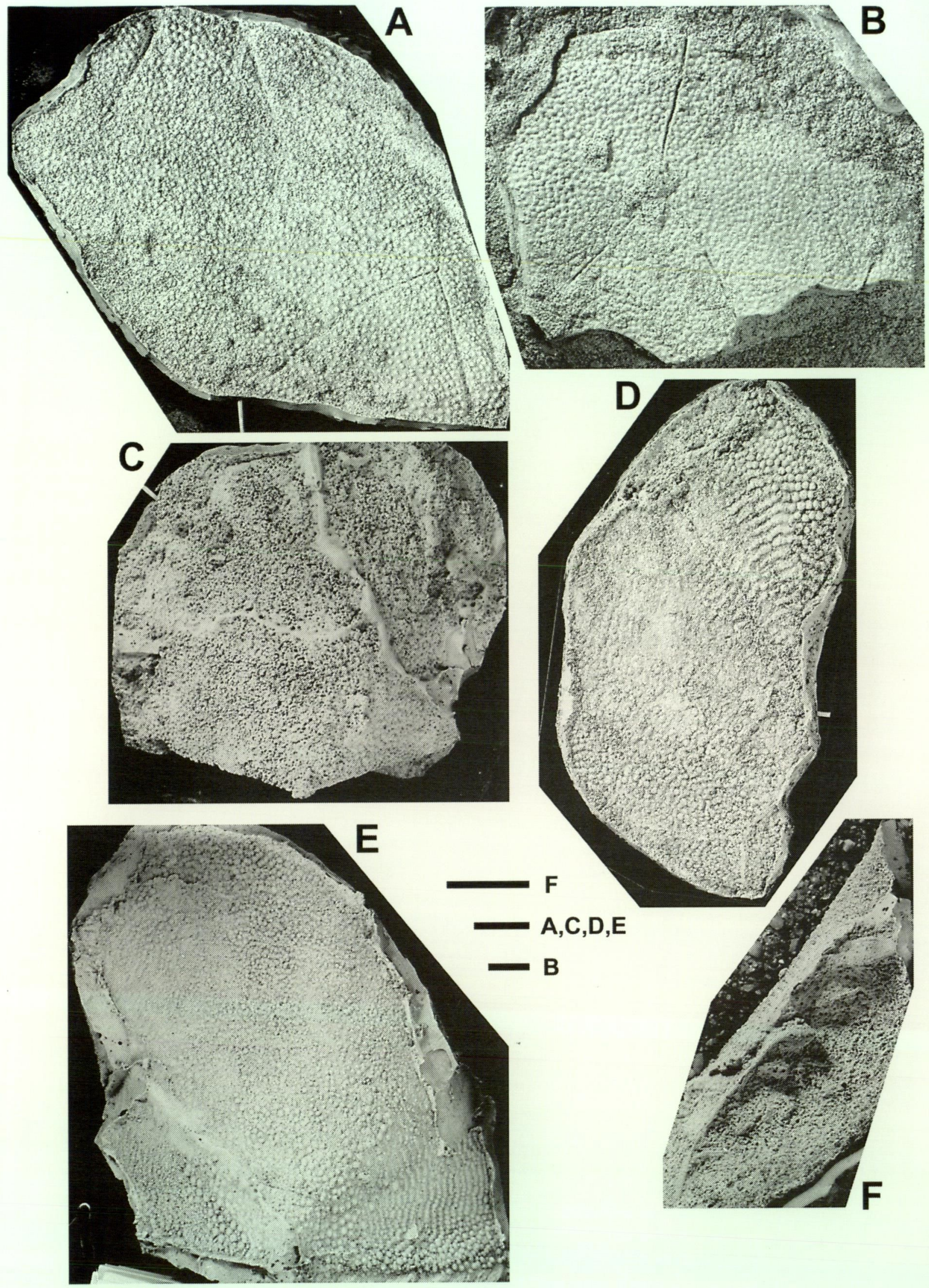

Figure 15 A-B, Toombalepis tuberculata gen. et sp. nov. A, holotype, an incomplete anterior portion of skull in dorsal view (CPC 36932); B, left M and C plate from skull, external view (CPC 36939). C-E, Tnoralaspis petercooki gen. et sp. nov. C, Nu plate from the Cravens Peak Beds, dorsal view (CPC 36940); D, undetermined plate associated with the holotype, external view (CPC 24664); E, Nu plate from the Pertnjara Group, Amadeus Basin, dorsal view (holotype, CPC 24664); F, Lurapullaspis johannseni gen. et sp. nov., incomplete trunk armour (CPC 36927) in anterior view. All specimens are latex rubber casts whitened with ammonium chloride; scale bars $=10 \mathrm{~mm}$. 
placed ossification centre, which invites comparison with Wuttagoonaspis, but there are several significant differences. The main lateral notches are clearly for the C plates (n.C, Figure 14B), which are not developed in Wuttagoonaspis. The posterior part of the notch has a slight overlap area, but anteriorly the edge is vertical, with no overlap. The anterior margin has a median notch with overlap areas for the Pi plate, which normally occupies this position (e.g. in petalichthyids). A postpineal element as in some arthrodires (e.g. Aethaspis; Denison 1984: fig. 2B) seems unlikely given the length of the Nu plate. Laterally are notches for the $\mathrm{PrO}$ and $\mathrm{PtO}$ plates, with narrow overlap areas, as does the notch behind, but this is very slight. The Nu was evidently broader between the PtO's than in Wuttagoonaspis, and it seems likely that PrO plates were not as big as in Wuttagoonaspis (or else the Pi would have been disproportionately large). Ornament is not well preserved, but traces of concentric ridges are seen peripherally and are most clear posteriorly as rows of coalesced low tubercles. Some large scattered tubercles (second generation) are preserved in the central part of the specimen.

The partly exposed inner surface shows a narrow median ridge posteriorly, and slight ridges under the posterior pitlines. In front of the ossification centre the bone thickens to form a bulbous ventral projection in the midline about $75 \%$ of plate length from the posterior margin, from which the surface slopes up anteriorly towards the pineal notch.

A second skull specimen (CPC 36932; holotype) shows a diagonal slice covered with pustulose tubercular ornament (Figure 15A) about $100 \mathrm{~mm}$ across, from the anterior portion of a considerably larger skull. Only the right margin may be complete

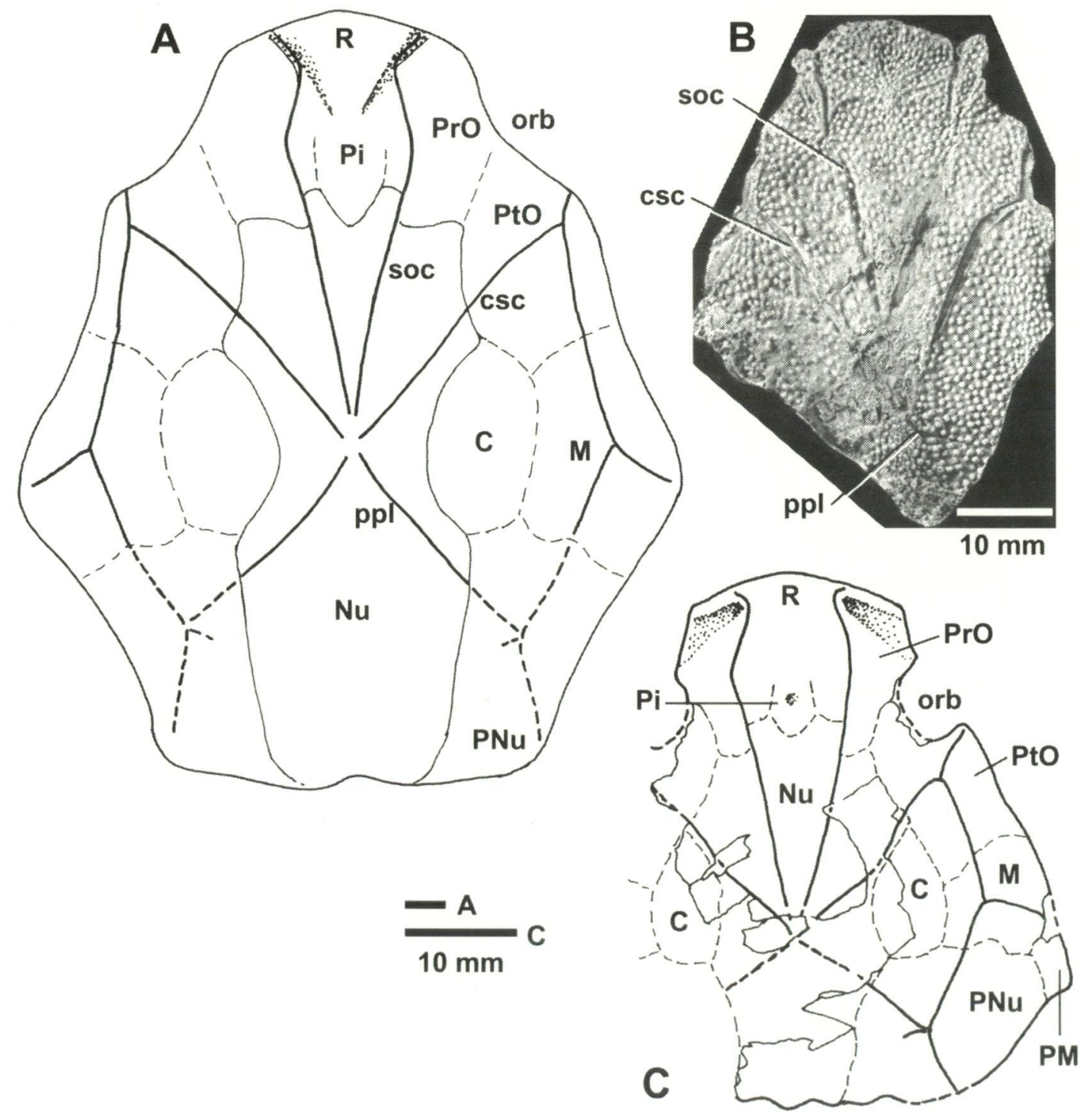

Figure 16 Three representatives of the actinolepid family Antarctaspidae. A, Toombalepis tuberculata gen. et sp. nov., attempted skull reconstruction after Figs 14, 15A-B. B, incomplete skull of Antarctaspis mcmurdoensis White, 1968 (holotype, BMP 49160; latex rubber cast whitened with ammonium chloride); C, reinterpretation of Yujiangolepis liujingensis, based on the holotype (Wang et al. 1998: pl. 1, fig. 1), with inferred bone sutures and sensory canal pattern indicated on the right side. 
(Figure 14A). The supraorbital and central sensory canals converge towards the ossification centre of the $\mathrm{Nu}$ plate, which is missing. The junction of the central canal with the main lateral line canal marks the ossification centre of the PtO plate. Here the curvature to the lateral side of an otherwise rather flat impression suggests that the preserved edge of the specimen approximates to the lateral skull margin, with the sensory groove continuing forward to a partly preserved shallow orbital notch (orb). A very clear suture triple-junction between the $\mathrm{PrO}, \mathrm{PtO}$, and $\mathrm{Nu}$ plates has the same position as in the previous specimen, with an angular projection of the $\mathrm{Nu}$ between the sensory grooves. In the midline this suture is indistinct, but a similar notch for the Pi plate is suggested by ornament rows. The distance between supraorbital sensory canals at the level of the anterior $\mathrm{Nu}$ margin is about $22 \mathrm{~mm}$, compared to $13 \mathrm{~mm}$ for CPC 36938, so CPC 36932 probably came from a skull some 1.5 times larger. Anteriorly, the supraorbital sensory canals are inflected inward, probably indicating the position of the PrO ossification centre. This characteristic pattern is seen in a smaller incomplete skull (AMF 53721; $78 \mathrm{~mm}$ preserved length) from Tambua Station in the Darling Basin (A. Ritchie, pers. comm.), which combines the converging canals on the $\mathrm{Nu}$ with an ornament of coarser second generation tubercles superimposed on an earlier concentric ridged ornament. In both specimens anterior paired shallow unornamented depressions converge posteriorly, and possibly indicate the lateral edge of the $R$ plate. In CPC 36932 the anterior preserved ends of the supraorbital canals widen, and on the left side the groove turns laterally, indicating proximity to the anterior skull margin (soc, Figure 14A). The maximum distance between the supraorbital canals on this specimen $(33 \mathrm{~mm})$, compared to the composite reconstruction of Figure 16A, indicates a total skull length of some $190 \mathrm{~mm}$.

CPC 36931 is an incomplete fragment showing four sensory grooves converging to the broken edge, presumably a remnant of the thickened anterior half of the $\mathrm{Nu}$, the thin posterior part having broken off. Similar preservation is seen in the Darling Basin collection (AMF 54070; Wuttagoona Station). CPC 36937 is a similar fragment from a much smaller specimen.

CPC 36939 (Figure 14C) shows the branching of the postmarginal groove from the lateral line canal which characterises the $\mathrm{M}$ plate in arthrodires. The impression is $100 \mathrm{~mm}$ across, and thus comes from a still larger skull than the previous example. This is a left plate, showing clear sutures for the contact with the $C$ plate, and a posterior margin, assumed to be complete, which indicates the shape of the contact with the PNu. A slightly depressed area at a similar distance inside the anterior and posterior margins (Figure 15B) may be a stress related growth phenomenon. This specimen is provisionally included here on the basis of large size and similar ornament.

A skull restoration based on available material is given in Figure $16 \mathrm{~A}$, and compared with Liujiangolepis from China, and Antarctaspis mcmurdoensis from Antarctica. As noted above, the length of the Nu in CPC 36938, combined with the orientation of the posterior pitline, indicates that the ossification centre for the PNu must have been positioned well in front of the posterior margin. A centrally placed PNu ossification centre is distinctive of actinolepid rather than phlyctaeniid arthrodires.

The remaining specimens described here are from the trunk armour, and are only provisionally referred to this taxon on the basis of large size and coarse tubercular ornament.

CPC 36936 is interpreted as the posterior portion of a right $\mathrm{ADL}$, with an elongate ornamented part bearing coarse tubercles which is most similar in shape to Bryantolepis or Kujdanowiaspis amongst the ADL's figured by Denison (1958: fig. 108). It differs from these, and also Wuttagoonaspis, in the fact that it narrows posteriorly, and has a longer lower overlap area for the MD (Figure 17D). AMF 55327 from the Darling Basin is a similar but more complete $\mathrm{ADL}$, at the anterior margin showing an articular flange of actinolepid type. The interpreted sensory groove in CPC 36936 is only poorly preserved near the posterior end, and an alternative interpretation of this plate is a PL of similar shape to that of Bryantolepis (see Denison 1958: fig. 111E). CPC 36935 is characterised by very coarse ornament for its size (estimated $50-60 \mathrm{~mm}$ in height), and is interpreted as an AL plate in Figure 17C. Tubercles are aligned along the posterodorsal margin, and in front of the pectoral notch are fused to form ridges oriented as in Wuttagoonaspis (Ritchie 1973: fig. $2 \mathrm{~d}, \mathrm{e})$. The posterior margin has two distinct angles, somewhat similar to Wuttagoonaspis, but higher and more pronounced. The inner surface near this margin is preserved, and shows two contact faces interpreted as for the PL and PDL plates. That for the PL is more extensive than any AL figured by Denison (1958: fig. 110). Further material is required to confirm that these examples belong with the distinctive skull of Toombalepis tuberculata.

CPC 36934 (Figure 17A,B) is a fragmentary portion of the ventral armour of a large actinolepid, again with coarse tubercular ornament. It shows the displaced mesial end of a left IL attached to AV and AVL plates, essentially as in the portion of Aethaspis major illustrated by Denison (1958: fig. 98D, 99B), which shows similar development of contact faces on the inner surface for the AMV plate (not preserved). The margins of the $A V$ plate are unclear, and externally it seems displaced and 


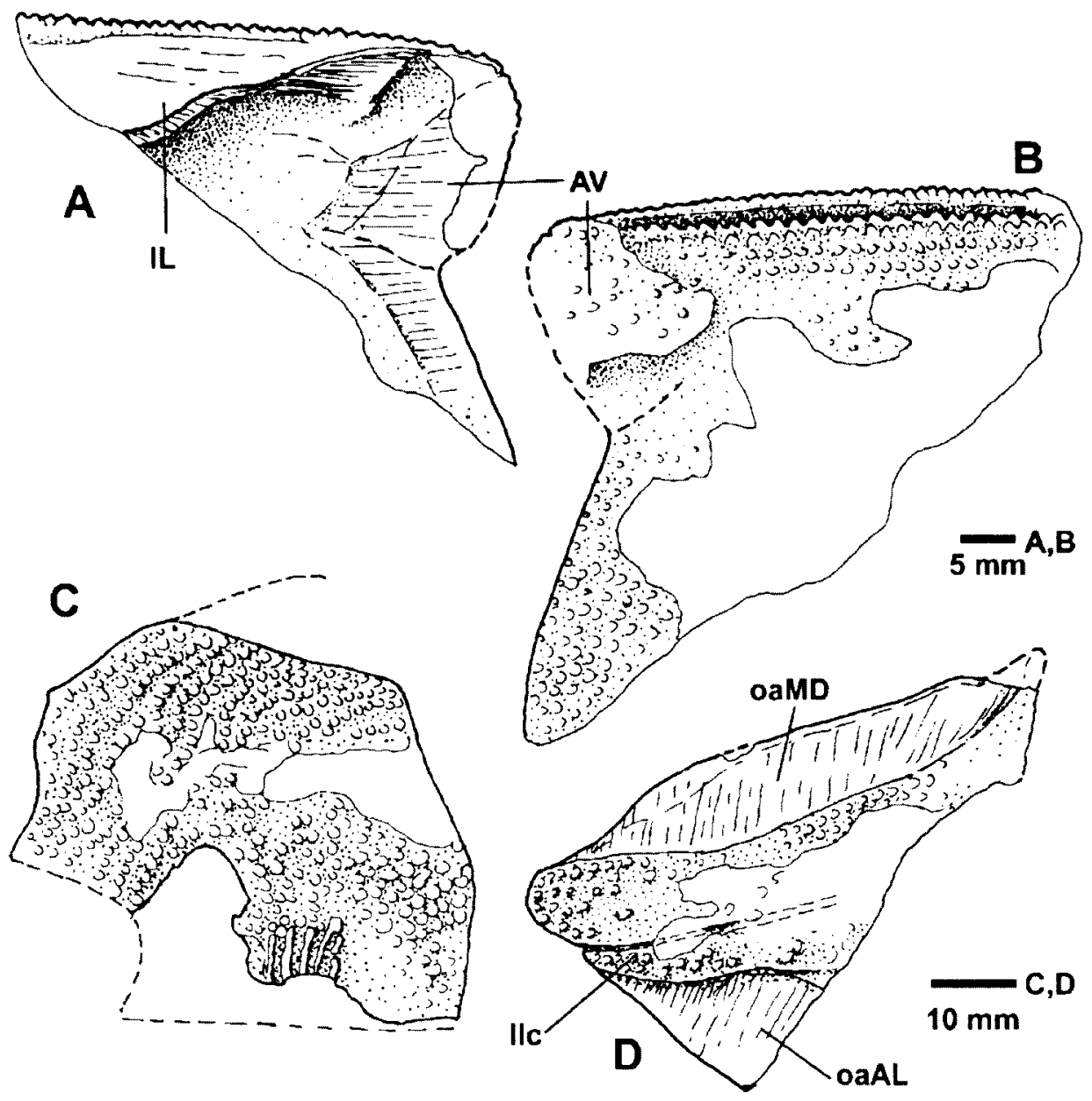

Figure 17 Toombalepis tuberculata gen. et sp. nov., trunk armour bones provisionally referred to the taxon. A,B, incomplete left IL and attached AV plate in internal (A) and external (B) views (CPC 36934); C, incomplete right AL plate (CPC 36935); D, incomplete right ?ADL plate (CPC 36936).

covered with large tubercles (AV, Figure 17B), although the surface is poorly preserved. A strong groove flanked by straight rows of large slightly pointed tubercles is the transverse sulcus (possibly for cutaneous sense organs) often developed on the IL of arthrodires. At least five transverse tubercle rows ornament the ventral lamina of the IL. More scattered tubercles further back are probably on the AVL, but a suture is not evident. This specimen is again only provisionally included here.

\section{Actinolepidoidei incertae sedis \\ Tnoralaspis gen. nov.}

Tnoralaspis petercooki sp. nov. Figure 15C-E

fragment of arthrodiran armour: Johnstone et al. 1968: 610

fragmentary arthrodiran fish plates; Gosses Bluff arthrodire: Gilbert-Tomlinson 1968: 197, 203, figure 2 nuchal plate ... of a euarthrodiran; smaller specimen from the Toko Syncline: Young 1985: 242.

\section{Material}

CPC 24664 (holotype), an incomplete nuchal plate preserved in part and counterpart, with an associated indeterminate element; CPC 36940-941.

\section{Localities and Horizon}

The holotype comes from the eastern rim of Gosses Bluff, Amadeus Basin, Northern Territory. The other specimens come from locality $77 / 19$ in the Georgina Basin (Cravens Peak Beds; Figure 1D). The type locality has a complex geology (see Young 1985: fig. 3). Two possible stratigraphic interpretations were put forward, but subsequent discovery of remains of Wuttagoonaspis sp. in the basal Pertnjara Group at Mount Winter, in the western Macdonnell Ranges (Young 1988a: fig. 13), supports a similar position for the Gosses Bluff fish locality; i.e. the upper alternative for locality 1 , at the top of the Mereenie Sandstone, given in Young (1985: fig. 2). Details of the stratigraphic section at 
Mount Winter are provided in Young and Turner (2000). A locality summary for each taxon is given in Table 1, and locality details for each specimen are listed in the Appendix.

\section{Diagnosis}

A presumed actinolepidoid with a high vaulted armour, forming an angle of about $100^{\circ}$ in the dorsal midline. Nu slightly shorter than broad, with maximum breadth posteriorly, and a transverse anterior margin. MD with posteriorly placed transverse thickening, at the level of the lateral corners, and possible narrow overlap area for the ADL along the anterolateral margin. Ornament of coarse tubercles, sometimes with concentric alignment.

\section{Etymology}

From Tnorala, an Aboriginal Arrernte (Aranda) place name for Gosses Bluff, an impact structure in the Amadeus Basin, central Australia (the type locality). The species name acknowledges the collector, geologist Dr P.J. Cook.

\section{Remarks}

This new taxon provisionally groups together a small number of specimens, all median bones apparently belonging to an arthrodire with a high vaulted armour. They can be assumed not to belong to Toombalepis tuberculata described above, which, judging by its skull roof, had a relatively flat armour. Assuming they belong to one of the major arthrodire subgroups, the short broad MD plate suggests actinolepidoid affinity. However a possible $\mathrm{Nu}$ plate has a shape consistent with that of phlyctaenioids. If these two bones are correctly interpreted, and do belong to one taxon, it could be a brachythoracid, which combines these features. Further material is needed to clarify the affinities of this taxon, which for the present is assumed to be an actinolepidoid.

The morphological similarity between the two specimens identified as $\mathrm{Nu}$ plates, collected nearly $600 \mathrm{~km}$ apart, was noted by Young (1985: 242). The third specimen is provisionally included because it has similar ornament, combined with a high vaulted form.

\section{Description}

The holotype (Figure 15E), collected from the rim of Gosses Bluff in 1966 by P.J. Cook, was briefly described (Young 1985: 242) as a large unpaired plate at least $80 \mathrm{~mm}$ long, preserved in part and counterpart. The external surface is covered in coarse tubercles that have a strong concentric alignment in the posterolateral parts of the bone (see Young 1985: fig. 5A). A short broad shape was suggested by the ornament, although anterior and lateral margins are incomplete. The specimen is noteworthy for its strongly arched form, with left and right laminae enclosing an angle of about $100^{\circ}$ at the posterior margin. The counterpart shows a strong internal thickening along the posterior margin, interpreted as a nuchal thickening. An associated ornamented plate (Figure 15D) presumably comes from the same fish, but no margins are preserved. It may be an AVL or PVL from the trunk armour.

The second example (CPC 36940; Figure 15C), previously referred to as a 'somewhat smaller specimen from the Toko Syncline in the Georgina Basin' (Young 1985: 242), has only the external and posterior surfaces preserved. It is again clearly an unpaired bone, with a fairly straight posterior margin, and a high median angle between left and right laminae of about $100^{\circ}$. The poorly preserved ornament suggests similar coarse tubercles, which show faint concentric alignment posterolaterally. The median angle of the plate is slightly pointed, projecting back as a slight posterior process (not completely preserved on the holotype). Again, this plate came from a high, vaulted armour, with a similar angle between laminae to the holotype. The thickened posterior face shows the transverse nuchal thickening just inside the posterior margin, again as in the other specimen. The anterior and lateral margins are less well preserved, but sufficient to confirm the short broad shape of this bone (length $61 \mathrm{~mm}$; breadth $64 \mathrm{~mm}$ ).

These two specimens are provisionally identified as Nu plates of quite different size. The Gosses Bluff specimen preserves the ornament in good detail, but not the margins, whereas the Toko specimen shows general shape and margins, but lacks ornament detail. Direct comparison of latex casts confirms their identical configuration in posterior view, with flat lateral laminae and straight posterior margins meeting sharply at almost a right angle in the midline. In lateral profile both plates are again closely similar, with a slight convexity posteriorly, and a shallow median depression anteriorly.

The third specimen (CPC 36941) is another unpaired impression from the same locality, preserved in part and counterpart. It has a different shape, with greatest breadth in about the middle of the length of the plate, rather than at the posterior margin as in the presumed $\mathrm{Nu}$ plates just described. This specimen is therefore interpreted as an MD plate from the trunk armour. The outer surface near the posterior margin shows coarse tubercular ornament, becoming finer with some concentric alignment towards the anterior margin. The plate is about $57 \mathrm{~mm}$ long, with estimated breadth (based on a camera lucida sketch) of $77 \mathrm{~mm}$. Again, the two laminae are about $100^{\circ}$ apart, indicating a high vaulted armour as in the Nu plates just described. The transverse thickening on the visceral surface is 
posteriorly placed, at the level of the lateral corners. Anteriorly there is a slight median ventral ridge, as in Actinolepis (e.g. Mark-Kurik 1973: pl. 11, fig. 4). Contact faces for the dorsolateral plates are not clear because of poor preservation, and a depressed area along the anterolateral margin of the external surface resembles a narrow overlap area. An overlap for the ADL onto the MD is seen in only a few other placoderms, for example Eurycaraspis (Liu 1991: fig. 4A).

\section{Ethabukaspis gen. nov.}

Ethabukaspis leios sp. nov. Figure 18

\section{Material}

CPC 36942-944.

\section{Localities and Horizon}

$77 / 3,4,19$, in the Cravens Peak Beds (Figure 1D). A locality summary for each taxon is given in Table 1 , and locality details for each specimen are listed in the Appendix.

\section{Diagnosis}

A presumed actinolepidoid arthrodire with a high vaulted armour, forming an angle of about $70^{\circ}$ in the dorsal midline. $\mathrm{Nu}$ with a convex posterior margin. MD with curved dorsal spine projecting from anterior margin. External surface of dermal bones smooth, lacking ornament.

\section{Etymology}

After Ethabuka, a locality in the Toko Syncline area, aspis (Greek), a shield, and leios (Greek), smooth or bald, with reference to the absence of tubercular ornament on the dermal bones.

\section{Remarks}

This taxon differs from that previously described in possessing a high vaulted $\mathrm{MD}$, which has an even steeper angle at the midline, with a strong dorsal spine or crest. It also lacks ornament, which distinguishes it from all other actinolepidoids so far identified in this fauna. The short broad MD plate is assumed to indicate actinolepidoid affinity, and it could be a close relative of Tnoralaspis gen. nov. described above. Alternatively, the dorsal spine might indicate affinity to Lurapullaspis gen. nov.

CPC 36943 differs from the MD described under the previous taxon in having an even steeper angle, a strong dorsal spine or crest, and lacking ornament. It is unlikely to be a smooth species of the genus Tnoralaspis, because of differences in the form of the MD. Some other smooth remains are provisionally included.

\section{Description}

CPC 36943 (the holotype; Figure 18A,C) is a high vaulted $\mathrm{MD}$ with laminae set at about $70^{\circ}$ to each other. The preserved impression includes the posterior margin of the left lamina, which exposes the smooth external surface. The plate is about 38 $\mathrm{mm}$ across and $45 \mathrm{~mm}$ long. A transverse

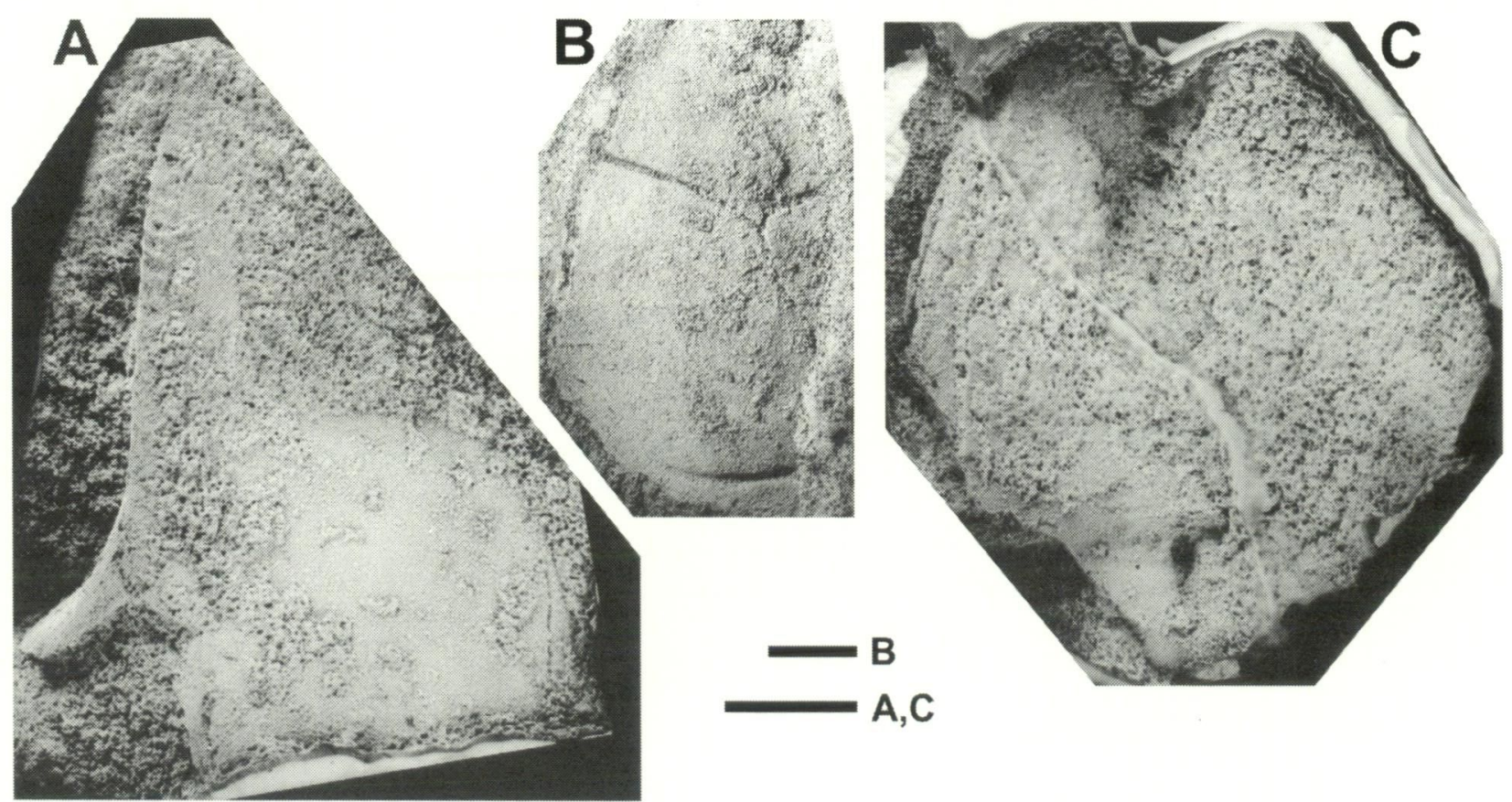

Figure 18 Ethabukaspis leios gen. et sp. nov. A,C, holotype (CPC 36943), an incomplete dorsal trunk armour in left lateral (A) and ventral (C) views. B, CPC 36944, an assumed left M plate from the skull, provisionally referred to the taxon. Both specimens latex rubber casts whitened with ammonium chloride; scale bars $=10 \mathrm{~mm}$. 
thickening on the visceral surface (Figure 18C) is at the level of the lateral corners, as in Actinolepis (e.g. Mark-Kurik 1973: pl. 11, fig. 4), but in this specimen placed much farther back. Behind the thickening is a median pit. The posterior median angle of the bone is elevated to a point, and possibly was extended as crest behind the dorsal spine.

The counterpart preserves the remaining smooth external impression of the left lamina, with a curved spine emanating from the anterior edge of the assumed midline (Figure 18A). The notched anterior margin is asymmetrical and must be broken, and the specimen may be slightly distorted. The dorsal spine slopes posteriorly and is about 35 $\mathrm{mm}$ long and $10 \mathrm{~mm}$ wide at the base, but it is not clear whether it continued to the posterior margin as a crest.

CPC 36944 (Figure 18B) is another smooth impression 55 by $30 \mathrm{~mm}$ across, lacking all margins, but showing a sensory groove triple junction, and
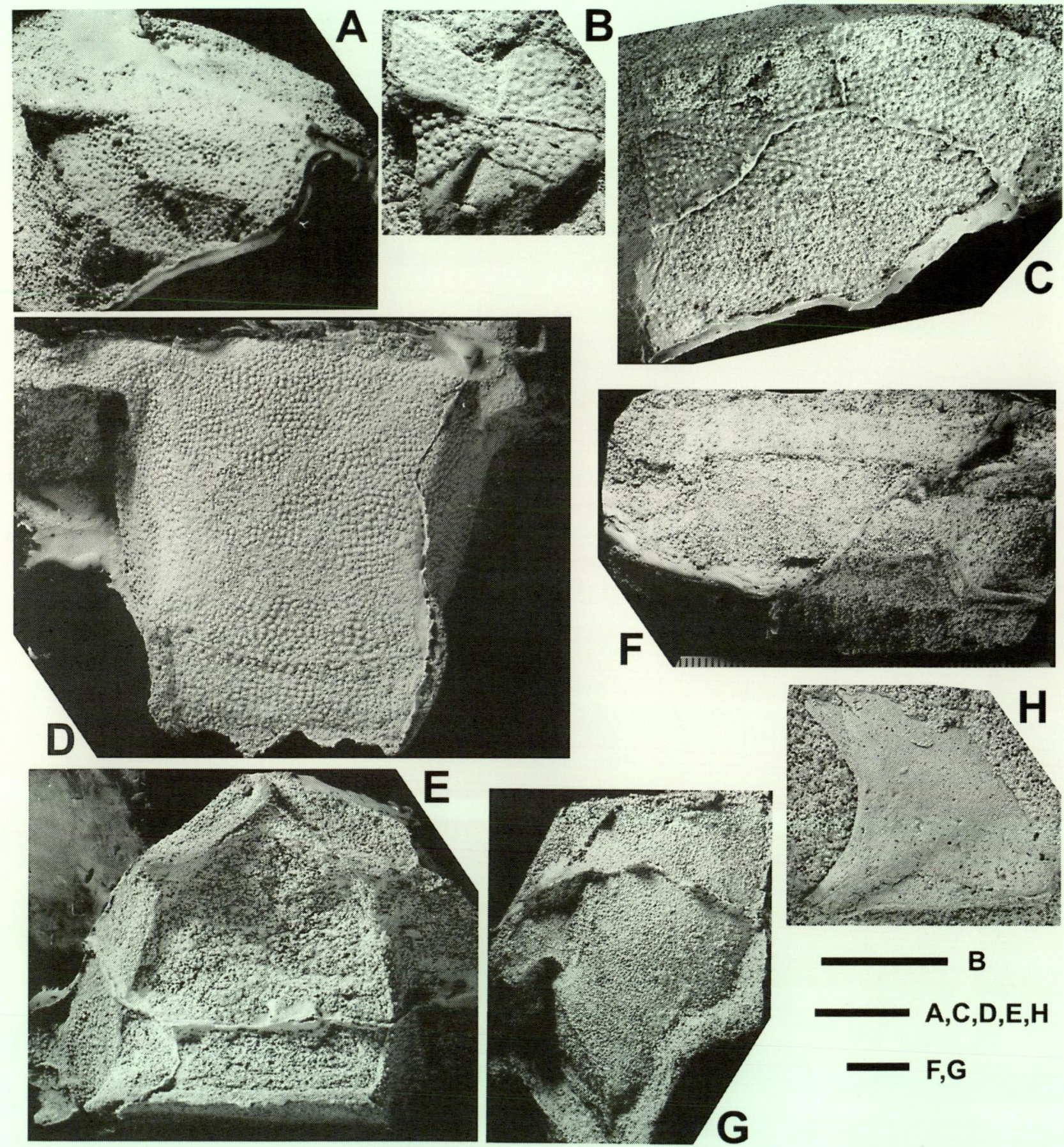

$A, C, D, E, H$

F,G

Figure 19 Huginaspis australis sp. nov. A, holotype (CPC 36947), right lateral view; B, CPC 36948, a right PDL in lateral view; C, CPC 36958, an incomplete trunk armour in left lateral view; D,E, CPC 36955, an incomplete trunk armour in ventral (D) and posterior (E) views; F, G, CPC 36959, an incomplete trunk armour in left lateral (F) and ventral $(G)$ views; $H$, left $A L$ plate, internal view (CPC 36957). All specimens are latex rubber casts whitened with ammonium chloride; scale bars $=10 \mathrm{~mm}$. 
another unconnected groove. It is on the same block as the Nu of Toombalepis (CPC 36938). It presumably comes from the skull (or possibly the cheek), but is too incomplete to determine. CPC 36942 is possibly a $\mathrm{Nu}$ plate of the same form (poorly preserved), with a similar high angle between laminae, and a convex posterior margin.

\section{Suborder Phlyctaenioidei Miles, 1973}

\section{Family Phlyctaeniidae Fowler, 1947}

\section{Genus Huginaspis Heintz, 1929a}

\section{Diagnosis}

See Denison (1978: 58)

\section{Remarks}

This poorly known taxon is represented only by trunk armours, but judging by the specimen illustrated by Heintz (1929b: pl. 2, fig. 1), the ADL plates may not have been in midline contact beneath the MD. If correct, this would be a difference to both Arctolepis and Dicksonosteus (e.g. Goujet 1984a), and to all groenlandaspids as defined below. As previously noted (Goujet 1984a: 252) the family Phlyctaeniidae is probably paraphyletic.

Huginaspis australis sp. nov. Figures 19-22, 23A,B

diverse arthrodires: Young 1991a: 67 (pars)

phlyctaeniid euarthrodires: Haines et al. 1991: 32

\section{Material}

CPC 36945-959.

\section{Localities and Horizon}

$74 / 11,14$ (northwestern part of the Dulcie Syncline, in the Dulcie Sandstone); 77/2, 19 (Cravens Peak Beds). For localities see Figure 1. A locality summary for each taxon is given in Table 1, and locality details for each specimen are listed in the Appendix.

\section{Diagnosis}

A Huginaspis which has a low median dorsal crest with a slightly angular apex closer to the posterior end, but lacking a pronounced posterior process.

\section{Etymology \\ From australis (L), southern.}

\section{Remarks}

In all preserved features this small collection of specimens is closely similar to the poorly known
Spitsbergen genus Huginaspis, for which two species were erected by Heintz (1929a-b). However the crest on the MD plate is somewhat lower, and less rounded in profile, than in the type species $H$. vogti (the holotype and only known specimen), as illustrated by Heintz (1929a: pl. 20, fig. 2). In addition, the posterior part of the crest does not project as a prominent process as is seen in $H$. broggeri (Heintz 1929b: fig. 8, pl. 2, fig. 1). H. broggeri also displays the characteristic dorsolateral processes, which are prominent (but perhaps less elongate) in all specimens of $H$. australis with this part preserved. Some minor differences in the shape of the crest are noted below, but are assumed for the present to be intraspecific variation perhaps related to size or sex. Probably a closely related form from the Darling Basin, with a higher more anterior angle to the crest, was illustrated by Neef $e t$ al. (1996: fig. 3C2).

\section{Description}

This small collection comprises several articulated trunk armours from locality $74 / 14$, one from loc. $74 / 11$, and others from $77 / 2$. All three examples from the first locality are similarly preserved as sections showing the posterior end of small trunk armours (Figure 21). CPC 36955 is the largest example from this locality (Figure 19D,E). It shows a posterior section of the trunk-armour, and most of the ventral surface (except the anterior margin), and the lateral margins up to the pectoral fenestrae (incomplete anteriorly). In posterior view (Figure 21D) it is about $34 \mathrm{~mm}$ high in the midline, and broadest $(32 \mathrm{~mm})$ across the lateral expansions of the subanal laminae. The ventral surface is almost completely flat except for these expansions, which project somewhat ventrally (Figure 21F). All sutures are unclear, but their approximate positions are indicated by alignment of tubercles on the ventral surface (Figure 20D). Presence of a reverse overlap between the two PVL's is indicated by a transverse line in the ornament crossing the ventral laminae between ossification centres. However, the ornament rows suggest that the left plate overlapped the right in front, and the right overlapped the left behind the line, which is the opposite arrangement to that of Dicksonosteus (Goujet 1984a: fig. 67). This may be a generic or specific character.

Parts of both pectoral fenestrae are preserved in this specimen, with the right side more complete (f.pect, Figure 20D). The transverse orientation of its ventral border is commonly seen in phlyctaenioids with a long SP (e.g. Dicksonosteus; Goujet 1984a: pl. 11, fig. 1). This is assumed to be the case for this species, although not seen in any specimen.

CPC 36953 (Figure 21B) is a smaller specimen from the same locality. The posterior opening of the trunk armour is about $18 \mathrm{~mm}$ high, with the 


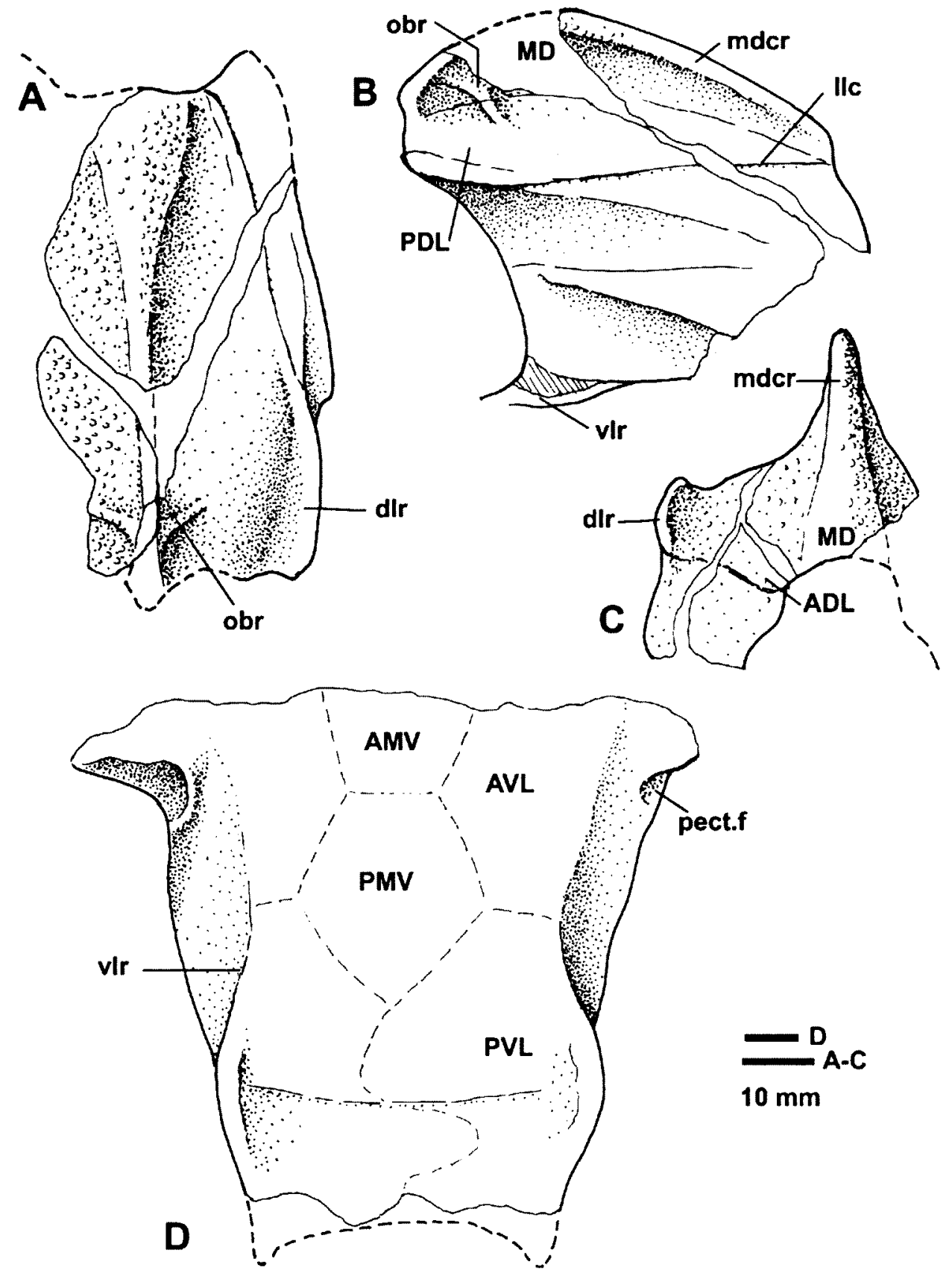

Figure 20 Huginaspis australis sp. nov. A-C, part restoration of the holotype (CPC 36947), an incomplete trunk armour in dorsal (A), right lateral (B) and anterior (C) views; D, incomplete trunk armour in ventral view (CPC 36955).

posterior $10 \mathrm{~mm}$ of the median dorsal crest preserved, which has a slightly rounded border and in lateral view a similar curved shape to the holotype, but with a less steep posterior margin. CPC 36954 (Figure 21C) is the smallest example, about $17 \mathrm{~mm}$ high in the midline, increasing to about $23 \mathrm{~mm}$ at the anterior preserved edge, only some $8 \mathrm{~mm}$ in from the posterior margin. All surfaces carry fine tubercular ornament. This specimen differs from the other two in the sharper dorsolateral and lateral crests, and the sharper and more angular median crest, presumably juvenile characteristics.
CPC 36947 (the holotype; Figure 20A-C) is a slightly distorted right side of the trunk armour including the dorsal midline showing the anterior part of the crest, which closedly conforms to the shape illustrated on the holotype of $H$. vogti (see Heintz 1929a: pl. 20, fig. 2). The posterior part of the crest is incompletely preserved as an impression of the lateral surface (crest length $\sim 33 \mathrm{~mm}$ ), but the shape of the dorsal border is shown in CPC 36953954. The latter is less curved than in H.vogti, with a narrow ridge compared to the more rounded preserved crest on CPC 36947 . A short oblique ridge (obr) passes down onto the PDL from the rear end 

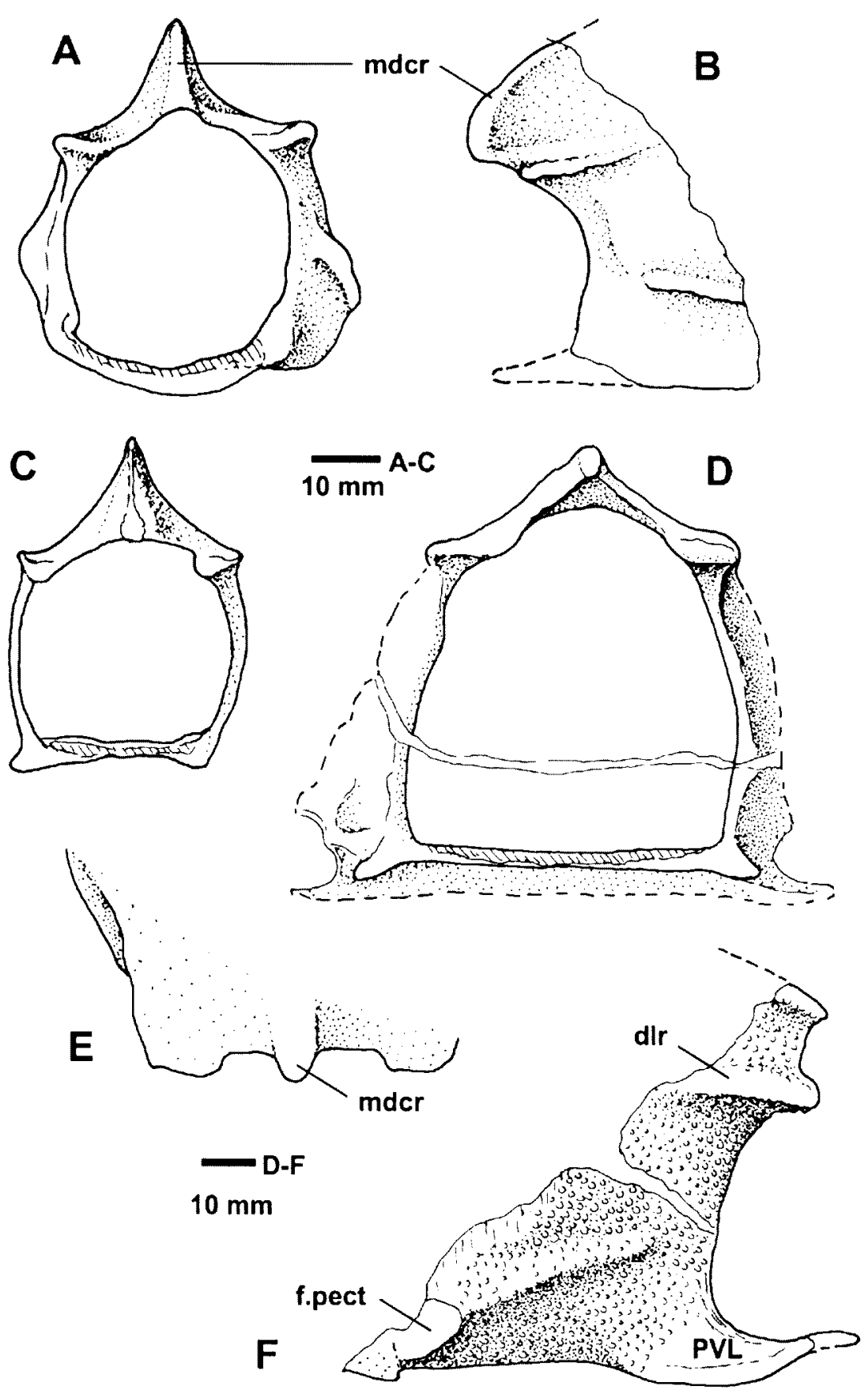

Figure 21 Huginaspis australis sp. nov. Incomplete trunk armours. A,B, CPC 36953 in posterior and right lateral views; C, CPC 36954 in posterior view; D-F, CPC 36955 in posterior (D), dorsal (E) and left lateral (F) views.

of the median crest, possibly equivalent to that seen in H. vogti (Heintz 1929a: pl. 20, fig. 2). The same structure is seen on CPC 36946. A similar ridge is developed in some groenlandaspids (see below).

CPC 36958 (Figure 19C) is a similarly preserved but larger example, also showing the left side, with a crest $44 \mathrm{~mm}$ long, but less pronounced than in the previous specimen, or in $H$. vogti. The articular condyle is partly preserved (Figure 23B), with a trace of the anterior part of the $\mathrm{ADL} / \mathrm{MD}$ suture, showing how narrow the MD is at the front, with the articular condyles very closely spaced. In both these specimens the main lateral line sensory groove (llc) runs diagonally across the armour, with a narrow ridge just above it at anterior and posterior extremities. There is no dorsal inflection on the PDL as developed in groenlandaspids (see below). A similar orientation of the sensory groove was inferred for the Spitsbergen material (Heintz 1929b: fig. 6). As preserved, the posterior margin of the PL is convex, but this appears not to be complete, because there is no pronounced lateral projection on the PDL as seen in the previous specimen. However, some enlarged tubercles beneath the dorsolateral ridge suggest proximity to the ossification centre of the PDL, although 


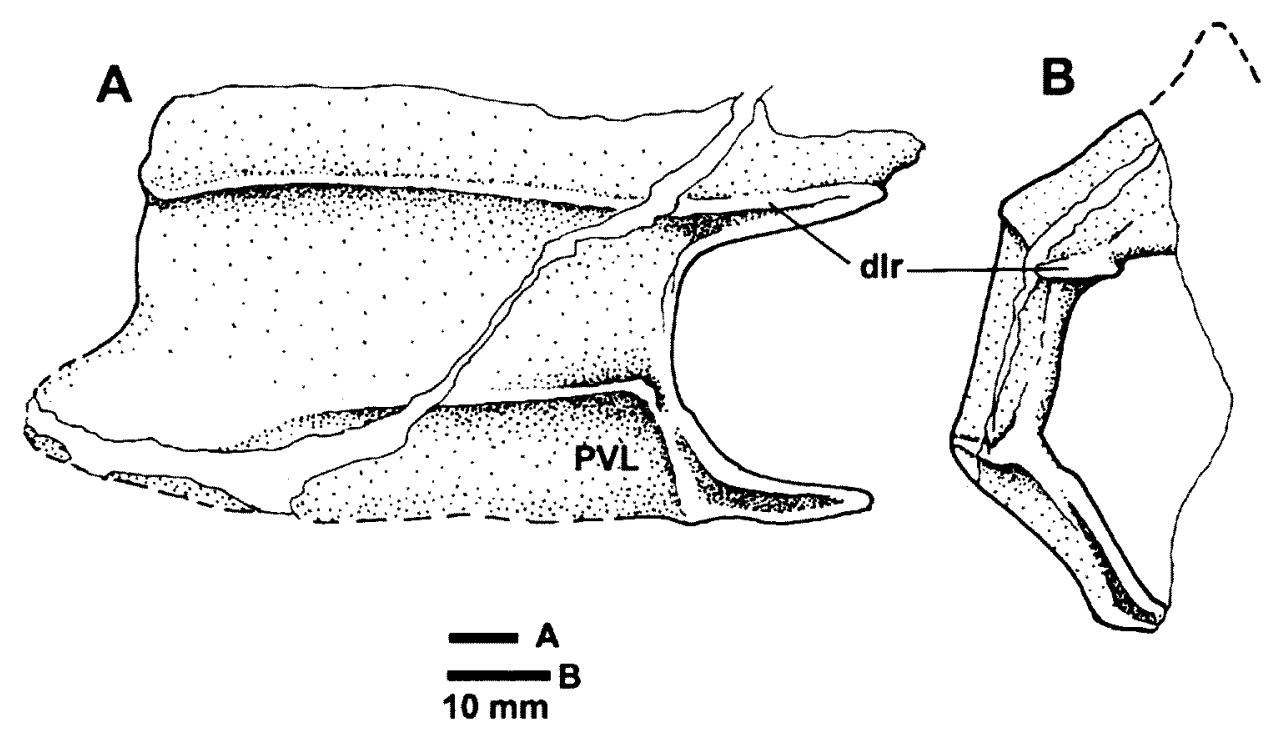

Figure 22 Huginaspis australis sp. nov. Incomplete trunk armour (CPC 36959) in left lateral (A) and posterior (B) views.

completeness of this part is unclear. Part of the supraspinal lamina of the $\mathrm{AL}$ is preserved at the anteroventral corner; otherwise all margins are broken.

This specimen has an ornament of stellate tubercles, and was clearly a lower and broader armour than in $H$. vogti, with a less pronounced crest which lacks an anterior projection. The convex posterior margin of the PDL (if complete) would be a difference to the previous specimen, but for the present these remains are assumed to be conspecific. CPC 36952 is another incompletely preserved armour of similar size to CPC 36955, showing the left supraspinal lamina of the $\mathrm{AL}$, but the dorsal wall has been lost.

CPC 36959 (Figure 19F,G) appears more elongate than the previous specimens, but the dorsal crest is not preserved. Total preserved length in left lateral view is $62 \mathrm{~mm}$, with length of the lateral wall $39 \mathrm{~mm}$. The counterpart includes the right SP plate, and shows the ventral trunk armour wall to be $35-40 \mathrm{~mm}$ wide at that level. The angle the outer edge of the SP plate makes with the ventrolateral ridge of the trunk armour is about $40^{\circ}$. The preserved proximal part shows less curvature than some Spitsbergen taxa, including $H$. vogti, Arctolepis and Dicksonosteus (Heintz 1929a: pl. 20; Goujet 1984a: pls. 10-12, 1920). The straighter SP of Heintzosteus or Elegantaspis (Goujet 1984a: pls. 23; Denison 1978: fig. 39B) is more comparable, but both forms differ in having a probably longer SP, which is more widely angled to the trunk armour. A poorly preserved steinkern of this specimen shows an internal midline height of 28-30 mm for the trunk armour.

No specimen shows the subanal lamina in entirety, so its shape in Figure 20D is restored after Heintz (1929b: fig. 5). The transverse crest at the level of the ossification centres for PVL's is clear in CPC 36955 (Figure 19D), so based on Heintz's proportions only the posterolateral processes are missing, as was the case in the earlier described specimen (Heintz 1929a: pl. 20, fig. 1). That they were present is assumed from the prominent development of posterior processes at the dorsolateral corners in all specimens, as figured by Heintz in the second specimen $(H$. broggeri, 1929b: fig. 8, pl. 2). In H. australis they are broad and spatulate in the largest specimen. This material may be compared with a specimen from the Darling Basin (AMF 54675, from a ridge $N$ of Kurries Tank, Tambua Station), which shows a ventral trunk armour wall with a more elongate and narrow subanal portion, combined with short curved SP plates.

Several less complete specimens are provisionally included in Huginaspis australis. CPC 36959 (Figure 19B) is a small right PDL $16 \mathrm{~mm}$ high by $15 \mathrm{~mm}$ long, and thus much lower than this bone as developed in groenlandaspids, Tiaraspis or Africanaspis. The dorsolateral ridge is developed behind the ossification centre as a lappet, and on this evidence it is provisionally included with this taxon, even though the tubercular ornament is somewhat coarser for its size than in the other specimens described above. Similar ornament is seen on CPC 36951, an incomplete right $\mathrm{AL}$ plate. CPC 36956 is another small armour showing part of the lateral wall.

\section{Tokolepis gen. nov.}

Tokolepis ulpe sp. nov. Figures 24, 25A-D

diverse arthrodires: Young 1991a: 67 (pars) actinolepid nov.: Young et al. 1993: 247 (pars)

\section{Material \\ CPC 36960-963.}




\section{Localities and Horizon}

74/11 (southern limb of the Dulcie Syncline, in the Dulcie Sandstone); $77 / 3$ (Cravens Peak Beds; upper fish horizon). For localities see Figure 1. A locality summary for each taxon is given in Table 1 , and locality details for each specimen are listed in the Appendix.

\section{Diagnosis}

A phlyctaeniid arthrodire with a skull roof attaining at least $80 \mathrm{~mm}$ in length. Skull with a very broad rostral margin, inflected at about $90^{\circ}$ to the dorsal surface, with a pronounced ventral median process. $R$ plate broad, with anteriomesial inflection of supraorbital sensory canals towards its ossification centre. Orbits small, anteriorly placed, with prominent dermal postorbital processes. Interorbital part of skull broad and flat, lacking a rostro-nasal groove. Supraorbital and central sensory grooves converging posteriorly towards ossification centre of $C$ plates. MD plate possibly short and broad; trunk armour otherwise not known. External ornament almost smooth, with very fine tuberculation, and enlarged tubercles around rostral skull margin.

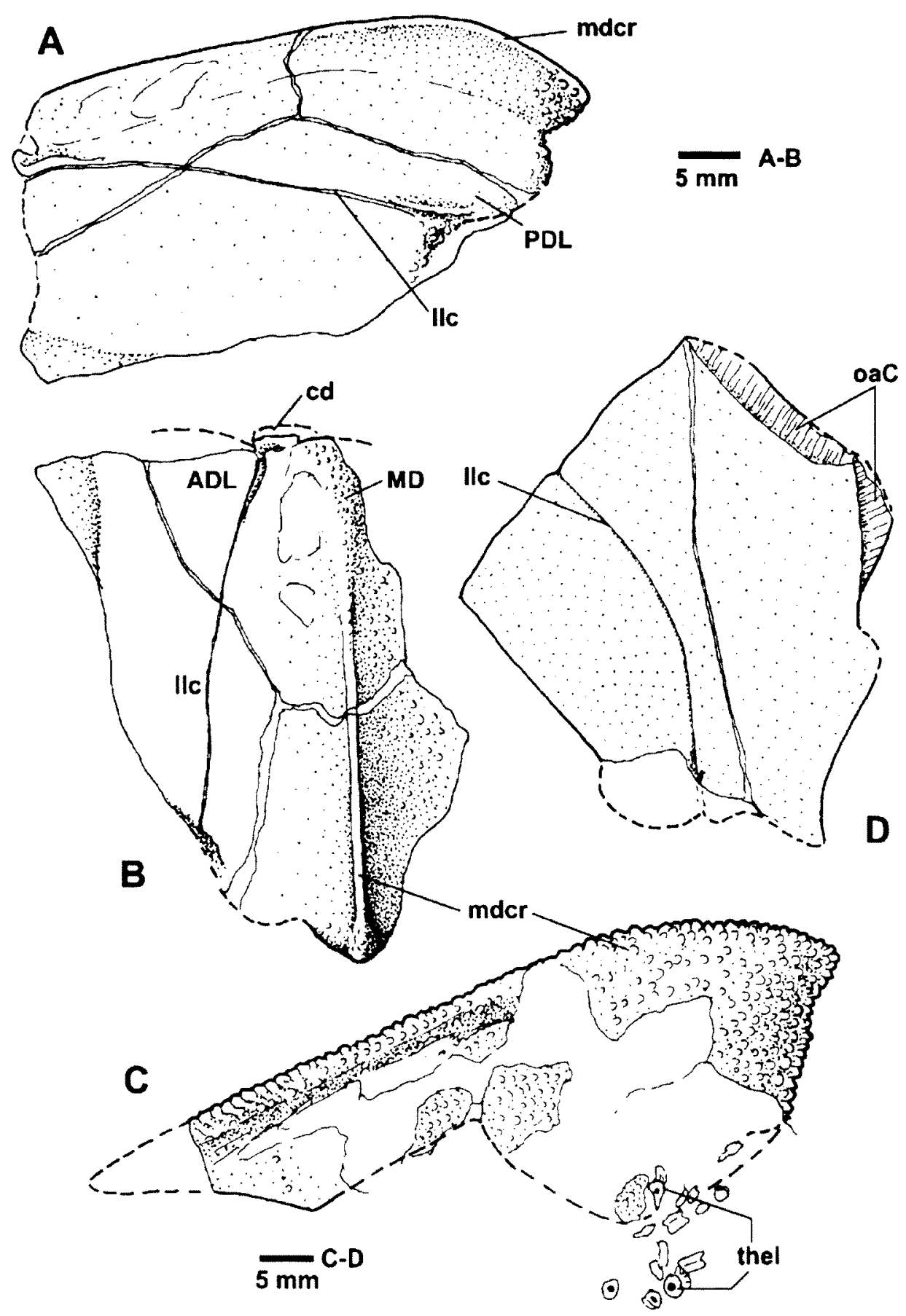

Figure 23 A,B, Huginaspis australis sp. nov., incomplete trunk armour in left lateral (A) and dorsal (B) views. C,D, cf. Groenlandaspis sp. indet. 1. C, MD plate, left lateral view (CPC 36982); D, left PNu plate (CPC 36983). 


\section{Etymology}

After the Toko Range, lepis (Greek), a scale, and ulpe (Arrernte language), meaning 'fine or smooth consistency' (Henderson and Dobson 1994), with reference to the fine dermal ornament.

\section{Remarks}

This is a poorly known arthrodire with fine ornament, represented by two skulls with a distinctive very broad rostral margin. Comparisons are made below with the phlyctaeniids Arctolepis, Dicksonosteus and Heintzosteus from the Early Devonian of Spitsbergen, with which it was evidently closely related. Other material with fine or smooth ornament described above is assumed to belong to an actinolepidoid, and with a high vaulted trunk armour is unlikely to go with the flat skull roof described below. The new genus resembles Arctolepis from Spitsbergen in its broad rostral margin, but differs in the fact that the supraorbital sensory canals have a more mesial position, are inflected anteriorly towards the midline, and posteriorly extend well past the level of the pineal opening, to the ossification centre the $C$ plates. The much broader MD plate, if corrected included in this new taxon, is also a difference from the more elongate MD of most other phlyctaeniids. The skull also differs from Arctolepis, Dicksonosteus and Heintzosteus in its finer ornamention, and smaller, more anteriorly placed orbits. It differs from Arctolepis in the more prominent dermal postorbital process and smaller orbit, broader $\mathrm{R}$ plate, and probably the shape of the Pi plate. The Pi was apparently larger than in Heintzosteus, but similar in shape to that of Dicksonosteus, but the interorbital part of the external skull roof is much broader and flatter, without any sign of a rostronasal groove. The rostral margin has a much broader blunt shape than in Dicksonosteus.

\section{Description}

This taxon is based on two incomplete skull impressions that clearly differ from all other known arthrodires. CPC 36962 (the holotype) is an incomplete skull roof, mainly from the left side, preserved in part and counterpart (Figure 25A,B). The preserved portion has a midline length of about $60 \mathrm{~mm}$. It is flat in longitudinal profile, with a broad blunt rostral margin and small, deep orbital notches. The external surface is covered with very fine tubercular ornament. Sutures are indistinct, but some indication of bone margins is provided on the internal surface. The position of the midline can be approximated from the position of the pineal fossa on the inner surface (Figure 24B), and the transverse contour of the skull, which posteriorly is flat to slightly concave in the central portion. A slight imperfection in the surface anteriorly, probably marks the position of the pineal foramen (pi, Figure
$24 \mathrm{~A})$. The inner surface indicates that the anterior end of the $\mathrm{Nu}$ is probably included. Faint concentric ornament suggests that the ossification centre of the $\mathrm{Nu}$ plate was located not far behind the posterior preserved margin. Most of the left $M$ plate is missing, and there is no information on the $\mathrm{PNu}$ plates. CPC 36961 (Figure 25C) is a smaller example of the same form, preserved only as an external impression. It is almost smooth externally, although fine tubercles are visible around the margins. This specimen has a clear depression anteriorly in the midline for the pineal opening, and also preserves the right $M$ plate and lateral corner of the skull, with the postmarginal sensory groove (pmc, Figure 24C).

Both these skulls are characterised by broad blunt rostral margins, small orbits, fine ornament, and a posteriorly converging sensory canal pattern. Similar features are seen in the Early Devonian arthrodires from Spitsbergen, for example 'Jaekelaspis' illustrated by Heintz (1929b: pl. 1, fig. 1), now synonymised with Arctolepis (Denison 1978; Goujet 1984a). On neither specimen are bone sutures clear, but it is assumed that the sensory canals converge posteriorly on paired $C$ plates, as in most arthrodires, rather than on a large $\mathrm{Nu}$ plate, as in Toombalepis gen. nov. described above. In Actinolepis the supraorbital sensory canals converge to the midline on a fused PrO plate (Mark-Kurik 1973), but there is no evidence to suggest that interpretation here. Although the supraorbital sensory canals often pass back to the ossification centres of paired $C$ plates in various brachythoracid arthrodires, this is generally not the case in either actinolepids or phlyctaeniids (Goujet 1984a; Denison 1978, figs. 31, 38). Exceptions are the skull of Groenlandaspis (Figure 26C), and some variations in sensory groove pattern observed in Arctolepis (Goujet 1984a: fig. 80; pl. 17, fig. 1).

The skulls of the three Spitsbergen phlyctaeniids (Arctolepis, Dicksonosteus and Heintzosteus) are all readily distinguished from Tokolepis gen. nov. in their coarser tuberculation (Goujet 1984a: pls 2, 15, 22). The new genus resembles Arctolepis in the broad rostral margin (Goujet 1984a: fig. 77), but evidently has the $\mathrm{Pi}$ plate still in the primitive position in front of the PrO plates, as in Dicksonosteus. However. Dicksonosteus has a more narrow and rounded rostral margin (Goujet 1984a: fig. 31). The external skull surface of Dicksonosteus shows a conspicuous 'rostro-nasal groove' demarcating the rostral capsule from the postorbital part of the skull (e.g. Goujet 1984a: pl. 2). In contrast, the interorbital part of the skull in Tokolepis is much broader and flatter, with no groove, and only a slight depression marking the position of the pineal body. In Heintzosteus the Pi extended back to partly or completely separate the PrO plates (Goujet 1984a, figs. 94-96), probably a more advanced 


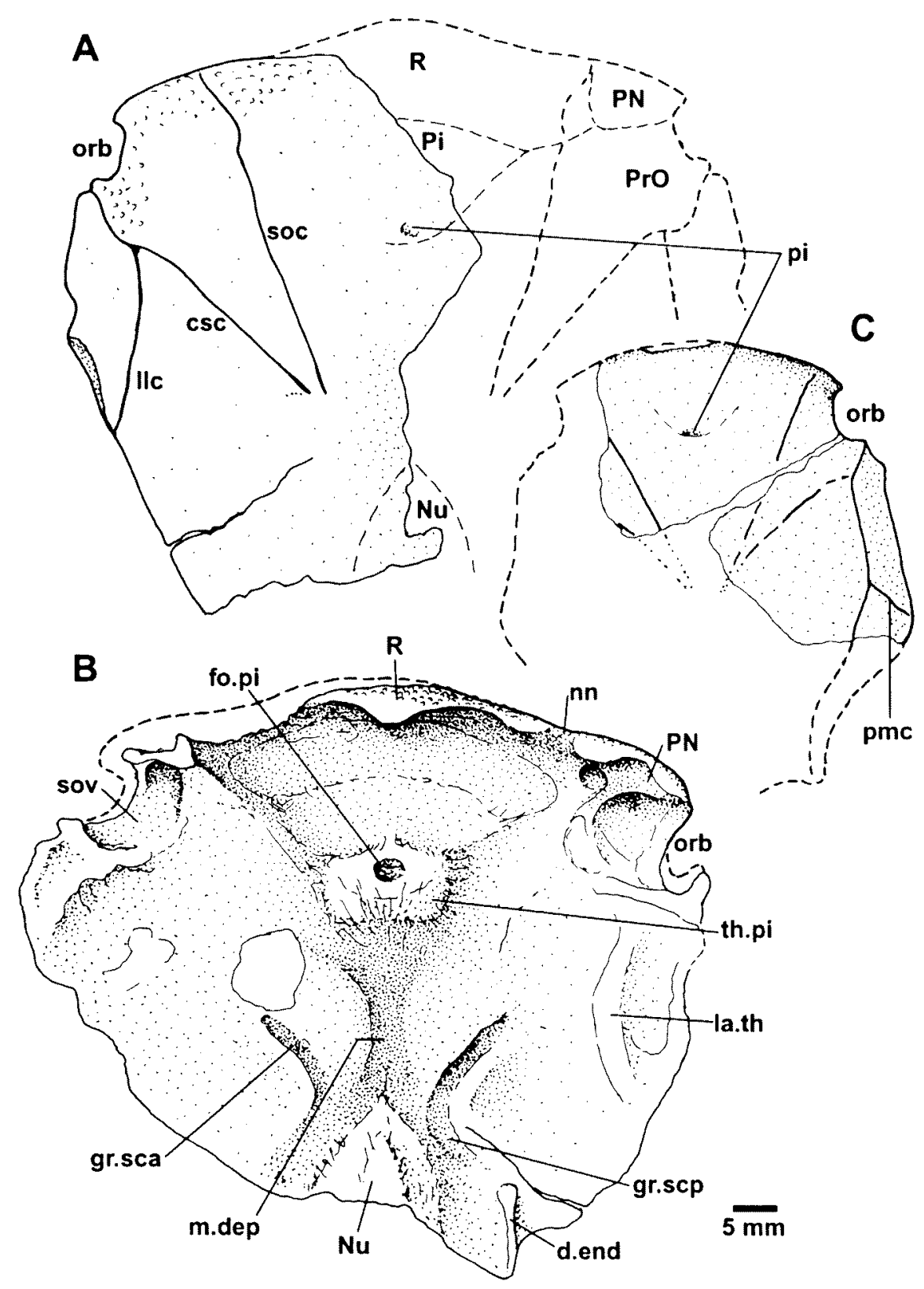

Figure 24 Tokolepis ulpe gen. et sp. nov. A, B, incomplete skull in dorsal (A) and ventral (B) views (holotype, CPC 36962); C, CPC 36961, an incomplete skull in dorsal view.

condition than in Dicksonosteus or Tokolepis gen. nov.

The inner surface impression of CPC 36962 shows the anterior border of the $\mathrm{R}$ plate inflected at about $90^{\circ}$ to the skull surface, with a pronounced median process, but not bilobed as in the reconstruction of Dicksonosteus (Goujet 1984a: fig. 32). An arcuate irregular trace in front of the deep pineal fossa (fo.pi, Figure 24B) evidently corresponds to the Pi/R suture of Dicksonosteus. There is a thickening around and behind the pineal fossa. Faint radiating striations behind the fossa could belong to paired $C$ plates, but also possibly to an elongate $\mathrm{Nu}$ reaching between them. However, it is more likely that the $\mathrm{Nu}$ only extended as far forward as the junction of the anterior and posterior semicircular canals of the inner ear, which have left grooves on the dermal bone (gr.sca, scp). The assumed inner surface of the $\mathrm{Nu}$ is marked by a median thickening $(\mathrm{Nu})$, in front of which is a median depression (m.dep) along the presumed midline suture between the $C$ plates.

A shallow groove runs anterolaterally from the pineal thickening, to form a thickening beneath the dermal preorbital process, which is assumed to represent fused PN plates (PN). On the left side a distinct nasal notch is preserved mesial to the PN plate (nn). A lateral thickening on the left side of the skull roof (la.th) presumably lay beneath the infraorbital sensory groove of the $\mathrm{M}$ plate.

Only one trunk armour plate is provisionally referred to this new taxon. CPC 36960 (Figure $25 \mathrm{D})$ is a small MD plate with similar fine ornament to the skull specimens (poorly 

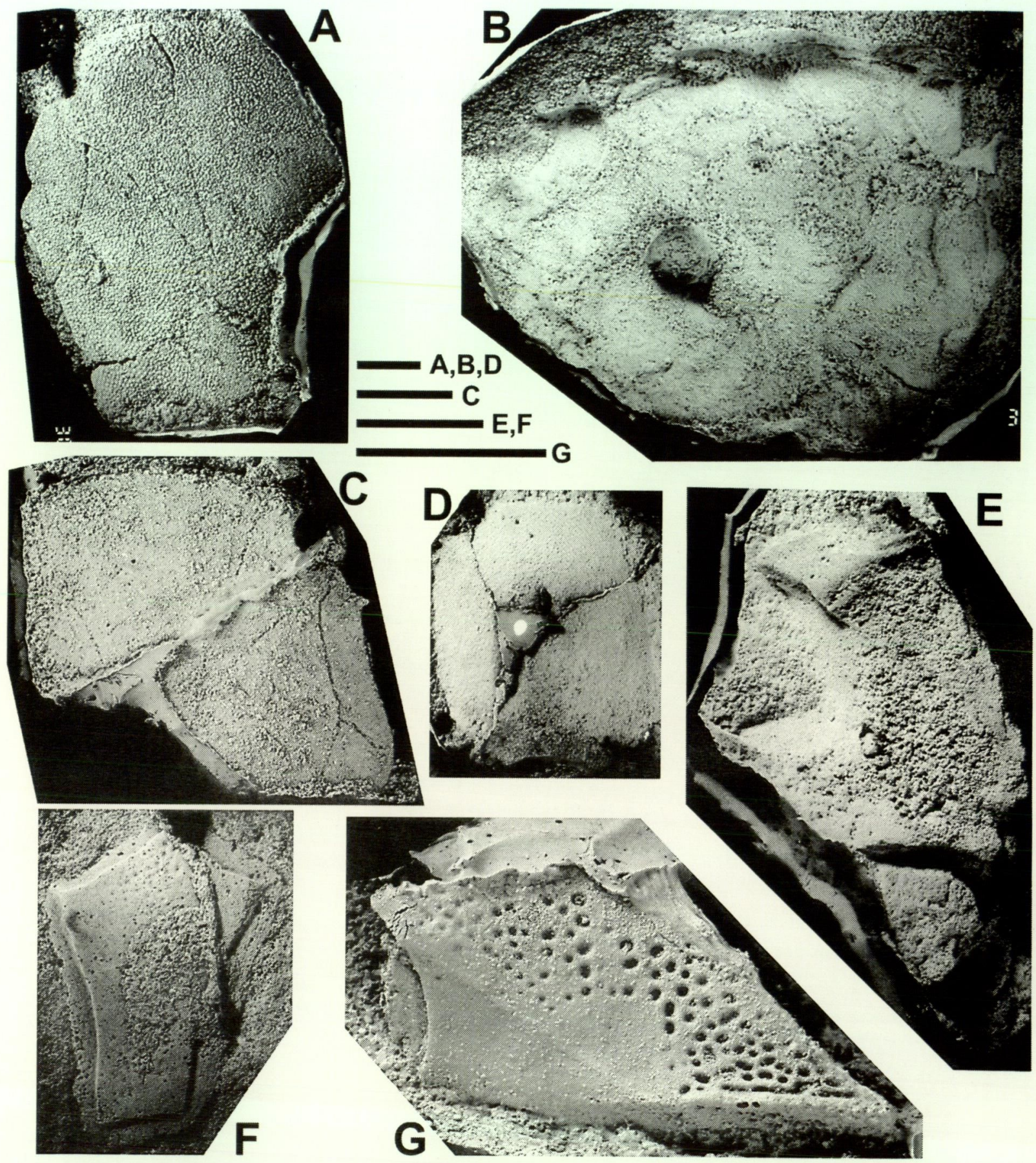

Figure 25 A-D, Tokolepis ulpe gen. et sp. nov. A, B, incomplete skull (holotype, CPC 36962) in dorsal (A) and ventral (B) views; C, incomplete skull in dorsal view(CPC 36961); D, MD plate, provisionally referred to the taxon (CPC 36960). E-G, Cravenaspis trematosus gen. et sp. nov. E, incomplete right AL, lateral view (CPC 36965); F, AMV plate, ventral view (CPC 36966); G, holotype, left PVL in left lateral view (CPC 36964). All specimens are latex rubber casts whitened with ammonium chloride; scale bars $=10 \mathrm{~mm}$.

preserved), with a flat anterior surface, rising to a slight median angle posteriorly, which matches the flat configuration of the skulls just described. It is about $40 \mathrm{~mm}$ long, but unusually broad for a phlyctaeniid ( $35 \mathrm{~mm}$ restored breadth), in this respect resembling actinolepid $\mathrm{MD}$ plates. It is included on the basis of comparison with similar small rounded MD plates from the Darling Basin (e.g. AMF 53668, Tambua Station), occurring in association with a small phlyctaeniid skull of similar broad-snouted shape to those described above. 
Family Arctaspididae Goujet, 1984a

\section{Remarks}

Goujet (1984a: 251) proposed three synapomorphies for this family, but only the first (dermal ornament) can be assessed for the new taxon described below.

\section{Cravenaspis gen. nov.}

Cravenaspis trematosus sp. nov. Figures 25E-G, 29A, B

diverse arthrodires: Young 1991a: 67 (pars)

\section{Material}

CPC 36964-967.

\section{Localities and Horizon}

74/11, 14 (northwestern part of the Dulcie Syncline, in the Dulcie Sandstone); 77/19, 24 (Cravens Peak Beds). For localities see Figure 1. A locality summary for each taxon is given in Table 1 , and locality details for each specimen are listed in the Appendix.

\section{Diagnosis}

A phlyctaeniid arthrodire with dermal ornament of widely spaced subcircular to irregular pits or holes on a smooth surface, which may leave a reticulate pattern. Trunk armour with strong ventrolateral ridge, and diagonal ridge crossing from AL plate onto anterodorsal corner of PVL. Lateral lamina of PVL unusually short and high, with posterior margin extending to posterolateral corner of subanal lamina.

\section{Etymology}

After the Cravens Peak Beds, aspis (Greek), a shield, and trematos (Greek) a hole, with reference to the pitted appearance of the surface ornament.

\section{Remarks}

These specimens are grouped together because of their similar distinctive ornament, which comprises a smooth surface with widely spaced subcircular to irregular pits which may leave a reticulate pattern. An ornament of round pits set in a smooth surface is seen on parts of the dermal bones of Holonema radiatum described from the Middle Devonian of Spain by Lelièvre et al. (1990: pl. 2, figs. A,D,F). However direct comparison with some of these bones (e.g. the extrascapulars) shows that the flat surface between the pits is covered with fine tubercles, and on most of the bones the predominant ornament is of radiating ridges and grooves. We consider there is no evidence here of a close relationship to Cravenaspis gen. nov. The Spitsbergen phlyctaeniid Arctaspis has an ornament of large regularly spaced pits, formed as deep depressions within a reticulate pattern of ridges (Heintz 1929b: pl.1, fig. 2). However, the ridges are more strut-like, without the flat tops or areas of smooth surface, and there are tubercles at the intersections of the ridges. It is possible that the ornament described here represents a variant of that type, which might indicate some relationship to Arctaspis, so this poorly known new taxon, is provisionally placed in the family Arctaspididae.

\section{Description}

CPC 36966 (Figure 25F) is a slightly distorted median ventral plate preserved in part and counterpart, interpreted here as a phlyctaeniid AMV with five overlaps for the IL, AVL and PMV plates (Figure 29B). It is assumed not to be an actinolepid AMV, which as typically developed has larger anterior overlap areas for the AV plates, with an extensive midline contact, as seen for example in Wuttagoonaspis (Ritchie 1973: fig. 2c). The plate is much narrower anteriorly than the AMV of Groenlandaspis. With orientation reversed it could be interpreted as a PMV of a groenlandaspid, but in this case the single overlap at the interpreted posterior end (oaPMV, Figure 29B) would be anomalous. In placoderms generally anterior bones normally overlap those behind, and in actinolepids the AMV overlaps the PMV (Denison 1958: fig. $113 \mathrm{C}-\mathrm{D})$. In phlyctaeniids it may be the reverse, with the PMV overlapping the AMV, as noted by Denison (1958: 534). This is apparently the situation in Dicksonosteus (Goujet 1984a: fig. 64), and Africanaspis (Long et al. 1997a: fig. 12D), and may be a defining character for phlyctaeniids.

The exposed part of this bone was smooth, with scattered shallow pits in the central part at the front to give a distinctive ornamented surface, displayed also by a few other specimens.

CPC 36964 (the holotype; Figure 25G) is an incomplete left PVL, with the same type of ornament, and an unusual shape. The lateral lamina is fairly complete, and is unusually short and high (at least $13 \mathrm{~mm}$ high for a length of $28 \mathrm{~mm}$ including the anterior overlap for the AVL). Its posterior margin shows the very unusual condition of extending down right to the posterolateral corner of the subanal lamina. This lamina is identified by a strong ventrolateral ridge (vlr, Figure 29A), the presence of which may suggest affinity with Huginaspis described above. A slight ridge crosses the lateral lamina diagonally from the ossification centre to the anterodorsal corner, beneath which the surface is entirely smooth, with scattered pits posterodorsally and and more concentrated above the ventrolateral ridge (Figure 25G). Only the lateral edge of the ventral lamina can be seen, but this was evidently also smooth. CPC 36965 (Figure 25E) is a poorly preserved right $A L$ and $S P$ plate 
(incomplete). The AL shows a marginal zone with a smooth surface, and a diagonal ridge running from the posteroventral corner, clearly a continuation of that on the PVL just described, and very similarly developed.

CPC 36967 is a bone fragment $45 \mathrm{~mm}$ long, but 5 $\mathrm{mm}$ thick, indicating that it came from a large form, possibly a right $\mathrm{PNu}$ plate. Short segments of a sensory groove are visible on a smooth surface except for an area near the presumed posterior edge where the characteristic pitted ornament is developed.

\section{Family Groenlandaspidae Obruchev, 1964}

\section{Diagnosis}

Phlyctaeniids in which the pineal plate separates the PrO's, which form the anterior dermal corner of the orbit, the central sensory lines pass back onto the $C$ plates, the dermal neckjoint of each side is placed close to the midline, the anterior and posterior dorsolateral plates of each side have midline contact with each other, and the MD is elevated as a narrow crest or spine. The lateral line sensory groove has a sharp dorsal inflection on the PDL plate.

\section{Remarks}

Ritchie (1975: 571) defined this family using the following characters: unreduced lateral trunk shield, lacking AV plates, with long contact between lateral and ventral walls; large SP and medium pectoral fenestra; MD plate long, extremely narrow with high pointed laterally compressed dorsal ridge; dorsolateral plates of trunk high and short, with angular dorsal flexure in sensory groove on PDL plate; headshield subpentagonal, with convex or angular posterior margin, and articular condyles situated rather close together. Most of these are features of all phlyctaenioids, and we have retained in the above diagnosis only those characters that separate off Groenlandaspis and a few closely related taxa.

Young (1981: fig. 16) outlined some possible synapomorphies of groenlandaspids and related forms, but included Holonema, now considered (e.g.
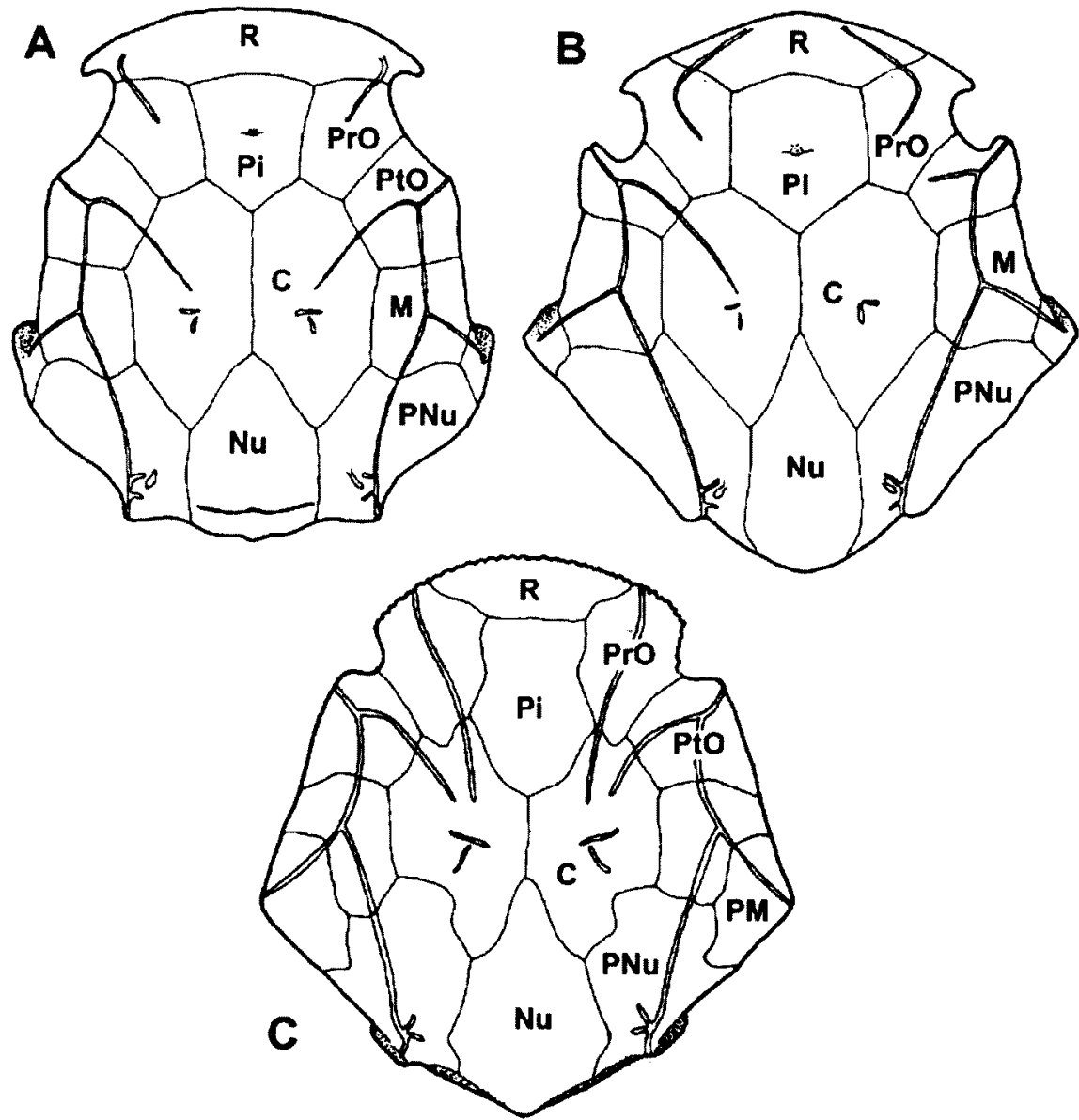

Figure 26 Comparisons of skull roof patterns in some phlyctaenioid arthrodires (not to scale). A, Arctolepis decipiens (Woodward) after Goujet (1984a: fig. 77); B, groenlandaspid gen. et sp. nov. from the Mulga Downs Group, Darling Basin, after Ritchie (1969: fig. 3), AMF 61624, 625 (Mt. Jack, western NSW); C, Groenlandaspis antarctica Ritchie, after Ritchie (1975). 
Dennis and Miles 1979; Lelièvre 1995) to be a brachythoracid. Schultze (1984: fig. 6) proposed an alternative synapomorphy scheme with Holonema excluded (involving independent acquisition of several characters), and with Tiaraspis as a primitive groenlandaspid. The poorly known Prosphymaspis may be a more primitive sister group to Tiaraspis, with an elevated armour, but lacking the dorsal inflection of the sensory groove on the PDL (Denison 1978: 60; Schultze 1984). However it is more informative to consider adequately known taxa, such as the genus Arctolepis.

Arctolepis resembles members of the family Groenlandaspidae in possessing a large Pi plate separating the PrO plates, and its MD also has a slight median ridge. The ADL's are in contact in the midline beneath the MD (also the case in Dicksonosteus), but Arctolepis differs from the groenlandaspids as defined above in having the PDL plates still separated internally beneath the MD. On this evidence Arctolepis and related forms may be the sister group to the groenlandaspids. Tiaraspis differs from Groenlandaspis spp. and Boomeraspis Long, 1995b in lacking the dorsal inflection of the lateral line groove on the PDL. Tiaraspis could be considered the most primitive member within the family, as suggested by Ritchie (1975), or immediately related to the family, if defined as above. Alternatively, Long (1995b) suggested that the more elongate PDL and PL in the Antarctic form Boomeraspis may indicate that it is more primitive than either Tiaraspis or Groenlandaspis. A decision on the interrelationships of these taxa requires more detailed character analysis, with better information on Boomeraspis, in which the PDL plates are probably in midline contact, but this is not demonstrated on the available material (Long 1995b: 39).

groenlandaspid gen. nov.

Figures 3D, 26B, 27A-D, 28A, 30E

new genus from the Mulga Downs Group: Ritchie 1975: 571, 572, figure $3 \mathrm{f}$

placoderms: Shergold 1985: 21

new genus Mulgaspis: Ritchie 1987: 253 (nomen nudum)

diverse arthrodires: Young 1991a: 67 (pars)

groenlandaspid nov:: Young et al. 1993: 247

arthrodire belonging to the Groenlandaspididae:

Neef et al. 1996: 6, figure 3B

new undescribed form from the Mulga Downs Group: Long 1995b: 39

\section{Material}

CPC 36968-981.

\section{Localities and Horizon}

$74 / 13,15$ (northwestern part of the Dulcie Syncline, in the Dulcie Sandstone); $77 / 5,14,17,19$, 20, 23 (Cravens Peak Beds). For localities see Figure 1. A locality summary for each taxon is given in Table 1, and locality details for each specimen are listed in the Appendix.

\section{Remarks}

Groenlandaspid arthrodires were recorded in the Wuttagoonaspis fauna of the Mulga Downs Group by Ritchie $(1969,1973,1975)$. Three illustrations have been published (Ritchie 1969: figs 3-4; 1975 fig. 3f), but the material remains undescribed. The skull of this form is ornamented with fine tubercles (Ritchie 1969: fig. 3). Comparison of specimens from the Cravens Peak Beds with Mulga Downs Group material (including examples in the American Overseas Petroleum collection at AGSO, and casts of Australian Museum specimens, e.g. AMF 61625) show the skull to be close to the Spitsbergen genus Arctolepis, with a large pentagonal pineal plate. However the Australian form seems to be distinguished by at least three features (Figure 26B): the anterior sutures of the $\mathrm{PrO}^{\prime} s$ are angled anteriorly, to include the anterior border of the orbit, whereas in Arctolepis they run straight across in line with the anterior edge of the Pi (Goujet 1984a: fig. 77); the dermal neck articulations of each side are much closer together (e.g. Ritchie 1969: fig. 3 ); and possibly the skull is broader across the lateral corners (but flattening may contribute to this).

Ritchie (1975: 570) noted a large quantity of disarticulated arthrodire material from the Mulga Downs Group, including this new genus of groenlandaspid. Probably the same or a closely related taxon is represented by the Georgina Basin material described below. Ritchie (1969: fig. 4) presented a sketch restoration of the trunk armour, and the shape of the MD plate was later described as intermediate between the high pointed MD of the Early Devonian Tiaraspis, and the lower MD of the Late Devonian Groenlandaspis (Ritchie 1975: 570). Even though both lower crests (described above in Huginaspis australis), and very high-crested MD plates (described below as Mithakaspis gen nov.) are present in the Georgina Basin material, only one MD approaching the shape illustrated by Ritchie (1975: fig. 3f) has been identified. The significance of this difference in the faunas is unclear, but there is considerable variation in MD height amongst the Mulga Downs Group material, which is much more comprehensive than the fragmentary remains dealt with here. Accordingly we leave our treatment in open nomenclature until the formal description of the new genus and species from the Mulga Downs Group. Pustulose ornament seems to characterise this form, and provisionally 

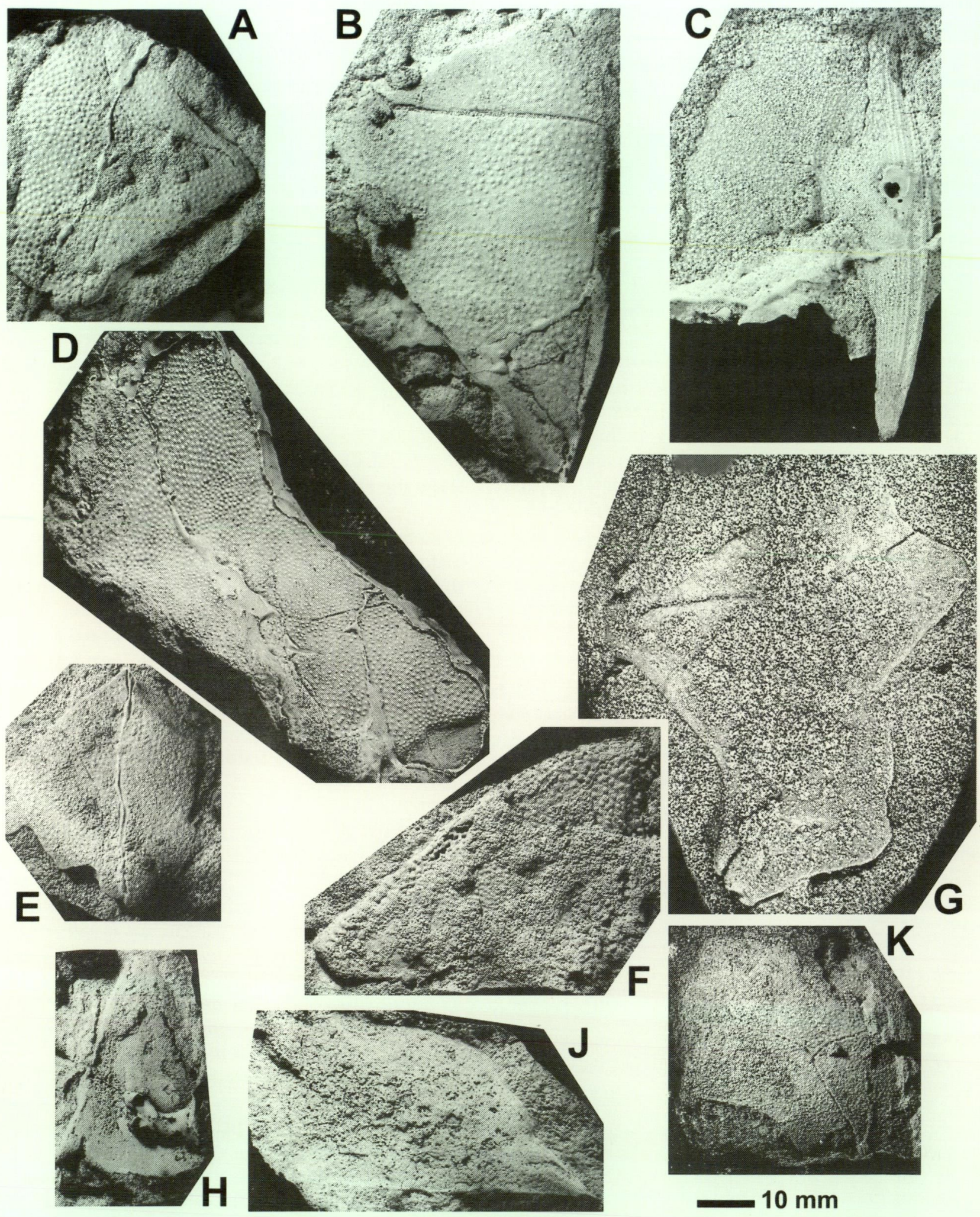

$10 \mathrm{~mm}$

Figure 27 A-D, groenlandaspid gen. et sp. nov. A, right posterolateral skull roof portion (CPC 36974); B, left posterolateral skull roof portion (CPC 36970); C, left AVL and SP plate, ventral view (CPC 36971); D, incomplete trunk armour, right lateral view (CPC 36976). E-F, cf. Groenlandaspis sp. indet. 1. E, left PNu plate, dorsal view (CPC 36983); F, MD plate, left lateral view (CPC 36982). G-K, cf. Groenlandaspis sp. indet. 2. G, left posterolateral skull roof portion (CPC 36986); H, MD plate, left lateral view (CPC 36991); J, right AL plate, lateral view (CPC 36989); K, left M plate from the skull, external view (CPC 36988). All specimens are latex rubber casts whitened with ammonium chloride; scale bars $=10 \mathrm{~mm}$. 


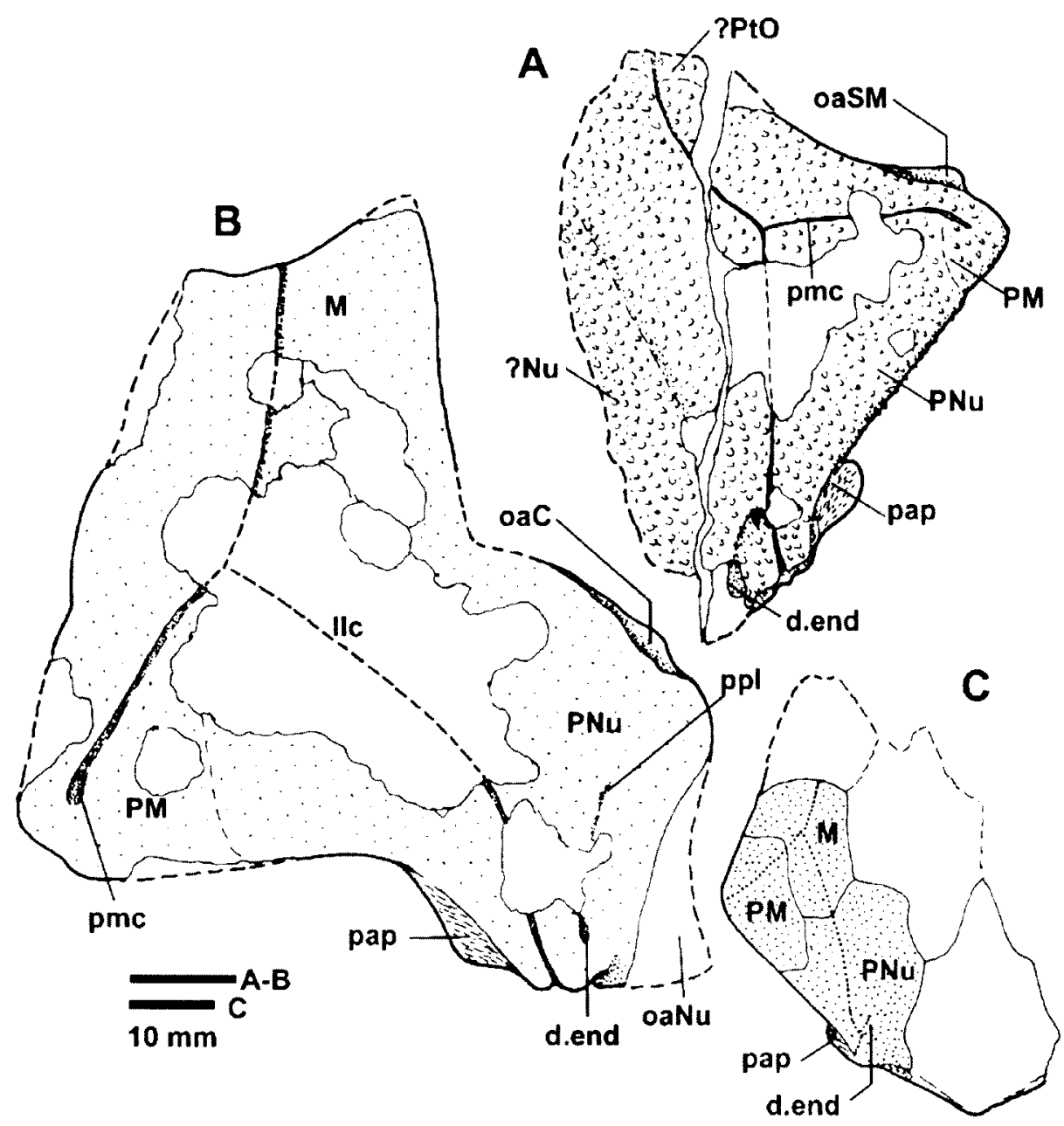

Figure 28 A, groenlandaspid gen. et sp. nov., right posterolateral skull roof portion (CPC 36974; cf. Figure 27A); B, cf. Groenlandaspis sp. indet. 2, left posterolateral portion of skull roof (CPC 36986; cf. Figure 27G). C, corresponding parts of the skull of Groenlandaspis antarctica, after Ritchie (1975).

included here are some incomplete fragments showing this ornament type.

\section{Description}

CPC 36974 (Figure 27A) is a $50 \times 40 \mathrm{~mm}$ portion of the right side of a small skull, with remnants of the dermal neckjoint including a well preserved para-articular process indicating that it belonged to a phlyctaenioid arthrodire. There is a strong lateral (postmarginal) corner to the skull (PM, Figure $28 \mathrm{~A}$ ), and a slight notch at the position of the $\mathrm{PM} / \mathrm{M}$ suture. Other sutures are indistinct, but the sensory groove pattern indicates that $\mathrm{PNu}$ and $\mathrm{M}$ plates, and possibly parts of the $\mathrm{Nu}$ and $\mathrm{PtO}$ plates are included. The external surface is covered with pustulose ornament lacking clear alignment, which is rather coarse given the size of the skull roof. The central part of the external surface is lost, but otherwise the ornament is well preserved for this material, many of the tubercles showing the typical stellate bases seen in many placoderms. The complete lateral border shows two unusual features: an unornamented overlap area in front of the PM plate, which must have been for the SM (oaSM), and a subobstantic margin which carries tubercles right around its margin, and therefore was not overlapped by the AL plate. The paraarticular process is well preserved (pap), with the 'siebknocken' texture typical of an articular surface. The posterolateral corner of the $\mathrm{PNu}$ is apparently incomplete, and a faint impression of the inner surface of the missing portion is restored in outline in Figure 28A. A depression marks the position of the endolymphatic duct opening (d.end).

Although much bigger, this specimen compares closely with the small groenlandaspid material from the Darling Basin. Compared with two small skulls (AMF 61624) from the Mulga Downs Group (MNHN cast), which are only $35-40 \mathrm{~mm}$ in total length, there is a very similar pustulose ornament of scattered tubercles, and in particular a strong angular postmarginal corner to the skull. Detailed points of similarity are the small overlap for the SM plate, and the ornamented subobstantic margin. The right para-articular process on the left skull of AMF 
61624 has identical morphology to that described above for CPC 36974 .

Other skull specimens with similar pustulose ornament are CPC 36969 , portion of a probable left $\mathrm{PNu}$ (preserved length $35 \mathrm{~mm}$ ) in part and counterpart, and CPC 36970 (Figure 27B), probably a diagonal slice $(75 \mathrm{~mm}$ across) from the posterolateral part of a large skull. CPC 36975 is another portion of a large skull, probably a central plate. CPC 36977 is the right half of a small skull roof showing the postmarginal corner and associated sensory grooves, but lacking anterior and posterior margins (preserved length $25 \mathrm{~mm}$ ).

Various trunk armour remains are mainly from larger individuals. The most informative is CPC 36976 (Figure 27D), a diagonal slice across the right wall of a trunk armour ( 90 by $30 \mathrm{~mm}$ ) displaying regular tubercular ornament, which includes part of the MD and right PDL and ADL, the latter with an incomplete overlap area for the AL. Both plates are crossed by the lateral line groove, which shows its dorsal flexure on the PDL apparently close to its anterior margin (compared to species of Groenlandaspis; Figure 30), although sutures between the bones are indistinct. The change of angle of the external surface gives an approximation of the ventral edge of the MD, which has a preserved height of about $35 \mathrm{~mm}$ (dorsal extremity and anterior margin not preserved). The posterior margin of the MD is relatively straight, as in the MD previously figured by Ritchie (1975: fig. $3 \mathrm{f}$ ), and carries a row of enlarged tubercles. Ornament on the preserved lateral surface of the MD shows some alignment into meandering horizontal rows, as also developed in AMF 54567 (personal observation), which is however a much larger specimen (ventral margin of MD about 115 $\mathrm{mm})$.

More fragmentary remains with similar ornament include CPC 36973, part of an AL plate, and CPC 36968 (Figure 3D), probably the ventral lamina of a large AVL. CPC 36981 shows two incomplete trunk armour plates, and CPC 36979 is a similar plate crossed by an inflected lateral line groove, and

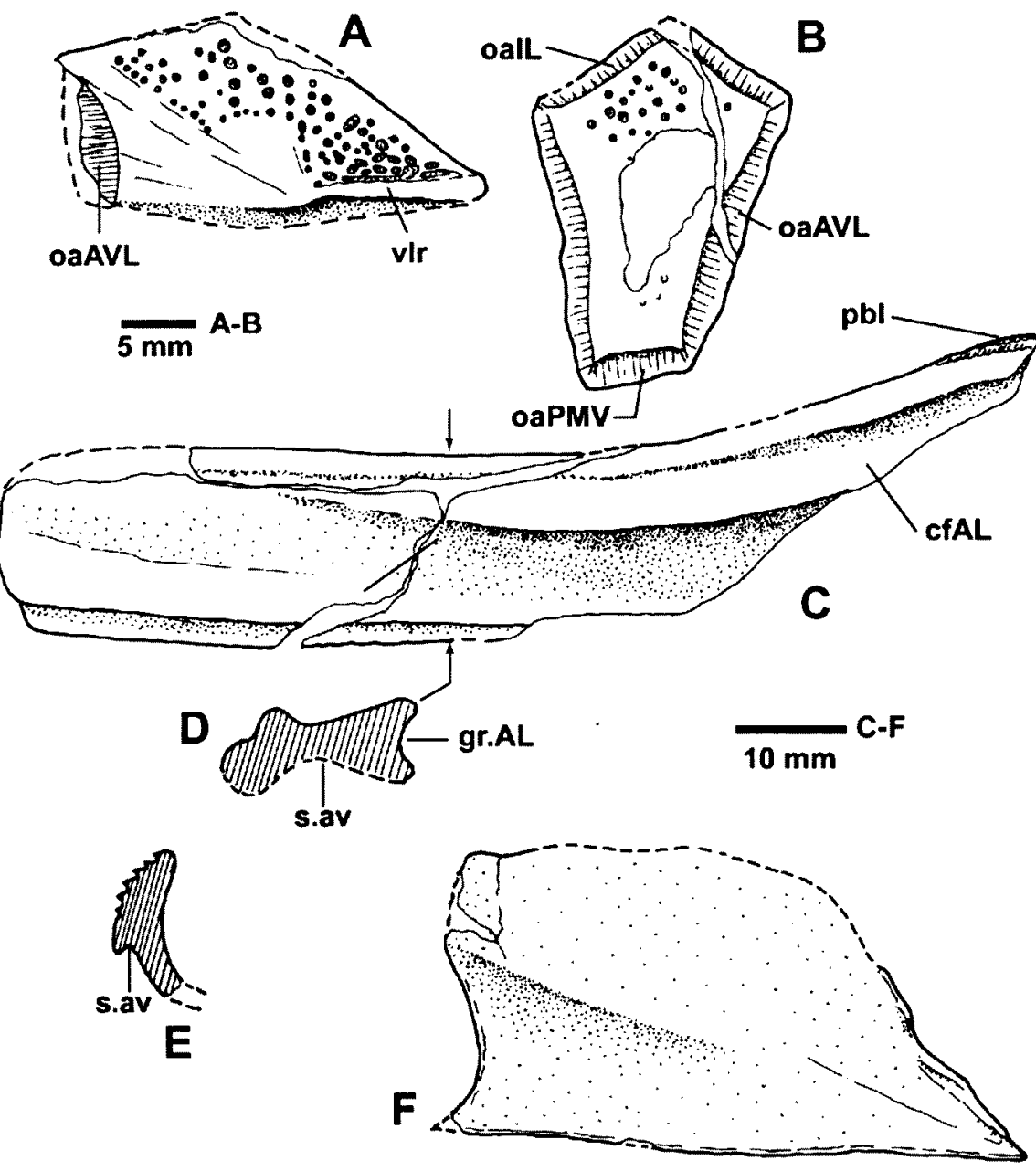

Figure 29 A,B, Cravenaspis trematosus gen. et sp. nov; A, left PVL in left lateral view (holotype, CPC 36964); B, AMV plate, ventral view (CPC 36966). C-E, phlyctaenioid indet. 2. C,D, right IL plate (CPC 37011) in dorsal view (C), with section at level shown (D). E, section through another IL plate (CPC 37010; see Figure 36C). F, cf. Groenlandaspis sp. indet. 2, right AL plate in lateral view (CPC 36989). 
therefore determined as a PDL. CPC 36980 is an incomplete ?right PVL (subanal lamina).

CPC 36971 (Figure 27C) is a left AVL and SP showing the association of particular spine morphology with normal tubercular ornament on the AVL. It compares closely in spinal ornament and angle with AMF 54695 (Tambua Station, T2 locality) and 56252 (Mt Jack Station) in the Darling Basin. The margins of the AVL are very unclear, but it was at least $40 \mathrm{~mm}$ long, with a preserved spinal length of $56 \mathrm{~mm}$. The ventral surface of the SP carried eight longitudinal denticulate ridges at the level of the posterior margin of the infraspinal lamina. The denticles are more prominent proximally, and distally the tubercles tend to fuse to form continuous slightly nodose ridges. The ridges are separated by a broader anterior groove from the ornament of the leading edge of the spine, which comprises double tubercle rows above and below a narrow groove on the anterior spine margin, here termed the 'leading edge groove'. The leading edge tubercles are larger than those forming the ornamental ridges of the spine surface.

The same spine ornamentation is seen in CPC 36978, a SP segment about $55 \mathrm{~mm}$ long assumed to come from the right side, with portion of the supraspinal lamina of the $\mathrm{AL}$ attached. This is ornamented with scattered tubercles, with the dorsal spine surface (proximal end) carrying finely denticulate ridges again separated by a broader groove from the leading edge tubercles. As in the previous specimen, the leading edge comprises double rows of enlarged elongate tubercles flanking a narrow groove on the anterior margin. The ventral surface of the SP (almost flat) carried unornamented ridges (poorly preserved).

\section{Genus Groenlandaspis Heintz, 1932}

\section{cf. Groenlandaspis sp. indet. 1.} Figures 23D, 27E, F

Groenlandaspis: Haines et al. 1991: 32 (pars)

\section{Material}

CPC 36982-984.

\section{Localities and Horizon}

74/14 (northwestern part of the Dulcie Syncline, in the Dulcie Sandstone); 77/18, 24 (Cravens Peak Beds). For localities see Figure 1. A locality summary for each taxon is given in Table 1, and locality details for each specimen are listed in the Appendix.

\section{Remarks}

These few remains recall various aspects of species of Groenlandaspis. The included MD had a crest more pronounced than the material described above as Huginaspis, but much lower than that included below in Mithakaspis gen. nov. It is also lower and of different shape to the MD assumed to belong to the previous groenlandaspid, so it is treated separately on the basis of comparison with described species of Groenlandaspis (Figure 30).

\section{Description}

CPC 36983 (Figure 27E) is a broken left PNu with coarse tubercular ornament, but poorly preserved. The thickened posterior part near the neckjoint is broken, as is the straight anterolateral edge of the impression. The complete mesial margin shows a slight postnuchal process and short contact with the $\mathrm{Nu}$ plate, and two sections of overlap (Figure 23D), which corresponds to the shape of the $\mathrm{PNu} / \mathrm{C}$ suture in Groenlandaspis antarctica and some other species (Figure $28 \mathrm{C}$ ), rather than the straight suture of more primitive taxa (Figure 26A-B).

CPC 36982 (Figure 27F) is an incomplete MD, estimated length $70 \mathrm{~mm}$, with a crest up to $25 \mathrm{~mm}$ high, associated with thelodont scale impressions (thel, Figure 23C). The anterior margin is assumed broken and most of the ventral margin is unclear, so overall shape is uncertain. However the crest is more pronounced than other material described above as Huginaspis, so this form is treated separately. The plate is covered in coarse tubercles, crowded along the dorsal and part of the posterior margin of the crest, but more widely spaced on the lateral surfaces, although the surface is abraded. Compared to described Groenlandaspis species, it may have had a crest of similar height to the MD of $G$. riniensis (Figure 30B), but apparently with a concave posterior margin as in the undescribed Grenfell species (Figure $30 \mathrm{C}$ ), although it was evidently not as high as in that form, which is also distinguished by its lack of tubercular ornament (Ritchie et al. 1992).

CPC 36984 shows portion of a tuberculate plate about $40 \mathrm{~mm}$ across at the assumed ventral border (broken), which shows an anterior overlap area and is crossed by an angular sensory groove which recalls that on the PDL of Groenlandaspis. If correctly determined as the upper part of a left PDL, it differs from previous forms in narrowing dorsally, with a convex posterior margin, rather than the concave margin and posterior projection as in previously described species (Figure 30).

\section{cf. Groenlandaspis sp. indet. 2.} Figures $27 \mathrm{G}-\mathrm{K}, 28 \mathrm{~B}, 29 \mathrm{~F}$

\section{Material}

CPC 36985-991.

\section{Localities and Horizon}

77/4, 15, 19, 20 (Cravens Peak Beds; see Figure 


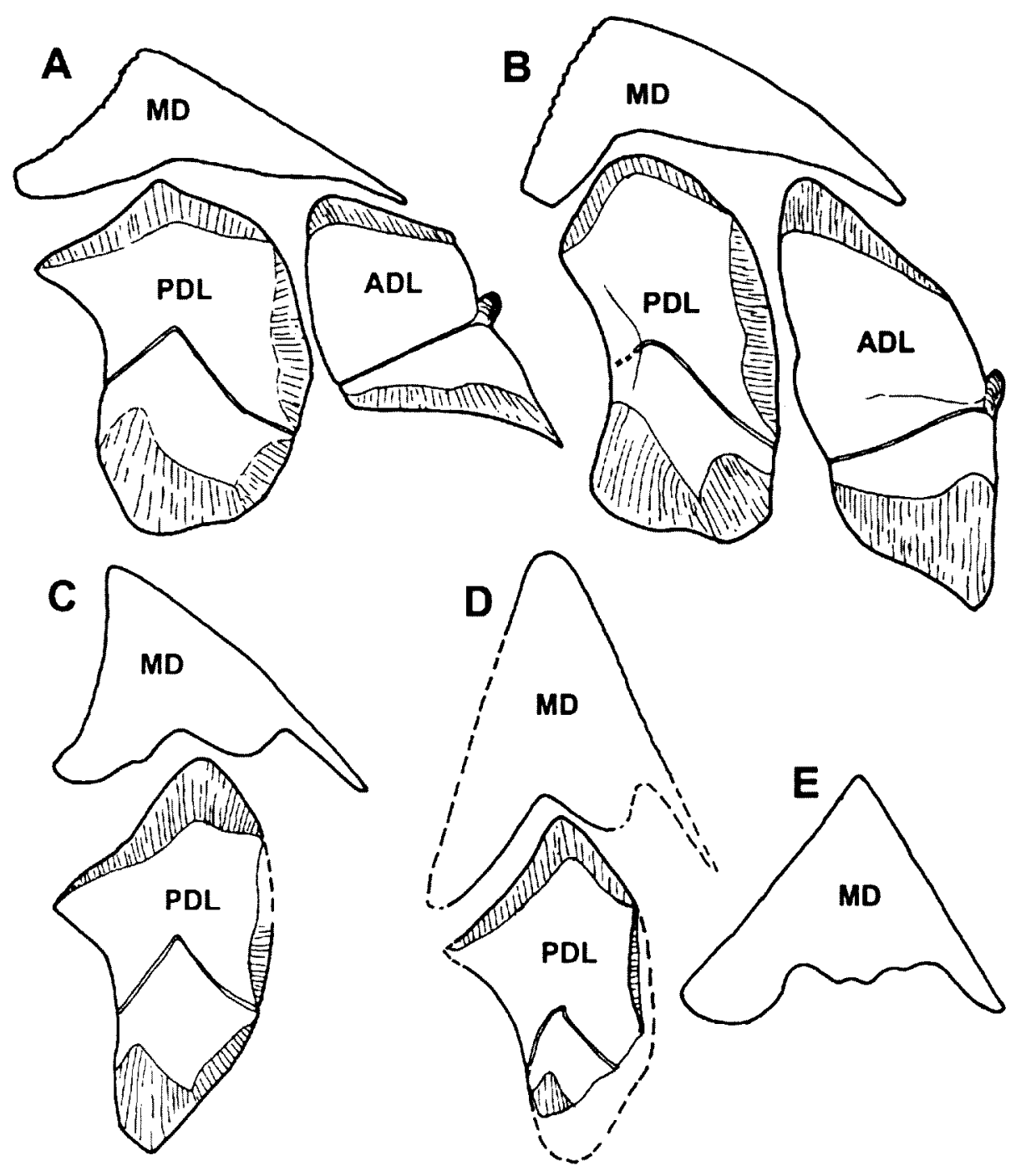

Figure 30 A-D, MD plate and dorsolateral plates (where known) from the trunk armour of some Gondwanan species of Groenlandaspis (right lateral view; not to scale); A, Groenlandaspis antarctica (after Ritchie 1975: fig. 2c); B, G. riniensis (after Long et al. 1997: fig. 8); C, Groenlandaspis sp. nov. from Grenfell, NSW; MD after Ritchie (1975: fig. 3e), and PDL after Janvier and Ritchie (1977: fig. 2B); D, G. seni (after Janvier and Ritchie 1977: fig. 1). E, groenlandaspid gen. et sp. nov., MD plate from the Mulga Downs Group, western NSW (after Ritchie 1975: fig. 3f).

1D). A locality summary for each taxon is given in Table 1, and locality details for each specimen are listed in the Appendix.

\section{Remarks}

These few incomplete specimens also recall various aspects of species of Groenlandaspis, but differ from the specimens just described in lacking tuberculate ornament. They are currently too poorly known for formal assignment to this genus.

\section{Description}

CPC 36986 (Figure 27G) is a smooth impression (75 $\mathrm{mm}$ long, $65 \mathrm{~mm}$ across) on the same sandstone block as the large AVL and SP of Wuttagoonaspis in Figure $8 \mathrm{D}$. It is the left posterolateral part of a large skull, which carried three sensory grooves reaching the margins. The posterior corner is notched for the main lateral line canal (llc, Figure 28B), beneath which the fossa for the dermal neckjoint is partly preserved, flanked by a well preserved para-articular process (pap). The central part of the external surface has been abraded, but a normal branching arrangement of the postmarginal sensory canal (pmc) from the main lateral line canal (llc) can be inferred. The mesial margin appears complete, but it can be assumed that an overlap area for the adjacent $\mathrm{Nu}$ plate has been broken off (oaNu). A shallow pit for the endolymphatic opening (d.end), and a faint groove for the posterior pitline (ppl) correspond to the position of these structures in other phlyctaenioid 
arthrodires. A faint depression and notch are in the correct position for the PM/PNu suture, and there is a small overlap area in the embayed antero-mesial margin (oaC).

By comparison with the corresponding region of the skull of Groenlandaspis (Figure 28C) three skull bones are represented in this specimen. It differs somewhat in the shape of the notch for the $C$ plate, and the pronounced posterior direction of the posterolateral (subobstantic) skull margin. However the overall similarity indicates that this specimen is reasonably referred to a large species of Groenlandaspis which lacked ornament, and had a more rectangular $C$ plate and posteriorly placed postmarginal corners than G. antarctica.

CPC 36989 (Figure 27J) is the impression of a right AL plate. It is convex rather than concave, so it cannot be an internal impression, and is grouped with the previous specimen on the lack of tubercular ornament, and very elongate proportions (Figure 29F). Its ventral border is 57 $\mathrm{mm}$ long, even though the plate is only $27 \mathrm{~mm}$ high. This shape is not seen in phlyctaeniids (e.g. Denison 1958: fig. 110) with the exception of groenlandaspids (Ritchie 1975). The height/length index of 47 is less than both of the previously illustrated Groenlandaspis species: 54 for $G$. antarctica (Ritchie 1975: fig. 2c), and 83-98 for $G$. riniensis (Long et al. 1997a: 258). On these proportions this specimen could be referred to Groenlandaspis sp.

CPC 36985 is another AL of similar shape (estimated length $80 \mathrm{~mm}$, height $45 \mathrm{~mm}$ ), but only the inner surface is exposed, so the ornament is unknown. It possibly belongs in this taxon.

CPC 36990-991 are smooth impressions with shape reminiscent of a tiaraspid MD (Figure $27 \mathrm{H})$. It is not confirmed that both sides of these specimens are smooth, but the latter is associated with another smooth plate crossed by a sensory groove. If they belong to this smooth groenlandaspid, they would represent higher more narrow MD plates than any illustrated by Ritchie (1975: fig. 3) or the species described by Janvier and Ritchie (1977). Both can be distinguished from the more complete high MD plates with reduced ornament referred below to Mithakaspis gen. nov. (e.g. CPC 36993, 997) by the absence of fringing ornamentation.

CPC 36988 (Figure 27K) is a smooth impression showing the junction of three sensory grooves, and assumed to come from the left side of a small skull roof of this species. CPC 36987 is a sample showing four associated impressions, including a possible right $\mathrm{AL}$ plate, and incomplete ventral trunk armour plates, all apparently lacking tuberculate ornament, which is also provisionally included here.

\section{Mithakaspis gen. nov.}

Mithakaspis lyentye sp. nov. Figures $31-34$

groenlandaspid ... in the northern Dulcie Range: Ritchie 1975: 572

diverse arthrodires: Young 1991a: 67 (pars)

phlyctaeniid; Groenlandaspis: Haines et al. 1991: 32 (pars)

tiaraspid nov.: Young et al. 1993: 247

\section{Material}

CPC 36992-37007.

\section{Localities and Horizon}

BC1, BC7, 74/10, 11, 16, 17 (northwestern part of the Dulcie Syncline, in the Dulcie Sandstone); $77 / 3$, 4, 12, 20 (Cravens Peak Beds). For localities see Figure 1. A locality summary for each taxon is given in Table 1, and locality details for each specimen are listed in the Appendix.

\section{Diagnosis}

A groenlandaspid arthrodire in which the MD plate is at least 1.5 times as high as long, with its anterior margin more than 1.25 times as long as the posterior margin. Ventral notch on MD not bilobed, and positioned in the middle or just within the anterior half of the ventral margin. ADL plates overlapping the MD, probably with an internal midline suture, and a short external suture in front of the MD. PDL plates probably partly overlapping the MD. Main lateral line groove on ADL oriented posterodorsally, with strong dorsal inflection. Articular condyles closely spaced. Ornament of trunk armour tuberculate, showing alignment into antero-posterior rows on $\mathrm{MD}$, which has fringing ornament of larger tubercles on anterior and posterior margins separated by a groove from the lateral surface. Tuberculate rows on lateral surface may coalesce into non-tuberculate ridges, or be reduced to a smooth surface. Skull roof unknown.

\section{Etymology}

From aspis (Greek), a shield, and Mithaka Waterhole, about $20 \mathrm{~km} \mathrm{~N}$ of the Toomba Range, and just west of the Queensland-Northern Territory border. The specific name is the Arrernte language word lyentye for 'spear tip' (Henderson and Dobson 1994), with reference to the elongate pointed shape of the MD plate.

\section{Remarks}

Included here are two specimens comprising trunk armour remains associated with high MD plates, and a range of isolated high MD plates which resemble the German genus Tiaraspis Gross, 


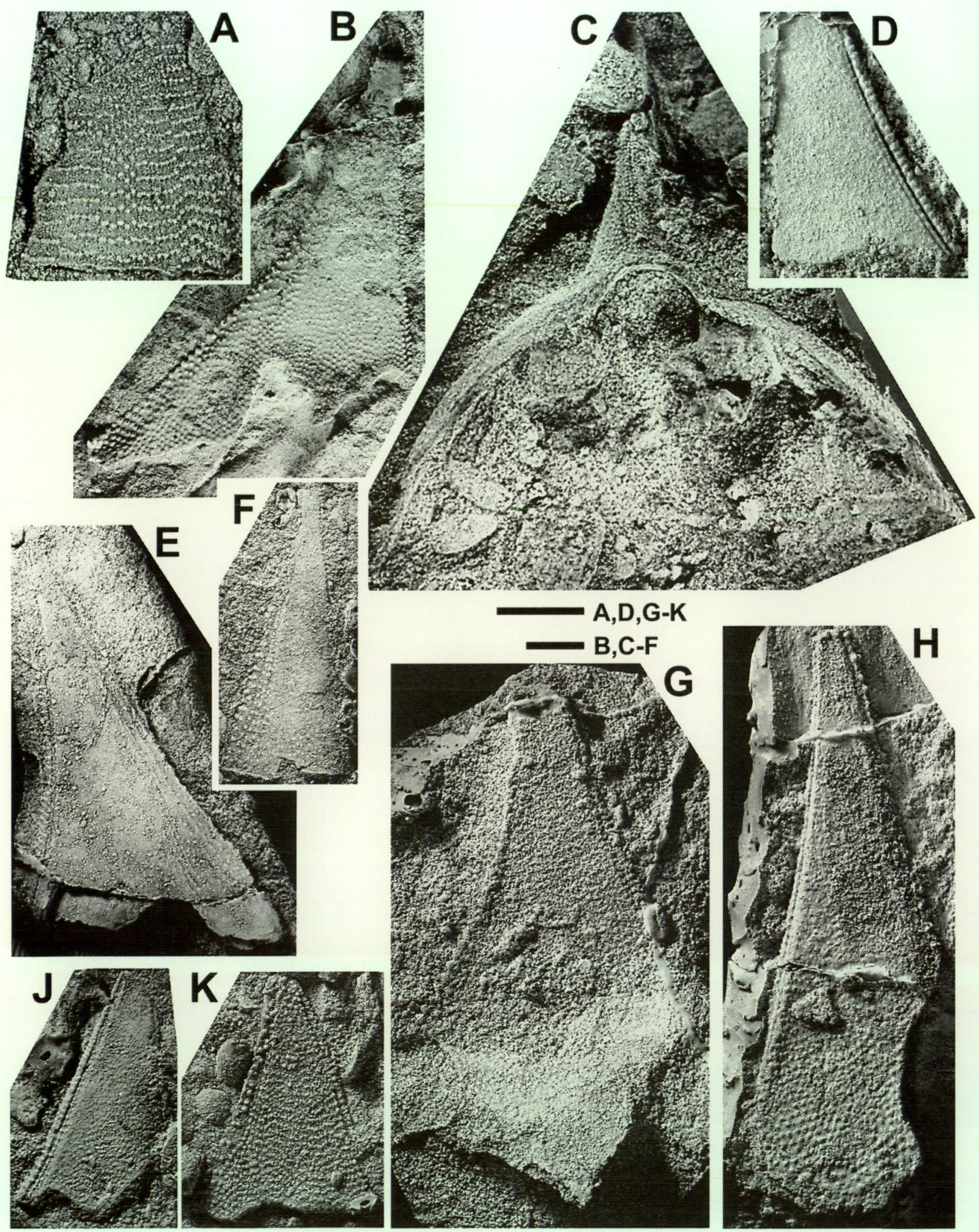

Figure 31 Mithakaspis lyentye gen. et sp. nov., incomplete MD plates. A, CPC 36992; B, holotype (CPC 37007), left lateral view; C, CPC 36999, with both ADL plates attached, anterior view; D, CPC 36997, right lateral view; E, CPC 36993, right lateral view; F, CPC 36998, left lateral view; G, CPC 37002, with attached dorsolateral plates, right lateral view; H, CPC 37006, ?left lateral view; J, CPC 37001, left lateral view; K, CPC 37000, right lateral view. All specimens are latex rubber casts whitened with ammonium chloride; scale bars $=10$ $\mathrm{mm}$. 
1962. The MD's vary in shape and ornament, and it is not clear if several taxa may be involved. For the present these incomplete remains are provisionally described together as one taxon. The MD's have consistently higher and more narrow shapes than the MD of the new groenlandaspid genus from the Mulga Downs Group dealt with above. However, a close relationship is suggested by similarities in ornament, and some other features. Mithakaspis gen. nov. is therefore included within the Groenlandaspidae.

The genus Africanaspis Long et al. (1997a), and another new form described by Daeschler et al. (in press), are other groenlandaspids with high narrow MD plates (both of Famennian age). However, based on CPC 37007, selected as holotype, and CPC 36999, a second partly articulated specimen, the following features distinguish this new genus from previously described forms: proportions and shape of the MD, which has a longer anterior than posterior border (in this respect it resembles some species of Groenlandaspis, although shape of the MD is quite different); posterodorsal orientation of the lateral line canal on the ADL; the fact that the ADL overlaps, and the PDL partly overlaps, the MD plate, rather than the reverse (the normal placoderm condition); and the external midline contact between ADL's in front of the MD (the last not documented in any other arthrodire).

\section{Description}

The material included here is very much larger than the European form Tiaraspis, in which the MD plates are generally less than $30 \mathrm{~mm}$ high (e.g.

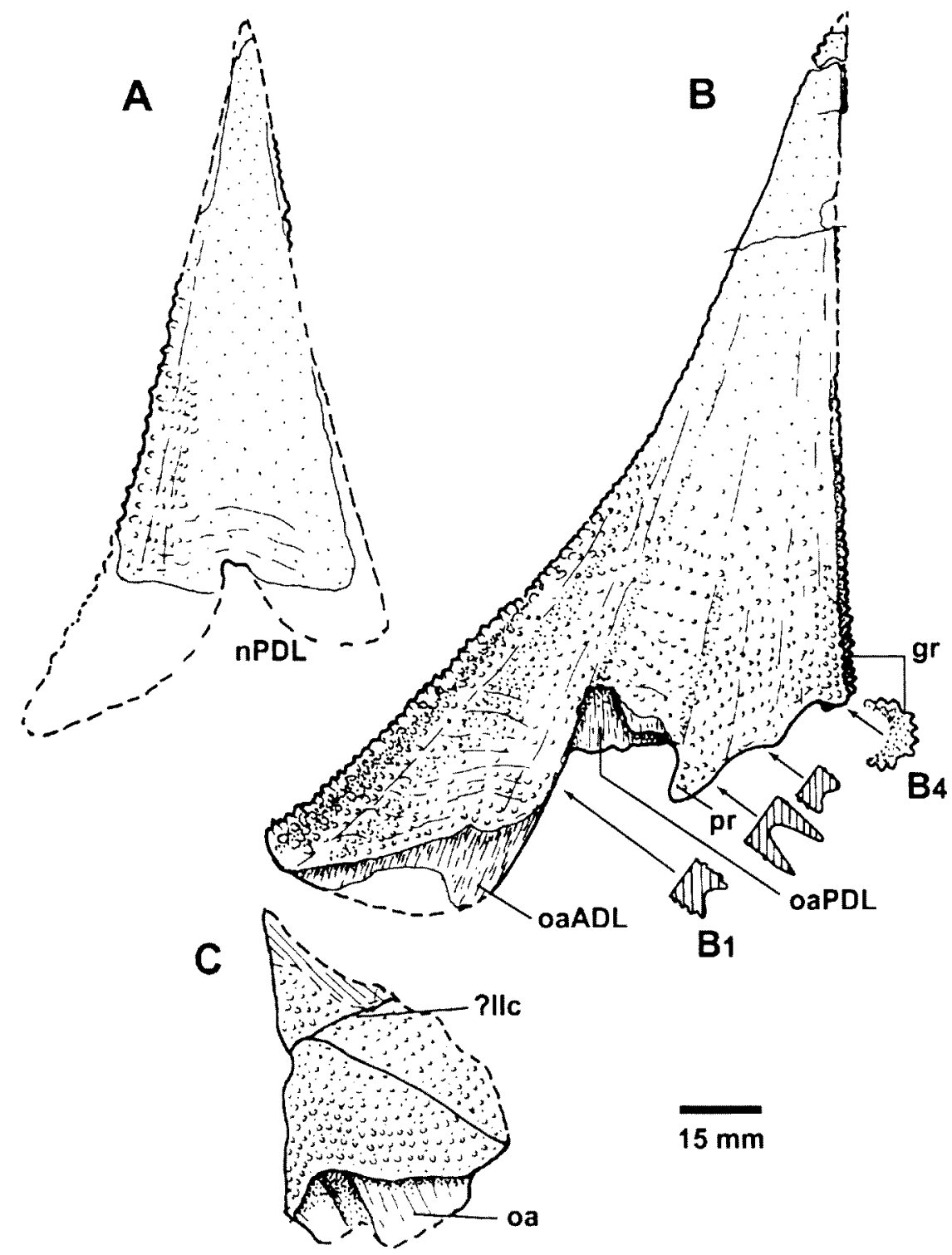

Figure 32 Mithakaspis lyentye gen. et sp. nov. A, incomplete MD plate, left lateral view (CPC 36998). B,C, the holotype (CPC 37007); $M D$ plate (B), with four basal sections at levels indicated (B1-B4), and associated left ADL plate $(C)$, both in left lateral view. 
Gross 1962), with the Belgian example of Gross (1965a) being $20 \mathrm{~mm}$ high. Only the Gondwanan genus Africanaspis is comparable in size. Long et al. (1997a: 261) defined Africanaspis as a 'groenlandaspid arthrodire' with the following characters: $\mathrm{MD}$ plate very short and high $(\mathrm{H} / \mathrm{L}$ ratio $>2$ ); $A D L$ and PDL with well developed dorsolateral ridge; deep midline contact between PDL's, at least half the height of the plate; AL very narrow (H/L index 60-67); ornament of widely spaced tubercles, coalescing to vertical ridges on MD. The two specimens with associated trunk armour remains, provisionally grouped together here, both show significant differences to this form.

CPC 37007 (the holotype; Figure 31B) comprises several elements in association with an MD of large size (height $93 \mathrm{~mm}$, breadth at base $53 \mathrm{~mm}$ ) exposed in left lateral view. It has a distinctive shape (Figure $32 \mathrm{~B})$, with the anterior margin $(90 \mathrm{~mm}$ ) being just over 1.5 times the length of the posterior margin (58 $\mathrm{mm}$ ). The anterior part of the ventral margin shows a clear overlap area (oaADL), and behind is an irregular notch for the PDL. Tuberculate rows of ornament follow the notched margin, indicating that it is complete. The steep anterior border of the notch preserves the entire inner edge, which was solid bone forming a shallow groove which must have been for the anterodorsal margin of the PDL plates of both sides (Figure 32B1). These must have had a very narrow overlap area in this region. Since the thickness of the bone decreases to the overlap area for the ADL it seems impossible that the ADL could have been overlapped by the MD. The overlap area for the PDL is more complete on the right side (inner surface preserved). This middle region, including the dermal process behind, is the only part of the ventral border of the MD which has a central concavity, with left and right laminae. A short process (pr) indicates the anterior limit of overlap of the MD onto the PDL. Behind this level to the posterior corner the bone had a solid concave edge (Figure 32B4).

The ornament of spaced discrete tubercles forms antero-posterior rows. Ventrally these meander to follow the borders of the bone. The rows are much less distinct than in Tiaraspis from the Upper Devonian of Belgium (Gross 1965a: pl. 2, figs. 2,3). The poorly illustrated type species of Tiaraspis (Gross 1933: pl. 5, fig. 8) appears to show rows with a strong dorsal curvature following the deep PDL notch. The anterior border of CPC 37007 shows one row of enlarged tubercles, but since only one side is preserved, we assume there was a double row at least. A distinct shallow groove just inside the posterior margin ( $\mathrm{gr}$ ) extends between the vertical tubercle rows at least in the lower half of the margin, and separates the main lateral ornamented surface from the posterior margin. Ventrally there were four tubercles in rows crossing this margin
(Figure 32B4). In material from Overath, Germany, such fringing ornament was not illustrated by Gross (1962: fig. 1), but it can be seen on the posterior margin of the specimen illustrated (upside down) in Gross (1933: pl. 5, fig. 8).

Several ornamented fragmentary bone impressions are preserved adjacent to the MD. Only one can be provisionally identified, as an incomplete ADL preserved $13 \mathrm{~mm}$ away from the anterior corner of the MD. Its assumed anterior ornamented margin seems complete, but lacks the articular condyle. Part of an overlap area is preserved on the presumed ventral margin (oa, Figure $32 \mathrm{C}$ ), with a strong groove which may have received a prominent postbranchial ridge on the innner surface of the AL plate. The posterior border of the overlapped part seems complete, and probably indicates the extent of underlap of the PDL. The ornamented surface shows two faint grooves running back from the anterior margin, the ventral groove being slightly more prominent. The posterodorsal course of the assumed main lateral line groove (?llc, Figure 32C) is different to that of Groenlandaspis (Figure 30), Africanaspis (Long et al. 1997a), Tiaraspis (Gross 1962: fig. 6; Schultze 1984: fig. 3), and all the ADLs illustrated by Denison (1958: fig. 108). Proportions of the ADL and MD are consistent with them belonging to the same animal, as is the similar ornament.

The second associated specimen (CPC 36999; Figure $31 \mathrm{C}$ ) is the anterior portion of a partlyarticulated trunk armour ornamented with fine closely spaced tubercles. It includes the MD, both ADLs and the left PDL, and shows both articular condyles. The MD was evidently high and narrow, but only the anterior edge is preserved, so whether it had the same shape as in the previous specimen is unknown. The ornament on the anterior border of the MD shows some alignment, but is coarser in CPC 37007, although this could be from a larger individual. There is considerable ornament variation in all the material provisionally included here. Because of the different preservation of these two specimens it is not established that they belong to the same taxon.

The total armour in anterior view is rounded in section (dorsal half), with a width at the level of the ADL/AL overlap of about $85 \mathrm{~mm}$. However the two articular condyles (cd, Figure 34) are separated by a gap of only $9 \mathrm{~mm}$. In the midline above the condyles is a distinct rounded notch (n.ptnu), with a grooved margin which must have abutted against the posterior skull margin. The notch is delimited by slight angles above the condyles, beneath which the bone edge is narrow, and must have slid over the skull margin. The condyles project down from the inside edge of the ADL, and present an oblong shape in anterior view. Only some $6 \mathrm{~mm}$ of the left lateral surface of the MD spine is preserved, and its 


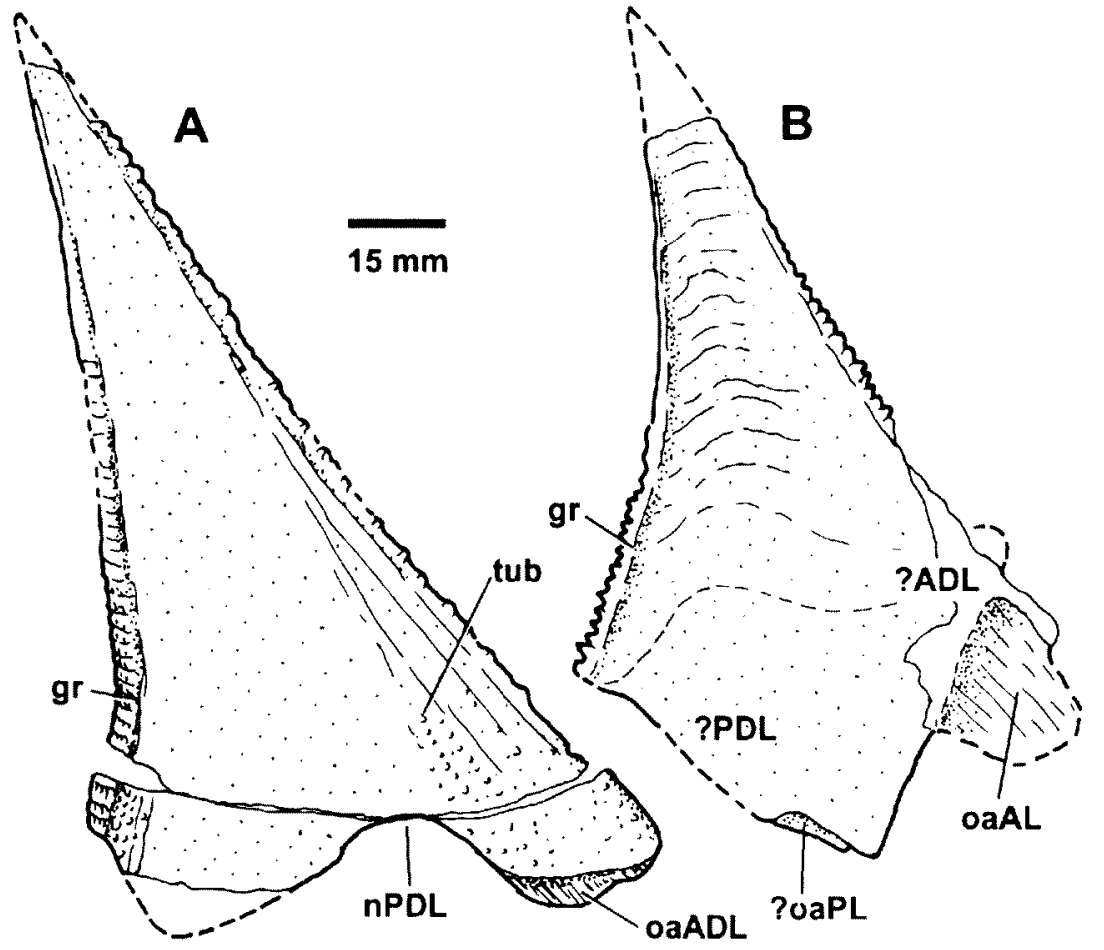

Figure 33 Mithakaspis lyentye gen. et sp. nov. MD plates, right lateral view. A, CPC 36993; B, CPC 37002, with dorsolateral plates attached.

upper preserved limit (incomplete) is $51 \mathrm{~mm}$ above the edge of the post-nuchal notch. The right side of the armour preserves the overlap area for the $\mathrm{AL}$ plate, and the left side includes part of the PDL, with an extensive overlap for one or both lateral plates.

The arrangement of sensory grooves and sutures is highly unusual. The faint lateral line groove on both sides ran steeply upwards and backwards (llc, Figure 34), in contrast to all other groenlandaspids (Figure 30). On the right side it is seen to turn down just inside the preserved edge, forming a dorsal inflection, as on the PDL of other high-spined groenlandaspids (Long et al. 1997a; Daeschler et al. in press). A clear suture runs down on the right side of the anterior edge of the $\mathrm{MD}$, and appears to cross the midline 4-5 $\mathrm{mm}$ behind the anterior edge of the post-nuchal notch, in front of which the surface levels out slightly. This suggests that the ADL plates had external midline contact in front of the MD, a unique condition amongst placoderms. As with the lateral line groove, this suture is inflected downwards just inside the preserved edge of the specimen, and it is clear from other MD plates described below that the MD was overlapped at this point, a highly unusual condition only seen in a few other taxa (e.g. Eurycaraspis; Liu 1991). Another possible interpretation, but much less likely, is suggested by a faint lineation running back from the anterior angle above the articular condyle of the ADL, in the expected position of its suture with the MD. This could indicate an extra 'anterodorsal' plate, possibly differentiated (with extreme narrowing of the armour) to retain an overlap of the ADL in the normal manner, and forming a midline junction between the MD as in other groenlandaspids (in this case both externally and internally).

All other specimens are much less complete, mainly MD impressions. CPC 36993 (Figure 31E) is from the right side and is complete except for the tip of the spine, the posterior part of the ventral margin, and short sections of anterior and posterior margins (Figure 33A). Estimated central height is 68 $\mathrm{mm}$, and breadth of the base is $43 \mathrm{~mm}$, with anterior margin about 1.25 times the length of the posterior. The main portion of the external surface lacks ornament, except near the anterior ventral corner, where a shallow depression with faint striations, shows some poorly defined tubercle rows. Dorsally the depression narrows to a groove running inside the anterior margin, apparently ornamented with regular tubercles (poorly defined) and assumed to be the same as on the posterior margin, which has a similar slight groove (gr, Figure 33A). The ventral part of this margin is better preserved as a rounded border carrying slight ridges that slope slightly upwards and backwards. Beneath the cracked ventral part this ornament is best preserved, each ridge comprising small dorsoventrally elongate tubercles (4-5 on each side). The notch in the ventral border for the PDL (nPDL) is closer to the front, as in T. subtilis (Gross 1962: fig. 1). In Groenlandaspis it is towards the posterior end of the 
MD (Ritchie 1975; Long et al. 1997a), whilst in the Late Devonian Africanaspis africana there is a bilobed notch for both the ADL and the PDL (Long et al. 1997a: fig. 13).

CPC 37002 (Figure 31G) is a poorly preserved MD with both margins showing fringing ornament of enlarged tubercles, on one margin separated by a thin groove from the main surface, which is covered with fine tubercles aligned in antero-posterior rows. The dorsal extremity is missing and ventrally the MD is apparently attached to both dorsolateral plates, but the impression is very poorly preserved, with the lateral line canal completely lost, so they provide little information apart from two possible overlaps (oaPL, oaAL, Figure 33B), assuming this is the right side, as suggested by the more concave (i.e. posterior) border being on the left. Again the anterior margin is about 1.25 times as long as the posterior. Ornament seems similar to the holotype, possibly with more distinct rows, but is poorly preserved.

CPC 37000 (Figure $31 \mathrm{~K}$ ) is a similar MD, with ornament better preserved. CPC 36998 (Figure 31F)

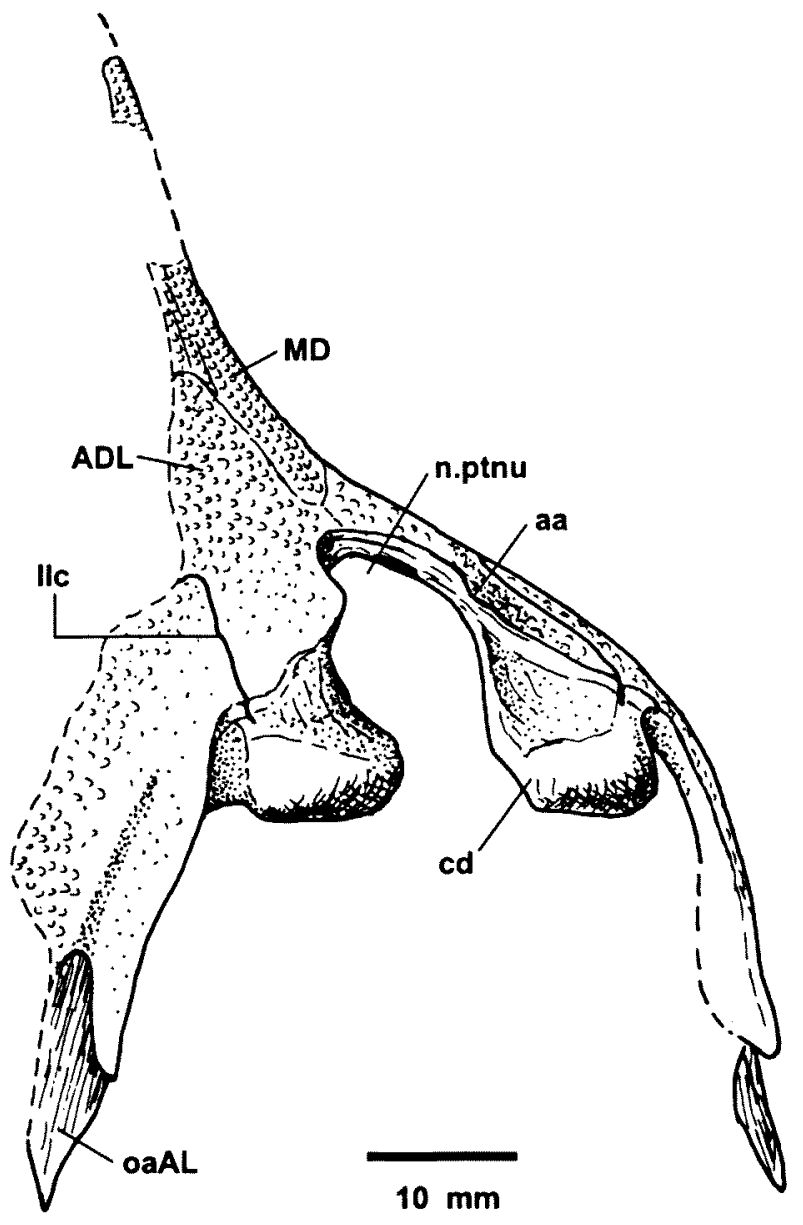

Figure 34 Mithakaspis lyentye gen. et sp. nov. Incomplete articulated trunk armour (CPC 36999), right anterolateral view (cf. Figure 31C). is a more elongate example, with a truncated ventral margin carrying a small irregular notch, possibly complete since the ornament rows seem to approximate its contour. Again the ornament is pustulose tubercles in antero-posterior rows. The left margin as preserved has these tubercles enlarged around the border, very similar to the anterior margin of CPC 37007, so this example is interpreted as a broken dorsal portion of the MD of the same morphotype (Figure 32A). CPC 36992 (Figure 31A) is an incomplete fragment $25 \mathrm{~mm}$ high showing ornament of tubercles in 15 widely spaced rows (cf. CPC 37000). CPC 37001 (Figure 31J) is a small example $30-35 \mathrm{~mm}$ in estimated height, with a different ventral configuration of the plate (possibly broken). It is sufficiently complete to show that the anterior margin is longer than the posterior, as in CPC 37007. This specimen has similar ornament rows to CPC 37000 , but much reduced tubercles. CPC 36997 (Figure 31D) shows complete reduction of the tubercles, but the same fringing ornament and groove indicates that this is intraspecific variation.

CPC 36994 is a large fragment ( 50 by $35 \mathrm{~mm}$ ) preserving only the ventral portion, but with fine ornament showing some alignment as in CPC 37007 . CPC 36995 is a broken fragment $25 \mathrm{~mm}$ across showing both ornament faces. Compared to CPC 36992, the widely separated rows are coalesced into smooth ridges with no tuberculation. CPC 36996 has similar widely separated ridges.

Apart from the holotype, all the specimens so far described come from the Dulcie Range, but a similar degree of ornament variation is indicated for the following examples from the Cravens Peak Beds. CPC 37003-004 are two poorly preserved MD's, one at least $90 \mathrm{~mm}$ high, with fringing ornament and a smooth lateral surface as in CPC 37005. The other is at least $70 \mathrm{~mm}$ high and an estimated $30 \mathrm{~mm}$ across at the (preserved) base, and has fine tubercles in rows. CPC 37005 is a large MD, preserved height $74 \mathrm{~mm}$, with a smooth lateral surface but with three to four vertical tubercle rows running down inside the posterior margin. The anterior margin is very well preserved, clearly delineated on both sides by a groove. Between the grooves the slightly flattened anterior border is crossed by horizontal rows of six to eight tubercles, with the ventral rows being slightly asymmetric and biserial. There is an associated indeterminate plate impression with fine ornament. CPC 37006 (Figure $31 \mathrm{H}$ ) is another elongate $\mathrm{MD}$, ornamented with aligned tubercles. It is assumed to be broken ventrally, and possibly includes parts of the dorsolateral plates. Both margins are almost straight, so when complete this MD was probably higher than in the holotype.

In summary, two different ornament groupings can be suggested for these high MD plates, but their 
taxonomic status is uncertain. Possibly CPC 37000 36992, and 36995-996 (smaller to larger Dulcie Sandstone specimens) can be separated from the others in showing a growth series from tubercles forming discrete antero-posterior rows, which in larger examples coalesce as strong antero-posterior ridges lacking tubercles. The second grouping, with fine tubercular ornament in which alignment is less marked, as in CPC 37006, 007, can show reduction (CPC 36993, 37001) to complete loss of ornament except at the margins (CPC 36997, 37005). However retention of the same fringing ornament and groove, and sometimes a few tubercle rows running up inside the margins, suggests that this is intraspecific variation.

\section{Phlyctaenioidei incertae sedis}

\section{phlyctaenioid indet. 1}

Figure 36A, D

\section{Material}

CPC 37008-009.

\section{Localities and Horizon}

74/15, 17 (northern limb of the Dulcie Syncline, in the Dulcie Sandstone; see Figure 1C). A locality summary for each taxon is given in Table 1 , and locality details for each specimen are listed in the Appendix.

\section{Remarks}

These two specimens, tentatively grouped together, are from individuals of large size, and have a similar ornament of low rounded tubercles.

\section{Description}

One of these large impressions (CPC 37009; Figure $36 \mathrm{~A}$ ) is $80 \mathrm{~mm}$ across, and crossed by a sensory groove. One natural margin is symmetrical with a straight median section, flanked by bevelled slightly concave lateral sections, indicating the posterior margin of a Nu plate. The orientation of the sensory groove shows that the $\mathrm{PNu}$ ossification centre was at the posterior margin, so this must have belonged to a large phlyctaeniid, but apparently not a groenlandaspid, judging by the shape of the posterior margin, which suggests a trapezoidal $\mathrm{Nu}$ of brachythoracid type. The affinities of this specimen remain very uncertain.

CPC 37008 (Figure 36D) is interpreted as part of a right $\mathrm{AL}$ plate. Its ornament of low rounded tubercles is similar to that of the previous specimen. When complete it would have been at least $50 \mathrm{~mm}$ high. A distinctive feature is a short ridge preserved near the posterodorsal margin, which is assumed to be the anterior end of a lateral ridge crossing part of the PL plate, although no suture is visible. A similar feature was described above in Huginaspis australis sp. nov., but CPC 37008 is considerably larger than any specimens referred to that taxon, and has different ornament. It could however represent a much larger related taxon.

\section{phlyctaenioid indet. 2}

Figures 29C-E, 36B, C

\section{Material \\ CPC 37010-011.}

\section{Localities and Horizon}

$74 / 11,16$ (northwestern part of the Dulcie Syncline, in the Dulcie Sandstone; see Figure 1C). A locality summary for each taxon is given in Table 1 , and locality details for each specimen are listed in the Appendix

\section{Remarks}

These two specimens are clearly conspecific, and presumably belong to one of the arthrodires described above. They are separated out here to emphasise the fact that they belong to the same species, which cannot be properly assigned without associated remains.

\section{Description}

CPC 37011 (Figure 36B) is the internal impression of a large right IL plate, apparently incomplete laterally, where three ridges of special ornament typical of the postbranchial lamina are preserved (pbl, Figure 29C). As incompletely preserved, with the main lateral part of the postbranchial lamina apparently missing, the specimen is still $97 \mathrm{~mm}$ long, so it must have come from a very large animal. The mesial margin is assumed complete. The preserved surface is concave with three strong ridges, the groove behind the most anterior ridge at the lateral preserved edge assumed to be the contact face for the AL plate ( $\mathrm{CfAL}$ ). The posterior surface is also concave, forming a groove in the bone of the ventral lamina that is some $8 \mathrm{~mm}$ thick. This groove must have received the anterior edge of the AVL plate (gr.AL, Figure 29D).

The second specimen (CPC 37010; Figure 36C) has identical ornament on the postbranchial lamina. The postbranchial ornamental ridges carry slender denticles oriented ventrolaterally, an arrangement quite differently developed to the strong ridges seen on the IL and AVL of Wuttagoonaspis (see above). In anterior view (Figure 36C) there are 8-9 ridges laterally, reducing to 5-6 at the mesial end of the preserved portion. Beneath this is a zone of normal external ornament of crowded tubercles, and a ventrally facing groove, the anteroventral sulcus of the trunk armour (s.av, Figure 29E). 


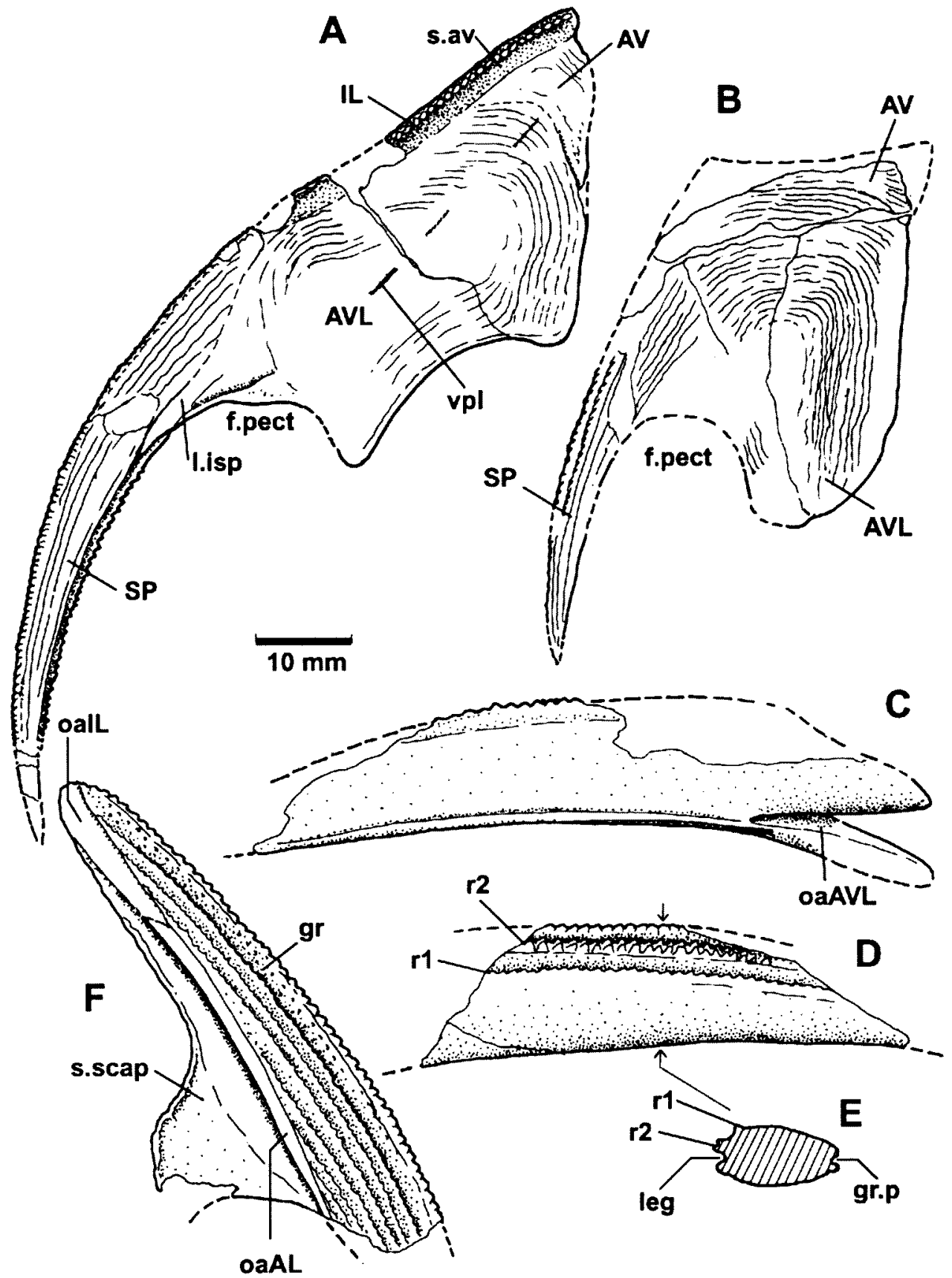

Figure 35 A, ?petalichthyid gen. et sp. indet., right AVL, AV, IL and SP plates in ventral view (CPC 37021); B, Wuttagoonaspis sp., right AVL, AV, IL and SP plates in ventral view (CPC 36859; cf. Figure 3A). C-E, phlyctaenioid indet. 3, incomplete right SP plate (CPC 37016) in ventral (C) and dorsal (D) views, with section at level shown (E). F, phlyctaenioid indet. 3, incomplete right SP plate (CPC 37017); dorsal view of proximal end.

phlyctaenioid indet. 3

Figures 35C-F, 36E-G

\section{Material}

CPC 37012-019.

\section{Localities and Horizon}

$74 / 12,15$ (northern limb of the Dulcie Syncline, in the Dulcie Sandstone); $77 / 2,17,19,20$ (Cravens Peak Beds). For localities see Figure 1. A locality summary for each taxon is given in Table 1, and locality details for each specimen are listed in the Appendix.

\section{Remarks}

Described here are various broken portions of SP plates, of which there seem to be several types. All of the arthrodires described above would have had SP plates, but, without associated material, it is not clear which spine type belongs to which taxon.

\section{Description}

CPC 37019 is an ornamented proximal portion of a SP plate $30 \mathrm{~mm}$ long and $11 \mathrm{~mm}$ wide, with eight ridges behind a very wide anterior groove. It differs 
from the SP plates assigned above to groenlandaspid gen. nov. in the stronger ridging, which lacks tuberculation. CPC 37012, 015 are similarly developed spine fragments (Figure 36E,F). The following SP plates may represent the same spine type, but display minor differences. CPC 37014 shows the leading edge of an almost complete SP $70 \mathrm{~mm}$ long. It has a broad central groove, again separating dorsal and ventral tuberculate ridges which over most of the spine length comprise double rows of elongate tubercles, although at the proximal end they are three tubercles across. Distally (15 $\mathrm{mm}$ from the tip) they become smooth ridges. The leading edge groove continues right to the spine tip. The distal $20 \mathrm{~mm}$ shows two smooth narrow ridges separated by shallow grooves on both dorsal and ventral surfaces (only anterior parts preserved). This example differs from those described above in having a broader central groove on the leading edge, and in the more ordered arrangement of the double rows, in which the tubercles are more elongate.

CPC 37017 (Figure 35F) is an incomplete right SP segment (length $57 \mathrm{~mm}$ ) including part of the infraspinal lamina of the AVL. The inner surface of this lamina shows the outline of the scapulocoracoid (s.scap, Figure 35F), essentially as in Dicksonosteus (e.g. Goujet 1984a: pl. 11, fig. 2). In section the SP plate is gently convex dorsally, and almost flat ventrally. The free part of the SP is broken off. The inner edge of the anterior attached part carries two smooth overlap areas, for the AL posteriorly and the IL anteriorly (oaAL, oaIL). The leading edge of the SP is ornamented with an upper single and lower double row of tubercles proximally, changing to two double rows distally. The more convex dorsal surface has a broad shallow groove $(\mathrm{gr})$ behind the anterior tubeculate margin, in which fine separate denticles are arranged in longitudinal rows. Behind this at the level of the free spine portion the dorsal surface carries seven longitudinal ridges, reducing to three proximally. These are more denticulate anteriorly and proximally, and distally form continuous narrow ridges. The flatter ventral surface also has a wide shallow groove behind the leading edge tubercles, but it lacks ornament and is not quite as wide as the dorsal groove. Behind this three denticulate ridges give way to tubercular ornament of the AVL plate (poorly preserved). Minor differences exhibited by CPC 37017 are that the ridges are thinner and more continuous, there are fine denticles in the anterior groove on the dorsal surface, which is proportionately wider, and the leading edge tubercles are coarser. The double rows alternate against the leading edge groove, which is very narrow.

A second spine type is characterised by reduction of the ornament. CPC 37016 (Figure 35C-E), is portion of a right SP plate, mainly preserving the ventral surface, with the distal end missing (preserved length $75 \mathrm{~mm}$ ). Its gentle curvature indicates the anterior and posterior margins. The ventral surface is almost complete proximally, and shows an overlap area (oaAVL, Figure 35C) which would have received the infraspinal lamina of the AVL plate (1.isp, Figure 35A). Apart from a rounded posterior ridge the surface is smooth. The dorsal surface is also smooth posteriorly, with a ridge of single pointed tubercles towards the anterior edge (r1, Figure 35D-E), separated by a marked groove from another ridge with double tubercles ( $\mathrm{r} 2$, poorly preserved). An anteroventral ridge might also have been tuberculate, but is too poorly preserved in the short preserved section. The leading edge of the spine is a narrow groove, and another on the trailing edge is a deeper groove (leg, gr.p, Figure 35E). This is presumably a phlyctaeniid spine, which possibly belongs to one of the taxa described above with reduced ornament.

A much larger SP plate (CPC 37018; Figure 36G) has the proximal part preserved (110 $\mathrm{mm}$ long). Dorsal and ventral surfaces are smooth, as in the previous specimen. The leading edge is only preserved at the proximal end, again showing a distinct groove with tuberculate ridges (double) above and below. The well-preserved posterior opening for the internal cavity shows no supraspinal or infraspinal lamina, and the posterior groove of the previous specimen is filled with a rounded ridge carrying alternating denticles (Figure 36G). A similar posterior ridge between two grooves, but with one row of denticles, is seen on spines of Cosmacanthus from Scaat Craig in Scotland, and in Groenlandaspis mirabilis from Greenland (A. Ivanov, pers. comm., Paris, 1999). Denison (1978: 105) interpreted Cosmacanthus as a placoderm SP plate 'possibly ... related to Groenlandaspis'. CPC 37013 is another example of this spine type. It is a short distal part of a SP 26 $\mathrm{mm}$ long with a concave leading edge flanked by two (?) denticulate ridges (only one preserved), behind which is a deep broad groove, a smooth ridge and a shallow narrow groove. The preserved posterior half of the spine surface is completely smooth. The posterior face is not preserved, so the presence or absence of a posterior groove or denticulate ridge could not be confirmed.

\section{Order Petalichthyida Jaekel, 1911}

?petalichthyid gen. et sp. indet. Figures 35A, 36H, J

diverse arthrodires: Young 1991a: 67 (pars)

\section{Material}

CPC 37020-021. 


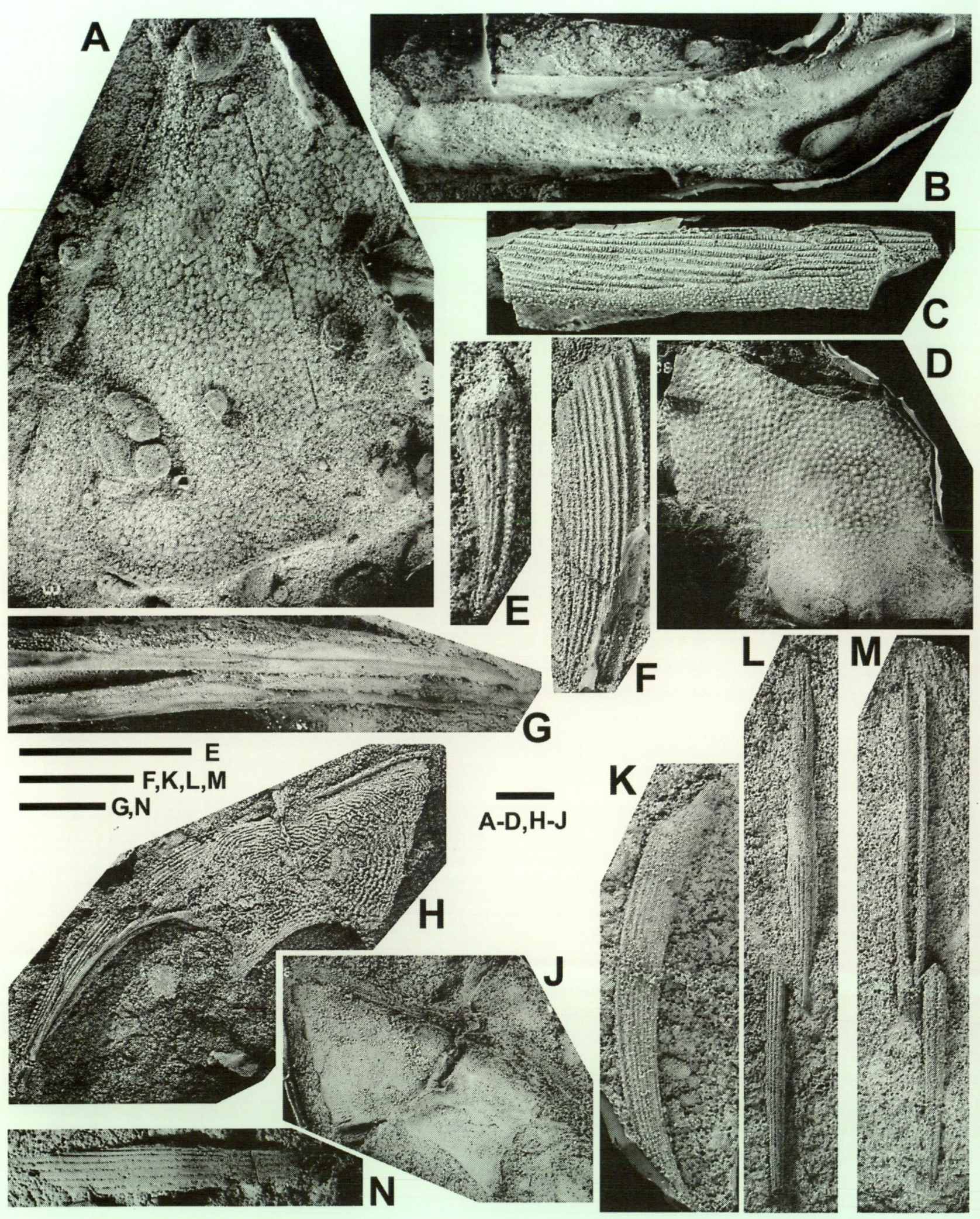

Figure 36 A,D, phlyctaenioid indet. 1. A, Nu and right PNu plates, dorsal view (CPC 37009); D, right AL plate, lateral view (CPC 37008). B,C, phlyctaenioid indet. 2., IL plates. B, CPC 37011, inner view (cf. Figure 29C); C, CPC 37010, external view; E-G, phlyctaenioid indet. 3., SP plates. E, CPC 37015; F, CPC 37012; G, CPC 37018 (posterior view). $\mathrm{H}_{\mathrm{J}}$, ?petalichthyid gen. et sp. indet., right AVL, AV, IL and SP plates (CPC 37021); H, ventral view (cf. Figure 35A); J, internal view. K-N, acanthodian indet., fin spines. K, CPC 37022; L,M, CPC 37023 in anterior (L) and posterior (M) views; N, CPC 37025. All specimens are latex rubber casts whitened with ammonium chloride; scale bars $=10 \mathrm{~mm}$. 


\section{Localities and Horizon}

74/17 (northwestern part of the Dulcie Syncline, in the Dulcie Sandstone); 77/19 (Cravens Peak Beds). For localities see Figure 1. A locality summary for each taxon is given in Table 1, and locality details for each specimen are listed in the Appendix.

\section{Remarks}

CPC 37021 is provisionally referred to the Petalichthyida, because of the short broad form of the AVL, and the elongate divergent SP plate. It has a separately ossified AV plate, as in the Chinese taxa Diandongpetalichthys, Quasipetalichthys, and Eurycaraspis. It is distinguished from these, and all other known petalichthyids, by the distinctly concave posterior margin, and the oblique orientation of the anterior margin. The presence of an AV plate is a symplesiomorphy with arthrodires, and otherwise this taxon is represented only by the AVL and SP, so it is left in open nomenclature.

\section{Description}

CPC 37021 (Figure $36 \mathrm{H}, \mathrm{J}$ ) is an associated right AVL, AV, IL and SP plate preserved in part and counterpart. It is notable for the oblique orientation of the anterior edge of the armour, the short and broad AVL, and its concave posterior margin (Figure 35A), all features unique to this animal. Otherwise, the short broad form is reminiscent of petalichthyids, for example the associated AVL and SP plates, probably belonging to Macropetalichthys, which were originally called 'Acanthaspis' (see Denison 1978: fig. 27). CPC 37021 also shows a separately ossified AV plate, an element never identified in Euramerican petalichthyids, but present in the Chinese taxa Diandongpetalichthys, Quasipetalichthys, and Eurycaraspis (Liu 1991; Zhu 1991). The posterior suture of the AV is indicated on the mesial margin by a slight notch, tracable with difficulty across the ornamented surface between ridges. The AVL is ornamented with concentric ridges, made of interconnected tubercles, sometimes broken into shorter sections, with a more reticulate arrangement and areas lacking ornament in the central part around the ossification centre (smooth areas may be due to abrasion or weathering). Traces of a sensory pitline pass posterolaterally from the AV plate across the centre of the AVL (vpl). The infraspinal lamina of the AVL (l.isp) is clearly indicated because of slight displacement, although the anterior course of the suture with the SP is unclear, and shown only by the arrangement of the ornament.

The SP carries longitudinal ridges on the ventral and dorsal surface (only the anterior part of the latter is visible). The ventral surface has $2-3$ ridges distally and $5-6$ proximally, the anterior one more tuberculate than those behind, and proximally merging with the tuberculate zone of the leading edge. The tubercles along the leading edge are arranged in vertical rows, in anterior view sloping slightly downwards and inwards (each row has 4-5 tubercles proximally, 2-3 in the most distal preserved part). The posterior margin has a rounded smooth ridge ventrally, which continues across the posterior border of the infraspinal lamina, and a single denticle row dorsally. Overall the spine is much flatter and more curved in comparison with Wuttagoonaspis (e.g. CPC 36859; Figure 35B). It does not show the broad groove separating the tuberculate leading edge from the ridges behind, which is seen in some other SP fragments described above (e.g. Figure $36 \mathrm{E}, \mathrm{F}$ ). The IL is preserved in position, the anterior margin of its ventral lamina defined by a distinctive ridge of connected tubercles, behind which is a deep unornamented groove (s.av, the anteroventral sulcus). The anterior face of the IL is also partly preserved, and shows tuberculate ornament on its ventral part. The visceral surface (Figure $36 \mathrm{~J}$ ) shows a sharp ridge crossing transversely from the posteromesial corner, to broaden at the ossification centre. A corresponding but less conspicuous ridge may be present in Eurycaraspis (Liu 1991: pl. 3G).

This specimen indicates the overall rounded ventral contour of the trunk armour. In contrast to the flat ventral surface in most of the arthrodires described above, the SP plate in anterior view is elevated above the tumid AVL, suggesting a more demersal rather than benthonic habitat for this fish.

CPC 37020 might also belong to this taxon, but is much less well preserved. It is a curved spine 77 $\mathrm{mm}$ long, carrying longitudinal ridges (12 across the exposed surface proximally, with at least four within $15 \mathrm{~mm}$ of the tip). The ridges are nodose proximally, and smooth distally. The overlap area for the infraspinal lamina, and pectoral embayment are partly preserved.

Liu (1991: fig. 20) considered petalichtlyids to be nested with two 'arthrodiran' groups (actinolepidoids, phlyctaenioids), and the trunk armour of the primitive petalichthyid Eurycaraspis is similar to actinolepids in many respects, including the form of the AL and SP (Liu 1991: fig. 5). Diandonpetalichthys, another primitive Chinese 'petalichthyid' (in the sense that it has an orbital notch rather than enclosed by a fused SO plate), has an AVL with a divergent SP plate as described here, also with an AV plate, and a concave (but shorter) posterior margin (Zhu 1991: fig. 4D). The ornament has a concentric alignment, but it differs in retaining discrete tubercles (Zhu 1991: pl. 2), rather than the ridges seen in CPC 37021. We also note a specimen from Mount Jack Station in the Darling Basin (AMF 54149) which seems to show a separate anterior $\mathrm{PNu}$ plate with a central endolymphatic duct 
opening (a petalichthyid character), but with the $C$ plates meeting in front of the $\mathrm{Nu}$ (as in most arthrodires). This skull may belong to a related form to CPC 37021 , but it differs in having tuberculate rather than ridged ornament. From the skull of Diandonpetalichthys it differs also in the fact that the main lateral line groove apparently passes laterally to the anterior $\mathrm{PNu}$, in the presence of an additional bone (posterior $\mathrm{M}$ plate) giving an anteriorly placed postmarginal corner formed by the anterior $M$ (and ?PM), and the fact that the central sensory canal groove passes back onto the $C$ plate.

\section{Class Acanthodii Owen, 1846 \\ acanthodian gen. et sp. indet. Figure $36 \mathrm{~K}-\mathrm{N}$}

acanthodians: Shergold 1985: 21

acanthodian ... spines: Young 1991a: 67

acanthodian spines: Haines et al. 1991: 32

Material

CPC 37022-025.

\section{Localities and Horizon}

$74 / 11,14$ (northwestern part of the Dulcie Syncline, in the Dulcie Sandstone); 77/24 (Cravens Peak Beds). For localities see Figure 1. A locality summary for each taxon is given in Table 1 , and locality details for each specimen are listed in the Appendix.

\section{Remarks}

Acanthodian fin spines are rarely encountered in this material, but because of their small size they may have been broken and less readily seen than the robust placoderm bones. Here we illustrate some isolated fin spines. A more detailed treatment of acanthodian remains from the calcareous beds previously assumed to lie at the base of the Cravens Peak Beds is given by Burrow and Young (in prep.).

\section{Description}

CPC 37023 (Figure 36L-M) is a straight presumably unpaired fin spine about $50 \mathrm{~mm}$ long, preserved in part and counterpart. The inserted portion is $18 \mathrm{~mm}$ long, and the posterior spine cavity extends about $50 \%$ of spine length. The exserted portion carries smooth longitudinal ribbing, with a posterior groove on the distal half. CPC 37025 (Figure $36 \mathrm{~N}$ ) is a similar straight spine, but much larger ( $5 \mathrm{~mm}$ wide, but only about $37 \mathrm{~mm}$ length is preserved). This type of spine could be assigned to the genus Onchus (e.g. Denison 1979).

CPC 37022 (Figure $36 \mathrm{~K}$ ) is a different spine type, highly curved and at least $40 \mathrm{~mm}$ long, presumably unpaired, with a shorter inserted portion.

\section{Class Osteichthyes Huxley, 1880}

\section{Subclass Sarcopterygii Romer, 1955}

\section{Remarks}

Most of the osteichthyan impressions recognised in the collection are of three types: isolated teeth, incomplete bones with teeth, and ornamented dermal bones, probably from the shoulder girdle. There is one associated cheek unit. Disarticulated skull bones of cosmine-covered forms may have been overlooked in this type of preservation because they lack distinctive dermal ornament.

Material described below indicates at least three taxa, provisionally assigned to three major sarcopterygian subgroups (Rhizodontida, Porolepiformes, Onychodontida). Apart from an onychodontid tooth, all assignments need to be substantiated with better preserved material. Gilbert-Tomlinson (1968: 203; also Johnstone et al. 1968: 611) referred to a 'possible dipnoan fragment' from near Eurithethera Soak, but this is an erroneous determination, and there is no evidence of dipnoans in the material studied here. However dipnoan remains are known from the associated calcareous beds (Young 1984: 66).

\section{Order Rhizodontida Andrews and Westoll, 1970}

?rhizodontid gen. et sp. indet. Figure 37A, B, D

crossopterygians: Shergold 1985: 21

rhipidistian fragments: Young 1991a: 67 (pars)

crossopterygians: Haines et al. 1991: 32

rhizodontid indet.: Young et al. 1993: 247

\section{Material}

CPC 37026-032.

\section{Localities and Horizon}

$74 / 16,17$ (northern limb of the Dulcie Syncline, in the Dulcie Sandstone); 77/15, 17, 19, 23 (Cravens Peak Beds). For localities see Figure 1. A locality summary for each taxon is given in Table 1 , and locality details for each specimen are listed in the Appendix.

\section{Remarks}

Andrews and Westoll (1970: 461) listed eight characters by which the dermal skeleton of the shoulder girdle in rhizodontids could be distinguished from other sarcopterygians. Of these, the depressed posterior flange on the cleithrum, and 

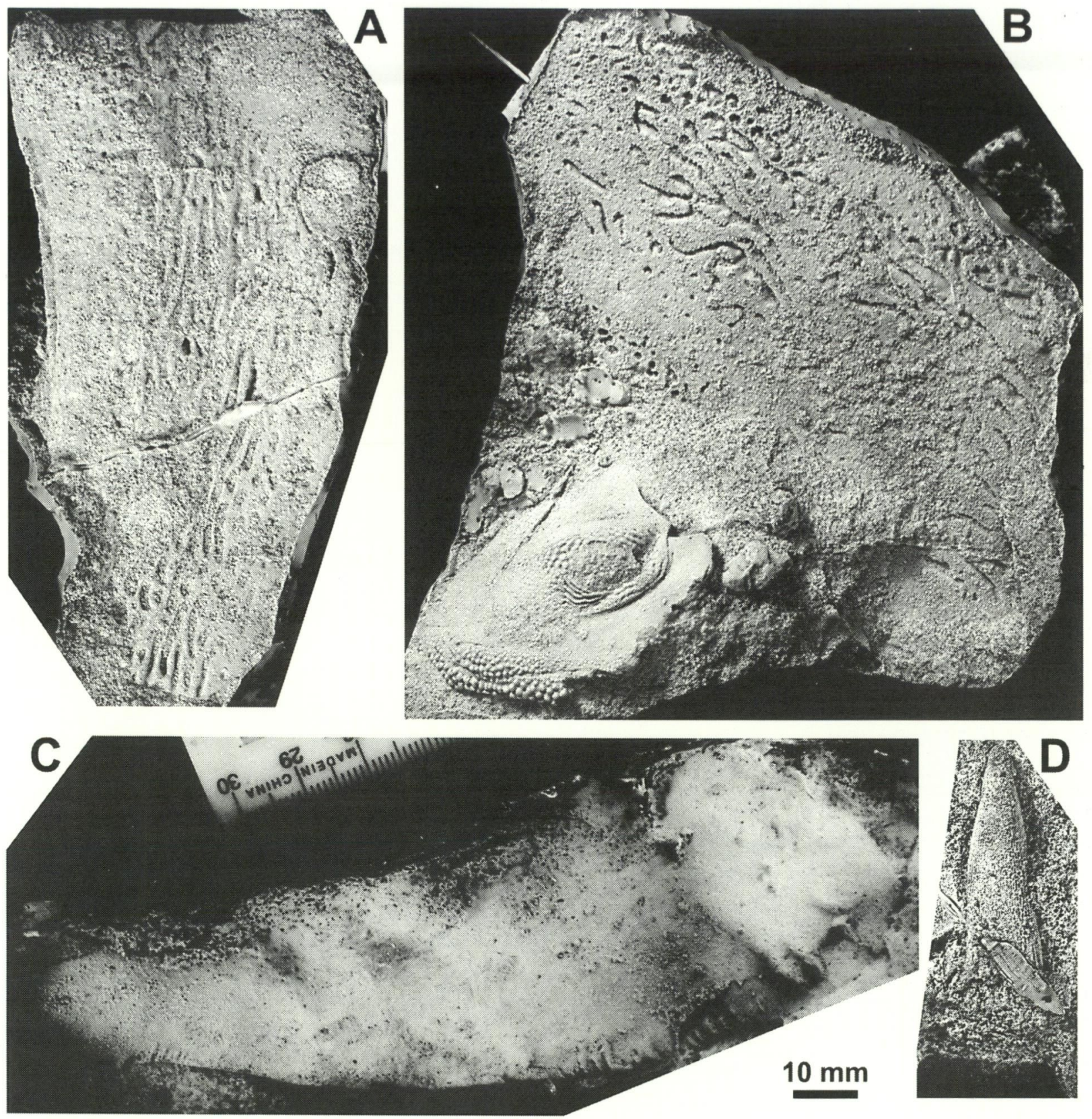

Figure 37 ?Rhizodontid gen. et sp. indet. A, CPC 37028, incomplete ?left cleithrum, external view; B, undetermined large ornamented bone (CPC 37030, upper right), associated with portion of a Wuttagoonaspis skull (CPC 36875, lower left); C, presumed shoulder girdle element, inner surface (ANU V2974); D, isolated tooth (CPC 37032). All specimens are latex rubber casts whitened with ammonium chloride.

its double overlap with the clavicle, were cited as synapomorphies of rhizodontids by Cloutier and Ahlberg (1996: 459; characters 114, 116). However Johanson and Ahlberg (2001: 67) listed seven different rhizodontid characters, and, regarding the shoulder girdle, a high position for the scapular attachment, and lateral line pores on the cleithrum, were noted as rhizondontid features of the new form Gooloogongia (but total length of the cleithrum in this form is unclear; op cit.: 54). The lack of a posterior flange and narrow 'waist' on the cleithrum are atypical, and were cited as features making Gooloogongia 'uniquely primitive among Rhizodontida' (Johanson and Ahlberg 2001: 68).
Such characters cannot be demonstrated in the very incomplete remains described below, which include bone impressions from a large fish with distinctive dermal ornament, comprising a flat surface in which flat-topped ridges separate steepsided grooves and pits. Together with large size, this ornament is suggestive of rhizondontid remains from the Northern Hemisphere (E. Vorobjeva, pers. comm.). More complete material is needed to clarify the affinities of this material, which we provisionally refer to the Rhizodontida, a group more typical of Carboniferous deposits in both hemispheres (e.g. Vorobjeva 1962, 1977; Long 1989; Johanson et al. 2000). From the Devonian 
rhizodontids are otherwise recorded from the Famennian of North America (Andrews and Westoll 1970; Davis et al. 2001) and Colombia (Janvier and Villarroel 2000), from the ?GivetianFrasnian Aztec Siltstone of Antarctica (Young et al. 1992; Johanson and Ahlberg 2001), and from the Frasnian of Canowindra in NSW (Johanson and Ahlberg 1998, 2001). Since Johanson and Ahlberg $(1998,2001)$ suggest that the new form Gooloogongia is the sister group to all other known rhizodontids, the existence of older representatives in Australia would not be unexpected.

\section{Description}

Portions of large sarcopterygian bones with distinctive ornament come from three localities (74/ $17,77 / 15,17)$. An indeterminate fragment from 74 / 16 might represent the same ornament type from a small individual. CPC 37028 (Figure 37A) is the impression of a bone portion $100 \mathrm{~mm}$ long and 45 $\mathrm{mm}$ wide with one natural margin showing a slight selvage. The ornament of flat-topped ridges separated by pits and grooves is aligned along the longer preserved part. The external surface is smooth along the natural margin, and slightly concave, flaring outwards towards the nonpreserved ventral part as oriented in Figure 37A, as is typical in rhizodont cleithra (e.g. Johanson et al. 2000: fig. 3B). This specimen can be interpreted as the dorsal part of a left rhizodont cleithrum. It is not clear that the presumed dorsal margin is complete, but if it is, then the shape resembles that of Rhizodus (Andrews and Westoll 1970: pl. 6, 7) rather than Strepsodus, which is rounded dorsally (op. cit.: p. 461). A smooth inner flange sloping upwards and backwards is preserved as an impression inside the dorsal part of the anterior edge. This may be part of a postbranchial lamina. If correctly interpreted as a cleithrum, this example approaches Rhizodus in size (e.g. Andrews and Westoll 1970: pl. 6), and is much bigger than the cleithra attributed to Strepsodus from the Early Carboniferous of Queensland by Johanson et al. (2000).

CPC 37030 (Figure 37B) is an irregular fragment $(50 \times 110 \mathrm{~mm})$ with the same ornament, but no natural margins, on the same block as an incomplete Wuttagoonaspis skull roof. CPC 37027 is the broken end of another ornamented piece $60 \mathrm{~mm}$ wide, with bone $5 \mathrm{~mm}$ thick. The similar width of these fragments suggests that they also come from elongate ornamented elements, presumably cleithra, which in some large forms (e.g. rhizodontids) are relatively thick for their size, and consequently the only well-known remains. Associated with CPC 37030 is a large elongate bone, preserved in visceral view, with one thickened margin, identified as a possible gular plate (CPC 37029).
Two other specimens are provisionally included here. CPC 37032 (Figure 37D) is a large tusk about $40 \mathrm{~mm}$ long, with fine striations, and suggestions of folding near the base. Only the large ornamented impressions just described came from a fish of sufficient size to have had such large teeth, which are comparable in size to those of Eusthenodon or Notorhizodon (Jarvik 1952; Young et al. 1992). The second specimen (CPC 37031), from a much smaller individual, is the ventral portion of a left clavicle, with a ventral lamina some $65 \mathrm{~mm}$ long. The mesial margin is complete, with a rounded anterior corner, and as far as preserved the shape is similar to the rhizodont clavicle assigned to Notorhizodon by Young et al. (1992: fig. 40), recently renamed Aztecia mahalae by Johanson and Ahlberg (2001). The external surface of the ventral lamina shows an ornament of deep pits and short grooves similar to that on another Antarctic rhizodontid specimen (Young et al. 1992: fig. 43B). About half of the preserved width forms a mesial smooth zone, covered with very fine tuberculation. If correctly referred to the Rhizodontida, this specimen possibly belongs to a different taxon to the larger impressions included above.

\section{Order Porolepiformes Jarvik, 1942}

?porolepiform gen. et sp. indet. Figures 37C, 38C, E, G-J, 39-41, 42A-C rhipidistian fragments: Young 1991a: 67 (pars)

\section{Material \\ CPC 37033-41; ANU V2974.}

\section{Localities and Horizon}

74/11, 15 (northwestern part of the Dulcie Syncline, in the Dulcie Sandstone); 77/4, 17, 19, (Cravens Peak Beds). For localities see Figure 1. A locality summary for each taxon is given in Table 1 , and locality details for each specimen are listed in the Appendix.

\section{Remarks}

Apart from the large impressions just described, and a few onychodontid specimens described below, the remaining sarcopterygian material all comes from individuals in a similar size range. Most are indeterminate fragments, but there are a few indications that a porolepiform is represented in the material. The specimens are provisionally grouped together for the purpose of description.

\section{Description}

CPC 37040 (Figure 38C) is the impression of the inner surface of a left cheek unit $115 \mathrm{~mm}$ long and $73 \mathrm{~mm}$ high, with a broken anterior margin. A separate elongate bone impression is superimposed 

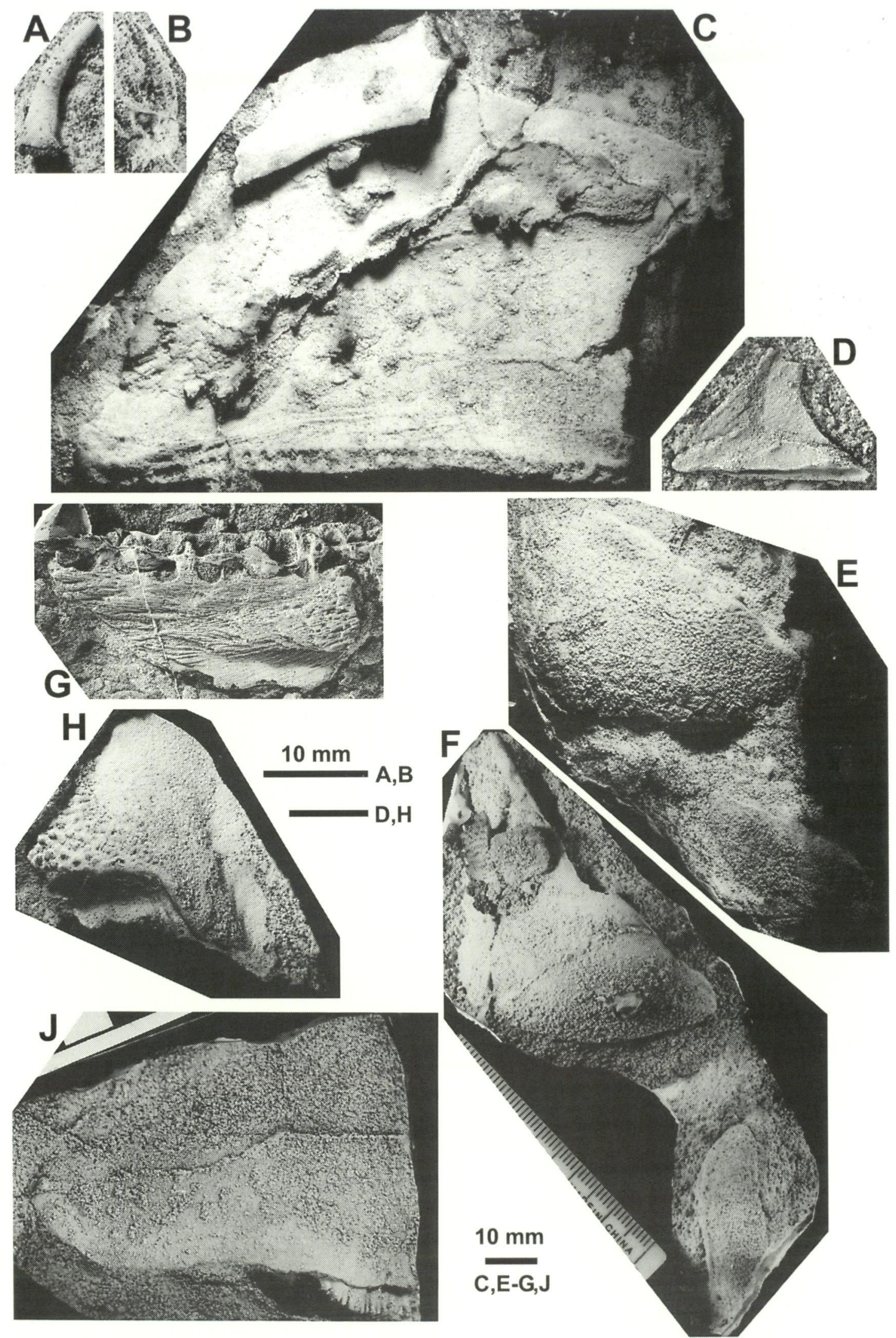

Figure $38 \mathrm{~A}, \mathrm{~B}, \mathrm{D}, \mathrm{F}$, onychodontid gen. et sp. indet. A,B, parasymphysial tooth (CPC 37044) in left and right views (part and counterpart); D, CPC 37042, a possible right clavicle (incomplete; inner view), F, CPC 37045, a right cleithrum and associated left element in external view. C, E, G-J, ?porolepiform gen. et sp. indet. C,E, left cheek unit (CPC 37040) in internal (C) and external (E) views; G, jaw element, internal view (CPC 37035); $\mathrm{H}$, incomplete left clavicle, ventral view (CPC 37037); J, presumed shoulder girdle element, incomplete outer surface (CPC 37038). All specimens are latex rubber casts whitened with ammonium chloride. 
inside its dorsal margin. Part of the external surface is preserved on the counterpart, which includes another associated bone impression lying beneath the jaw margin (Figure 38E). The external surface is not well preserved, but was apparently ornamented rather than smooth, suggesting that this form lacked cosmine on the dermal bones. The unit has both dorsoventral and longitudinal curvature, and its ventral margin carries a single row of tooth sockets extending almost to the posterior corner, an unusual condition suggesting the posteriorly extended maxilla of onychodontids or actinopterygians. However, with the possible exception of the Middle Devonian Grossius (Schultze 1973), the maxilla of onychodontids typically shows a marked downward inflection posteriorly (e.g. Jessen 1966: fig. 13; Long 2001), whereas the maxilla in this specimen is almost straight. A presumed suture runs back from the broken anterior edge to define its dorsal margin, indicating a long low element (Mx, Figure 39), perhaps most similar in shape to porolepiforms (e.g. Jarvik 1972: fig. 63; Schultze 2000: fig. 3). Posteriorly the inner surface of the maxilla becomes more convex, and a notch in the ventral margin behind the most posterior tooth socket may define its contact with another small bone (?quadratojugal) which forms the posterior corner of the cheek unit. Poorly defined sutures suggest an anterior splint of this bone running forward inside the posterior end of the tooth row (Qj, Figure 39A). This small bone has a more thickened rugose inner surface, with a ventral cup-

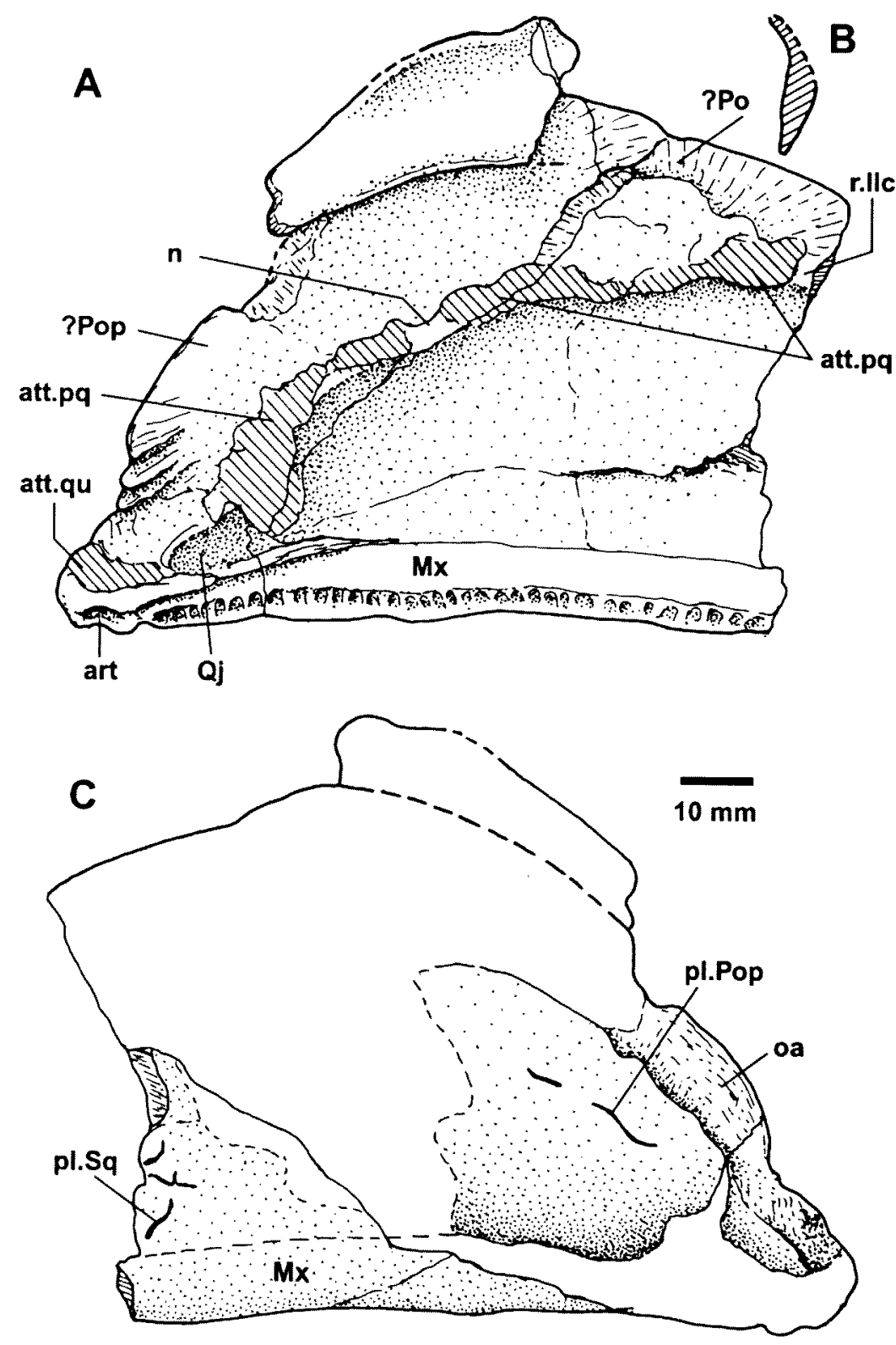

Figure 39 ?Porolepiform gen. et sp. indet., left cheek unit, CPC 37040 (cf. Figure 38C,E). A, inner view; B, section through anterior end of associated dorsal element (lateral side to right); $C$, preserved parts of external surface. 
shaped depression (art) suggesting either a small articulation associated with the mandibular joint, or perhaps an opening for a sensory tube, as illustrated for example in Gogonasus (Long et al. 1997b). The counterpart (Figure 38E) shows the complete upper margin of the quadratojugal to be flattened as a broad unornamented surface above and in front of the rounded posterior corner. No external suture could be discerned, but it may be obscured by a large fracture crossing the specimen (Figure 39C), assuming that the bone was smaller externally than internally. The quadratojugal is extensively overlapped by surrounding bones in some forms (e.g. Jarvik 1944a: fig. 9; Gardiner 1984: fig. 63), although in porolepiforms it may be a larger bone (e.g. Cloutier and Schultze 1996).

Above the quadratojugal the posterodorsal margin has a convex flange with shallow notches at either end, and growth striations indicating another bone (?Pop, Figure 39A). Both surfaces of this flange are preserved, the smooth outer surface indicating loose overlap by another bone (oa, Figure 39B). Its shape is reminiscent of the preopercular in Porolepis (Jarvik 1972: pl. 6, fig. 1), but in that form evidently the opercular and subopercular were overlapped by the preopercular, whereas it seems to be the reverse in this specimen. The counterpart shows an irregular but apparently natural dorsal margin to this bone, with an intermittent groove suggesting a pitline (pl.Pop). No pitlines are shown on the preopercular of porolepiforms (Jarvik 1972, figs 4344 ), but there is one on the preopercular of Eusthenopteron (Jarvik 1944a: fig. 9) and Mimia (Gardiner 1984: fig. 63), so this might be the primitive osteichthyan condition.

Other sutures suggested for the inner surface are very uncertain. The anterodorsal corner of the specimen might be natural, and radiating texture suggests a separate bone extending back to a slight notch in the dorsal margin (?Po, Figure 39A). Assuming that the straight horizontal suture of the maxilla is correctly identified, another bone above it might be indicated by a broken notch in the anterior edge (Figure $38 \mathrm{C}$ ). This could be a fracture, but the anterior edge suggests that the upper bone was overlapped by the lower at this point. The lower bone was evidently also slightly overlapped by the maxilla. Since the outer surface is a continuous uninterrupted curve on the broken edge, neither junction is considered to be a fracture. On the external surface just behind the broken edge there are several short grooves (pl.Sq, Figure 39C), possibly pitlines indicating, by comparison with Porolepis (e.g. Jarvik, 1972: fig. 43C), that this may be a lower or subsquamosal (?Ssq, Figure 42A). Possibly there is another bone behind (?Sq1), and a larger element (Sq2) making up the remainder of the cheek unit. An irregularly preserved ridge curving across the inner surface (r.llc) is assumed to indicate the position of the sensory canal passing through the cheek unit. Superimposed on the ridge are several roughened areas that are interpreted as attachments for the palatoquadrate (att.pq, Figure 39A). An expanded thickening underlies the presumed postorbital bone, and a distinct notch (n) might correspond to the opening above the quadrate attachment for passage of the $r$. mandibularis externus in arthrodires (e.g. Young 1979: fig. 14). Alternatively this nerve could have passed immediately above the quadrate ossification, which in CPC 37040 evidently had an attachment to the inside of the quadratojugal (the roughened area; att.qu) which was separate from the attachment on the presumed preopercular. The concave surface above this attachment shows no sign of the ridge for the sensory canal, which could have passed posteriorly through the preopercular as in Porolepis, rather than through the quadratojugal (the evidence is equivocal on this point). Although the palatoquadrate may be firmly attached to the outer dermal cheek bones in primitive actinopterygians (e.g. Gardiner 1984: 283), this is not the case in the osteolepid Gogonasus, where in acid prepared material it comes away as a completely separate element (Long et al. 1997b). An extensive attachment area inside the dermal cheek as described above seems not to be otherwise documented for sarcopterygians, and may be a primitive feature.

Of the two bones associated with this cheek unit, that inside the dorsal margin is clearly not a hyomandibula, since it has a flat inner and rounded outer surface (Figure 39B). Its notched posterior end might be natural, but it is broken anteriorly. It was an elongate dermal bone, possibly sitting outside the hyomandibula as does the dermohyal in basal actinopterygians. If not much displaced, it must have filled a gap between the cheek unit and the skull roof, its bevelled ventral margin clearly showing that it was loosely overlapped by the cheek unit. The postspiracular of Eusthenopteron, prespiracular of Porolepis (e.g. Jarvik 1972: fig. 63A), or opercular and prespiracular of onychodontids, might be potential homologues.

The ventral bone in the counterpart (Figure 38E) shows a longitudinal ornament of meandering ridges and grooves, an overlap area along one side, and a notched anterior margin. Judging by the poorly preserved posterior end projecting from beneath the maxilla it was a somewhat ovate bone 65-70 mm long (Figure 42C). The inner surface of the anterior end shows a thickened ridge on one side (th, Figure 42B), similar to that illustrated by Young and Gorter (1981: pl. 9, fig. 11) in an osteolepid gular plate. This specimen is therefore identified as a left principal gular, with the anterior notch (n) for a median gular, a bone supposedly absent in porolepiforms (Jarvik 1972: 131), although 
apparently lost within the group (present in Porolepis; Jarvik 1980: fig. 187C). The overlap surface on the median margin (oaGu) must have been for the right gular, as for example in the porolepiform Laccognathus (Vorobyeva 1980: fig. 6).

The cheek unit of CPC 37040 is difficult to interpret due to lack of information, and its affinities are uncertain, but the interpreted bone pattern (Figure 42A) shows several interesting and unusual characteristics. The posterior extension of the tooth row on the maxilla is reminiscent of some onychodontids and actinopterygians, but in the former group the quadratojugal is missing (Jessen 1966; Long 2001). If the postorbital is correctly interpreted as a separate bone (?Po, Figure 39A), then the jugal sensory canal (a defining sarcopterygian feature according to $\mathrm{Zhu}$ and Schultze 2001) has a different course to that previously described, passing from the squamosal directly to the postorbital, rather than turning down into the jugal. The palatoquadrate attachment is also an unusual feature. The presence of subsquamosals has been proposed as a synapomorphy of porolepiforms (Cloutier and Schultze 1996: 267), and in Porolepis the maxilla is also long and low, although the quadratojugal is a larger bone than restored here (e.g. Jarvik 1972: fig. 43C), and there are other differences as noted above. In addition Porolepis was a cosmine-covered form. However Nasogaluakus Schultze, 2000 is an Early Devonian porolepiform interpreted as a basal holoptychiid, with delicately ornamented dermal bones (Schultze 2000). Taxonomic assignment of CPC 37040 remains very uncertain until better material is found.

Other impressions of fragmentary isolated teeth or jaw portions provide much less information. CPC 37039 is a poorly preserved marginal tooth row on a bone about $25 \mathrm{~mm}$ deep and $50 \mathrm{~mm}$ long, with a concave inner surface. The external surface is too

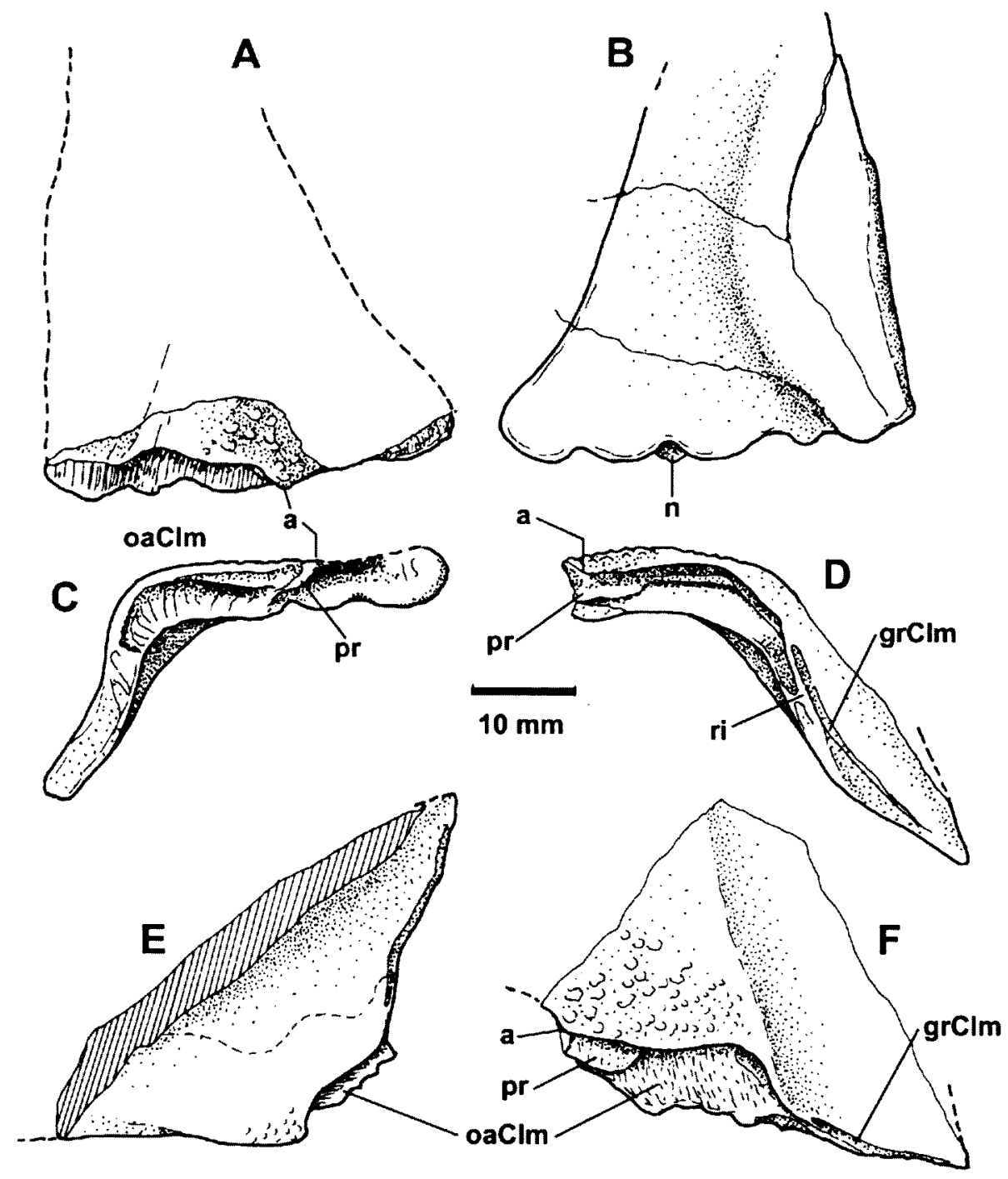

Figure 40 ?Porolepiform gen. et sp. indet., clavicles. A-C, right clavicle (CPC 37034) in ventral (A), dorsal (B) and posterior (C) views. D-F, left clavicle (CPC 37037) in posterior (D), left lateral (E) and ventral (F) views (C,D inverted, with dorsal edge toward bottom of page). 
poorly preserved to show details of ornament. CPC 37035 (Figure 38G) shows possibly two rows of teeth. It cannot be interpreted as an onychodontid, because the teeth show signs of complex folding, so it is provisionally referred to the porolepiform. The counterpart shows an area of fine tuberculate ornament indicating that it was one of the bones lining the inside of the mouth, perhaps a dermopalatine or entopterygoid, or the infradentary from the lower jaw. CPC 37036 is a poor impression of an outer surface showing three teeth along its margin. CPC 37033 is the impression of a short stout slightly curved tooth $10 \mathrm{~mm}$ long with a round basal section $5 \mathrm{~mm}$ across, also showing characteristic infolding. CPC 37041 is a possible gular preserved in part and counterpart, which lacks ornament (?cosmine covered). It compares with the gular of Porolepis spp. figured by Jarvik (1972: pl. 13, fig. 2)

Remaining specimens all come from the shoulder girdle. CPC 37034 (Figure 40A-C) and CPC 37037 (Figure 38H, 40D-F) represent incomplete impressions of the same bone (clavicle), but from left and right sides (Figure 41). They are described together from two widely separated localities, since their similar morphology indicates that they come from the same species of fish. The two individuals were of similar size; a slight angle on the mesial side of the posterior margin (a, Figure 40) is $12 \mathrm{~mm}$ from the ventrolateral angle in CPC 37034, and 15 $\mathrm{mm}$ in CPC 37037. Both examples have a flat to slightly concave ventral lamina, with scattered tubercles on its outer surface (Figure $38 \mathrm{H}$ ). The smooth, concave lateral lamina (external surface not preserved in CPC 37034), encloses an angle of 115$120^{\circ}$. The ventral lamina is gently arched rostrocaudally in the more completely preserved
CPC 37034 (anterior margin incomplete). In CPC 37037 the incomplete lateral lamina is much more extensive; its dorsal edge is apparently broken except possibly for the most dorsal part (Figure 40E). A faint suture on internal and external surfaces, and around the posterior margin, has an equivalent position to the apparently complete upper edge of the lateral lamina in CPC 37034. This might indicate a separate lateral ossification of the clavicle.

The well preserved posterior margin in both specimens shows a deep overlap surface (oaClm), which also extends up the lateral lamina (ascending process). The overlap area is undercut, particularly around the ventrolateral angle, so that there was an interlocking arrangement with the cleithrum, essentially as illustrated for Glyptolepis by Jarvik (1944b: fig. 9A,C,D). Both specimens show an internal notch about midway along the posterior margin of the ventral lamina (n), where a small process of the cleithrum must have inserted, beneath the angle on the external margin (a). There is an additional internal process (pr; larger on CPC 37037), which formed a double insertion at this point. On the mesial side of the notch in CPC 37034 (not preserved in CPC 37037) the posterior edge carries a groove for contact with the cleithrum, but still with greater overlap of the cleithrum onto the clavicle. The overlap for the cleithrum continues up the lateral lamina in CPC 37034, but is less extensive (possibly incomplete) in CPC 37037, with a distinct narrow groove on the external surface just inside the posterior margin ( $\mathrm{grClm}$ ). This shows that the cleithrum also slightly overlapped the clavicle for a short section of the margin, with an intervening ridge (ri, Figure 40D) contained within a groove on the anterior border of the cleithrum. Otherwise the
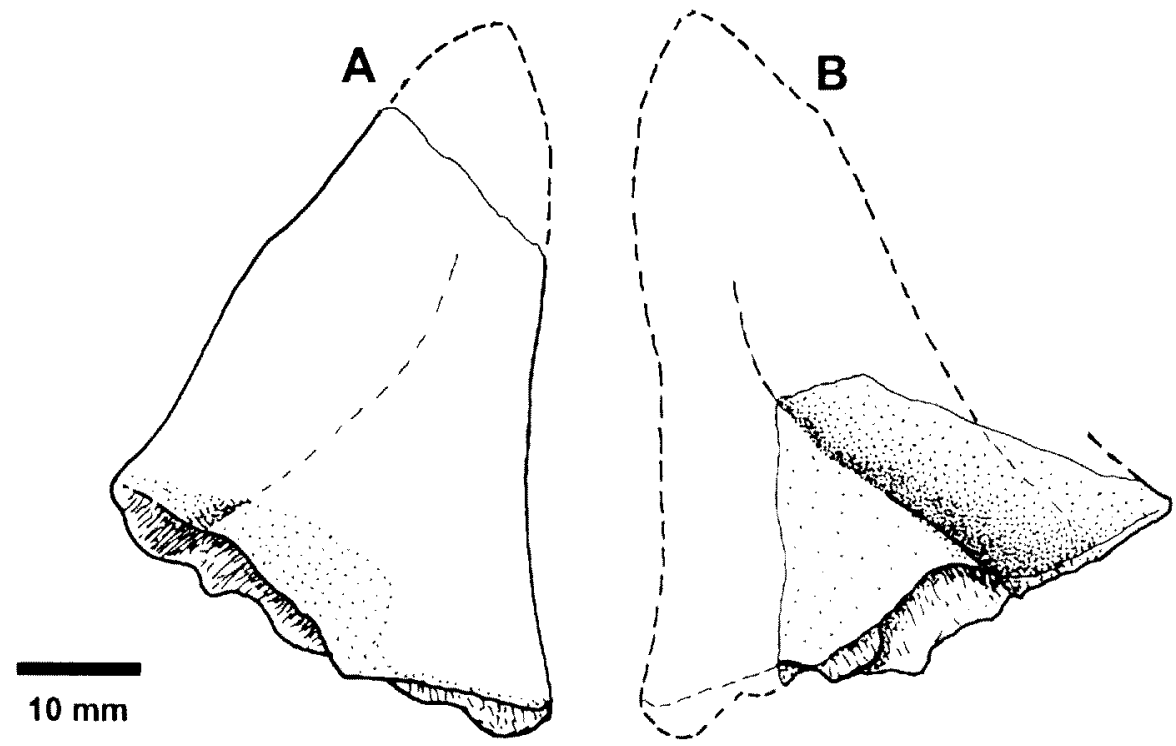

Figure 41 ?Porolepiform gen. et sp. indet., ventral reconstruction of left and right clavicles. A, after CPC 37034; B, after CPC 37037 (slightly reduced). 
lateral ascending process of the clavicle was clearly external with respect to the cleithrum. There is no sign of an inflected upper margin, considered to characterise rhizodontids (e.g. Janvier et al. 1984: fig. 9B1,2). Andrews and Westoll (1970: 438) contrasted the internal unornamented dorsal process in osteolepids and porolepids (Eusthenopteron, Megalichthys, Glyptolepis) to the condition in rhizodontids, where it overlapped the cleithrum. They suggested that the dorsal structure in rhizodontids was not homologous to the dorsal (ascending) process of the clavicle in Eusthenopteron, but it is more likely that the same structure is differently developed in various sarcopterygian groups. The specimens described here show that the cleithrum overlapped the clavicle ventrally, supposedly the reverse of the situation in tristichopterids, as exemplified by Eusthenopteron (Jarvik 1944b; Andrews and Westoll 1970). Andrews and Westoll (1970: 407, 469) considered the difference between Eusthenopteron and Glyptolepis to be one of degree rather than kind, but in contrast they argued that the reverse overlap between cleithrum and clavicle in rhizodontids was of significance (op. cit.: 438). In Gogonasus the clavicle overlaps the cleithrum ventrally (Long et al. 1997b: 41), and a similar situation occurs in the Gogo onychodontid (e.g. ANU V2975; K.S.W. Campbell, pers. comm.). The internal position of the ascending lamina in osteolepiforms (e.g. Cladarosymblema; Fox et al. 1996: fig. 61) is clearly different from the condition described here.

Two other incomplete specimens from the shoulder girdle are rather different, and may not belong to the same taxon. CPC 37038 (Figure 38J) is a larger impression some $80 \mathrm{~mm}$ across, with a smooth external surface, folded $\left(130^{\circ}\right)$ into two laminae. The only preserved margin of the smaller (?ventral) lamina has an overlap surface, incomplete mesially, with a serrated tooth-like posterior edge. ANU V2974 (Figure 37C) is a much bigger example (at least $130 \mathrm{~mm}$ across) with similar curvature, and the inner surface of the only preserved margin showing irregular striations similar to those on the cleithrum named Grenfellia by Johanson and Ritchie (2000: figs. 3A-B, 4), which comes from the Upper Devonian of NSW. This could therefore be a posterior margin from the left side of the shoulder girdle, which overlapped the scales of the body. The outer surface and dermal ornament are unknown.

\section{Osteichthyes incertae sedis}

\section{Subclass Struniiformes Jessen, 1966}

Family Onychodontidae Woodward, 1891

\section{Remarks}

This group (subclass Onychodontia of Andrews
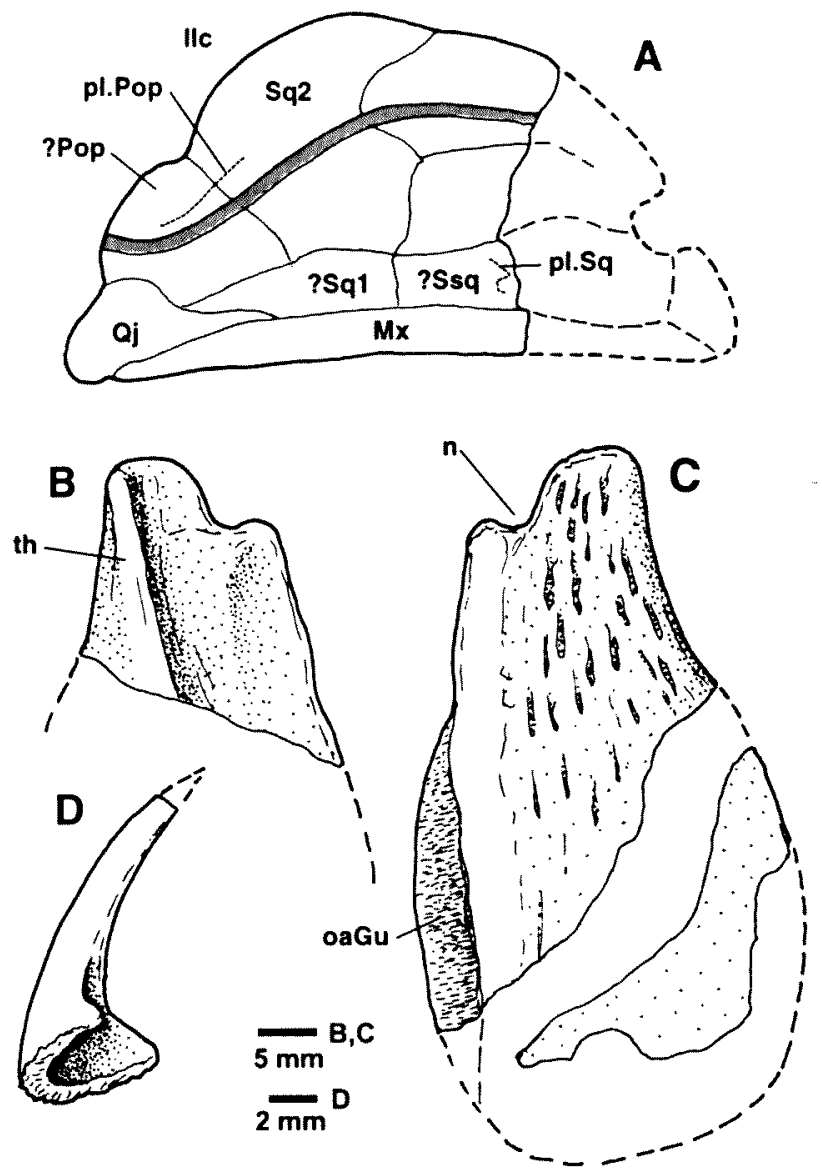

Figure $42 \mathrm{~A}-\mathrm{C}$, ?porolepiform gen. et sp. indet. A, attempted reconstruction of bone and sensory canal pattern of the cheek, right side, based on CPC 37040; B,C, left principal gular associated in CPC 37040 , showing preserved internal (B) and external (C) surfaces. D, onychodontid gen. et sp. indet., parasymphysial tooth (cf. Figure 38A) represented in ventrolateral and slightly posterior view to show two-pronged base and posterior concavity (CPC 37044).

and Westoll 1970) is of uncertain phylogenetic position, variously considered as the sister group to all other osteichthyans, to actinistians, or to other sarcopterygians (e.g. Zhu and Schultze 2001: fig. 17.1). Long (2001) has suggested a close relationship to Psarolepis from China, which has been interpreted as a basal osteichthyan (Zhu et al. 1999), or as a basal sarcopterygian (Basden et al. 2000, Basden and Young 2001).

onychodontid gen. et sp. indet.

Figures 38A, B, D, F, 42D

onychodontid ... fragments: Young 1991a: 67

onychodontid indet.: Young et al. 1993: 247

\section{Material}

CPC 37042-045. 
Localities and Horizon

$74 / 11$ (southern limb of the Dulcie Syncline, in the Dulcie Sandstone); 77/2, 3 (Cravens Peak Beds). For localities see Figure 1. A locality summary for each taxon is given in Table 1, and locality details for each specimen are listed in the Appendix.

\section{Description}

CPC 37044 (Figure 38A, B) is a curved parasymphysial tooth of an onychodontid, $14 \mathrm{~mm}$ long and thus larger than Strunius, but smaller than those of Onychodus figured by Jessen (1966: pls 17, $19,20)$. Characteristic of the group is the twopronged base, and posterior concavity (Figure 42D), just as figured by Gross (1965b: fig. 1d-e). This tooth lacks the reverse hook of some Onychodus species (e.g. Jessen 1966; Upeniece 1995), and the surface is smooth, without the fine enamel striations said to characterise the group (e.g. Janvier 1996: 198). Comparisons with the tooth whorls of acidprepared 'Onychodus' material from the Frasnian Gogo fish fauna of W.A. (e.g. ANU V2976, 2978) suggest that the teeth of that form differ in having a more pronounced anterior projection at the tooth base.

Although a smaller onychodontid is known from the associated calcareous beds (Young 1984: 66), this tooth is the only definite evidence for the presence of the group in the sandstones of the Cravens Peak Beds. However a few other specimens are provisionally assigned to the group. CPC 37042 (Figure 38D) is an impression which compares with the inner view of the clavicle of Strunius illustrated by Jessen (1966: pl. 8, fig. 1). It is missing the dorsal part, and may be incomplete posteriorly, so its shape is uncertain. CPC 37045 (Figure 38F) shows impressions of left and right elements of a shoulder girdle; that from the right side is almost complete. It can be interpreted as a right cleithrum with a narrow dorsal margin, a feature of the cleithrum of onychodontids, actinistians, actinopterygians (Cloutier 1996: fig. 14) and Psarolepis, which might therefore be primitive (Long 2001: 817). Direct comparison with the shoulder girdle of a Gogo 'Onychodus' (ANU V2976) shows that CPC 37045 is broader, with a more rounded posterior margin which lacks the sharp posterior angle, and has a less elongate ventral lamina than illustrated by Long (2001: fig. 1). There is no sign of a contact face for the ascending process of the clavicle, which in some Gogo material abutts against a broad anterior edge of the cleithrum (K.S.W. Campbell, pers. comm.; cf. the reconstruction of Long 2001). Ventrally the clavicle also overlaps the cleithrum, but again there is no evidence of an overlap in this specimen (Figure 38F). If correctly interpreted as an onychodontid, this specimen indicates that a new taxon is probably represented in the Cravens Peak fauna.

\section{ACKNOWLEDGEMENTS}

Peter Davis, Ray Tracey, Graham Menisky, Stuart Roach and Ian Steptoe provided assistance with field-work, and John Draper is thanked for providing details on some fossil localities, outcrop and stratigraphy of the Cravens Peak Beds, and field collaboration. The hospitality of various landowners, including Lindsay Johannsen and family (Baikal Station), and John and Audrey Turner (Jinka Station), is gratefully acknowledged. P.J. Jones provided locality advice on early collections of thelodonts from the Toko Range area, and other information on field localities and Georgina Basin geology was given by J.H. Shergold, and E.C. Druce. P. Kruse provided copies of recent geological maps, and other helpful information. $M$. Freeman, N. Donellan and D. Morris advised on other fish localities noted by the NTGS.

R. W. Brown, H.M. Doyle, and W. Peters (AGSO) assisted with latex casting and photography. Special mention is made of H.M (Mike) Doyle, who managed and undertook the preparation and latex casting of the entire collection from the Dulcie Sandstone and Cravens Peak Beds. R.E. Barwick, E. Siebert, J. Caton and B. Harrold and are thanked for help with scanning and computer preparation of illustrations. A. Haupt provided translations of German texts.

Dr A. Ritchie provided unpublished information and casts for comparison from the extensive fish collection from the Mulga Downs Group in the Australian Museum. Prof. K. Campbell discussed the sarcopterygian material, made available Gogo specimens for comparison, and kindly read through and made helpful suggestions on the manuscript. Dr C. Burrow discussed the acanthodian spines, and provided illustrations of Bulbocanthus spines. Dr E. Mark-Kurik provided information and photographs of related material from Severnaya Zemlya. Other colleagues who provided opinions and advice on the material included P. Ahlberg, A. Ivanov, P. Janvier, Z. Johanson, H. Lelièvre, J. Long, M. Otto, H.-P. Schultze, and E. Vorobjeva. We acknowledge their collective contribution. Dr John Long read through the manuscript and made many helpful suggestions.

E. Resiak and J. Laurie (AGSO) provided access to the Georgina Basin palaeontological collections, and located material rendered obscure in the move to the new AGSO building. Margaret Drury helped with early air photos of the Georgina Basin in the AGSO library. Ben Young assisted with sorting of latex casts and matching to original specimens, prepared Excel spreadsheets of all specimens, and gave other general assistance. Louisa Young helped with whitening and photography of specimens. Stuart Duncan (NT Place Names Committee) provided information on the Aboriginal word Tnorala, and Bob Carr provided digital images of two specimens. 
This research was a contribution to IGCP Projects 328, 406 and 410. Financial support was provided by ANU Faculties Research Fund Grant F00108, and Professor D. Ellis and Dr P. De Deckker are thanked for provision of facilities in the Geology Dept., ANU (GCY). The comparative study of this collection commenced during a visiting professorship for GCY at the Muséum National d'Histoire Naturelle during 1999, and provision of facilities and technical assistance is gratefully acknowledged. Finally, GCY acknowledges the support of the Alexander von Humboldt Foundation, and provision of facilities in the Museum für Naturkunde, Berlin (Prof. H.-P. Schultze), during the tenure of a Humboldt Award (2000-2001).

\section{REFERENCES}

Alder, J.D., Bembrick, C., Hartung-Kagi, B., Mullard, B., Pratt, D.A., Scott, J. and Shaw, R.D. (1998). A reassessment of the petroleum potential of the Darling Basin: a Discovery 2000 initiative. APPEA Journal, 1998: $278-310$.

Allen, G.R. (1989). Freshwater fishes of Australia. T.F.H. Publications, 240 pp.

Allen, G.R., Midgley, S.H. and Allen, M. (2002). Field guide to the freshwater fishes of Australia. Western Australian Museum, Perth, W.A. 394 pp.

Andrews, S.M. and Westoll, T.S. (1970). The postcranial skeleton of rhipidistian fishes excluding Eusthenopteron. Transactions of the Royal Society of Edinburgh, 68: 391-489.

Basden, A.M., Young, G.C., Coates, M.I. and Ritchie, A. (2000). The most primitive osteichthyan braincase? Nature 403: 185-188.

Basden, A.M. and Young, G.C. (2001). A primitive actinopterygian neurocranium from the Early Devonian of southeastern Australia. Journal of Vertebrate Paleontology, 21: 754-766.

Bembrick, C. (1997). A re-appraisal of the Darling Basin Devonian sequence. Geological Survey of NSW, Quarterly Notes 105: 1-16.

Bjerstedt, T.W. (1987). Latest Devonian-earliest Mississippian nearshore trace-fossil assemblages from West Virginia, Pennsylvania, and Maryland. Journal of Paleontology 61: 865-889.

Blieck, A. \& Cloutier, R. (2000). Biostratigraphical correlations of Early Devonian vertebrate assemblages of the Old Red Sandstone Continent. Courier Forschungsinstitut Senckenberg 223: 223-269.

Blieck, A., Goujet, D. and Janvier, P. (1987). The vertebrate stratigraphy of the Lower Devonian (Red Bay Group and Wood Bay Formation) of Spitsbergen. Modern Geology, 11: 197-217.

Boreham, C.J., Hope, J.M. and Roksandic, Z. (1997): Multiple filling history in the Gilmore gas field, Adavale Basin, central Queensland. AGSO Research Newsletter 27: 8-10.

Bryant, W.L. (1932). Lower Devonian fishes of Bear Tooth Butte, Wyoming. Proceedings of the American Philosophical Society 71: 224-254.
Bryant, W.L. (1934). The fish fauna of Beartooth Butte, Wyoming. Parts II and III. Proceedings of the American Philosophical Society 73: 127-167.

Burrow, C.T. and Young, G.C. (in prep.) The acanthodian fauna from the Cravens Peak Beds (Early to Middle Devonian), western Queensland.

Capetta, H., Duffin, C. and Zidek, J. (1994). Chondrichthyes. In: Benton, M.J. (ed.), The Fossil Record 2: 593-609. Chapman \& Hall, London.

Cloutier, R. (1996). The primitive actinistian Miguashaia bureaui Schultze (Sarcopterygii). In: Schultze, H.-P. and Cloutier, R. (eds), Devonian fishes and plants of Miguasha, Quebec, Canada: 227-247, Verlag Dr Friedrich Pfeil, Munich.

Cloutier, R. and Ahlberg, P.E. (1996). Morphology, characters, and the interrelationships of basal sarcopterygians. In: Stiassny, M.L.J., Parenti, L.R. and Johnson, G.D. (eds) Interrelationships of Fishes: 445479, Academic Press, San Diego.

Cloutier, R. and Schultze, H.-P. (1996). Porolepiform fishes (Sarcopterygii). In: Schultze, H.-P. and Cloutier, R. (eds), Devonian fishes and plants of Miguasha, Quebec, Canada: 248-270, Verlag Dr Friedrich Pfeil, Munich.

Cooper, R. (1964). Etude géologique de la partie sud du Bassin de Georgina. French Petroleum Company (Australia) Pty Ltd. Geologie Operationelle R.G. 304.

Davis, M.C., Shubin, N.H. and Daeschler, E.B. (2001). Immature rhizodontids from the Devonian of North America. Bulletin of the Museum of Comparative Zoology 156: 171-187.

Daeschler, E.B., Frumes, A.C. and Mullison, C.F. (in press). Groenlandaspid placoderm fishes from the Devonian of North America. Records of the Australian Museum. in press.

Denison, R.H. (1958). Early Devonian fishes from Utah. Part III. Arthrodira. Fieldiana Geology 11: 357-458.

Denison, R.H. (1978). Placodermi. In: Schultze, H.-P. (ed.), Handbook of Paleoichthyology, volume 2, $128 \mathrm{pp}$. Gustav Fischer Verlag, Stuttgart.

Denison, R.H. (1979). Acanthodii. In: Schultze, H.-P. (ed.), Handbook of Paleoichthyology, volume 5, 62 pp. Gustav Fischer Verlag, Stuttgart.

Denison, R.H. (1984). Further consideration of the phylogeny and classification of the order Arthrodira (Pisces: Placodermi). Journal of Vertebrate Paleontology 4: $396-412$.

Dennis, K.D. and Miles, R.S. (1979). Eubrachythoracid arthrodires with tubular rostral plates from Gogo, Western Australia. Zoological Journal of the Linnean Society 67: 297-328.

Draper, J.J. (1976). The Devonian rocks of the Toko Syncline, western Queensland. Bureau of Mineral Resources, Australia, Record 1976/29, 16 pp.

Elliott, D.K. and Ilyes, R.R. (1996). Lower Devonian vertebrate biostratigraphy of the western United States. Modern Geology 20: 253-262.

Elliott, D.K. and Johnson, G. (1997). Use of vertebrates to solve biostratigraphic problems: examples from the Lower and Middle Devonian of western North America. Geological Society of America, Special Paper 321: 179-188.

Fletcher, H.O. (1964). New linguloid shells from the 
Lower Ordovician and Middle Palaeozoic rocks of New South Wales. Records of the Australian Museum 26: 283-294.

Fowler, H.W. (1947). New taxonomic names of fish-like vertebrates. Notulae naturae. Academy of Natural Sciences of Philadelphia 187: 1-16.

Fox, R.C., Campbell, K.S.W., Barwick, R.E. and Long, J.A. (1995). A new osteolepiform fish from the Lower Carboniferous Raymond Formation, Drummond Basin, Queensland. Memoirs of the Queensland Museum 38: $97-221$.

Freeman, M.J. (1986). Huckitta SF53-11. 1:250000 Geological Map Series. Explanatory Notes. Northern Territory Geological Survey, $58 \mathrm{pp}$.

Frey, R.W. (1978). Behavioral and ecological implications of trace fossils. Society of Economic Paleontologists and Mineralogists, Oklahoma City: Short Course 5: 133-183.

Gardiner, B.G. (1984). The relationships of the palaeoniscid fishes, a review based on new specimens of Mimia and Moythomasia from the Upper Devonian of Western Australia. British Museum (Natural History) Bulletin (Geology) 37: 173-427.

Gilbert-Tomlinson, J. (1968). A new record of Bothriolepis in the Northern Territory of Australia. Bureau of Mineral Resources, Australia, Bulletin 80: 191-224.

Glen, R.A. (1987). Geology of the Wrightville 1:100,000 sheet 8034. Geological Survey of NSW, 1-257 pp.

Glen, R.A., Powell, C.McA. and Khaiami, R. (1987). Devonian to ?Carboniferous sedimentary rocks. In: Glen, R.A. (1987), Geology of the Wrightwille 1:100,000 sheet 8034: 149-252, Geological Survey of NSW.

Glen, R.A. Dallmeyer, R.D. and Black, L.P. (1992). Isotopic dating of basin inversion - the Palaeozoic Cobar Basin, Lachlan Orogen, Australia. Tectonophysics 214: 249-268.

Goujet, D. (1984a). Les poissons placodermes du Spitsberg. Cahiers de Paléontologie, Section Vertébrés, CNRS, Paris, 284 pp, 30 pl.

Goujet, D. (1984b). Placoderm interrelationships: a new interpretation, with a short review of placoderm classifications. Proceedings of the Linnean Society of New South Wales 107: 211-243.

Goujet, D. and Young, G.C. (1995). Interrelationships of placoderms revisited. Geobios, Memoire special 19: 89. 96.

Gross, W. (1933). Die unterdevonischen Fische und Gigantostraken von Overath. Abhandlungen der Preussischen geologischen Landesanstalt 145: 41-77.

Gross, W. (1962). Neuuntersuchung der Dolichothoraci aus dem Unterdevon von Overath bei Koln. Palaontologischen Zeitschrift, H. Schmidt-Festband: 4563.

Gross, W. (1965a). Uber die Placodermen-Gattungen Asterolepis und Tiaraspis aus dem Devon Belgiens und einen fraglichen Tiaraspis-Rest aus dem Devon Spitzbergens. Institut royal des Sciences naturelles de Belgique, Bulletin 41: 1-19.

Gross, W. (1965b). Onychodus jaekeli Gross (Crossopterygii, Oberdevon), Baudes Symphysenknockens und siener Zähne. Senckenbergiana Lethaiea. 46a: 123-131.

Gross, W. (1971). Unter devonische Thelodontier- und
Acanthodier- Schuppen aus Westaustralien. Palaontologischen Zeitschrift 45: 97-106.

Haines, P.W., Bagas, L., Wyche, S., Simons, B. and Morris, D.G. (1991). Barrow Creek SF53-6. 1:250 000 Geological Map Series Explanatory Notes. Northern Territory Geological Survey, Darwin, $53 \mathrm{pp}$.

Heintz, A. (1929a). Die downtonischen und devonischen Vertebraten von Spitzbergen II. Acanthaspida. Skrifter om Svalbard og Ishavet 22: 1-81.

Heintz, A. (1929b). Die downtonischen und devonischen Vertebraten von Spitzbergen III. Acanthaspida. Skrifter om Sualbard og Ishavet 23: 1-20.

Heintz, A. (1932). Beitrag zur Kentniss der devonischen fischfaunen Ost-Gronlands. Skrifter om Svalbard og Ishavet 42: 1-27.

Henderson, J. and Dobson, V. (1994). Eastern and Central Arrernte to English Dictionary. Institute for Aboriginal Development Press, Alice Springs.

Hills, E.S. (1959). Record of Bothriolepis and Phyllolepis (Upper Devonian) from the Northern Territory of Australia. Journal and Proceedings of the Royal Society of N.S.W. 92: 174-175.

Huxley, T.H. (1880). On the application of the laws of evolution to the arrangement of the Vertebrata and more particularly the Mammalia. Proceedings of the Zoological Society of London 1880: 649-662.

Jaekel, O. (1911). Die Wirbeltiere. Eine Ubersich uber die fossilen und lebende Formen. Berlin.

Janvier, P. (1996). Early Vertebrates. 393 pp. Clarendon Press, Oxford.

Janvier, P. and Ritchie, A. (1977). Le genre Groenlandaspis Heintz (Pisces, Placodermi, Arthrodira) dans le Dévonien d'Asie. Colloques Recherches Academie des Sciences de Paris, series D, 284: 1385-1388.

Janvier, P., Lethiers, F., Monod, O. and Balkas, O. (1984). Discovery of a vertebrate fauna at the Devonian-Carboniferous boundary in south-eastern Turkey (Hakkari Province). Journal of Petroleum Geology 7: 147-168.

Janvier, P. and Villarroel, C. (2000). Devonian vertebrates from Colombia. Palaeontology 43: 729-763.

Jarvik, E. (1942). On the structure of the snout of crossopterygians and lower gnathostomes in general. Zoologica Bidrag fran Uppsala 21: 235-675.

Jarvik, E. (1944a). On the dermal bones, sensory canals and pit- lines of the skull in Eusthenopteron foordi Whiteaves, with some remarks on E. save-soderberghi Jarvik. Kungliga svenska VetenskapAkademiens Handlingar, Stockholm, 3(21), 3: 1-48.

Jarvik, E. (1944b). On the exoskeletal shoulder-girdle of teleostomian fishes with special reference to Eusthenopteron foordi Whiteaves. Kungliga svenska VetenskapAkademiens Handlingar, Stockholm, 3(21), 7: 132

Jarvik, E. (1952). On the fish-like tail in the ichthyostegid stegocephalians with descriptions of a new stegocephalian and a new crossopterygian from the Upper Devonian of East Greenland. Meddelelser om Gronland 114: 1-90.

Jarvik, E. (1972). Middle and Upper Devonian Porolepiformes from East Greenland with special reference to Glyptolepis groenlandica n.sp. and a 
discussion of the structure of the head in Porolepiformes. Meddelelser om Gronland 187: 1-307.

Jarvik, E. (1980). Basic structure and evolution of vertebrates, Volumes 1 and 2. London: Academic Press. 575, 337 pp.

Jessen, H. (1966). Die Crossopterygier des Oberen Plattenkalkes (Devon) der Bergisch-Gladbach Paffrather Mulde (Rheinisches Schiefergebirge) unter Berucksichtigung von amerikanischem und europaischem Onychodus-Material. Arkiv for Zoologi 18: 305-389.

Johanson, Z. and Ahlberg, P.E. (1998). A complete primitive rhizodont from Australia. Nature 394: 569573.

Johanson, Z. and Ahlberg, P.E. (2001). Devonian rhizodontids and tristichopterids (Sarcopterygii; Tetrapodomorpha) from East Gondwana. Transactions of the Royal Society of Edinburgh: Earth Sciences 92: 4374.

Johanson, Z. and Ritchie, A. (2000). Rhipidistians (Sarcopterygii) from the Hunter Siltstone (Late Famennian) near Grenfell, NSW, Australia. Mitteilungen aus dem Museum für Naturkunde in Berlin, Geowissenschaftliche Reihe 3: 111-136.

Johanson, Z., Turner, S., and Warren, A. (2000). First East Gondwanan record of Strepsodus (Sarcopterygii, Rhizodontida) from the Lower Carboniferous Ducabrook Formation, central Queensland, Australia. Geodiversitas 22: 161-169.

Johnson, H.G., Elliott, D.K. and Wittke, J.H. (2000). A new actinolepid arthrodire (Class Placodermi) from the Lower Devonian Sevy Dolomite, East-Central Nevada. Zoological Journal of the Linnean Society of London 129: 241-266.

Johnstone, M.H., Jones, P.J., Koop, W.J., Roberts, J., Gilbert-Tomlinson, J. Veevers, J.J. and Wells, A.T. (1968). Devonian of Western and Central Australia. International Symposium on the Devonian System, Calgary 1967, 1: 599-612.

Lelièvre, H. (1995). Description of Maideria falipoui n.g., n. sp., a long snouted brachythoracid (Vertebrata, Placodermi, Arthrodira) from the Givetian of Maider (South Morocco), with a phylogenetic analysis of primitive brachythoracids. Bulletin du Muséum national d'Histoire naturelle, Paris 17: 163-207.

Lelièvre, H., Goujet, D. and Henn, A. (1990). Un nouveau spécimen d'Holonema radiatum (Placodermi, Arthrodira) du Dévonien moyen de la région d'Oviedo, Espagne. Bulletin du Muséum national d'Histoire naturelle, Paris 12: 53-83.

Liu Yu-Hai (1991). On a new petalichthyid, Eurycaraspis incilis gen. et sp. nov., (Placodermi, Pisces) from the Middle Devonian of Zhanyi, Yunnan. In: Chang, M.M., Liu, Y.H. and Zhang, G.R. (editors), Early Vertebrates and Related Problems of Evolutionary Biology: 139-177. Science Press, Beijing.

Long, J.A. (1989). A new rhizodontiform fish from the Early Carboniferous of Victoria, Australia, with remarks on the phylogenetic position of the group. Journal of Vertebrate Paleontology 9: 1-17.

Long, J.A. (1995a). The Rise of Fishes. 500 million years of evolution. University of New South Wales Press, Sydney, $223 \mathrm{pp}$.
Long, J.A. (1995b). A new groenlandaspidid arthrodire (Pisces; Placodermi) from the Middle Devonian Aztec Siltstone, southern Victoria Land, Antarctica. Records of the Western Australian Museum 17: 35-41.

Long, J.A. (2001). On the relationships of Psarolepis and the onychodontiform fishes. Journal of Vertebrate Paleontology 21: 815-820.

Long, J.A., Turner, S. and Young, G.C. (1988). A Devonian fish fauna from subsurface sediments in the eastern Officer Basin, South Australia. Alcheringa 12: 61-78.

Long, J.A., Anderson, M.E., Gess, R.W. and Hiller, N. (1997a). New placoderm fishes from the Late Devonian of South Africa. Journal of Vertebrate Paleontology 17: 253-268.

Long, J.A., Barwick, R.E. and Campbell, K.S.W. (1997b). Osteology and functional morphology of the osteolepiform fish Gogonasus andrewsae Long, 1985, from the Upper Devonian Gogo Formation, Western Australia. Records of the Western Australian Museum, Supplement 53: 1-89.

McCoy, F. (1848). On some new fossil fishes of the Carboniferous period. Annals and Magazine of Natural History 2: 1-10.

Mark-Kurik, E. (1973). Actinolepis (Arthrodira) from the Middle Devonian of Estonia. Palaeontographica 143A: 89-108.

Mark-Kurik, E. (1998). Placoderms in the Lower and Middle Devonian of Severnaya Zemlya. Ichthyolith Issues, Special Publication 4: 33-35.

Miles, R.S. (1971). The Holonematidae (placoderm fishes), a review based on new specimens of Holonema from the Upper Devonian of Western Australia. Philosophical Transactions of the Royal Society of London. B. Biological Sciences 263: 101-234.

Miles, R.S. (1973). An actinolepid arthrodire from the Lower Devonian of Peel Sound Formation, Prince of Wales Island. Palaeontographica 143A: 109-118.

Miles, R.S. and Young, G.C. (1977). Placoderm interrelationships reconsidered in the light of new ptyctodontids from Gogo, Western Australia. In: S.M. Andrews, R.S. Miles \& A.D. Walker (eds), Problems in Vertebrate Evolution, Linnean Society Symposium Series, 4: 123-198, 35 text-figs., 5 plates.

Mulholland, C.St]. (1940). Geology and underground water resources of the East Darling district. New South Wales Geological Survey - Mineral Resources 39: 1-80.

Neef, G., Bottrill, R.S. and Ritchie, A. (1995): Phanerozoic stratigraphy and structure of the northern Barrier Ranges, western New South Wales. Australian Journal of Earth Science 42: 557-570.

Neef, G., Larsen, D.F. and Ritchie, A. (1996): Late Silurian and Devonian fluvial strata in western Darling Basin, far west New South Wales. Australian Sedimentologists Group Field Guide Series 10. Geological Society of Australia, Sydney, $30 \mathrm{pp}$.

Obruchev, D.V. (1964). Osnovy Paleontologii v. 11, Beschelyostni i Ribi. Moscow [English translation: Fundamentals of Paleontology, Agnatha $\mathcal{E}$ Pisces; Israel program for scientific translation, 1967]

Owen, R. (1846). Lecture on the comparative anatomy and physiology of the vertebrate animals, delivered at the Royal 
College of Surgeons of England. I, Fishes. Longman Brown, Green \& Longmans, London, 308 pp.

Rade, J. (1964). Upper Devonian fish from the Mount Jack area, New South Wales, Australia. Journal of Palaeontology, 38: 929-932.

Reynolds, M.A. and Pritchard, P.W. (1964). The geology of the Glenormiston 1:250,000 Sheet area. Bureau of Mineral Resources, Australia, Record 1964/28.

Ritchie, A. (1969). Ancient fish of Australia. Australian Natural History, 16: 218-223.

Ritchie, A. (1973). Wuttagoonaspis gen. nov, an unusual arthrodire from the Devonian of Western New South Wales, Australia. Palaeontographica 143A: 58-72.

Ritchie, A. (1975). Groenlandaspis in Antarctica, Australia and Europe. Nature 254: 569-73.

Ritchie, A. (1987). Appendix 1. Identification of fossil fish parts from the Merrimerriwa Formation. In: Glen, R.A. (1987). Geology of the Wrightville 1:100,000 sheet 8034: 253. Geological Survey of NSW.

Ritchie, A., Wang, S.T., Young, G.C. and Zhang, G.R. (1992). The Sinolepidae, a family of antiarchs (placoderm fishes) from the Devonian of South China and eastern Australia. Records of the Australian Museum 44: 319-370

Romer, A.S. (1955). Herpetichthyes, Amphibioidei, Choanichthyes or Sarcopterygii? Nature 176: 126-127.

Schultze, H.-P. (1973). Crossopterygier mit heterozerker Schwanzenflosse aus dem Oberdevon Kanadas, nebst einer Beschreibung von Onychodontida-Resten aus dem Mittel devon Spaniens und aus dem Karbon der USA. Palaeontographica, 143A: 188-208.

Schultze, H.-P. (1984). The head shield of Tiaraspis subtilis (Gross) [Pisces, Arthrodira]. Proceedings of the Linnean Society of New South Wales 107: 355-365.

Schultze, H.-P. (2000). A porolepiform rhipidistian from the Lower Devonian of the Canadian Arctic. Mitteilungen aus dem Museum für Naturkunde in Berlin, Geowissenschaftliche Reihe 3: 99-109.

Seilacher, A. (1967). Bathymetry of trace fossils. Marine Geology 5: 413-428.

Seilacher, A. (1978). Use of trace fossils for recognizing depositional environments. Society of Economic Paleontologists and Mineralogists, Oklahoma City: Short Course 5: 185-201.

Shergold, J.H. (1985). Notes to accompany the Hay RiverMount Whelan Special 1:250 000 Geological Sheet, southern Georgina Basin. Bureau of Mineral Resources, Australia, Report 251: 1-47.

Sherwin, L. (1987). Appendix 2. Identification of invertebrates. In: Glen, R.A. (1987). Geology of the Wrightville 1:100,000 sheet 8034: 254-257, Geological Survey of NSW.

Sherwin, L. (1994). Palaeozoic stratigraphy of the Narromine 1:250000 Sheet area. New South Wales Geological Survey, Quarterly Notes 96: 1-37.

Sherwin, L. (1995). Siluro-Devonian brachiopods from the Amphitheatre and Winduck Groups (Cobar Subgroup), western New South Wales. Mermoir of the Association of Australasian Palaeontologists 18: 61-96.

Smith, K.G. (1972). Stratigraphy of the Georgina Basin. Bureau of Mineral Resources, Australia, Bulletin 111: 1156.
Smith, K.G. and Milligan E.N. (1964). Barrow Creek, N.T. 1:250 000 Geological Series. Explanatory Notes. SF/53-6. Bureau of Mineral Resources, Australia.

Smith, G.R., Stearley, R.F. and Badgley, C.E. (1988). Taphonomic bias in fish diversity from Cenozoic floodplain environments. Palaeogeography, Palaeoclimatology, Palaeoecology 63: 263-273.

Stidolph, P.A., Bagas, L., Donnellan, N., Whalley, A.M., Morris, D.G. and Simons, B. (1988). Elkedra SF53-7. 1:250 000 Geological Map Series Explanatory Notes. Northern Territory Geological Survey, Darwin, 54 pp.

Tindale, N.B. (1931). Geological notes on the Iliaura country northeast of the MacDonnell Range, central Australia. Transactions of the Royal Society of South Australia 55: 32-38.

Turner, S. and Young, G.C. (1987): Shark teeth from the Early-Middle Devonian Cravens Peak Beds, Georgina Basin, Queensland. Alcheringa 11: 233-244.

Turner, S., Jones, P.J., and Draper, J.J. (1981): Early Devonian thelodonts (Agnatha) from the Toko Syncline, western Queensland, and a review of other Australian discoveries. BMR Journal of Australian Geology \& Geophysics 6: 51-69.

Upeniece, 1. (1995). A new species of Strunius (Sarcopterygii, Onychodontida) from Latvia, Lode Quarry (Upper Devonian). Geobios, Memoire Special 19: 281-284.

Vorobjeva, E.I. (1962). Rhizodontid crossopterygians of the main Devonian field in the USSR. Trudy Paleontologicheskogo Instituta. Akademiya Nauk SSSR 94: 1-139. [In Russian.]

Vorobjeva, E.I. (1977). Morfologiya i osobennosti evolyutsii kisteperykh ryb. Trudy Paleontologicheskogo Instituta. Akademiya Nauk SSSR 163: 1-240. [In Russian.]

Vorobjeva, E.I. (1980). Observations on two rhipidistian fishes from the Upper Devonian of Lode, Latvia. Zoological Journal of the Linnean Society 70: 191-201.

Wang J.Q. and Wang S.T. (1983). A new genus of Coccosteidae. Vertebrata PalAsiatica 21: 1-8. [Chinese, English summary].

Wang S.T., Pan J., and Wang J.Q. (1998). Early Devonian fishes from central and southern Guangxi and correlation of the vertebrate biostratigraphy in South China. Vertebrata PalAsiatica 36: 58-69 [Chinese, English summary].

White, E.I. (1968). Devonian fishes of the Mawson-Mulock area, Victoria Land, Antarctica. Trans-Antarctic Expedition 1955- 1958. Scientific Reports, Geology, 16: 1-26.

Wilson, R.B. (1963). Geology and oil prospects of O.P.63, Northern Territory. Alliance Petroleum Australia N.L. [unpublished report].

Woodward, A.S. (1891). Catalogue of Fossil Fishes. Part 2. British Museum (Natural History), London.

Young, G.C. (1979). New information on the structure and relationships of Buchanosteus (Placodermi, Euarthrodira) from the Early Devonian of New South Wales. Zoological Journal of the Linnean Society 66: 309352.

Young, G.C. (1980). A new Early Devonian placoderm from New South Wales, Australia, with a discussion 
of placoderm phylogeny. Palaeontographica 167A: 1076.

Young, G.C. (1981). New Early Devonian brachythoracids (placoderm fishes) from the Taemas - Wee Jasper region of New South Wales. Alcheringa 5: 247-271.

Young, G.C. (1982). Devonian sharks from southeastern Australia and Antarctica. Palaeontology 25: 817-843.

Young, G.C. (1984). An asterolepidoid antiarch (placoderm fish) from the Early Devonian of the Georgina Basin, central Australia. Alcheringa 8: 65-80.

Young, G.C. (1985). New discoveries of Devonian vertebrates from the Amadeus Basin, central Australia. BMR Journal of Australian Geology $\mathcal{E}$ Geophysics 9: 239-254.

Young, G.C. (1986). The relationships of placoderm fishes. Zoological Journal of the Linnean Society 88: 1-57.

Young, G.C. (1988a). New occurrences of phyllolepid placoderms from the Devonian of central Australia. BMR Journal of Australian Geolology $\mathcal{E}$ Geophysics 10: 363-376.

Young, G.C. (1988b). Antiarchs (placoderm fishes) from the Devonian Aztec Siltstone, southern Victoria Land, Antarctica. Palaeontographica 202A: 1-125.

Young, G.C. (1991a). The first armoured agnathan vertebrates from the Devonian of Australia. In: Chang, M.M., Liu, Y.H., and Zhang, G.R. (eds), Early Vertebrates and Related Problems of Evolutionary Biology: 67-85. Science Press, Beijing.

Young, G.C. (1991b). Fossil fishes from Antarctica. In: Tingey, R.J. (ed.), The Geology of Antarctica: 538-567. Oxford University Press.

Young, G.C. (1993). Middle Palaeozoic macrovertebrate biostratigraphy of Eastern Gondwana. In: Long, J.A. (ed.), Palaeozoic Vertebrate Biostratigraphy and Biogeography: 208-251. Belhaven Press, London.

Young, G.C. (1995). Timescales 4. Devonian. Biostratigraphic charts and explanatory notes. Second Series. Australian Geological Survey Organisation, Record 1995/33: 1-47.

Young, G.C. (1996). Devonian (chart 4). In: Young, G.C. and Laurie, J.R. (eds), An Australian Phanerozoic Timescale: 96-109. Oxford University Press, Melbourne.
Young, G.C. (1997). Ordovician microvertebrate remains from the Amadeus Basin, central Australia. Journal of Vertebrate Paleontology, 17: 1-25.

Young G.C. and Gorter, J.D. (1981). A new fish fauna of Middle Devonian age from the Taemas/Wee Jasper region of New South Wales. Bureau of Mineral Resources Geology \& Geophysics, Bulletin 209: 83-147.

Young, G.C., Long, J.A. and Ritchie, A.R. (1992). Crossopterygian fishes from the Devonian of Antarctica: systematics, relationships and biogeographic significance. Records of the Australian Museum, Supplement 14: 1-77.

Young, G.C., Long, J.A. and Turner, S. (1993). Faunal lists of Eastern Gondwana Devonian macrovertebrate assemblages. In: Long J.A. (ed.), Palaeozoic Vertebrate Biostratigraphy and Biogeography: 246-251, Belhaven Press, London.

Young, G.C. and Turner, S. (2000). Devonian microvertebrates and marine-nonmarine correlation in East Gondwana: Overview. Courier Forschungsinstitut Senckenberg 223: 453-470.

Zangerl, R. (1981). Chondrichthyes I. Paleozoic Elasmobranchii In: Schultze, H.-P. (ed.), Handbook of Paleoichthyology, volume $3 a$, Gustav Fischer Verlag, Stuttgart.

Zhu M. (1991). New information on Diandongpetalichthys (Placodermi: Petalichthyida). In: Chang, M.M., Liu, Y.H. and Zhang, G.R. (eds), Early Vertebrates and Related Problems of Evolutionary Biology: 179-194, Science Press, Beijing.

Zhu M. (2000). Catalogue of Devonian vertebrates in China, with notes on bio-events. Courier Forschungsinstitut Senckenberg 223: 373-390.

Zhu, M., Yu, X. and Janvier, P. (1999). A primitive fossil fish sheds light on the origin of bony fishes. Nature 397: 607-610.

Zhu M. and Schultze, H.-P. (2001). Interrelationships of basal osteichthyans. In: Ahlberg, P.E. (ed.), Major Events in Early Vertebrate Evolution. Systematics Association Special Volume 61: 289-314.

Zhu M., Wang N., and Wang J. (2000). Devonian macroand microvertebrate assemblages of China. Courier Forschungsinstitut Senckenberg 223: 361-372.

Manuscript received 15 April 2002; accepted 8 November 2002 
APPENDIX - SPECIMEN LIST

Wuttagoonaspis milligani sp. nov.

\begin{tabular}{|c|c|c|c|}
\hline $\begin{array}{c}\text { CPC or ANU [V] } \\
\text { Number }\end{array}$ & $\begin{array}{c}\text { Year } \\
\text { collected }\end{array}$ & Locality & $\begin{array}{l}\text { Field/specimen } \\
\text { number }\end{array}$ \\
\hline 36859 & 61 & $\mathrm{BC} 7$ & F21984 \\
\hline 36860 & 61 & $\mathrm{BC} 7$ & F21987 \\
\hline 36861 & 61 & $\mathrm{BC} 1$ & F21990 \\
\hline 36862 & 61 & $\mathrm{BC} 1$ & F22000 \\
\hline 36863 & 61 & $\mathrm{BC} 1$ & F22004 \\
\hline 36864 & 61 & $\mathrm{BC} 1$ & F22006 \\
\hline 36865 & 74 & 11 & $11 \mathrm{C}$ \\
\hline 36866 & 74 & 11 & $11^{\prime}$ \\
\hline 36867 & 74 & 16 & $16 \mathrm{C}$ \\
\hline 36868 & 77 & 2 & 2 \\
\hline 36869 & 77 & 3 & $3^{\prime}$ \\
\hline V2970 & 77 & $? 3$ & $? 3 \mathrm{~A}$ \\
\hline 36870 & 77 & 3 & $3 \mathrm{M}$ \\
\hline 36871 & 77 & 3 & $3 \mathrm{~T}$ \\
\hline 36872 & 77 & 3 & $3 \mathrm{U}$ \\
\hline 36873 & 77 & 3 & $3 Z$ \\
\hline 36874 & 77 & 15 & $15 \mathrm{~A}$ \\
\hline 36875 & 77 & 17 & $17(13)$ \\
\hline 36876 & 77 & 17 & 17 alpha \\
\hline V2971 & 77 & 19 & $19 \mathrm{U} .2$ \\
\hline 36877 & 77 & 19 & $19 \mathrm{~B}$ \\
\hline 36878 & 77 & 19 & $19(11)$ \\
\hline 36879 & 77 & 19 & $19 \mathrm{M}$ \\
\hline 36880 & 77 & 19 & $19 \mathrm{P}$ \\
\hline 36881 & 77 & 19 & $19 \mathrm{t} 7$ \\
\hline 36882 & 77 & 19 & $19 y$ \\
\hline 36883 & 77 & 22 & $22 \mathrm{~L}$ \\
\hline 36884 & 77 & 20 & $20 \mathrm{~A}$ \\
\hline 36885 & 75 & GEO $035 / 007$ & V710 \\
\hline 36886 & 77 & 3 & $3 \mathrm{~J}$ \\
\hline 25343 & 77 & 19 & \\
\hline 36887 & 77 & 19 & $19 S$ \\
\hline 36888 & 77 & 19 & 19T.1,1A \\
\hline 36889 & 77 & 19 & 19T.2,2A \\
\hline 36890 & 77 & 19 & 19T.3A,B \\
\hline 36891 & 77 & 19 & 19Т.4a, 4 \\
\hline V2972 & 77 & 19 & 19T.6 \\
\hline 36892 & 77 & 19 & 19T.5 \\
\hline 36893 & 77 & 19 & 19T.7 \\
\hline 36894 & 77 & 19 & $19 t 8 \mathrm{~A}$ \\
\hline 36895 & 77 & 19 & $19 \mathrm{t} 8 \mathrm{~B}$ \\
\hline 36896 & 77 & 19 & $19 \mathrm{U} .4$ \\
\hline 36897 & 77 & 19 & 19U.5 \\
\hline 36898 & 77 & 19 & $22 \mathrm{~A}$ \\
\hline 36899 & 74 & 11 & $11 Q$ \\
\hline V2973 & 74 & 14 & field latex only \\
\hline 36900 & 74 & 11 & $11 S$ \\
\hline 36901 & 74 & 14 & 14alpha \\
\hline 36902 & 74 & 14 & 14BETA \\
\hline 36903 & 77 & 2 & $2 Z$ \\
\hline 36904 & 77 & 3 & 3 \\
\hline 36905 & 77 & 4 & $4 \mathrm{~A}$ \\
\hline
\end{tabular}




$\begin{array}{cccc}\begin{array}{c}\text { CPC or ANU [V] } \\ \text { Number }\end{array} & \begin{array}{c}\text { Year } \\ \text { collected }\end{array} & \begin{array}{c}\text { Locality } \\ \text { Field/specimen } \\ \text { number }\end{array} & \begin{array}{c}\text { (2C } \\ 36906\end{array} \\ 36907 & 77 & 12 & 14 \mathrm{~A} \\ 36908 & 77 & 14 & 19 S^{\prime} \\ 36909 & 77 & 19 & 19 \mathrm{~T} .2 \\ 36910 & 77 & 19 & 19 \mathrm{t}(8) \\ 36911 & 77 & 19 & 22 \mathrm{X} \\ 36912 & 77 & 19 & 21\end{array}$

Lurapullaspis johannseni gen. et sp. nov.

$\begin{array}{ccc}36914 & 61 & \text { BC1 } \\ 36915 & 74 & 11 \\ 36916 & 74 & 14 \\ 36917 & 74 & 14 \\ 36918 & 74 & 14 \\ 36919 & 74 & 16 \\ 36920 & 74 & 17 \\ 36921 & 74 & 17 \\ 36922 & 74 & 17 \\ 36923 & 74 & 17 \\ 36924 & 74 & 17 \\ 36925 & 77 & 3 \\ 36926 & 77 & 3 \\ 36927 & 77 & 3 \\ 36928 & 77 & 3 \\ 36929 & 77 & 3 \\ 36930 & 77 & 20\end{array}$

F21998

11alpha

14

$14 \mathrm{E}$

$14 \mathrm{~K}$

$16 \mathrm{D}$

17A

17E

$17 \mathrm{f}$

171

17]

3 alpha

$3 \mathrm{H}$

3K

$3 \mathrm{M}$

3R

20 alpha

Toombalepis tuberculata gen. et sp. nov.

36931

36932

36933

36934

36935

36936

36937

36938

36939

36940

36941

24664

36942

36943

36944

36945

36946

36947

36948

36949

36950
74

77

77

77

77

77

77

77

77

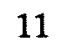

17

17

17

18

19

19

19

20
$11 \mathrm{~W}$

$$
17
$$

17 (10)

17 (11)

18B

19 (15)

19 (20)

19R

20B
Tnoralaspis petercooki gen. et sp. nov.

$\begin{array}{lcc}77 & 19 & 19 \mathrm{D} \\ 77 & 19 & 22 \mathrm{G} \\ - & - & \mathrm{V} 1792\end{array}$

Ethabukaspis leios gen. et sp. nov.

$\begin{array}{ccc}77 & 3 & 3 \text { theta } \\ 77 & 4 & 4 C \\ 77 & 19 & 19 R\end{array}$

Huginaspis australis sp. nov.

$\begin{array}{ccc}74 & 11 & \text { 11ALPHA } \\ 74 & 11 & 11 \text { BETA } \\ 74 & 11 & 11 \mathrm{~L} \\ 74 & 11 & 11 \mathrm{M} \\ 74 & 11 & 11 \mathrm{SP} \\ 74 & 11 & 11 \mathrm{X}\end{array}$




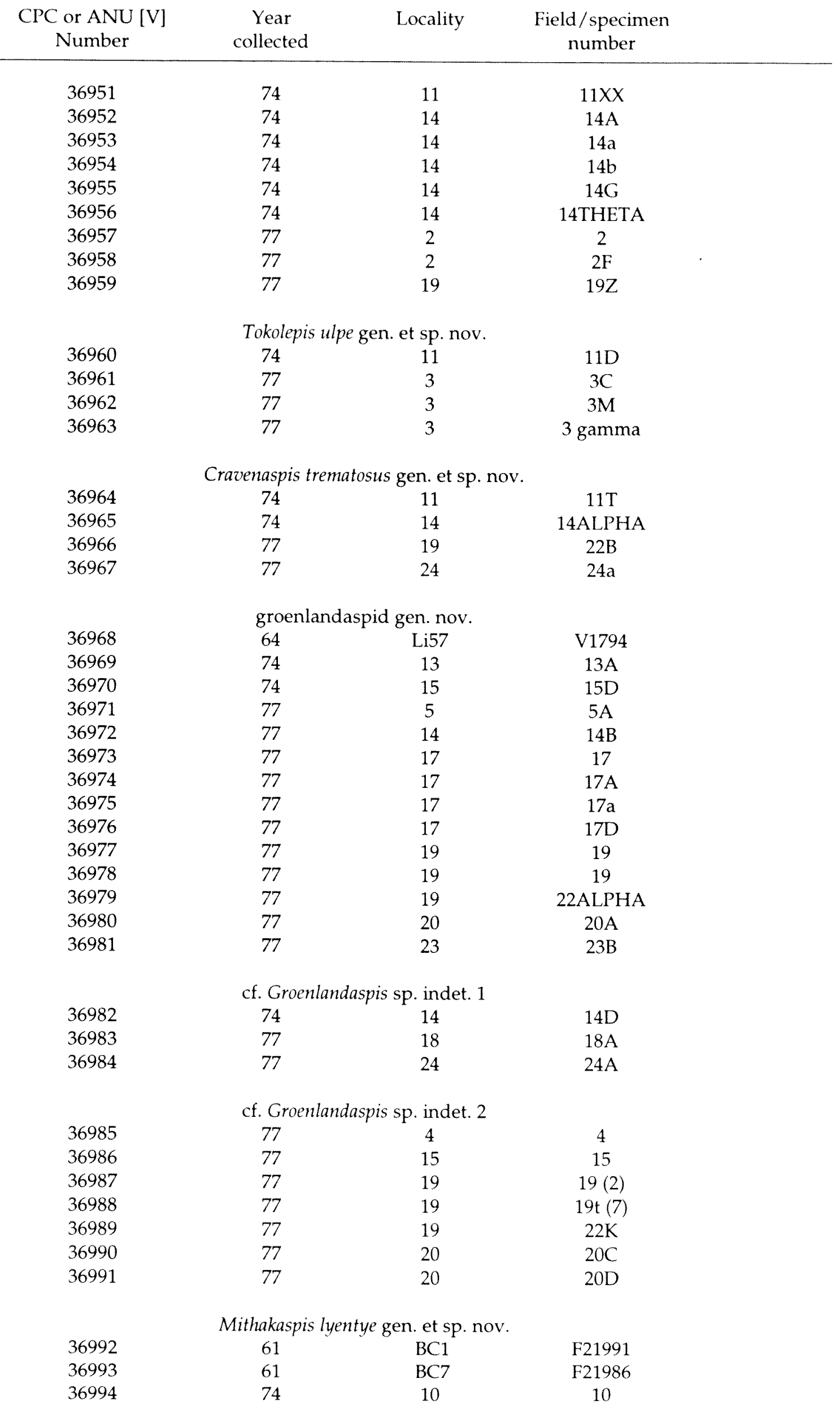




\begin{tabular}{|c|c|c|c|}
\hline $\begin{array}{c}\text { CPC or ANU [V] } \\
\text { Number }\end{array}$ & $\begin{array}{c}\text { Year } \\
\text { collected }\end{array}$ & Locality & $\begin{array}{l}\text { Field / specimen } \\
\text { number }\end{array}$ \\
\hline 36995 & 74 & 11 & $11 \mathrm{~A}$ \\
\hline 36996 & 74 & 11 & $11 \mathrm{E}$ \\
\hline 36997 & 74 & 11 & $11 L^{*}$ \\
\hline 36998 & 74 & 16 & 16 \\
\hline 36999 & 74 & 17 & 17 \\
\hline 37000 & 74 & 17 & 17 ALPHA \\
\hline 37001 & 74 & 17 & 17B \\
\hline 37002 & 74 & 17 & $17 \mathrm{D}$ \\
\hline 37003 & 77 & 3 & 3 \\
\hline 37004 & 77 & 3 & $3 \mathrm{~N}$ \\
\hline 37005 & 77 & 4 & $4 \mathrm{C}$ \\
\hline 37006 & 77 & 12 & $12 \mathrm{~A}$ \\
\hline 37007 & 77 & 20 & $20 \mathrm{E}$ \\
\hline \multicolumn{4}{|c|}{ phlyctaenioid indet. 1} \\
\hline 37008 & 74 & 15 & 15 \\
\hline 37009 & 74 & 17 & $17 \mathrm{H}$ \\
\hline \multicolumn{4}{|c|}{ phlyctaenioid indet. 2} \\
\hline 37010 & 74 & 11 & $11 \mathrm{~N}$ \\
\hline 37011 & 74 & 16 & $16 \mathrm{~A}$ \\
\hline \multicolumn{4}{|c|}{ phlyctaenioid indet. 3} \\
\hline 37012 & 74 & 12 & $12 \mathrm{~A}$ \\
\hline 37013 & 74 & 15 & 15 \\
\hline 37014 & 74 & 15 & $15 B$ \\
\hline 37015 & 77 & 2 & 2 \\
\hline 37016 & 77 & 17 & $17(9)$ \\
\hline 37017 & 77 & 19 & $19 \mathrm{M}$ \\
\hline 37018 & 77 & 19 & $19 t(7)$ \\
\hline 37019 & 77 & 20 & 20 \\
\hline \multicolumn{4}{|c|}{ ?petalichthyid gen. et sp. indet. } \\
\hline 37020 & 74 & 17 & 17 beta \\
\hline 37021 & 77 & 19 & $22 \mathrm{H}$ \\
\hline \multicolumn{4}{|c|}{ acanthodian gen. et sp. indet. } \\
\hline 37022 & 74 & 11 & 11 \\
\hline 37023 & 74 & 11 & $11 \mathrm{~K}$ \\
\hline 37024 & 74 & 14 & 14 \\
\hline 37025 & 77 & 24 & $24 A^{\prime}$ \\
\hline \multicolumn{4}{|c|}{ ?rhizodontid gen. et sp.indet. } \\
\hline 37026 & 74 & 16 & 16 \\
\hline 37027 & 74 & 17 & $17 \mathrm{C}$ \\
\hline 37028 & 77 & 15 & 15B \\
\hline 37029 & 77 & 17 & $17(12)$ \\
\hline 37030 & 77 & 17 & $17(13)$ \\
\hline 37031 & 77 & 19 & $19 \mathrm{~T}(8)$ \\
\hline 37032 & 77 & 23 & 23 \\
\hline \multicolumn{4}{|c|}{ ?porolepiform gen. et sp. indet. } \\
\hline 37033 & 74 & 11 & 11 OMEGA \\
\hline 37034 & 74 & 11 & $11 \mathrm{U}$ \\
\hline 37035 & 74 & 15 & $15 \mathrm{~A}$ \\
\hline 37036 & 77 & 4 & 4 \\
\hline
\end{tabular}




\begin{tabular}{cccc}
$\begin{array}{c}\text { CPC or ANU [V] } \\
\text { Number }\end{array}$ & $\begin{array}{c}\text { Year } \\
\text { collected }\end{array}$ & $\begin{array}{c}\text { Locality } \\
37037\end{array}$ & $\begin{array}{c}\text { Field/specimen } \\
\text { number }\end{array}$ \\
37038 & 77 & 17 & $17(8)$ \\
37039 & 77 & 17 & $17(14)$ \\
V2974 & 77 & 19 & $19 \mathrm{~A}$ \\
37040 & 77 & 19 & $19 \mathrm{~T}(6)$ \\
37041 & 77 & 19 & $19 \mathrm{U} 3$ \\
& 77 & 19 & $22 \mathrm{M}$ \\
37042 & onychodontid gen. et sp. indet. \\
37043 & 74 & 11 & 11 TRIANGLE \\
37044 & 74 & 11 & 11THETA \\
37045 & 77 & 2 & 2E \\
\multicolumn{4}{c}{ other specimens [plaster copies of Oil Company samples] } \\
37046 & 64 & {$[28]$} & FPCA 170 \\
37047 & 64 & [28] & FPCA 170
\end{tabular}

